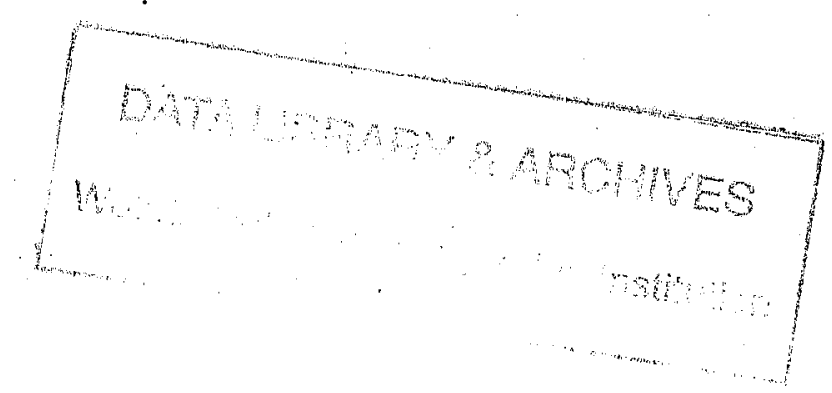

Bel'kovitch, V. M. and M. N. Sh'ekotov

The Belukha Whale: Natural Behavior and Bioacoustics

[Belukha. Povedenie i bioakustika $v$ prirode]

Translated by Marina A. Svanidze

Edited by J. Christopher Haney and Cheri Recchia

Woods Hole Oceanographic Institution

1993

QL

7377

1433

$\beta^{4} 413$

1993

C. 2 


\section{USSR Academy of Sciences}

Shirshov Institute of Oceanology

Bel'kovitch, V. M. and M. N. Sh'ekotov

The Belukha Whale: Natural Behavior and Bioacoustics

[Belukha. Povedenie i bioakustika v prirode]

Translated by Marina A. Svanidze

Edited by J. Christopher Haney and Cheri Recchia

Moscow 1990

Woods Hole Oceanographic Institution 1993 
Available from: Office of the Research Librarian

Woods Hole Oceanographic Institution

Clark 131

Woods Hole, MA 02543

USA

(508) $457-2000$, ext. 2865

$\$ 20.00$ US each plus $\$ 2.00$ postage and handling per copy

ISBN 1-880224-07-0 
Translated from the Russian by Marina A. Svanidze, research associate (IMEMO, Russian Academy of Sciences, 23 Profsoyuznaya Street, Moscow, Russia 117418) from 15 May 25 July 1992 at Biology Department, Woods Hole Oceanographic Institution, Woods Hole, MA 02543 U.S.A.

Edited by J. Christopher Haney, Guest Investigator, and Cheri Recchia, Joint Program Graduate Student, in the Biology Department, Woods Hole Oceanographic Institution, Woods Hole, MA 02543 U.S.A. We thank William A. Watkins, Senior Research Specialist, Biology Department, Woods Hole Oceanographic Institution, Woods Hole, MA 02543 U.S.A, for his comments and suggestions.

This translation follows as closely as possible the original meaning and intention of the Russian version. Errors in presentation, of omission or commission, published in the original may still be present in the translation. We have drawn attention to some of these by editorial comments in brackets using bold-face type. Additional errors are the sole responsibility of the translator and editors. 
This book contains new original data concerning the behavior and bioacoustics of the belukha whale in natural environments, as well as data analysis of acoustic signals of the whales and methodological problems of ethological-acoustic research. This book is of interest to oceanologists, zoologists, ethologists, zoopsychologists, and bioacousticians.

Chief editor, M. M. Bel'kovitch 


\begin{abstract}
This monograph presents new original material on the behavior and bioacoustic signals of the belukha whale in its natural environment. A typological classification of this species' signals is based on researches that were conducted for many years. This book as well contains descriptions of the time-frequency characteristics of the main classes of sounds. Comparison of the behavior and signals of the belukha whale synchronized by time, enabled development of an ethological-acoustical model of individual behavioral activity in search and hunting, and this study reveals the function of certain sounds. Also, the study made it possible to obtain data on the navigation mechanism (or orientation mechanism) and emphasizes the role of sounds in all the different behavioral activities of the belukha whale. Studies conducted at the extreme points of its range enabled, for the first time, comparison of the ethological-acoustic attributes of the belukha whale in the White Sea and the Amur River estuary.
\end{abstract}

Key words: belukha whale, white whale, Delphinapterus leucas, bioacoustics, Cetacea, animal communication 


\section{Foreward}

The belukha whale (Delphinapterus leucas Pall., 1776) may reach a length of up to 5.5 $\mathrm{m}$ and weight of up to 1.5 tons. Up to now, the belukha is still rather numerous along the Arctic mainland, islands, and in the vicinity of river estuaries. It is well-known in Europe and America, where it has been kept for a considerable time in oceanariums and often takes part in circus performances.

The anatomical characteristics, geographic distribution, feeding, breeding, age and size parameters of the belukha whale have been described in numerous publications during the last 200 years. In 1964, Professor S. E. Kleinenberg and coauthors issued a summary "The belukha whale: a monograph of the species" that is up to now considered an outstanding work among all written about whales.

Thirty years ago, while working on this book, we did not yet know a lot about the acoustics of the belukha whale, except probably the fact that since ancient times fishermen and whalers used to call it "sea canary", due to twittering sounds that could be well-heard in boats. Also, the expression "to howl like a belukha" was widespread and originated from the belukha whale's behavior in extreme situations. However, this expression was often misattributed by many people to the fish (white sturgeon, Huso huso), large and delicious and better known than the Arctic white whale.

Knowledge of the behavior of the belukha whale was similar - it was accumulated through observations made by fishermen and captains for use in successfully hunting the whale, although this kind of hunting was always unstable due in particular to the belukha whale's quick adaptation to certain tools and methods of the hunting process.

These gaps in man's knowledge of the belukha whale's behavior and bioacoustics necessitated our systematic research on this subject. We began studies in the end of the 1970 s in the White Sea, where we determined appropriate sites for observation of the belukha whale in its natural environment (the Summer Shore [Letniy Bereg] on Onega Bay). Data conceming the behavior and bioacoustics of belukhas were collected during times of intense hunting. Then these works were expanded towards the east to the Amur River estuary. The results obtained from these particular researches were analyzed and comprise this book.

Studies of the belukha whale's behavior and bioacoustics are continuing. At the present time, we are continuing to obtain data on ethological-acoustic characteristics of 
belukha populations in Chukotka (Anadyr Bay) and, on the Sea of Okhotsk, studies of the belukha whale have begun. Thus, we managed to collect a uniquely complete library of belukha sounds that are synchronized by time in accordance with the whale's behavioral activity.

The analyzed materials enabled, for the first time, composition of the most complete "frequency glossary" of belukha signals; description of the signals in time-frequency models at a range up to $16 \mathrm{kHz}$; determination of which particular signals and how often belukha whales use them in different portions of the species range; and also preliminary direct and inverse correlations between acoustic signals and behavioral activities inherent to this species.

We would like to stress that all achievements were possible because of systematic research over many years - thousands of hours of observations, hundreds of hours of recordings, hundreds of photographs. Our methods of studying marine mammals in their natural environment reduced to a minimum signs of a researcher's presence, and allowed simultaneous reception of acoustic and visual data and their subsequent processing. These methods have been described in detail in previous publications (Bel'kovitch 1978, 1987).

Multi-year systematic observations not only gave us an opportunity to collect the most complete acoustic materials, but we could also watch the extreme plasticity in the belukha whale's behavior. For example, its searching and hunting behaviors in certain years were similar to the Black Sea porpoise (solo trawling of the sea bottom layer - "hunting by squares" in our terminology), and in other years more typical "caldrons", "carousels", or group hunting occurred.

In another example, we saw on the ocean surface only the white (or gray) portions of the belukha whale's dorsum rolling slowly from side to side. Only a few observers have succeeded in watching the entire whale in the ocean, typically while whales are lying motionless on the water's surface during sleep. It turned out that these whales were often sound asleep - repeated bumps by other whales' heads or tails did not wake sleeping whales. However, one very effective means of waking whales is when companions jump 3-4 m out of the water and splash water out of their mouths upon the head of the sleeping one.

The belukha whale is distributed throughout the severe climate of the Arctic, a fact that leads to interesting adaptative developments including those concerning its sonar system, signals, composition of flocks, and searching and hunting activities. Some of these matters are discussed in this book; others are still being analyzed or are expected to be explored in the future. 
During the process of research, data collection and processing, we had the cooperation and support of the management of Shirshov Institute of Oceanology, in particular professor V.S. Yastrevob and corresponding member of the USSR Academy of Sciences M. E. Vinogradov, the chiefs of departments I. I. Tynyankin, A. L. Genkin, colleagues from IEMEG of the USSR Academy of Sciences - Professor V. A. Lemskiy, doctor of biology Romanenko, V.I. Markov, the director of the Acoustic Institute, Professor N. A. Dubrovskiy, colleagues from the Siberian branch of PINRO (Arkhangelsk), the director of candidates of biology V. A. Pot'elov, and candidate of biology Yu. K. Timoshenko. The large and fruitful work in these studies was done by all the staff of the Marine Bioacoustic Laboratory of the Shirshov Institute of Oceanology of the USSR Academy of Sciences. An important participation in preparing illustrations were done by A. V. Agabonov and candidate of biology G. A. Boyko. Gratitude to all.

Doctor of biology,

V. Bel'kovitch 


\section{TABLE OF CONTENTS}

Chapter 1. A brief review of acoustic signals of cetaceans 1

Suborder: Mysticeti 1

Suborder: Odontoceti 13

Summary and conclusions 29

Chapter 2. Acoustic signals of the belukha whale 34

Communicative and emotional signals 34

Echlocation signals 41

Chapter 3. Ethological-acoustic characteristics of the belukha 42

The belukhas of the White Sea 42

Size and structure of groups $\quad 42$

Individual activity in searching and hunting $\quad 46$

Searching and hunting in groups of belukhas $\quad 60$

The Amur belukha 67

Size and structure of groups $\quad 67$

Individual searching and hunting activity $\quad 67$

Searching and hunting activity of groups of belukha 71

$\begin{array}{ll}\text { Communication in different situations } & 71\end{array}$

Conclusions: the distinguishing features of the behavior and acoustic signals of belukhas in two areas $\quad 74$

Searching and hunting behavior $\quad 74$

$\begin{array}{ll}\text { Acoustic activity } & 76\end{array}$

Echlocation strategy $\quad 79$

Some features of social organization $\quad 80$

$\begin{array}{ll}\text { Literature Cited } & 87\end{array}$

Russian references $\quad 87$

Western references 91

$\begin{array}{lc}\text { Figure Legends } & 113\end{array}$ 

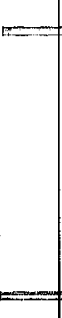


\section{Chapter 1. A brief review of acoustic signals of cetaceans.}

A large amount of data from research on cetacean sounds has been obtained, and the number of such studies continues to grow. Until the 1940s, there were only sporadic descriptions of whale sounds, often recorded primarily in air (Lindholm 1888, Rawitz 1899,1900 , and others). Later, some descriptions of dolphins' sounds were made in captivity (Tomilin 1957, McBride and Hebb 1948, Wood 1952, and others). Only since the 1950s have tape recordings of whales' "voices" been analyzed (Schevill and Lawrence 1949, 1950, Kellogg 1953, 1961, Evans and Prescott 1962, and others).

Today, all researchers agree that whale sounds play an important role in orientation and are used in communication. Minding the purpose of this review, we pay most attention to systematic generalizations of accumulated data. The problems concerning communication and orientation need specific attention, thus they are mentioned and described only in general to outline the whole problem. It is worthwhile to note that communication signals carry information important for navigation, stating location, behavior character of the source, allowing its identification and so on. Evidently, another factor is true as well: location signals given by one of the animals to others contain certain additional information about the character of its behavioral activity. So, due to their physical nature, all the acoustic signals are polyfunctional although still specialized.

Before we begin this review, it is necessary to note that cetaceans produce lots of sounds that by hearing can be characterized as "roar", "groan", "sigh" (deep breath), "mooing", "squeal", "crack", "trill", "whistle", "squeak", "buzz", "blow", "shot", and so on. Today, the fact that all cetaceans produce sounds is considered to be entirely determined, although the level of studies varies within different families and genera.

1. Suborder: (Mysticeti Flower, 1864)

A. Family: right whales (Balaenidae Gray, 1825)

Genus: (Balaena Linnaeus, 1758)

bowhead whale (Balaena mysticetus Linnaeus, 1758)

Bowhead whales produce very loud sounds of breathing than can be heard at distance of a mile (Lepekhin 1905). This sound is of low frequency, and corresponds to the exhaled breath. According to tape recordings made in the Arctic (Poulter 1966, 1968, 1971), submarine acoustic signals of the bowhead whale are represented by low-frequency and narrowband cries of duration 1-2 sec. More detailed analysis of these sounds was made difficult by the fact that they were obtained along with the sounds of a seal, and Poulter (1971) considered that the signals of these two species were similar. Thus, the seal's signals could interfere with the the whale's signals and as a result modify the spectral 
picture. Bowhead whales, squeezed by ice, produced "clicks" that were recorded with the help of a stethoscope (Beamish 1974).

Genus: southern right whales (Eubalaena Gray, 1864)

northern right whale (Eubalaena glacialis glacialis, 1781)

In air, northern right whales produce muted metallic sounds (Matthews 1938) and "moo" when wounded. The acoustic signals of the northern right whale were the first to be recorded. They were low-frequency "groans" and "howls" in the frequency range up to $0.4 \mathrm{kHz}$ (Schevill and Watkins 1962, Payne and Payne 1971, Cummings et al. 1972), probably of coherent character. The use of a broadband (up to $150 \mathrm{kHz}$ ) recording device did not reveal pulsed signals suitable for echolocation in this species. Additional sounds concerned feeding in the upper layers (Watkins and Schevill 1976) and probably were of communicative significance.

In Newfoundland, Cummings and Phillipi (1970) recorded repeated signals ("stanzas") of 11-14 min duration, composed of short pulses ("blips") and "screams" at frequencies of 20-175 Hz. Payne and Payne (1972) did not discover such "stanzas", but they used a recording device with a low-frequency limit of over $175 \mathrm{~Hz}$, and thus were unable to record such low-frequency sounds. However, the known signals of both bowhead and northern right whales are similar (Schevill and Watkins 1962) and do not contain "stanzas" as in the humpback whale. [Complicated signal systems in the humpback whale occur only in tropical waters in the period of December-April, although one should not exclude the opportunity to hear a wide spectrum of different signals in this region of its range (Payne and McVay 1971, Winn et al. 1970a, Winn and Winn 1978). However, near Newfoundland at the end of December they also can produce sounds while preparing to migrate south.] Nevertheless, there is as yet no direct proof that northern right whales do not "sing". Long-term research studies of the species' bioacoustics are necessary. southern right whale (Eubalaena glacialis australis)

Concentrations of this species along the shores of Patagonia, where they come for breeding (Nuevo San Jose Bay; Gilmore 1969, Cummings et al. 1972, Payne and Payne 1971) contributed to studying its signals in conditions ideal for observation, and enabled observation and recording of signals with the possibility of correlating acoustics with behavior (Fish and Thompson 1972, Payne 1972). The most common sound is a "belch" of 0.9-2.2 sec duration (mean $1.4 \mathrm{sec}$ ), with the main energy at a frequency of $235 \mathrm{~Hz}$ and a frequency range of $30-2200 \mathrm{~Hz}$ (the majority to $500 \mathrm{~Hz}$ ). "Screams" (and "mooing") were a second type of sound. Single "moos" had durations of 0.6-1.6 sec in a narrow frequency range of $70-320 \mathrm{~Hz}$ (fundamental $160 \mathrm{~Hz}$ ). Complex "moos" had harmonics and were of longer duration, wider frequency range (between 30 and $1250 \mathrm{~Hz}$, 
fundamental $235 \mathrm{~Hz}$ ), and duration 0.2-4.1 sec. Pulsed signals in a frequency range of 20$2100 \mathrm{~Hz}$ and of $60 \mathrm{msec}$ duration were noticed often with "mooing" at the same time. Correlation of acoustic signals with time of day was not discovered. "Stanzas" that could be explained by differences in season, environment, geography, or populations were not discovered. Signals of Eubalaena glacialis australis during the breeding period were common. The "belch" sounds were heard more seldom and were substituted with "moos" and "screams" (by recorded frequencies) of more intensity. On the basis of 1750 sounds analyzed, the great majority of signals are similar to those produced by humpback whales (Watkins 1967), except strong "blasts" at $50-2200 \mathrm{~Hz}$ and also sounds of breathing.

Signals of Eubalaena glacialis australis (Payne and Payne 1971, Payne 1972) are similar in general to those known from the northern right whale. It was discovered that about two signals per hour were usually produced during daytime, but at night acoustic activity increased sharply (60-900 signals per hour). Frequencies were in the $50-500 \mathrm{~Hz}$ range; it is rare to record high-energy signals of greater than $1500 \mathrm{~Hz}$.

More recent research on the signals of southern right whales not only singles out a number of types, but in certain cases it has also been possible to determine their functional significance (Clark 1983). This author identified the following classes of acoustic signals: 1) "up calls" - low frequency tonal sounds of increasing frequency of $50 \mathrm{~Hz}$ to $200 \mathrm{~Hz}$ and duration 0.5-1.5 sec; 2) "down calls" -low-frequency tonal sounds of decreasing frequency of $200 \mathrm{~Hz}$ to $100 \mathrm{~Hz}$ and duration $0.5-1.5 \mathrm{sec} ; 3$ ) "constant calls" - tonal signals of this class have almost constant dominant frequency in the range of $50-500 \mathrm{~Hz}$ and $0.5-6 \mathrm{sec}$ duration; 4) "high calls" - key signals of $200-500 \mathrm{~Hz}$ with duration $0.5-2.5 \mathrm{sec}$, often ended with rapid frequency decreases; 5 ) "hybrid calls" - complex signals that begin like "high calls" but become pulsive at the end, with dominant frequency of $50-500 \mathrm{~Hz}$, duration 0.5-2.5 sec; 6) "pulsive calls" - complex, usually harsh, amplitude-modulated sounds that continue for $0.5-3.5 \mathrm{sec}$ at $50-200 \mathrm{~Hz} ; 7$ ) "blows" - noisy broadband sounds of frequency $100-400 \mathrm{~Hz}$ and duration of up to $26 \mathrm{sec} ; 8$ ) "slaps" - short, broadband signals with dominant frequency of $50-1000 \mathrm{~Hz}$ and duration $0.2 \mathrm{sec}$. Single whales typically produce signals of the first class. Excited female whales exchange signals of the fourth class. In a group of excited animals (mating behavior), signals of the fourth, fifth, sixth, seventh, and eight classes were common.

\section{B. Family: (Balaenopteridae Gray, 1864)}

Genus: rorqual whales (Balaenoptera Lacepede, 1804)

blue whale (Balaenoptera musculus Linnaeus, 1758)

Whalers knew rather monotonous sounds of breathing in this species, resembling loud groans (Millais 1906). Series of signals of $523 \mathrm{~Hz}$ and $37 \mathrm{sec}$ duration were recorded that 
repeated regularly every $100 \mathrm{sec}$. The signals spread out over $170 \mathrm{~km}$ and are evidently used for communication (Anonymous 1970).

Recently, new data have been obtained on the pulsed signals of the blue whale. "Clicks" and groups of clicks were recorded at a maximum frequency of $8 \mathrm{kHz}$ (Poulter 1968). In addition, recordings of typical echolocation signals were made (Beamish and Mitchell 1971) that had frequencies in the range up to $31 \mathrm{kHz}$ (intensity maxima of 6 and $25 \mathrm{kHz}$ ), durations of $0.5-1.0 \mathrm{msec}$, and maximum recurrent frequency 442 pulses per second. A total of 5000 clicks of feeding whales were recorded. Due to their physical characteristics, these signals of rather great power $(159 \mathrm{~dB}$ re $1 \mu \mathrm{Pa} / 1 \mathrm{~m})$ could be used to find prey and correlate with nutritional mode (stenophagia) in this species. The authors supposed that these signals are used to detect zooplankton.

On 30 and 31 May 1970 at Guafo Island, Chile, sounds of 2-4 whales of this particular species were recorded. The recording device had a frequency range of $25 \mathrm{~Hz}-18 \mathrm{kHz}( \pm 5$ $\mathrm{dB})$. The change in amplitude of the signals correlated with the movement of the whales. According to four estimates of intensity, the average meaning source level was $188 \mathrm{~dB}$ re $1 \mu \mathrm{Pa} / 1 \mathrm{~m}$.

Low-frequency and frequency-modulated cries in the $12-200 \mathrm{~Hz}$ range were of average duration $36.5 \mathrm{sec}$ (range 34.7-38.1 sec). They consisted of A, B and C parts, different by $4 \mathrm{M}$ degree. The signals of two whales had intervals between $\mathrm{B}$ and $\mathrm{C}$, and in one whale between A and B. Part A (frequency $390 \mathrm{~Hz}$ and duration 0.5-1.0 sec) always (27 signals) preceded part $C$. The strongest energy of all three parts of the cry was at 20,25 , and 31.5 $\mathrm{Hz}$. The interval between $\mathrm{B}$ and $\mathrm{C}$ was constant and averaged 100 and $106 \mathrm{sec}$ (two whales), but its duration was correlated with the breathing cycle: exhaling on the surface (Cummings and Thompson 1971a,b).

It is known that along the Chilean coast, blue whales produce $20 \mathrm{~Hz}$ sounds. During the same season, long multi-component signals of the species typify blue whales occurring in the northeast Pacific Ocean, thus giving evidence of geographic variation (Thompson et al. 1979). More recent studies showed that low-frequency long pulses of blue whales in Hawaii differ from sounds recorded in this species along the Chilean coast (Thompson and Friedl 1982).

Various kinds of groans are produced by blue whales: simple (average dominant frequency of $90 \mathrm{~Hz}$ that can reach $158-179 \mathrm{~Hz}$ ) and compound sounds (with additional pulses of $20-2000 \mathrm{~Hz}$, duration about $1 \mathrm{sec}$ ) have been noted by a number of researchers (Ljungblad et al. 1980, 1982, Edds 1982). Some blows of sharp-impulse, broadband sounds were recorded during spring migrations (Clark and Johnson 1984). The frequencies were $100-3500 \mathrm{~Hz}$, and signal durations varied from $0.3-0.7 \mathrm{sec}$. Intensity 
levels were $175-185 \mathrm{~dB}$ re $1 \mu \mathrm{Pa} / 1 \mathrm{~m}$ (Würsig et al. 1982). In spring, blue whales produce unique song-like consecutive sounds consisting of combinations of 2-3 tones as well as signals similar to the elephant's trumpet sounds; these have dominant frequencies up to 5 $\mathrm{kHz}$ (Ljungblad et al. 1982).

Studies of signals produced by blue whales along the Alaskan coast revealed groans of $25-900 \mathrm{~Hz}$ and songs recurring up to 20 times at $20-5000 \mathrm{~Hz}$ frequency (Cummings and Holliday 1987). The intensity maximum was $189 \mathrm{~dB}(1 \mu \mathrm{Pa} / 1 \mathrm{~m})$. The whales produced more signals in the morning (6-8 a.m.) and at night (4-6 p.m.).

A blue whale found trapped in drifting ice produced 7 series of short, sharp pulses during 3 hours; the number of pulses in a series varied from 7 to 27 . The duration of interpulse intervals also changed, being on average 15-21 msec (Beamish 1979). The signals were recorded by three hydrophones simultaneously; the author succeeded in showing that high-frequency signals were sent through the water off the forward part of the head.

fin whale (Balaenoptera physalus Linnaeus, 1758)

After the blue whale, this is the largest animal in the world. Pulsed signals recorded in the North Atlantic and in the Pacific Ocean have been ascribed to fin whales (Schevill et al. 1964). These signals were of frequency $20 \mathrm{~Hz}$ and duration $1 \mathrm{sec}$, and were produced with regular intervals several times per minute for many hours. The seasonal character of these signals, the distribution of signal sources ( 1 per 300 square miles), "aimless" movement at a speed of $3-5 \mathrm{~km}$ per hour (up to $12 \mathrm{~km}$ per hour), and low frequency and wattage (1-25 watts) all give credence to the idea that the signals originate from fin whales. Schevill et al. (1964) give persuasive evidence for specific identification. The breaks in signals may have related to the whale's appearance at the ocean surface. Later studies showed that sounds called " $20 \mathrm{~Hz}$ signals" actually varied in frequency. Presumably these sounds spread for hundreds of miles (Payne and Webb 1971). However, at an intensity of $170-185 \mathrm{~dB}$ (re $1 \mu \mathrm{Pa} / 1 \mathrm{~m}$ ), noise that hydrophone cables emit may strongly influence the estimate (Walker 1963). Accordingly, careful hydrophone placement is necessary to obtain more precise results.

These signals may be produced in pairs. Such doubled sounds have typical features, e.g., a doubled sound "22-15" sec (Patterson and Hamilton 1964). This refers to a $22 \mathrm{sec}$ interval between the sounds and $15 \mathrm{sec}$ interpulse interval with pulse duration about $1 \mathrm{sec}$. In some of the whale cases, a difference in main frequencies of pulses was observed. Pulses of the following frequencies were recorded: $17,18.5,19,20$, and $40 \mathrm{~Hz}$, all of which were useful in individual identification, although it is doubtful that whales can distinguish between differences of $1 \mathrm{~Hz}$. Echolocation signals of fin whales were recorded at 20 yards distance from the ship (Wright 1962); these signals had frequencies of 20-39 
$\mathrm{kHz}$. (These signals may have originated rather from sperm whales). Series of pulses (clicks) originating from two fin whales at $16-28 \mathrm{kHz}$ were recorded at 50 yards from the ship. Each pulse consisted of 3-4 parts that had durations of 3-4.4 msec, inter-pulse intervals of 250-336 msec, and durations for the whole series of $8.8 \mathrm{sec}$ (Thompson et al. 1979). Signals produced by two fin whales (125 miles off Bermuda) sounded like whistles of $1.5-2 \mathrm{kHz}$ (up to $5 \mathrm{kHz}$ ) and had durations of 50-600 msec (Perkins 1966). The author classified the sounds as "signals of alarm". However, although fin whales occur there, these signals sounded very similar to whistles of sei whales in their wintering range. These signals are worthy of further study. They have not been mentioned in later publications (Watkins 1981) in which fin whale signals and corresponding behaviors were analyzed in great detail. That author found communicative "high frequency sounds" with durations of about $0.3 \mathrm{sec}$ and $0.1-30 \mathrm{kHz}$ frequency. Certain pulses and "20 $\mathrm{Hz}$ " series concerned sexual behavior. "Ragged LF pulses " had frequencies lower than $30 \mathrm{kHz}$, and pulse durations of 0.1-1.0 sec. The following class of signals, "LF rumble", were used to demonstrate surprise or agression; this class of signals had frequencies less than $30 \mathrm{kHz}$ as well. Pulsed signals of fin whales were also recorded and concerned feeding on the ocean surface.

Bryde's whale (Balaenoptera edeni Anderson, 1878)

This species is common to warm waters between $40^{\circ}$ north and $400^{\circ}$ south latitude (Nishiwaki 1972). When compared to other species of this family, the distinguishing feature is three ridges along the dorsal portion of the snout, but from a distance it is difficult to distinguish from sei and fin whales.

Along the Mexican coast, 288 cries were recorded $( \pm 5 \mathrm{~dB}, 25 \mathrm{~Hz}-18 \mathrm{kHz})$ originating from one or two whales identified by underwater photography (Thompson and Cummings 1969). The signals varied in frequency and duration. Analysis of 23 signals showed that they occurred at $20-245 \mathrm{~Hz}$ with durations of $0.2-1.5 \mathrm{sec}$ (average $0.42 \mathrm{sec}$ ). The signals were produced sporadically at intervals of 0.2-9 minutes. Frequency modulation was on average $15.2 \mathrm{~Hz}$ up and down. The same day, 35 cries were recorded belonging to another individual, similar to preceding ones, although with average frequency $132 \mathrm{~Hz}$ and average duration 0.4 sec.

In California Bay, low frequency "groans" were successfully recorded in June. These signals had an average duration of $0.42 \mathrm{sec}$ and frequency of $124 \mathrm{~Hz}$, but $73 \%$ of the signals had whistling sounds with increasing and decreasing frequencies (Cummings et al. 1986). In the southern Atlantic Ocean ( $\left.30^{\circ} 07^{\prime}, 14^{\circ} 55^{\prime}\right)$, click series belonging to Bryde's whale were recorded, similar in sound to those of the minke whale (Beamish and Mitchell 1973). 
sei whale (Balaenoptera borealis Lesson, 1828)

This species is little-known from acoustic records; it may easily be confused with fin and Bryde's whales. In air, sei whales produce a loud whistle emanated from the throat and having a sharp sound like a metallic stroke (Tomilin 1957). In the region between Nova Scotia and Newfoundland (440 49', $\left.56^{\circ} 28^{\prime}\right)$, where a few individuals occurred close to the ship, click series were recorded (recording bandwidth $50-7500 \mathrm{~Hz}$ ) with maximum energy at $3 \mathrm{kHz}$; the total duration of a series was $7 \mathrm{sec}$ while the duration of a single click was $4 \mathrm{msec}$. "20 Hz signals" were recorded as well, but were concealed by cable noise. When common dolphins approached the recording site, low frequency clicks were recorded, but the above-mentioned click series are not known from dolphins (Busnel and Dziedzic 1966).

minke whale (Balaenoptera acutorostrata Lacepede, 1804)

With its sharply-shaped head, this is the smallest member of the genus Balaenoptera (maximum length is $10.2 \mathrm{~m}$; Nishiwaki 1966a), inhabiting all oceanic zones from polar regions to tropical seas. In air, loud sounds of exhaling ("groans") were heard, similar to those of the fin whale (Tomilin 1955, 1957). Schevill and Watkins (1972) were the first to report low frequency sounds of minke whales in the polynya off Ross Land, Antarctica (recording device bandwidth $30 \mathrm{~Hz}-30 \mathrm{kHz}$ ). During these signals, frequencies declined from $130-115 \mathrm{~Hz}$ to $60 \mathrm{~Hz}$. Sound intensity was $165 \mathrm{~dB}$ (re $1 \mu \mathrm{Pa} / 1 \mathrm{~m}$ ), and sound duration was $0.2-0.3 \mathrm{sec}$ with intervals of 8-97 sec.

Low-frequency "screams" were recorded at different frequencies from 80 to $140 \mathrm{~Hz}$ and durations of 165-320 msec (Winn and Perkins 1976). In frequency and duration these "screams" were similar to those recorded earlier (Schevill and Watkins 1972), but they were produced in series of regular and irregular intervals with a repetition rate of 2.1-2.3 pulses per second. The majority of minke whale sounds were organized into "series", sources long ago recorded in the ocean as A-series. The frequency of these signals is of changeable nature and may reach more than $800 \mathrm{~Hz}$ (most between 100 and $200 \mathrm{~Hz}$ ), although according to other notes, the energy minimum is $2 \mathrm{kHz}$. Individual variations of such signals by duration are $50-70 \mathrm{msec}$ with rather stable consecutive frequency, and total duration of the series is more than $1 \mathrm{~min}$. These signals are of individual character (Thompson 1979), similar to differences in frequencies of sound composition and recurrence among species.

Short series and clicks are divided into several groups according to dominant frequency (Winn and Perkins 1976): 1) $3.3-3.8 \mathrm{kHz}$; 2) $5.5-7.2 \mathrm{kHz}$; 3) $10.2-12.0 \mathrm{kHz}$, of $0.5-1$ msec duration. "Ratchet-like" pulses had a maximum frequency of $850 \mathrm{~Hz}$, duration of 1-6 msec in the case of single pulses and $25-30 \mathrm{msec}$ for groups of pulses. 
Genus: humpback whales (Megaptera Gray, 1846)

humpback whale (Megaptera novaeangliae Borowski, 1781)

In air, sounds produced by humpback whales used to be compared with steam locomotive horns (Rawitz 1900, Tomilin 1955). Watkins (1967) described an unusual signal - an exhalation with whistling. This sound, with a frequency of up to $2 \mathrm{kHz}$ and duration $2 \mathrm{sec}$, is evidently produced when exhaling and can be heard both underwater and in air. These sounds are supposed to be produced arbitrarily and are clearly different from those produced during normal exhaling. The noises sound much louder in air (by $35 \mathrm{~dB}$ ) than the typical sound of exhaling. Underwater, the sounds were of higher frequencies than normal exhalations, but of the same intensity level.

A large number of publications from the years 1949-1955 refer to underwater sounds of the humpback whale, but it was not until 1962 that spectrograms of underwater lowfrequency signals of this species were first published (Schevill and Watkins 1962). Tavolga (1968) described some of them, e.g., cries of $150-800 \mathrm{~Hz}$ of $1-1.5 \mathrm{sec}$ duration, and cries of $2 \mathrm{kHz}$ of $0.5 \mathrm{sec}$ duration. As well, higher frequency cries of $4-8 \mathrm{kHz}$ were mentioned (Levenson 1969, 1972). The most typical were "low grunts" at 120-250 Hz and "squalls", whistles, and "wailing turkey-like" sounds of dominant frequency of 0.5$1.65 \mathrm{kHz}$. The level of the sounds was 124.4-155.4 dB (re $1 \mu \mathrm{Pa} / 1 \mathrm{~m})$.

As defined recently, humpback whales are the most vocal whale species. In tropical waters during winter, complex and compound sounds including recurrent "songs" change constantly (Payne et al. 1983). The most obvious changes are when other individuals join in the group choruses. It was discovered that humpback whales "sing" (Winn et al. 1973, Tyack 1980, 1981, Darling et al. 1983, Glockner 1983). Each "singing" whale changes its "song" in accordance with other members of its group (Guinee et al. 1983). Humpback "songs" can be characterized as recurrent series of sounds of common frequency lower than $4 \mathrm{kHz}$ (Anonymous 1969, Payne and McVay 1971). They contain several acoustic themes, consisting of phrases or syllables (units according to Payne and McVay 1971). Themes and phrases sound in strict order and are repeated monotonously. The song may last for 7-36 min, but always has strictly organized structure. The difference in duration depends on the number of phrases or changes of each theme (Thompson and Winn 1977). Coming to the surface terminates the song, but after diving the song begins immediately once again. The song of humpback whales differs from bird song in terms of structure and song interval. On the whole, the character of the song (according to differences in sounds and phrase compositions) is in some way specific for mating and inter-generational transfer (with some individual variations). 
The analysis of dialects (Winn and Winn 1978) of different populations hardly allows distinguishing types of songs due to inadequate material and annual changes in song fragments (Winn and Winn 1978, Payne and Payne 1979). However, differences exist in fragments anddistinctive dialects probably occur among populations. For example, song phrases off New Zealand, Hawaii, and California do not sound similar to those from the northwestern Atlantic Ocean (Thompson et al. 1979). The major differences are between humpback whale songs recorded in the northern Pacific and the northern Atlantic oceans, although the basic structure of the "songs" has similar features (Payne and Guinee 1983). Studies of sounds of humpback whales in the Hawaiian Islands also identified atypical "songs", that formed from typical ones in natural and predictable ways (Frumhoff 1983). Some researchers offer an unusual interpretation of the functional meaning of humpback whale song as an indication of the male's physical condition, advertising length of time spent underwater (Chu and Harcourt 1986).

Besides songs, clicks at frequencies of $2-7 \mathrm{kHz}$, and noise signals emanated by nonsinging whales were produced (Winn et al. 1970a). Analysis of signals originating from a stranded whale near Newfoundland showed diversity, irregularity, and absence of songlike organization (Winn and Winn 1978).

Rather recently, an attempt was undertaken to discover the acoustic signals of humpback whales in their summer feeding regions in southeastern Alaskan waters (Thompson et al. 1986). Underwater signals of whales comprised mainly "groans" (20$1800 \mathrm{~Hz})$, "grunts" (25-1900 Hz), "piercing moans" (0.4-2 kHz), recurrent pulses (25-80 $\mathrm{Hz}$ ) and strikes on the surface. The "groans" contained harmonic sounds and could be subdivided into simple and complicated ones of average duration $800 \mathrm{msec}$. Most of the "groans" had slight frequency modulation. The "grunts" did not have any harmonic structure; they had a pulsed nature with increasing frequency modulation. Repetition rates of 850 "groans" and "grunts" were 1.8-3.2 sounds per minute. "Moans" (piercing and trumpet-like) had a plain harmonic structure and $400-600 \mathrm{msec}$ duration.

The duration of low-frequency pulses out of distinctive sequences varied from $300-400$ msec. Some of these pulse emanations had tonal characteristics, sometimes harmonized. The average frequency of emanations in repeated sequences was 5 times per min (duration of recording - 8.5 hours). All of the low-frequency pulse emanations were accompanied by unspecific enlargement of noise spectrum $(40-1250 \mathrm{~Hz})$ that as a rule decreased in intensity with duration. The authors attribute the pulses to generation of air bubbles when whales make spiral maneuvers during bubble-net feeding (for more details see: Wolman 1978, Earle 1979, Payne 1979). The accompanying noise $(40-1250 \mathrm{~Hz})$ was the result of air bubbles rising toward the ocean surface. 
Many "non-singing" sounds belonging to this species turned out to be closely connected with social interactions, in particular with the demonstration of aggressiveness and the state of excitement in groups of whales near the Hawaiian Islands (Silber 1986). The majority of such aggressive interactions are inherent to males (Baker and Herman 1984). Sounds recorded by Silber were of duration $0.25-5 \mathrm{sec}$ and in a frequency range up to $10 \mathrm{kHz}$, although the dominant frequency of most signals was not higher than $2 \mathrm{kHz}$. An increase in the size of the group caused an increase in the level of emanating signals. Humpback whales "sing" during migrations as well, their calls serving as indicators of migratory routes (Kibblewhite et al. 1967, Levenson and Leapley 1978, Mattila et al. 1987, Stone et al. 1987, Clapham and Mattila 1990).

C. Family: gray whales (Eschrichtiidae Ellerman et Morrison-Scott, 1981)

Genus: gray whales (Eschrichtius Gray, 1864) gray whale (Eschrichtius gibbosus Erxleben, 1877)

The gray whale's signals in air are exhaled breaths with inherent strong bass sounds. Signals were recorded at the $40-400 \mathrm{~Hz}$ range with energy maximum at $80-300 \mathrm{~Hz}$ (Eberhardt and Evans 1962). Each signal continued for about $0.1 \mathrm{sec}$ and consisted of 4-5 emanations. Neither whistles nor clicks were recorded. Schevill (1964) discovered whistles during mating activity of the gray whale, but did not record such sounds during feeding.

Gray whale signals recorded in the sea showed that the most typical "groaning" sounds occur at $20-200 \mathrm{~Hz}$ with a duration of $1.5 \mathrm{sec}$ (Cummings et al. 1968). "Whistling" signals with duration $1.25 \mathrm{sec}$ occur in the range of $15-175 \mathrm{~Hz}$; "gurgling" signals are more rare and occur in the range of $15-305 \mathrm{~Hz}$ with duration $0.7 \mathrm{sec}$. "Striking sounds" were as well noted at $350 \mathrm{~Hz}$. The intensity of these signals is $132-152 \mathrm{~dB}(\mathrm{re} 1 \mu \mathrm{Pa} / 1 \mathrm{~m})$. All these signals were recorded in all seasons of the year and it is still impossible to identify them with respect to particular kinds of gray whale activity.

Originally, some researchers denied the fact that these whales produce echolocation signals (Rasmussen and Heed 1965). Later, echolocation clicks were discovered in the frequency range of $70-3000 \mathrm{~Hz}$ (maximum energy at $400-800 \mathrm{~Hz}$ ). These sounds had durations of 10-15 msec, with an interval between pulses of 150-350 msec, and were reminiscent of sounds originating when rubbing the teeth of a comb (Asa-Dorian and Perkins 1967). A young gray whale (named Gigi) produced signals that sounded like "metallic pulsating signals", and resulted from human touches of the mammal's head. Signals consisted of 8-14 impulses with duration of $2 \mathrm{sec}$ and frequencies from $100 \mathrm{~Hz}$ to above $10 \mathrm{kHz}$ with energy maximum at $1.4 \mathrm{kHz}$. This signal was produced more than 5 
times a minute (Fish et al. 1974). "Moos" were also registered; they had a frequency of $100-200 \mathrm{~Hz}$ with the second peak at $115 \mathrm{kHz}$ (!) and duration of 1 sec.

Click series were recorded three times. In one case they sounded like the clicks of gray whales recorded in Viccashish Bay off Vancouver Island; these had a frequency range of 2$6 \mathrm{kHz}$ (maximum energy at $3.4-4 \mathrm{kHz}$ ). The number of signals in a series varied from 1833, repetition rate 9.5-36 times per sec [in Gigi] and 8-40 in an individual near Vancouver Island. The average duration of a click was $2 \mathrm{msec}$. The other proof of the fact that clicks occur was discovered by Norris et al. (1977) when recording sounds of young, stranded gray whales: these were sporadic series with repetition rates of more than 2 per sec. They differed from those produced by Gigi in having greater frequency range (above $20 \mathrm{kHz}$ ), longer duration ( $0.25 \mathrm{sec}$ vs. Gigi's $1-2 \mathrm{msec}$ ), and higher repetition rate. The data obtained give evidence that gray whales produce rather variable sounds depending on the situation.

Thus, whales' signals typically contain low-frequency "moans" that have a duration of 0.4-35 sec with predominant frequencies of $12-500 \mathrm{~Hz}$ (usually $20-200 \mathrm{~Hz}$ ). "Moans" may have marked harmonic structure or clear tones similar to " $20 \mathrm{~Hz}$ " signals that are produced by all the whale species except sei whales and minke whales.

The second group includes short-duration signals (grunt-like) produced by humpback whales and northern and southern right whales, bowhead whales, gray whales, fin whales, and minke whales. The durations of these signals are $50-500 \mathrm{msec}$, with maximum power at $40-200 \mathrm{~Hz}$.

The third group includes grinding-twittering sorts of sounds, moans and whistles of frequency $1 \mathrm{kHz}$. The first kind of sounds in this group is formed by short pulses (50-100 $\mathrm{msec}$ ) of discrete tones with quick changes of frequency and without harmonics, while moans and whistles are tonal signals with harmonics or without them.

The fourth group consists of $0.5-5 \mathrm{msec}$ duration and $20-30 \mathrm{kHz}$ frequency sounds of blue whales (Beamish and Mitchell 1971). Clicks of clear tones and of broadband frequency were recorded from minke, gray, humpback, sei, Bryde's, and fin whales. Species-specific signals are used by whales according to observations of humpback whales in the West Indies (Winn et al. 1975) and in the Caribbean Sea (Levenson and Leapley 1976). "Thump trains" inherent to minke whales were recorded in Antigua and that permitted clearing up its distribution to the south (Thompson et al. 1979). That is why acoustic information tranferred by bottom stations is an important means for increasing knowledge about different kinds of whales. 
Sperm whales (Backus and Schevill 1966), as well as other Physeteridae (Caldwell et al. 1972), were noted to produce signals of individual or particular character. Evidence exists that individual distinctions of recurrent frequency and signal range are possible in minke whale thump trains as well as fin whales' $20 \mathrm{~Hz}$ signals. Multivariate analysis techniques were used to show individual character of high frequency "moans" of humpback whales (Hafner et al. 1977). The individual signals that whales produce may be of great importance in their social organization.

The role of inter-species communication was demonstrated with the case when signals produced by killer whales influenced the behavior of migrating gray whales (Cummings and Thompson 1971). Data are also available concerning northern right whales' sounds, although those signals were rather weak (Cummings et al. 1972). Blue, fin, and minke whales produce ultrasonic clicks $(20 \mathrm{kHz})$. Humpback, minke, and gray whales produce clicks. However, in none of these cases was it proved that these species use echolocation (Norris 1969, Beamish 1974). It is difficult to suppose that signals of this kind are used for the discovery of such tiny organisms as plankton. But $25 \mathrm{kHz}$ signals emanating from blue whales may serve to detect concentrations of plankton (Beamish and Mitchell 1971), and minke whale's signals may detect fish (Beamish and Mitchell 1973). Humpback whales use mainly vision (Beamish 1978) for orientation and, when not operating, they bump into obstacles. Nevertheless, powerful low-frequency sounds produced by this whale supply it with information about depth, shoals and obstacles (Thompson et al. 1979), and echos accompanying these signals may be used by mysticete whales for echolocation.

Information on sound generation in the Mysticeti is insufficient. Mysticete whales do not have vocal chords, but the larynx and respiratory tracts may be used for producing sounds. Sounds are loudest when whales are within groups: about $190 \mathrm{~dB}$ for the blue whale (Cummings and Thompson 1971a). The sounds of minke whales are equal to 152.6 $\mathrm{dB}$ (Beamish and Mitchell 1973). The high-amplitude, low-frequency sounds of whales spread over several tens if not hundreds of miles under certain conditions. That is why use of the term "flock" with respect to whales needs to be taken in wider interpretation (Payne and Webb 1971), and this hampers studies on social structure of whale herds.

The auditory perception of whales is difficult to study experimentally due to the unwieldiness of sound projectors compared to those used for studying dolphins. It is known from observations that they react to noise originating from ships and sonic depth finders. Anatomic studies (Fleischer 1976) proved that mysticete whales have lower frequency hearing than the odontocetes. Mysticete whales may signal for food (Payne and Webb 1971) and partner location, for determining the behavior of partners, for individual 
identification, and for evaluation of flock size, etc. Singing humpback whales are active males (Tyack 1980, Darling et al. 1983, Glockner 1983) ready for mating (Winn et al. 1971), and this can be used for sex identification (Winn et al. 1973) and for finding a proportion between singing and non-singing whales (Winn et al. 1975).

Sporadic low-frequency "moans" of northern right whales represent communicative signals and are common when whales are moving towards plankton concentrations (Watkins and Schevill 1976). Specific behavior correlates with specific signals, e.g., humpback whale jumps (Winn et al. 1970a), or click series produced by a young gray whale while looking for its mother (Norris et al. 1977).

Southern right whales were noted to have periodic acoustic activity (Payne and Payne 1971), as well as gray whales (Painter 1963) and humpback whales in the Bermuda region (Payne and McVay 1971). The larger number of signals at night time can be explained by worsening visibility, although that is not true for humpback whales (Thompson et al. 1979). Ships cause changes in whales' behavior. Minke whales, for example, come closer to sounds.

In general, with the help of sounds, mysticete whales can tell: 1) mutual location; 2) individual and species attributes; 3) certain information about life, danger, partner; 4) evaluate the social structure of a flock; and 5) orient themselves by bottom, shoal, coast, etc.

\section{Suborder: toothed whales (Odontoceti Flower, 1867)}

The sonar range of toothed whales extends to $170-256 \mathrm{kHz}$. Among the sounds they produce, one can distinguish pulsed (single and series) and continuous sounds. The durations of certain pulses vary from a few $\mu \mathrm{sec}$ up to tens of $\mathrm{msec}$, and the duration of pulse series comprise sec. Pulse repetition rate can vary from a few per sec to hundreds per sec. Some long sounds may be considered to be almost monochromous whistles, amplitude- or frequency-modulated; others have complicated structure that can be identified as barking, roaring, howling, squealing, etc. These signals can consist of simultaneous pulses and whistles and continue from $\mathrm{msec}$ to several sec.

A. Family: river dolphins (Platanistidae Gray, 1863)

Genus: Amazon dolphins (Inia d'Orbigny, 1834)

Amazon dolphin (Inia geoffrensis Blainville, 1817)

The first records of this dolphin in an aquarium showed that Inia signals have common frequencies of $0.5 \mathrm{kHz}$. Later, 12 types of signals were recorded, including "barking", "squealing", and clicks (Layne and Caldwell 1964, Caldwell et al. 1966). On the whole, the sounds are monotonous, not of great power, and are of low frequency (up to $16 \mathrm{kHz}$ ). 
It was discovered that Inia produces pulsed signals in natural environments (Norris et al. 1972): single, with a duration of $100 \mu \mathrm{sec}$ (Evans 1973), doubled and tripled (doubled with small amplitude). According to Caldwell et al. (1966), Inia produces clicks within audible range and can change the spectral composition of the pulse series, but Penner and Murchinson (1970) recorded pulses in the range of $25-200 \mathrm{kHz}$ when experimenting with the animal's ability to determine target thickness. In the Rio Negro, regular amplitude alterations of pulsed signals were recorded when animals were passing by the hydrophones, giving evidence of the narrow angle of emanation (Norris et al. 1972). Japanese researchers noted the existence of whistling signals in Inia (Nakasai and Takemura 1975).

Genus: Ganges susu (Platanista Wagler, 1830)

Ganges susu (Platanista gangetica Lebeck, 1801)

Acoustic studies of a few dolphins in aquaria showed that $87 \%$ of the total number of signals were clicks with repetition rates of 5-500 pulses per sec and frequencies above 20 kHz. Echlocation "trills" ( $0.4 \mathrm{sec}$ duration) comprised 5\%, "twitter" 3\%, whistles $1 \%$ out of all the signals (Mizne et al. 1971). High-frequency clicks of not great power had maximum energy at about $10 \mathrm{kHz}$, and repetition rates of 80 pulses per sec (Herald et al. 1969, Andersen and Pilleri 1970). Durations of single clicks were within 75-150 $\mu \mathrm{sec}$ (Evans 1973).

Indus dolphin (Platanista indii Blyth, 1859)

Only pulsed signals with repetition rates of 90pulses per sec were recorded in aquaria and 124 pulses per sec in the river, with intervals between series of $1-60 \mathrm{sec}$, frequency $0.6-16 \mathrm{kHz}$ (communication) and $20-100 \mathrm{kHz}$ (Pileri et al. 1970).

Genus: Franciscana dolphins (Pontoporia Gray, 1846)

Franciscana, Pontoporia (Pontoporia blainvillei Gervais et d'Orbigny, 1844)

This species' signals were emanated out of of the Rio La Plata into the sea on a background of high acoustic activity of fish (Busnel et al. 1974). Three types of pulsed signals were recorded. Low-frequency signals had energy maxima in the range of 0.33$2.96 \mathrm{kHz}$, middle frequency $13-19 \mathrm{kHz}$, high-frequency of $16-24 \mathrm{kHz}$. Durations of signals of the first two groups were $1.5-5.0 \mathrm{msec}$ (average $3.1 \mathrm{msec}$ ), of the third group 0.25-0.4 msec (average $0.32 \mathrm{msec}$ ). This difference is explained by uncontrollable conditions of location of "receiver-emanator", that is by the diagram, as well as individual features. 
Genus: river dolphins (Lipotes Miller, 1918)

beiji (Lipotes vexillifer Miller, 1918)

In captivity beiji dolphins produced two main signals: whistles of $330 \mathrm{msec}$ duration and dominant frequency of 2-12 kHz, and pulsed signals, single and in series (Jing Xianying et al. 1981, 1982). In natural environments, whistles of $90-550 \mathrm{msec}$ duration (average $330 \mathrm{msec}$ ) were recorded with dominant frequency $6 \mathrm{kHz}$. These usually have 2 , 3 , and 4 harmonics and echolocation clicks of $8-160 \mathrm{kHz}$, emanating in series each of which is comprised of 5-6 single pulses (maximum up to 20); the phase of each click differs from following by $180^{\circ}$. A series can contain both high-frequency and lowfrequency pulses (Xiao Youtu and Jing Rongcai 1989).

The analysis of behavior and acoustic activity of beiji enabled the singling out of a number of correlations (Wang Ding et al. 1989). Signals of 0.13-0.32 sec (average 0.26 $\mathrm{sec}$ ) duration with power maxima at $12 \mathrm{kHz}$ were used for communication. "Squeals" (whistles) of dominant frequency $7.6 \mathrm{kHz}$ expressed the state of excitement and distress.

B. Family: oceanic dolphins (Delphinidae Gray, 1821)

Genus: rough-toothed dolphins (Steno Gray, 1846) rough-toothed dolphin (Steno bredanensis, 1828)

Signals of this species contain whistles and clicks (Busnel and Dziedzic 1966, Turner and Norris 1966). Four types of signals were identified according to frequency modulation and amplitude alteration. Whistle duration was $0.5 \mathrm{sec}$, and dominant frequency was 4-7 $\mathrm{kHz}$. The description of whistle characteristics is presented in Table 1, where serial "numbers" corresponds to frequency of occurrence.

Table 1. Characteristics of whistles of the rough-toothed dolphin.

\begin{tabular}{lcccccc}
\hline Number & $\begin{array}{c}\text { Duration } \\
(\mathrm{sec})\end{array}$ & $\begin{array}{c}\text { Initial } \\
\text { frequency } \\
(\mathrm{kHz})\end{array}$ & $\begin{array}{c}\text { Final } \\
\text { frequency } \\
(\mathrm{kHz})\end{array}$ & $\begin{array}{c}\text { Maximum } \\
\text { frequency } \\
(\mathrm{kHz})\end{array}$ & $\begin{array}{c}\text { Minimum } \\
\text { frequency } \\
(\mathrm{kHz})\end{array}$ & Harmonics \\
\hline 1 & 0.55 & 5.7 & 5.0 & 5.7 & 3.5 & 2 \\
2 & 0.61 & 7.0 & 7.0 & 7.0 & 7.0 & 2 \\
3 & 0.38 & 6.4 & 7.0 & 7.0 & 6.0 & 2 \\
4 & 0.50 & 5.7 & 6.0 & 7.5 & 5.7 & 2 \\
\hline
\end{tabular}

Echolocation clicks are typical and produced with varying repetition rates, increasing regularly during approach to the target. Power maxima of clicks were at $14-25 \mathrm{kHz}$ (equipment limit was $30 \mathrm{kHz}$ ). Norris and Evans (1967) discovered a marked frequency emanation up to $208 \mathrm{kHz}$ in the clicks of this dolphin species, having a maximum range of 
40-80 kHz and duration of 10-250 $\mu \mathrm{sec}$ (Norris 1969). Sonic pressure fell by $6 \mathrm{~dB}$ within $11^{\mathrm{o}}-17^{\circ}$ from the middle line $\left(0^{\circ}\right)$.

Genus: long-beaked dolphins (Sotalia Gray, 1866)

tucuxi (Sotalia fluviatilis Gervais, 1853)

Tucuxi make typical echolocation clicks and infrequent whistles (Mizue et al. 1971). Sotalia produced short, usually double, pulses for $60-120 \mu \mathrm{sec}$. In a series of double pulses, amplitude alterations were noticed for both the first and second pulses within 0.8$3.0 \mathrm{msec}$. Single clicks were also recorded that were always twice as short in duration as the double amplitude ones. Maximum repetition rate of double pulses was 960 pulses per sec (that is 1920 single pulses/sec), more usually 600 pulses $/ \mathrm{sec}$, and 10-70 pulses $/ \mathrm{sec}$ in migrating dolphins. The duration of pulses was $1.2-1.5 \mathrm{msec}$, intervals between pulse pairs was $0.5-8.0 \mathrm{msec}$, and maximum frequency at $8-15 \mathrm{kHz}$. Short whistles $(0.2 \mathrm{msec})$ were registered with maximum frequency $10-15 \mathrm{kHz}$ (Caldwell and Caldwell 1970b, Norris et al. 1972).

Genus: spotted dolphins (Stenella Gray, 1866) spotted dolphin (Stenella plagiodon Cope, 1866)

Studies of sounds of this species conducted in the sea showed whistles of $5-10 \mathrm{kHz}$ (mainly $6 \mathrm{kHz}$ ) and of $0.4 \mathrm{sec}$ duration (Schevill and Watkins 1962). Stenella signals in aquaria were well-described (Wood 1953, 1954). Caldwell and Caldwell (1966) noted rare loud whistles that occurred several times one after another when two females were studied. In acoustic isolation, the dolphins made twittering (chirping) sounds - short clear tones with increasing frequency. During feeding, series of clicks were noticed of low power (it was probably an artifact, because the authors were not certain about acoustic isolation from the neighboring aquarium basins with Tursiops). Few types of pulsed (frequency modulated) signals, "piercing screams", "peeps", "squeals", "barking", "growling", "cracking" (recording bandwidth: $40 \mathrm{~Hz}-20 \mathrm{kHz}$ ) were recorded. In the sea, this species' clicks have low power alternated with narrowband whistles (Caldwell and Caldwell 1971a). Other studies of spotted dolphin signals in the sea revealed whistles of $8-16 \mathrm{kHz}$ frequency and duration $0.3 \mathrm{sec}$, and also clicks (Schevill and Watkins 1962).

long-snouted spinner dolphin (Stenella longirostris Gray, 1828)

Signals of this species recorded by four hydrophones enabled detection of more power variability of pulses and whistles, as well dolphin location, measurement of the speed of their movement, their depth at the time of emanation and the trajectory of the animal's movement along the area of water (Watkins and Schevill 1974). 
Genus: white-sided dolphins (Delphinus Linnaeus, 1758) common dolphin (Delphinus delphis Linnaeus, 1758)

Signals produced by common dolphins were studied in their natural environment (Shishkova 1965, Busnel and Dziedric 1966) as well as in captivity (Vincent 1960, 1963, Titov and Tomilin 1970, Titov 1971, Titov and Yurkevitch 1971, etc.). Shiskova (1965) mentioned certain characteristics of the audible range of the signals produced by populations in the Black Sea. In the aquarium, clicks made by common dolphins had an average duration of $20 \mathrm{msec}$ (and much shorter), repetition rate of 5-100 pulses/sec in the range of $4-15 \mathrm{kHz}$ (Vincent 1960, 1963).

Studies conducted both in the sea and in aquaria revealed short series of clicks (each series was 2-3 clicks) of about $0.5 \mathrm{sec}$ duration inherent to this species (Busnel and Dziedric 1966), as well as squeaks (series of clicks of high repetition rate) with maximum power at $4.9 \mathrm{kHz}$. Five types of whistles with and without frequency modulation, both combined with clicks and others were recorded. The authors thought that these signals were associated with hunting, worrying, fright, calling for help, isolation, and flock behavior.

In aquaria, common dolphins also produced series of echolocation clicks of various repetition rates, that constituted $93 \%$ of total signal duration when the mammals spent the first 6 min getting acquainted (Titov 1971). Series of pulsed signals - "quacks" (Titov and Yurkevitch 1971) consisting of 8-20 signals, continuing for 0.1-0.8 sec and at frequencies of $4-80 \mathrm{kHz}$ with maximum energy in the range of $1.6-32 \mathrm{kHz}$ were recorded. The same authors described "croaks" of duration $50-70 \mathrm{msec}$, and frequency $1-6 \mathrm{kHz}$ with energy maximum at about $2 \mathrm{kHz}$; "croaks" of 15-50 msec duration with maximum frequency in the 2.5-8 kHz range, as well as different kinds of "moans" ("bark", "blast", "wail", "roar", whistles), with duration of the second portions up to $2 \mathrm{sec}$ in the range of $1-49 \mathrm{kHz}$. These are thought to express different emotions - pain, fear, hunger, calling of a partner and so on. For 18 signals, spectrographic presentations were made (Titov et al. 1971).

Genus: bottlenose dolphins (Tursiops Gervais, 1855)

bottlenose dolphin (Tursiops truncatus Montagu, 1821)

Sounds made by this species are probably studied by more researchers than any other, and mainly in captivity (Titov and Yurkevitch 1971, Titov and Nikolenko 1975, Kritzler 1952, Lilly and Miller 1961, Caldwell et al. 1962, Evans and Prescott 1962, Lilly 1962, Schevill and Watkins 1962, and others).

They discovered: 18 types of whistles in the frequency range of $4-18 \mathrm{kHz}$, and of duration of 0.1-3.6 sec; "barks" of fundamental frequency $0.2-0.3 \mathrm{kHz}$ with harmonics up to $16 \mathrm{kHz}$, and duration $0.1 \mathrm{sec}$; "mournful howls", "meowing", "whimpering", 
"squeals", "peep", "twitter", banging of jaws; signal of fright (alarm), maximum power at 0.1-8 kHz; signal of calamity (two frequency-modulated whistles of 0.2-0.6 sec duration); "squeaks", "grinding" with maximum at 20-170 kHz; single clicks 1-10 msec at 20-25 $\mathrm{kHz}$; series of clicks of repetition rate 2-1200 sounds per sec and of duration $0.1-1.0 \mathrm{sec}$ (and continuing for up to $15 \mathrm{sec}$ without rest)(Evans and Prescott 1962). Pulsed signals of this species have been also studied more thoroughly (Dubrovskiy 1975).

The study of this species' bioacoustics in natural environments during migration, searching, and hunting behavior (Bel'kovitch et al. 1978a,b) allowed singling out 28 types of signals/whistles, to find ethological-acoustic correlations, and to show the individual nature of echolocation series (Bel'kovitch et al. 1977, Bel'kovitch and Kaznadzey 1978).

Genus: gray dolphins (Grampus Gray, 1828)

Risso's dolphin (Grampus griseus G. Guvier, 1812)

Acoustic signals of this species are little-known. In the open sea, dual clicks were recorded that sounded for $10 \mathrm{msec}$, had low repetition rates with power maximum up to 10 $\mathrm{kHz}$, and "squeaks" (main frequency up to $4 \mathrm{kHz}$ ) and whistles in the range of $1.2-8 \mathrm{kHz}$ (Schevill and Watkins 1962).

Genus: short-headed dolphins (Lagenorhychus Gray, 1846)

Peale's dolphin (Lagenorhynchus australis Peale, 1848)

Sounds of this dolphin were recorded in the sea and then analyzed by Schevill and Watkins (1971). These records represent two types of clicks: low frequency at narrow range up to $2 \mathrm{kHz}$ with power maximum at $1 \mathrm{kHz}$, duration of $1.5-3 \mathrm{msec}$, and repetition rates of 5-25 pulses per sec; and clicks of $10-12 \mathrm{kHz}$ with maximum at $5 \mathrm{kHz}$, duration under $1 \mathrm{msec}$. In addition, short and loud squeaks sounding for 0.6-1.1 sec, were noticed, with fundamental frequency about $30 \mathrm{~Hz}$. The signals mentioned above may be classified as discriminatory and orientational (Norris et al. 1967), but at the time the authors supposed that the squeaks could be artifacts and that only clicks are real sounds of this species.

Atlantic white-sided dolphin (Lagenorhynchus acutus Gray, 1828)

Acoustic signals of this species were studied in the sea (Schevill and Watkins 1962) and in the aquarium (Rehman 1961). Different kinds of whistles in the frequency range of less than $1 \mathrm{kHz}$ were discovered, increasing up to $24 \mathrm{kHz}$, as well as echolocation clicks. Compared with other species, this dolphin when approaching a target produces clicks with repetition rates from 80 to 30 pulses/sec (Rehman 1961). These clicks sound at lower frequency range (Gales 1966). The navigation mechanisms of this dolphin evidently do not function as well as those of bottlenose dolphin (Norris 1964, 1969). 
white-beaked dolphin (Lagenorhynchus albirostris Gray, 1828)

This species' sounds were studied in the sea (Schevill and Watkins, 1962). Whistles prevailed over other signals. They had frequencies of $6.5-15 \mathrm{kHz}$ and with durations up to $0.5 \mathrm{sec}$. Also noted were series of pulsed signals with repetition rates up to 750 pulses $/ \mathrm{sec}$ (Mitson and Morris 1988). Frequency of the pulses reached up to $350 \mathrm{kHz}$.

Genus: right whale dolphins (Lissodelphis Glogeo, 1841) northern right whale dolphin (Lissodelphis borealis Peale, 1843)

In 1975, near the northern coast of California, signals of northern right whale dolphins were recorded (Fish and Turl 1977). The power of signals made by a flock comprised of 200 individuals was $170 \mathrm{~dB}$ (re $1 \mu \mathrm{Pa} / 1 \mathrm{~m}$ ). The signals consisted of series of pulses with a high repetition rate, blending into certain "groans". The researchers did not succeed in recording any whistling signals.

Four other atempts to study sounds made by northern right whale dolphins (Leatherwood and Walker 1979) were described in the literature (1961, 1971, 1972 , 1977). Small numbers of whistling sounds were recorded. They had frequencies of 10-16 $\mathrm{kHz}$ and durations of 0.3-0.5 sec. Other sounds were short low-frequency signals (1.1$4.0 \mathrm{kHz}$ ), consisting of four tones. More commonly, like in the study mentioned above, were series of pulses (clicks) with high repetition rates. The authors noted that some whistles of northern right whale dolphins consist of pulse series that repeat one after another with repetition rate $80-100$ pulses/sec, that are possible to record using the method described by Watkins (1967b).

Genus: motley dolphins (Cephalorhynchus Gray, 1846)

Heaviside's dolphin (Cephalorhynchus heavisidii Gray, 1828)

The only publication devoted to sounds produced by this species describes pulse series repeated with a frequency of 20-100 pulses/sec; signals of frequency up to $5 \mathrm{kHz}$ and moans with harmonic structure consisting of 300-500 pulses (Watkins et al. 1977). The authors stressed the similarity of certain signals to those of the harbor porpoise (Phocoena phocoena).

Chile dolphin (Cephalorhynchus eutropia Gray, 1846)

Recordings made by Schevill and Watkins in a natural environment (Vulaja region) demonstrated series of short pulses of very low power in the form of rather stereotyped successions (Goodall et al. 1988). The repetition rates of the pulse series reached 500 pulses per sec, but the durations of the series varied from 0.4-2 sec. Most likely, the low intensity of this species' signals is explained by the fact that the upper limit of the equipment used for recording was $30 \mathrm{kHz}$, while the peaks of power inherent to other representatives of Cephalorhynchus were much higher $(124-130 \mathrm{kHz})$. 
Commerson's dolphin (Cephalorhynchus commersonii Ardy, 1846)

Records made in captivity displayed series of high-frequency clicks and stereotyped "moans" of a pulsed nature (Watkins and Schevill 1980). Subsequent studies discovered acute orientation of echolocation series comprising short narrowband pulses with the peak of power at 124-130 kHz (Kamminga and Wiersma 1981, 1982, Shochi et al. 1982, Hackbarth et al. 1985). Durations of single pulses were 120-180 $\mu \mathrm{sec}$. The study of sounds inherent to this species in the natural environment showed a high proportion of double clicks of 350-500 $\mu \mathrm{sec}$ duration and main energy at $133 \mathrm{kHz}$ (Evans et al. 1988).

Hector's dolphin (Cephalorhynchus hectori Van Veneden, 1881)

Single and double pulses of low power were produced by Hector's dolphin in the form of series of pulses that followed one after another with much varied frequencies (Dawson 1988). Power peaks of pulses were at high frequencies of $120 \mathrm{kHz}$ and sounded very much like signals produced by Cephalorhynchus commersonii and Phocoenoides dalli. Durations of the majority of pulses were less than $200 \mu \mathrm{sec}$.

Genus: Irrawaddy dolphins (Orcaella Gray, 1866)

Irrawaddy dolphin (Orcaella brevirostris Gray, 1866)

In natural environments, Irrawaddy dolphins made clicks of 25-30 microsec duration with power maximum at $60 \mathrm{kHz}$ (Kamminga et al. 1983). Repetition rates of pulse series was 40-60 pulses per sec. Whistling sounds were not recorded.

Genus: false killer whales (Pseudorca Reinhardt, 1862)

false killer whale (Pseudorca crassidens Owen, 1846)

Recordings, conducted in the sea (Schevill and Watkins 1962), discovered loud clear whistles in the range of $4.6-8.0 \mathrm{kHz}$ of $0.3-0.6 \mathrm{sec}$ duration that sounded simultaneously with clicks of $0.08 \mathrm{msec}$ duration and of not large power with maximum at $8-12 \mathrm{kHz}$ (Bushel and Dziedric 1968). Studies of sounds produced by false killer whales in captivity discovered series of echolocation pulses with frequency peaks at $28 \mathrm{kHz}$, the duration of single clicks was about 60-75 $\mu \mathrm{sec}$ (Kaminga and van Velden 1987). Whistling signals of about $8 \mathrm{kHz}$ were also recorded.

Genus: killer whale (Orcinus Fitzinger, 1860)

killer whale (Orcinus orca Linnaeus, 1758)

The first records of this species were made in the sea with sonic depth finders aboard ships (Wenz 1964). Echolocation clicks of fundamental frequency at $0.75-1.5 \mathrm{kHz}$ of $2-4$ times longer duration than those of dolphins were recorded.

Later sounds were studied in detail in a killer whale named "Namu". Commonly, clicks had narrowband components of $0.25-0.50 \mathrm{kHz}$ as well as that of low amplitude, high-frequency components. Clicks were made in series of 10-25 sounds with low 
repetition rates. The spectral composition of clicks in a series went down to $0.5-0.35 \mathrm{kHz}$ at the end. The duration of each click was about 10-25 msec (Norris 1969). According to Singleton and Poulter (1968), these clicks produced strong echos that could be heard at a long distance, with the most energy concentrated in discrete harmonics. There were singled out 9 types of sounds inherent to a male that were distinctly different from those by a female. Those signals were powerful enough to communicate at $12 \mathrm{~km}$ distance. The most common signal started at $0.34-2 \mathrm{kHz}$ frequency and remained constant, or changed slowly during 0.25-3 sec. After that it changed an octave down and then jumped 1-2 octaves up over the starting frequency. In addition, in 0.2-0.3 sec after the signal started, there appeared a new spectral component at $1.05-6 \mathrm{kHz}$ (up to $1.64-7.5 \mathrm{kHz}$ ) and in 0.1 $0.2 \mathrm{sec}$ all the characteristics of that component returned to their initial values. The total duration of this complicated signal varied from $0.5-5 \mathrm{sec}$.

The study of sounds made by two remote killer whale populations enabled the identification of the following classes of signals: 1) clicks, $30-500 \mathrm{~Hz}$ frequency, usually made as a double signal; repetition rate of $10-30$ pulses/sec; 2) buzzes, main frequency under $5 \mathrm{kHz}$; 3) squeals, $0.5-16 \mathrm{kHz}$ frequency; 4) whistles. Certain geographic differences in signal production were shown (Jehl et al. 1980).

Certain sounds produced by killer whales correspond to hunting behavior (Steiner et al. 1979), and probably concern the coordination of actions of hunting animals. Underwater sounds of four isolated groups of killer whales were studied in the coastal waters of British Columbia (Ford and Fisher 1983). Three groups of signals were discovered: clicks of 0.8-25 msec duration that are probably used in echolocation (Schevill and Watkins 1966); whistles of main frequency $1.5-18 \mathrm{kHz}$ and duration $50 \mathrm{msec}$ to $10-12 \mathrm{sec}$; and pulsed "screams" at 1-6 kHz of duration $50 \mathrm{msec}-10 \mathrm{sec}$. The latter are, as the authors described, the individual (species) signals, and the combination of the signals made by whales referring to a certain group is the group-specific dialect. More studies indicated that 7-17 group-specific "moans" exist (Ford 1989).

Genus: pilot whales (Globicephala Lesson, 1828)

Sounds of long-finned and short-finned pilot whales are presented in a number of publications (Kritzler 1952, Brown 1960, Dreher and Evans 1962, Schevill and Watkins 1962). They provide general characteristics of the most typical sounds: squirts by blowholes, belches by blowholes, clicks, "squeaks", "whimpers", and whistles. Double clicks have also been described (Busnel et al. 1971).

long-finned pilot whale (Globicephala melaena Traill, 1809)

In natural environments whistles of $2-4.4 \mathrm{kHz}$ were recorded (Schevill and Watkins 1962). Pulses (clicks) were not recorded. In the sea, 5 types of signals were singled out 
from a flock containing 11 individuals (Busnel and Dziedzic 1966). The majority of sounds were whistles combined with "squeaks". These signals were repeated every 3-5 sec; sometimes series of them followed one another in 10-15 sec intervals. Sounds of the first type had a fundamental frequency of $4-8 \mathrm{kHz}$, and due to frequency variations in time, 3 different kinds of these signals were produced with durations of $0.39-0.87 \mathrm{sec}$. The second type of signal included pulsed signals with 3 different repetition rates. They could be described as "squeak", "trumpet sound" (blast), and "peep". The main frequencies were 0.8-1.5 kHz, series duration 0.1-0.2 sec; 0.5-1.4 sec and $0.2 \mathrm{sec}$ respectively.

The third type included long whistles $(1.4-2.7 \mathrm{sec})$, frequency-modulated and combined with squeaks. This was a rather common signal. Whistles were 2-3 times longer than squeaks, fundamental frequency was $8.8 \mathrm{kHz}$ with maximum energy at 2-15 $\mathrm{kHz}$. Frequencies up to $32 \mathrm{kHz}$ were often recorded.

The fourth type were also double signals, consisting of clicks and whistles. This was the most natural, repeated signal. The frequency was about $3 \mathrm{kHz}$, with a total duration of $0.55 \mathrm{sec}(0.18-0.27 \mathrm{sec}$ for clicks, 0.16-0.40 sec for whistles).

The fifth type was represented by a long whistle $(0.7-0.9 \mathrm{sec})$ that started at $3 \mathrm{kHz}$ and reached a maximum of $4 \mathrm{kHz}$. The increase was of linear character and equaled $250 \mathrm{~Hz}$ per $0.1 \mathrm{sec}$. Frequencies decreased by $740 \mathrm{~Hz}$ per $0.1 \mathrm{sec}$. A great variety of whistle contours were demonstrated while studying sounds of wild long-finned pilot whales (Taruski 1979). Seven main contours, described by the author, could be united with a certain number of intermediate forms. Other whistle attributes varied as well. The sounds were analyzed according to 14 behavior situations and in some cases acoustic activity correlated with the context of a situation and worrying. A great number of complicated whistles were associated with high levels of excitement. It is assumed that 5 out of 7 main contours are individually-based. The average frequencies were $3.5-4.7 \mathrm{kHz}$, average duration $0.65-1.0$ sec.

short-finned pilot whale (Globicephala macrorhynchus Gray, 1846)

There are rather few data on sounds made by this species. It was mentioned that shortfinned pilot whales produce whistles at frequencies varying from $2-12 \mathrm{kHz}$ (Schevill 1964).

Genus: porpoises (Phocoena G. Cuvier, 1817) harbor porpoise (Phocoena phocoena Linnaeus, 1758)

In aquaria, sounds produced by 3 females and 2 males were recorded. All the sounds made were of low frequency (below $2 \mathrm{kHz}$ ) and consisted of pulses with different repetition rates; whistles were not recorded (Busnel et al. 1963, Busnel and Dziedzic 1966). Signals were discovered that were specific to feeding on fish, dominating, mating 
and copulation, and different situations (alarm signal). Anomalous signals had durations of $0.65 \mathrm{sec}$ and fundamental frequency of $2 \mathrm{kHz}$, but some components of the sounds reached $12 \mathrm{kHz}$. Weak and narrowband clicks of $2 \mathrm{kHz}$ predominated and they had repetition rates up to 1000 pulses $/ \mathrm{sec}$. The maximum intensity was about 1 dyne $/ \mathrm{cm}^{2}$ at $1 \mathrm{~m}$ (Schevill et al. 1969, Watkins 1974), for clicks of $0.5-5 \mathrm{msec}$ duration and pulse series durations up to 2 sec.

At the same time, Dubrovsky et al. (1970) showed that these animals produce ultrasonic sounds at frequencies of at least $20-100 \mathrm{kHz} ; 120-140 \mathrm{kHz}$ (Voronov 1978); $110-160 \mathrm{kHz}$ (Møhl and Andersen 1973). These low-power sounds always precede but are rather strictly connected with sonic signals. Ultrasonic impulses have abrupt forefronts in contrast to the steadily increasing intensity of low-frequency signals. It is interesting to note that when porpoises are detecting targets, they may produce double pulses of low frequencies and both may have identical or different frequencies. "Audible-audible" couplets sound very irregular compared with "ultrasonic-audible" couplets, but at the same time they were not recorded when detecting fish.

Emotional signals are inherent to porpoises. These signals are fright, worry, pain that comes with catching and injury; as well as "squeals" of $0.4-4 \mathrm{kHz}$ frequency and $0.02-1.0$ sec duration; "twitter", bird-like "peep" of frequency $1.2-3 \mathrm{kHz}$ and $20-30 \mathrm{msec}$ duration (Titov and Yurkevitch 1971).

Genus: Dall's porpoise (Phocoenoides Andrews, 1911)

Dall's porpoise (Phocoenoides dalli True, 1885)

Sounds made by Dall's porpoise were recorded by W. Evans (Ridgway 1966). They were series of pulses (clicks) similar to those of harbor porpoises (Phocoena phocoena). Whistles inherent to many representatives of the family Delphinidae were not discovered. Careful analysis of pulsed signals of Dall's porpoise showed that the peak of power of clicks is $139 \mathrm{kHz}$ (Awbrey et al. 1979). Description of Dall's porpoise sounds made by Watkins (1980b) were very similar.

Genus: finless porpoises (Neophocoena Palmer, 1899) finless porpoise (Neophocoena phocaenoides G. Cuvier, 1829)

Clicks with repetition rates of $80-800$ pulses/sec and power at up to $4 \mathrm{kHz}$ were recorded; high frequency components were not discovered (Mizne et al. 1967, 1968).

Family: Monodontidae (narwhal and belukha whale)

Genus: belukha (Delphinapterus Lacepede, 1804)

belukha, beluga, or white whale (Delphinapterus leucas Pallas, 1776)

The belukha was for a very long time considered to be the most "talkative" species among the Cetacea. The sounds it produced underwater were so loud that they could be 
heard in a boat and taken for birds' trills and, for those made in air, for a woman's cry or bull's roar (Tomilin 1955). Schevill and Lawrence (1950) studied sounds of belukhas in their natural environment in the Saguenay Delta. They discovered that belukhas make whistles (0.5-10 kHz), "twitters", "squeals", clicks, "bubbling" and "grinding" sounds.

In the New York aquarium, more detailed and careful studies were conducted of sounds made by 2 females and a young belukha. During the 47 minutes of the experiment, the nine following types of sounds were discovered (Fish and Mowbray 1962): 1) clicks and creaks - series of sounds of duration less than $15 \mathrm{sec}$; intervals between distinct clicks were $50 \mathrm{msec}$, between creaks $100 \mathrm{msec} ; 2$ ) whistles - 70-695 msec duration and frequency $3.45-9.1 \mathrm{kHz} ; 3$ ) modulated whistles, amplitude- and frequency-modulated, fundamental frequency $4.05 \mathrm{kHz} ; 4)$ "trumpet" sounds made by a young whale calling its mother, with duration 1.16-1.66 sec and consisting of a large number of components up to $13 \mathrm{kHz}$; 5) "bark" - short staccato sounds produced by the adult females and repeated 44 times, duration 15-180 msec, each sound containing 2-12 components of frequencies 1.25$2.2 \mathrm{kHz}$ and more than 10 components of frequency $13 \mathrm{kHz}$; 6) "grinding" sounds, heard for 11 min close to the beginning of feeding, consisting of series of high-frequency pulses of more than $637 \mathrm{msec}$ duration, dominant frequency $1.25 \mathrm{kHz}$; 7) "peeping" sounds accompanied by barking and jaw clicking during the period of the highest activity. Twenty peeps were registered, 13 of which were made during half a minute after a meal. Peeps followed jaw clicking by $0.75 \mathrm{sec}$. The maximum frequency was $0.5-4 \mathrm{kHz}$, with some components up to $12 \mathrm{kHz} ; 8$ ) jaw clicking. Bangs followed barks or squeals immediately, or at the same time that the squeal occurred. Duration was about $4 \mathrm{msec}$; frequency - 4.4 $\mathrm{kHz}$. This sound serves as an alarm or warning; 9) "trills" were recorded 5 times, 4 of those immediately after the meal, with duration of $0.86-2.5 \mathrm{sec}$, average frequency of 1.28 $\mathrm{kHz}$ and always up to $12 \mathrm{kHz}$.

Studies of the belukha's reaction to sounds recorded in the aquarium and in natural environments puts forward the assumption that acoustic signals of belukhas are of evident situational nature, and that certain contexts can influence the perception of this or that class of signals (Morgan 1970, 1979). In 1972, sounds produced by a small flock of belukhas (10-15 individuals) were recorded, mostly of young animals. Acoustic signals recorded during $10 \mathrm{~min}$ were subdivided into 9 types: 1) pulses - produced in series of 1-4 sec duration. Pulse duration was about $1 \mathrm{msec}$, with repetition rates of 2-110 pulses/sec; 2) whistles - dominant frequencies of about $3.4 \mathrm{kHz}$; 3 ) frequency-modulated whistles duration of 0.08-0.11 sec, with dominant frequency of 4.2-9.4 kHz; 4) other whistles with duration $0.15-0.19 \mathrm{kHz}$, and dominant frequency of $3.3-8.7 \mathrm{kHz} ; 5)$ "knocks" - with duration of $0.02 \mathrm{sec}$, frequency $0.3-0.6 \mathrm{kHz} ; 6$ ) "neighing" - acute amplitude and unclear 
frequency modulation, dominant frequency $4-4.7 \mathrm{kHz}$; 7) "squeal" - acute frequency and amplitude modulation was inherent. Duration was about $0.15 \mathrm{sec}$, power maximum varied from 0.6-9.4 kHz; 8) "twitter" - duration was $0.22 \mathrm{sec}$, during which time 4 sounds of 4.9-5.3 kHz occurred; 9) "peep" - duration of about $0.15 \mathrm{sec}$, the clearest harmonic was the third (about $9 \mathrm{kHz}$ ).

When studying sounds made by salmon, some signals of Amur belukhas were occasionally recorded (Neproshin 1975). Whistles were discovered (frequency 2-10 kHz; duration less than $1.5 \mathrm{sec}$ ), and squeals up to $10-12 \mathrm{kHz}$. Pulse repetition rates in echolocation series varied from 30 to 210 pulses/sec.

A large variety of sounds made by belukhas were discovered during studies of its underwater acoustics conducted in Canadian waters (Sjare and Smith 1986b). The most common were whistles of frequency $2.0-5.9 \mathrm{kHz}$ and duration varying from $0.25-1.95$ sec. Pulses and noise were also heard. The average pulse repetition rate ranged from 203.9 up to 1289.0 pulses/sec. Researchers did not discover any distinctions in recordings made during different years.

The repetition rates of some classes of signals followed changes in the animals' behavior (Sjare and Smith 1986b). The general result of these studies was the discovery of a connection between the animal's behavior and acoustics. The behavior and acoustics of two flocks of White Sea belukhas of different age and sex were studied under the stressful conditions of hunting (Bel'kovitch and Schekotov 1987a). Situations of different levels of stressfulness were especially created. As stressful effects grew, consecutive and sudden changes towards lower levels of acoustic activity were recorded (communication and emotional signals are minded here). The main classes of sounds made by the White Sea belukha under stressful conditions are the following: "short whistle" of 0.05-0.35 sec duration, dominant frequency of $2-5 \mathrm{kHz}$; "sound of noise", duration varying from $0.55-$ $1.20 \mathrm{sec}$ without clear power maxima; "squeal" of 0.3-1.4 sec duration, fundamental frequencies in the range of 3-5 kHz; "peep" - short blast sound, dominant frequency of 3.0-7.5 kHz; "whistle" - duration of 0.4-1.1 sec, power maximum at 4-6 kHz; "bleating" duration $0.35-0.93 \mathrm{sec}$, dominant frequencies $0.5-1.9 \mathrm{kHz}$ and $6.8-11.0 \mathrm{kHz}$. When the stress is maximal (the beginning of belukha harpooning), both male and female animals show lower proportions of "sounds of noise" while "short whistles", "peeps", and "squeals" predominate in female whales and "short whistles", "whistles" and "squeals" in male whales. Rather specific to stressful situations were signals of the "Morse code" class that had durations of $0.83-1.06 \mathrm{sec}$, and dominant frequencies of $2.6-4.2 \mathrm{kHz}$ and $6.8-7.5$ $\mathrm{kHz}$. These signals are series of 8-9 tonal signals of $0.4-0.25 \mathrm{sec}$ duration, with a repetition rate of 8.5-9.5 signals per sec. 
The primary class of echolocation series of the belukhas of the White Sea under stressful influences was "intermediate target distance" (target at a distance of 6-50 m). The highest level of echolocation activity both for male and female whales was recorded during the first few hours of captivity, and can be explained by the attempts of the belukhas to escape the situation. Despite different behavioral reactions and different levels of acoustic activity of male and female whales during the first hours of captivity (male activity levels higher than female), increasing stress caused the same results - depressed movement and acoustic activity.

Our data on acoustic signals of belukhas of the White Sea and Amur River region are presented in Chapter 2.

Genus: narwhal (Monodon Linnaeus, 1758)

narwhal (Monodon monoceros Linnaeus, 1758)

Observations in natural environments typically compare sounds of this species to muted grumbling or groaning like that of a bear or a cow, car horn, or muffled moan (Tarasov 1960). In natural environments (Watkins et al. 1971), recordings were made by C. Ray using equipment with a $24 \mathrm{kHz}$ limit under less-than-ideal conditions. The analysis showed that the narwhal's acoustics are different from belukhas; recorded sounds were less variable and of higher frequency.

Clicks in the $1.5-24 \mathrm{kHz}$ frequency range(with maximum energy at $12-20 \mathrm{kHz}$ ) were recorded that were produced by short (12-24 clicks) and long series. Repetition rates of short series were 80-100 pulses/sec; of long series - maximum 300 pulses/sec. A series of 82 clicks was analyzed which displayed an increase of pulse repetition rate from 22 pulses/sec to 43 pulses/sec (5 pulses), 77 pulses/sec (16 pulses), and 100 pulses/sec (2867 pulses). After that, steadily decreasing click rates were noted: 71 pulses/sec (76 pulses), 48 pulses/sec ( 81 pulses), 36 pulses/sec ( 82 pulses). Interclick intervals in the majority of clicks in this series changed fluently by $1 \mathrm{msec}$, and in the middle 39 pulses by $0.5 \mathrm{msec}$.

This first recording of narwhals probably does not represent the whole variety of sounds produced by the species. The spectral anlysis of recorded signals is narrowband and may reflect the limitations of the equipment. However, attributes of narwhal clicks known today differ from the orientational signals of other odontocetes. The authors suppose that tonal signals and clicks are produced with the help of the very same mechanisms, and short whistles are actually long clicks. Observations conducted later gave evidence to this hypothesis (Ford and Fischer 1978).

Pulse series made by narwhal were also recorded by Soviet researchers (Bogorodskiy and Lebedev 1978). The authors noted that each following pulse in the series was of 
longer duration and higher coefficient of complexity. The duration of a series was several tens of seconds, of a single pulse $400-3700 \mu \mathrm{sec}$. Narwhals make sounds only through the larynx with the sonar field in two directions: rostral and ventral (Pilleri 1983).

A group of Danish scientists studied the pulses (clicks) of narwhals in natural environments using equipment with an upper frequency limit of $100 \mathrm{kHz}$ (Møhl et al. 1990). The duration of the majority of signals was about $55 \mu \mathrm{sec}$. The peak of the dominant frequency of the pulses was at $40 \mathrm{kHz}$, with a second smaller peak at $20 \mathrm{kHz}$, and a very small part of the power was in the form of audible sounds. Signals recorded at a depth of $100 \mathrm{~m}$, where the objects they were feeding on were located, were of 200-218 dB.

\section{Family: Physeteridae Gray, 1821}

Genus: sperm whales (Physeter Linnaeus, 1758) sperm whale (Physeter catodon Linnaeus, 1758)

The first records of the sounds produced by sperm whales (Worthington and Schevill 1957) described their pulsed nature, and showed that they consist of click series of $5 \mathrm{sec}$ duration, or series of 20-73 emanations with interclick intervals of 0.2-0.5 sec. No other sounds except clicks and squeaks (that is other than pulsed sounds) were recorded in this or in subsequent studies (Schevill et al. 1962, Perkins et al. 1966, Busnel and Dziedzic 1967, Dunn 1969, Levenson 1974).

The frequency range of clicks (according to Backus and Schevill 1966) is from $30 \mathrm{~Hz}$ to $30 \mathrm{kHz}$ (dominant frequency $5 \mathrm{kHz}$ ). Clicks consist of impulses (up to 9). Different animals produce different series of clicks. One series has all the clicks identical, but impulses in clicks are different. The first impulse of one click is similar to the first impulse of another one, the second impulse is similar to the second one and so on. Intervals between click series are 1-25 sec. Clicks are rather intensive and can be well heard at a distance of 3-6 km (Norris and Harvey 1972).

Impulse duration is $0.1-2 \mathrm{msec}$. The total click consists of 6 impulses of sound for a total duration of $26 \mathrm{msec}$. It it supposed that clicks serve for echolocation and communication. They were also recorded by means of a sonic depth finder. Analyzing the results of such an experiment, it was supposed that (if not only a coincidence) sperm whales "replied" to the emanations of the sonic depth finder. It is considered that, in general, pulse activity of sperm whales is of a strict individual nature and is used not only for orientation and searching for food, but also for communication purposes (Watkins and Schevill 1977a,b). The analysis of particular features of sounds made by sperm whales as well as single clicks (Watkins 1980a) bears witness to the following: 1) sperm whale clicks are probably weakly directed at best; 2 ) the repetition rate of clicks in a series is usually 
constant and does not change with decreasing distance to the object; 3) these animals are often silent for long periods, especially when they are alone or separated, 4) clicks are more intense than necessary for locating prey or obstacles; 5) clicks are of too long duration to be used for echolocation purposes (it would be difficult to receive echo-information from a distance shorter than $22 \mathrm{~m}$ when $30 \mu \mathrm{sec}$ clicks are emanated). Also, click duration remains constant during a series.

Later studies on behavior and acoustics conducted in the southeast Caribbean Sea described contact sounds consisting of rather long click series more often produced by scattered animals during long group diving (Watkins and Moore 1982, Watkins et al. 1985). The most common repetition rate is 1-3 clicks per sec. Other signals, representing animals' social activity, were more diverse with frequent clicks - up to 90 per sec. Individual "codas" are different compositions of clicks that were particularly produced when animals met one another on the surface or underwater. Some of those stereotyped compositions could be used during agonistic interactions (interplays). In certain cases, when, for example, sounds made by two adult whales were recorded, "codas" might not be present at all, but emanating clicks and squeaks were probably used in echolocation (Mullins et al. 1988).

Genus: pygmy sperm whales (Kogia Gray, 1846) pygmy sperm whale (Kogia breviceps Blainville, 1838)

Sounds made by Kogia in the open sea are not known. Attempts were undertaken to record sounds of stranded pygmy sperm whales that were then placed into an aquarium for 48 hours (Caldwell et al. 1966). During the first $30 \mathrm{~min}$, the animal produced no sounds at all even though the edge of its larynx was moving and a microphone was placed nearby. It was possible to record typical echolocation click series, but of very low intensity and power (frequencies were less than $1 \mathrm{kHz}$ ), and which evidently displayed the whale's poor physical condition.

Other attempts to record underwater sounds of Kogia in captivity also demonstrated only pulsed echolocation signals - frequency $13 \mathrm{kHz}$ (Watkins and Wartzok 1985, Caldwell and Caldwell 1987), and single sounds and couplets of 0.4-0.5 sec duration and frequency about $1.5 \mathrm{kHz}$ characterized by the authors as stress signals (Thomas et al. 1990).

\section{E. Family: Ziphiidae Gray, 1865}

Unfortunately, there are no recordings of this family's representatives (except the bottlenose whale, Hyperoodon ampullatus). All the data that have been obtained are limited to descriptions of sounds made in air. 
Genus: Mesoplodon Gervais, 1850

Sowerby's beaked whale (Mesoplodon bidens Sowerby, 1804)

A lot of information from the past century suggests that when Sowerby's beaked whale becomes dry, it makes sounds like mooing and groaning (Dumortier 1939, Gray 1866, von Haast 1816, Creig 1898). Dry individuals of this species may produce whistles of 0.15$0.20 \mathrm{sec}$ duration of $6 \mathrm{kHz}$ frequency (Caldwell and Caldwell 1967).

Blainville's beaked whale (Mesoplodon densirostris Blainville, 1817)

The frequency of whistling sounds made by a young male whale of this species varied from 0.5-5.5 kHz, and duration was 0.15-0.25 sec (Caldwell and Caldwell 1971.

Cuvier's beaked whale (Ziphius cavirostris G. Cuvier, 1823)

Sounds of Cuvier's beaked whale used to be compared to steamship horns (Dummerman 1926).

\section{Genus: Berardius Duvernoy, 1851}

Arnoux's beaked whale (Berardius arnuxii Duvernoy, 1851)

This species' sounds resemble a mooing (roaring) bull (Beddard 1900). Wounded whales of this species produced "low whistles" (Hole 1939).

Genus: bottlenose whales (Hyperoodon Lacepede, 1804) northern bottlenose whale (Hyperoodon ampullatus Forster, 1770)

Breathing sounds of dried northern bottlenose whales were compared with the "copper sounds" of a pipe (Racovitza 1903).

The first records of underwater sounds were made in August 1969 near the coast of Nova Scotia. Three groups of whales were recorded. Those groups contained 2, 5 and 5 animals (Winn et al. 1970b). Recorded sounds were of very low amplitude compared to those known from other odontocetes, but were very similar in other respects.

The durations of various whistles varied from 115-850 msec, frequencies were 3-16 $\mathrm{kHz}$ with maximum power at 3-6, 7-9 and 12-14 kHz. Some "moans" had constant modulated frequencies of about $4 \mathrm{kHz}$; others longer than $70-90$ msec varied in frequency from 4 to $13 \mathrm{kHz}$. A wide range of "roars" of $80-150 \mathrm{msec}$ duration was also recorded.

Clicks had frequencies in the range of $0.5-26 \mathrm{kHz}$ with maximum power at $8-12 \mathrm{kHz}$ and less, but recordings were limited by equipment characteristics. The duration of clicks was 2-17 msec, more commonly $11-12 \mathrm{msec}$, repetition rate $82 \mathrm{pulses} / \mathrm{sec}$. A series consisted of 3-50 clicks.

This summary shows that we do not yet possess data on sounds made by Fraser's dolphin (Lagenodelphis), melon-headed whales (Peponocephala), pygmy killer whales (Feresa) from the family Delphinidae as well as from representatives of the family Ziphiidae 
in general. In addition to sounds from several species not being well-studied, sometimes data from other species are sparse (Sotalia, Risso's dolphin, Kogia, and others). In spite of deficiencies in information, and several remaining questions, general conclusions about acoustic signaling in the odontocetes are possible.

Sounds made by odontocetes have frequencies in an extraordinarily wide range, from a few tens of $\mathrm{Hz}$ to about $300 \mathrm{kHz}$. Those signals can be divided into pulsed and continuous (or uninterrupted) sounds. Continuous signals can be identified by their whistle-like character, practically monochromatic, with amplitude and frequency modulations, of 0.1$3.6 \mathrm{sec}$ duration, and $4-20 \mathrm{kHz}$ frequency. Other signals are of more complex spectral structure and sound like roars, howls, trumpets, and so on. Many signals are complexes of whistles and pulses. Whistles are usually for communication but may also be used for echolocation. We will discuss some behavioral aspects of these signal types.

During hunting, common dolphins, bottlenose dolphins, belukhas, and pilot whales produce not only echolocation signals: "bursts" of acoustic activity (mainly whistles) precede the time when bottlenose dolphins act in groups, either for fishing, playing, orientation, or defense.

Belukha's "piercing moans" (duration $1.8 \mathrm{sec}$, fundamental frequencies of 0.6-0.75 $\mathrm{kHz}$ modulated by 10-20\%) accompany increasing feeding activity, for example during prey searches. Shrill banging sounds of belukhas and bottlenose dolphins are common during "hierarchical" behavior when feeding and mating. These sounds could be called warning or frightening signals. For porpoises, signals of domination consist of 2-3 consecutive "moans" sounding at about $2 \mathrm{kHz}$ with $0.2 \mathrm{sec}$ intervals (Busnel and Dziedzic 1966).

When belukhas finish feeding, it is common to hear "trills" - low amplitude signals of $2.5 \mathrm{sec}$ duration and frequency about $1.3 \mathrm{kHz}$. "Squeals", "barks", and "whimpering" sounds typify dolphin emotions during feeding and mating. Belukha's "squeals" of 50$180 \mathrm{msec}$ duration consist of short overlapping components at $1.25-2.2 \mathrm{kHz}$ (up to 13 $\mathrm{kHz}$ ) and are produced only by females. "Trumpet sounds" and "roars" are in contrast inherent only to males following females.

The mating sounds of porpoises and common and bottlenose dolphins are produced in similar situations. They are "squeaks" of great intensity of duration up to $1 \mathrm{sec}$ at $2-5 \mathrm{kHz}$, and are frequency-modulated (Busnel and Dziedzic 1966).

Sounds of clear tones have not been recorded in harbor porpoises, killer whales, sperm whales, Pontoporia, Kogia, or Dall's porpoises.

Dolphins in different stressful situations make a number of whistling sounds. Short whistles (duration about $2.5 \mathrm{sec}$ ) are usually produced by common dolphins when captured 
violently. This whistle begins and finishes at a frequency of $13 \mathrm{kHz}$ (minimum is at 8 $\mathrm{kHz}$ ).

Alarm signals are even shorter $(0.12 \mathrm{sec})$. They are frequent and repeated every 0.2 sec. These whistles' beginning and ending frequencies are $14 \mathrm{kHz}$ (minimum at $10 \mathrm{kHz}$ ). So, alarm signals are similar to solo signals in composition, but shorter and more frequent (Busnel and Dziedzic 1966).

Bottlenose dolphin females separated from their young make continuous whistling sounds (McBride and Kritzler 1951). Regular whistles of periodic character were produced by short-finned pilot whales, spotted dolphins, and rough-toothed dolphins that were taken aboard a ship or were tied to a ship (Evans 1967). Whistles were recorded from harpooned bottlenose dolphins, common dolphins, long-finned pilot whales and striped dolphins (Busnel and Dziedzic 1968). The hypothesis that such "signals of calamity" were species-specific was not confirmed by facts. Typical signals of calamity inherent to bottlenose dolphins were two whistles (0.2-0.6 sec duration); the first one begins at $3.5 \mathrm{kHz}$ and increases up to $8-20 \mathrm{kHz}$; the second one starts at $8-20 \mathrm{kHz}$ and decreases to 3-5 kHz (Lilly 1963). At the same time, Dreher and Evans (1964) characterized this signal as a short rising whistle. In the other case, harpooned bottlenose dolphins made series of almost constant whistles with short periods of uprises and slumps (Busnel and Dziedzic 1968). Acoustic studies of bottlenose dolphins in the sea during their searching and hunting activity revealed "signals of calamity" in absolutely normal conditionsand other researchers have suggested that they are used to convey individual identity (Bel'kovitch et al. 1978, Caldwell and Caldwell 1978).

Apparently, stereotyped stress signals are composed of repeated repetitions of the individually-specific sounds of dolphins. The information about which particular animal is found in calamity may be transmitted in this way (Caldwell and Caldwell 1965, 1968, 1970, 1971, Caldwell et al. 1971, 1973a, 1973b). Also, some observers noted that in situations of worrying or fright, animals may produce sounds of pulsed nature. Bottlenose dolphins (Caldwell et al. 1965) make signals of fright that can be equal in intensity to a gun shot. It has maximum power at $0.1-8 \mathrm{kHz}$, which allows it to spread over long distances (Evans and Prescott 1962).

Signals of anxiety made by porpoises are usually compared to bleating (duration 0.4$1.55 \mathrm{sec}$ with maximum at $2 \mathrm{kHz}$ ); click repetition rates are about $130-200 \mathrm{pulses} / \mathrm{sec}$. This signal is no longer produced after a few days of making acquaintance in the aquarium. Sounds of a similar nature are inherent to bottlenose dolphins (Lilly 1963, Caldwell et al. 1962), as well as to belukhas (Bel'kovitch and Schekotov 1987a,b). 
Blast-like exhalations of dolphins or "snorts" made in-air are associated with anxiety (Caldwell and Caldwell 1967). Broadband signals of "alarm" or "fright" were recorded when harbor porpoises were placed into an aquarium for the first time. Later, these signals were heard each time people approached the pool (Busnel and Dziedzic 1966). "Buzz" - a sound of echolocation type - may be produced by bottlenose dolphins meeting other individual conspecifics, in situations of evident threat and other emotional tension (Lilly 1961, 1962).

"Moans" made by wounded bottlenose dolphins and the subsequent signal of alarm did not cause any changes in the behavior of common dolphins (Busnel and Dziedzic 1966). This fact allows the assumption that different species make different sounds. Pilot whales confirm this idea in certain ways. It is known that the northern and southern pilot whales produce whistles of different spectral and temporal attributes (Schevill 1964).

Playing recordings of killer whales to flocks of belukhas discontinued all their vocalizations and caused a flight (Fish and Vania 1971).

Many studies in our country and abroad were conducted to investigate the echolocatory abilities of toothed whales. This problem has been well-studied on almost 10 species of dolphins. A whole number of summarizing works in this field were made in recent years (Dierks et al. 1973, Evans 1973, Dubrovsky 1975, Bel'kovitch and Dubrovsky 1976, Busnel and Fish 1980, and others). Summarizing research information on biosonar of dolphins, Evans (1973) united signals into four types:

1) narrowband $-0.4-20 \mathrm{kHz}$ with maximum energy at $4-20 \mathrm{kHz}$ and source level $25-30$ $\mathrm{dB}$ re $1.0 \mu \mathrm{Pa} / 1 \mathrm{~m}$ for Phocoena phocoena; [correct values are $2-4 \mathrm{kHz}$ in original reference, Editors]

2) broadband $-0.1-30 \mathrm{kHz}$ with maximum energy at $16-20 \mathrm{kHz}$ and source level of 70 $80 \mathrm{~dB}$ re $1.0 \mu \mathrm{Pa} / 1 \mathrm{~m}$ for Orcinus orca; [correct value is $78 \mathrm{~dB}$ in original reference, Editors]

3) broadband (up to $200 \mathrm{kHz}$ ), maximum energy at $60-80 \mathrm{kHz}$ and source level at 66 $\mathrm{dB}$ re $1.0 \mu \mathrm{Pa} / 1 \mathrm{~m}$ for Inia and Platanista; [correct values are $16-150 \mathrm{kHz}$ in original reference, Editors]

4) broadband $0.2-250 \mathrm{kHz}$, maximum energy at $30-60 \mathrm{kHz}$ and source level of $40-80$ $\mathrm{dB}$ re $1.0 \mu \mathrm{Pa} / 1 \mathrm{~m}$ for Tursiops, Lagenorhynchus, Delphinus. [correct values are

\section{$0.2-150 \mathrm{kHz}$ in original reference, Editors]}

The acoustic activity of dolphins very much depends on external conditions - not only on orientation and navigation situations, but on the time of day, behavioral activity, and social structure of a flock (Caldwell et al. 1967, Taylor and Saayman 1972, Bel'kovitch et al. 1978a, and others). The size of a flock impacts the acoustic activity as well. Increasing 
numbers of animals in a flock causes the ratio of signals/dolphin/hour to increase. Isolated dolphins initially produce recurrent signals. Animals staying isolated for a long time reduce their acoustic activity and become more "silent". At the same time, a group of dolphins sometimes increased their acoustic activity without any evident reasons, as observed in Florida aquaria (Caldwell et al. 1967). Acoustic activity correlates substantially with time of day (Poulter 1967), though it is more usual that acoustic activity is reduced in an aquarium and vision predominates (Bagdonas et al. 1970).

Many studies describe the ability of bottlenose dolphins to imitate human speech (the pitch, rhythm, phonetic duration) and electronic signals (Lilly 1961, 1962, 1965, 1967, Evans 1967, Caldwell and Caldwell 1972). J. Lilly also showed that bottlenose dolphins are able to imitate the number of syllables, syllable duration and general pitch of human speech; in $90 \%$ of voice exchange experiments between trainer and dolphin, Tursiops imitated the trainer with precision \pm 1 when the number of syllables was from 1 to 10 . Evans (1967) gave data on cases of dolphin imitations of whistles made by electronic generators. Caldwell and Caldwell (1972) noted that bottlenose dolphins succeed in imitating certain two-word phrases, bird trills, laughter, and human singing. After hearing a signal a few times, bottlenose dolphins were completely able to imitate a $10 \mathrm{kHz}$ sound, and after that the dolphin used the sound to attract the trainer's attention. Acoustic imitations are common among marine mammals, and this can be particularly well-observed in isolated young animals. Apparently, this ability is of great adaptive importance when adjusting to changing circumstances of life.

Difficulties of observing marine mammals in the sea hindered identifying many sources of recorded sounds. Sometimes these unknown sounds could be read as signals of $20 \mathrm{~Hz}$ frequency - fin whale signals. One of those unidentified sounds is a long narrowband "groan" of frequency $35 \mathrm{~Hz}$, and duration of more than $1 \mathrm{sec}$. "20 Hz" signals of fin whales could actually belong to blue whales (Payne 1977), the winter range of which is poorly-known. Signals made by fin whales near the Chilean coast (Cummings and Thompson 1971a) sound unlike those made in other regions. This may confirm the idea that sound characteristics of different populations of whales may be geographically different.

For many years in the Pacific, blows of possible biological nature were recorded (Schevill 1964), with fundamental frequency $10 \mathrm{~Hz}$, duration $4.5 \mathrm{sec}$, and intervals between separate sounds 8 and $40 \mathrm{sec}$. These signals are probably produced mechanically with great modulation. Quite possibly they are made by baleen whales.

It is hard to single out biosignals out of background noise, because many nonbiological sounds like ice movement, rough seas, etc, disguise them. But the majority of biosignals 
are rather well studied. An important task of further research is the identification of sources of unknown sounds that could promote knowledge on the distribution and life histories of marine species.

Many difficulties in the studies of marine mammal bioacoustics arise because, in cases in which sounds are still unknown, they may be from either whales or seals. The great variability in signals made by humpback and minke whales bears witness to this fact. Very little is known about the bioacoustics of some species: sei whale, Bryde's whale, and essentially nothing about the pygmy right whale. The analysis of the complicated songs produced by humpback whales is an example of a problem to be studied. Humpback whales change the structure of their songs every year (Winn and Winn 1978, Payne and Payne 1979, 1985), altering the sequence of sounds although the sounds themselves remain stable. This leads to the general conclusion that long and systematic studies are needed to analyze the most interesting species. Sounds produced by marine mammals enable determination of 1) the species, location, and direction of movement of an animal, 2) the population size, 3) group characteristics, and 4) behavioral attributes.

Although understanding the functions of different marine mammal sounds is difficult due to their multi-functional nature, such research will be profitable for studying the life history of mammals and for the development of one of the branches of ocean acoustics.

\section{Chapter 2. Acoustic signals of the belukha whale.}

A total of over fifty thousand acoustic signals of belukha whales were recorded in the White Sea and Amur region during 1978-1980, 1986-1987 (White Sea) and in 1980, 1983 (the Amur River estuary). Signals made by belukhas can be divided into two large groups: 1) communicative and emotional, and 2) echolocation.

1. Communicative and emotional signals.

Spectral analysis and laboratory studies of the whole suite of communicative and emotional signals (over 26 thousand) allowed the definition and description of 35 principle classes of belukha sounds. Certain time-frequency characterisics of belukha signals are shown in Table 2. 
Table 2. Time-frequency characteristics of belukha acoustic signals.

\begin{tabular}{|c|c|c|c|}
\hline $\begin{array}{l}\text { Class of } \\
\text { signals }\end{array}$ & $\begin{array}{r}\text { Duration of } \\
\text { signals (sec) }\end{array}$ & $\begin{array}{l}\text { Dominant } \\
\text { frequency }(\mathrm{kHz})\end{array}$ & $\begin{array}{l}\text { Number of signals analyzed spectrally; name of } \\
\text { of class; description; function }\end{array}$ \\
\hline \#1 & $0.03-0.18$ & $5.6-10.0$ & $\begin{array}{l}57 \text {; "peep". Short, jerky, blasting signals. } \\
\text { Dominant frequency of sound either remains } \\
\text { constant or increases by } 2.5-3.0 \mathrm{kHz} \text { (Fig. 1A). } \\
\text { Reflect emotional state of animals during some } \\
\text { kinds of activity (Fish and Mowbray 1962; } \\
\text { Morgan 1979). }\end{array}$ \\
\hline \#2 & $0.22-0.80$ & $1.3-11.0$ & $\begin{array}{l}47 \text {; "squeal". Signals of energetic character, often } \\
\text { with frequency and amplitude modulation. } \\
\text { Dominant frequency either remains constant or } \\
\text { decreases by } 0.5-2.0 \mathrm{kHz} \text { by the end of the } \\
\text { signal (Fig. 1B, C; } 2 \mathrm{~A} ; 39 \mathrm{~A} \text { ). Often associated } \\
\text { with high levels of excitement (Bel'kovitch and } \\
\text { Schekotov 1987a,b). }\end{array}$ \\
\hline \#3 & $0.02-0.17$ & $\begin{array}{l}0.4-0.8 \\
1.0-1.8 \\
2.6-3.5 \\
5.1-5.6 \\
6.8-9.0\end{array}$ & $\begin{array}{l}\text { 37; "a, o, i, ae". Sounds like vowels of human } \\
\text { speech. Main energy is usually concentrated in } \\
\text { a few (3-5) frequencies (Fig. 2B, C). Common } \\
\text { in "dialogues"; of possible communicative } \\
\text { purpose (Bel'kovitch and Schekotov 1987b). }\end{array}$ \\
\hline \#4 & $0.2-1.15$ & $2.6-10.0$ & $\begin{array}{l}\text { 69; "whistle". Narrowband continuous signal. } \\
\text { Contours are variable: } \\
\text { Dominant frequency can vary from 2-5 kHz } \\
\text { (Fig. 3A, B; 25B; 37B). Whistles produced by } \\
\text { dolphins reflect excitement (Saayman et al. 1973, } \\
\text { Norris and Dohl 1980, Bel'kovitch and } \\
\text { Schekotov 1987a,b) and are of communicative } \\
\text { purpose (Herman and Tavolga 1980). }\end{array}$ \\
\hline \#5 & $0.4-2.4$ & $\begin{array}{l}0.2-0.6 \\
1.4-2.2 \\
2.6-3.8\end{array}$ & $\begin{array}{l}28 \text {; "roar". Broadband pulsed signals with high } \\
\text { repetition rates ( } 60-100 \text { pulses/sec), that } \\
\text { sound continuous (Fig. 3C, D). } \\
\text { Communicative-emotional signals: bottlenose and }\end{array}$ \\
\hline
\end{tabular}




\begin{tabular}{|c|c|c|c|}
\hline$\# 6$ & $0.35-1.15$ & $\begin{array}{r}0.3-0.6 \\
1.2-1.8 \\
6.8-11.0\end{array}$ & $\begin{array}{l}\text { 25; "bleating". Produced as a series of fragments } \\
\text { (2-10) that sound almost continuous, at a rate of } \\
8-9 \text { signals/sec (Figs. 4A; 37A). Associated with } \\
\text { aggressive-subordinate and hierarchical behavior. }\end{array}$ \\
\hline$\# 7$ & $0.05-0.13$ & $2.6-10.0$ & $\begin{array}{l}\text { 34; "short whistle". Narrowband continuous } \\
\text { signal. Contours of signals: } \\
\text {. Can be produced in series of (2- } \\
\text { 8) signals (Figs. 4B, C). Produced in situations } \\
\text { when the animals are in a state of excitement } \\
\text { (Bel'kovitch and Schekotov 1987a). }\end{array}$ \\
\hline$\# 8$ & $0.03-0.40$ & $\begin{array}{l}0.9-1.3 \\
1.5-2.1\end{array}$ & $\begin{array}{l}270 \text {; "ooya". Characteristic screams (1-4) heard } \\
\text { during the initial stage of "hunting". Consists of } \\
\text { one, two, or a series of } 3-6 \text { fragments with } \\
\text { duration } 0.03-0.09 \text { sec (Figs. } 5 \mathrm{~A}, 31 \text { ). Dominant } \\
\text { frequency can increase slightly at the beginning } \\
\text { and either increase or decrease towards the end } \\
\text { (by } 0.2-0.7 \mathrm{kHz} \text { ). Individually identified signals } \\
\text { during "hunting". }\end{array}$ \\
\hline \#9 & $0.10-0.93$ & $\begin{array}{r}0.6-2.0 \\
4.6-12.0\end{array}$ & $\begin{array}{l}\text { 14; "squeak". Broadband pulsed signals (Figs. } \\
\text { 5B, C). High intensity squeaks were produced } \\
\text { by a common porpoise during pre-copulatory } \\
\text { behavior (Busnel and Dziedzic 1966). We } \\
\text { recorded the same sounds from belukhas. } \\
\text { Squeaks were made by bottlenose dolphins both } \\
\text { during games of tag and during conflicts } \\
\text { (Caldwell and Caldwell 1967). }\end{array}$ \\
\hline \#10 & $0.90-1.92$ & $\begin{array}{r}1.2-2.2 \\
5.6-10.0\end{array}$ & $\begin{array}{l}\text { 8; "grinding". Intensive pulsed signals of high } \\
\text { repetition rates - up to } 150 \text { pulses/sec (Figs. } \\
\text { 5D, 37B, 39C). "Calling" signals produced by } \\
\text { a female to a juvenile; other grindings reflect } \\
\text { aggressive behavior or excitement (Fish and } \\
\text { Mowbray 1962). }\end{array}$ \\
\hline \#11 & $5-260$ & $0.2-0.3$ & $\begin{array}{l}\text { 6; "rumble". Produced as a series of } \\
\text { fragments of rumbles per se, divided by two }\end{array}$ \\
\hline
\end{tabular}

white-sided dolphins produce roars when they are excited (Titov and Yurkevich 1971). 
short pauses and a sound of pumping air (Fig. 28B). Fragments of rumblings per se are series of low-frequency pulses produced at a rate of 24 45 pulses/sec. Duration of fragments - 0.9-5.5 sec, a pause before pumping - 0.07-0.45 sec, duration of pumping sound - 0.05-0.15 sec, and a pause after it - 0.05-0.22 sec. Reflect emotions and a level of excitement after terminating "hunting".

$\# 12 \quad 0.08-0.15$

$0.5-9.0$

26; "jaw clapping". Broad band pulsed signal reminiscent of a sharp clap or a shot (Fig. 6A).

Reflects an aggressive behavior - threat or warning (Fish and Mowbray 1962), and a high level of excitement (Morgan 1979).

$\# 13 \quad 0.55-1.2$ 13; "noise-like signal". Broadband noise-like signals (Figs. 6B, C). Weak energy maxima are at frequencies of $0.2,0.6,1.4$, and $1.9 \mathrm{kHz}$. Recorded during high levels of excitement (Bel'kovitch and Schekotov 1987a).

$\# 14 \quad 0.27-0.70$

0.2-0.6 112; "iyoo". Produced only during the initia 1.2-1.5 stages of "hunting", of great variability (Figs. 7,

3.1-3.8 8A, 29, 30, 32-35). Main energy can be

5.1-6.8 concentrated at one or a few frequencies.

7.5-9.0 Individually-identified signals during "hunting". $11.0-12.0$

$\# 15 \quad 0.1-0.2$

$0.6-1.1$

6; "ooee". Often produced as a series (4-8)

1.4-1.5 occur in "dialogues" (Fig. 8B).

2.6-3.5

\#16 $0.2-0.5$

$0.6-2.0$

4; "beating". Series of pulses with repetition 4.0-4.5 rates of 10-20 pulses/sec. (Fig. 8B). Often 6.5-7.0 begins and ends with a "peep". Possibly reflects emotional state.

$\# 17 \quad 0.10-1.16$

0.4-1.2 6; "eeyoo". Characteristic of the final stage of "hunting". Dominant frequency decreases from $0.8-1.2 \mathrm{kHz}$ to $0.4-0.6 \mathrm{kHz}$ (Fig. 28A). According to our recordings, these signals reflect 
the emotional state of animals during capture of fish.

\begin{tabular}{|c|c|c|c|}
\hline \#18 & $0.11-0.20$ & $0.2-0.4$ & $\begin{array}{l}\text { 8; "ooo". Frequency range } 0.2-2.0 \mathrm{kHz} \\
\text { (Fig.9A). Function unclear. }\end{array}$ \\
\hline$\# 19$ & $0.65-1.10$ & $\begin{array}{l}0.2-0.8 \\
1.2-2.2\end{array}$ & $\begin{array}{l}\text { 6; "growl". Series of low frequency } \\
\text { pulses, repition rate is } 30-40 \text { pulses/sec } \\
\text { (Fig. 9B). Function unclear. }\end{array}$ \\
\hline$\# 20$ & $0.10-0.16$ & $\begin{array}{l}0.5-1.5 \\
2.6-3.5 \\
4.2-5.6\end{array}$ & $\begin{array}{l}\text { 8; "ooaa". Sounds like two continously } \\
\text { pronounced vowels "oo" and "aa". Structure } \\
\text { complex, with a few dominant frequencies (Fig. } \\
\text { 9C, 10A). Function unclear. }\end{array}$ \\
\hline$\# 21$ & $0.03-0.12$ & $0.1-2.5$ & $\begin{array}{l}4 ; \text { "snort". Snorting, blasting signals. Consist of } \\
\text { series of pulses with repetition rate of } \\
200-300 \text { pulses/sec (Fig. 10B). Frequency is } \\
0.1-7.5 \mathrm{kHz} \text {. Blasting snorts made by a porpoise } \\
\text { were recorded during pre-copulative or } \\
\text { copulative behavior (Busnel and Dziedzic 1966). }\end{array}$ \\
\hline$\# 22$ & $0.27-0.95$ & $\begin{array}{l}1.0-2.0 \\
2.6-3.5\end{array}$ & $\begin{array}{l}\text { 12; "trill". Rather long amplitude-modulated } \\
\text { signals (Fig. 10C). In captivity, these were } \\
\text { produced at the end of feeding (Fish and } \\
\text { Mowbray 1962). }\end{array}$ \\
\hline$\# 23$ & $0.10-0.14$ & $6.2-8.3$ & $\begin{array}{l}\text { 7; "twitter". May be produced in a series. } \\
\text { Function unclear. }\end{array}$ \\
\hline \#24 & $0.32-0.60$ & $2.5-6.0$ & $\begin{array}{l}\text { 3; "buzzing". Broadband pulsed signals of } \\
\text { rather high frequency (Fig. 11A). Repetition rate } \\
\text { up to } 150 \text { per sec. Frequency range is } 0.1-12 \\
\text { kHz. Function unclear. }\end{array}$ \\
\hline$\# 25$ & $0.35-1.35$ & $\begin{array}{l}0.6-0.8 \\
1.0-1.2 \\
1.9-3.5\end{array}$ & $\begin{array}{l}11 \text {; "chirp". Scattered over different frequencies, } \\
\text { main energy at } 0.04-0.4 \mathrm{sec} \text { duration (Fig. } \\
11 B \text { ). Produced by juveniles during acoustic } \\
\text { contacts with mother. }\end{array}$ \\
\hline$\# 26$ & $0.37-0.50$ & $0.4-0.6$ & $\begin{array}{l}\text { 3; "howl". Low-frequency signals (Figs. 11C, } \\
\text { 12A). Function unclear. }\end{array}$ \\
\hline \#27 & $0.03-0.08$ & $2.0-10.0$ & $\begin{array}{l}\text { 6; "quacks". May be produced in a series, with } \\
\text { a repetition rate of } 8-9 \text { per sec (Fig. 12B). } \\
\text { Function unclear. }\end{array}$ \\
\hline
\end{tabular}




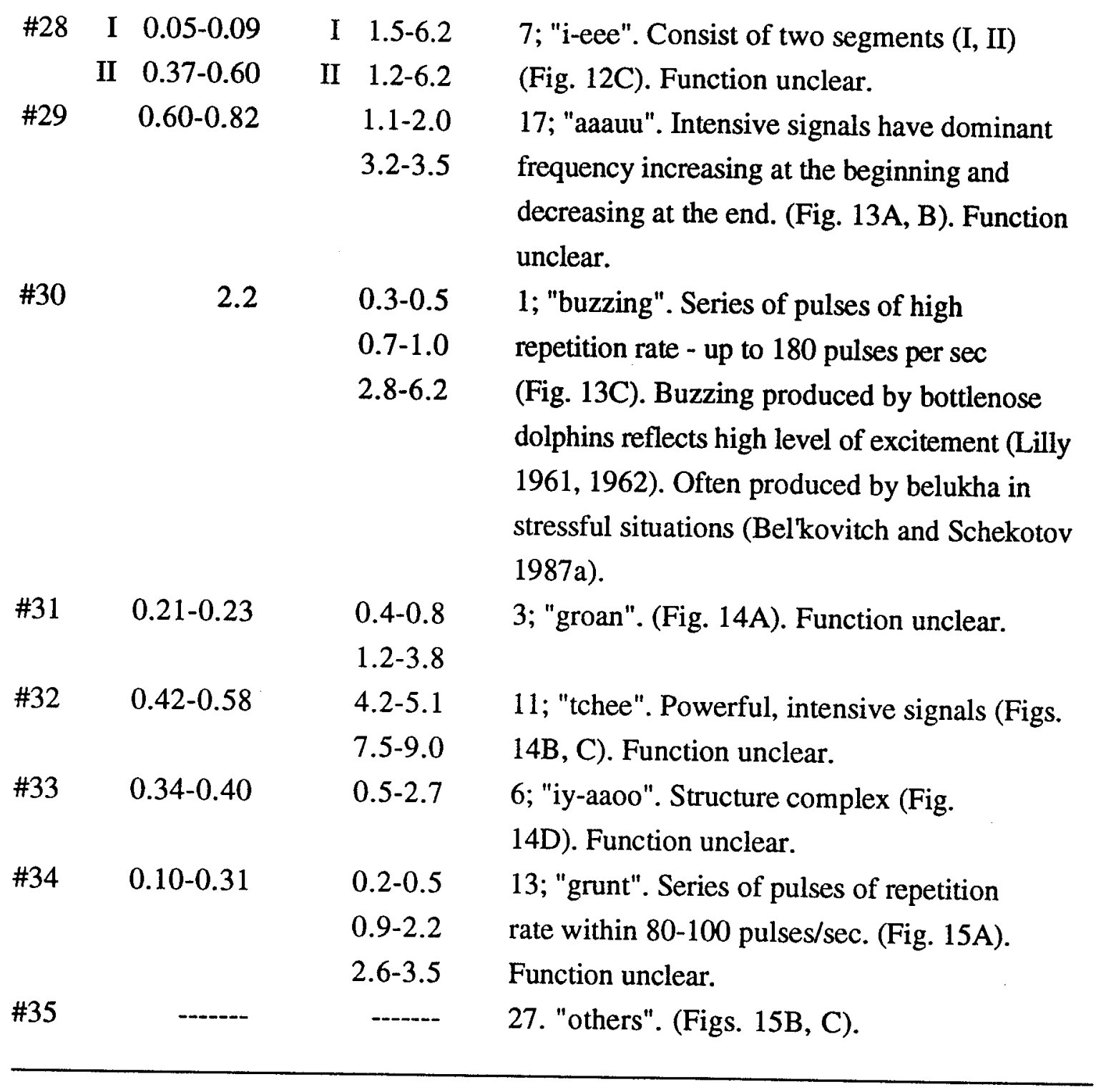

The number of signals of each class and their proportions in different areas of the belukha's range are given in Table 3.

Table 3. Numbers and proportions of recorded signals from belukhas in two regions.

\begin{tabular}{|c|c|c|c|c|}
\hline \multirow{2}{*}{$\begin{array}{l}\text { Class } \\
\text { name }\end{array}$} & \multirow{2}{*}{$\begin{array}{l}\text { Number of } \\
\text { recorded signals }\end{array}$} & \multirow{2}{*}{$\begin{array}{l}\% \text { of total } \\
\text { this class / }\end{array}$} & \multicolumn{2}{|c|}{$\begin{array}{l}\% \text { of the total number of signals of } \\
\mathrm{k} \text { of class }\end{array}$} \\
\hline & & & White Sea & Amur Estuary \\
\hline 1. "peep" & 4013 & 15.2 & $26.1 / 5$ & $73.9 / 1$ \\
\hline 2. "squeal" & 3769 & 14.3 & $49.7 / 1$ & $50.3 / 2$ \\
\hline 3. "a, o, i, ae" & 2806 & 10.6 & $42.2 / 3$ & $57.8 / 3$ \\
\hline
\end{tabular}




$\begin{array}{lrrrr}\text { 4. "whistle" } & 2181 & 8.3 & 78.5 / 2 & 21.5 / 7 \\ \text { 5. "roar" } & 1875 & 7.1 & 41.4 / 8 & 58.6 / 4 \\ \text { 6. "bleating" } & 1778 & 6.7 & 66.6 / 4 & 33.4 / 5 \\ \text { 7. "short whistle" } & 1172 & 4.4 & 74.1 / 7 & 25.9 / 9 \\ \text { 8. "ooya" } & 1008 & 3.8 & 100 / 6 & 0 \\ \text { 9. "squeak" } & 769 & 2.9 & 72.9 / 11 & 27.1 / 12 \\ \text { 10. "grinding" } & 761 & 2.9 & 85.2 / 10 & 14.8 / 17 \\ \text { 11. "rumble" } & 651 & 2.5 & 100 / 9 & 0 \\ \text { 12. "jaw clapping" } & 604 & 2.3 & 18.0 / 16 & 82.0 / 6 \\ \text { 13. "noise-like sig." } & 570 & 2.2 & 93.7 / 12 & 6.3 / 25 \\ \text { 14. "iyoo" } & 533 & 2.0 & 100 / 13 & 0 \\ \text { 15. "ooee" } & 409 & 1.6 & 22.0 / 18 & 78.0 / 8 \\ \text { 16. "beating" } & 365 & 1.4 & 18.1 / 20 & 81.9 / 10 \\ \text { 17. "eeyoo" } & 345 & 1.3 & 100 / 14 & 0 \\ \text { 18. "ooo" } & 332 & 1.2 & 87.3 / 15 & 12.7 / 23 \\ \text { 19. "growl" } & 291 & 1.1 & 7.2 / 26 & 92.8 / 11 \\ \text { 20. "ooaa" } & 166 & 0.6 & 26.5 / 23 & 73.5 / 15 \\ \text { 21. "snort" } & 159 & 0.6 & 7.6 / 28 & 92.4 / 13 \\ \text { 22. "trill" } & 150 & 0.6 & 22.7 / 24 & 77.3 / 16 \\ \text { 23. "twitter" } & 131 & 0.5 & 0 & 100 / 14 \\ \text { 24. "buzzing" } & 115 & 0.4 & 65.2 / 19 & 34.8 / 24 \\ \text { 25. "chirp" } & 96 & 0.4 & 100 / 17 & 0 \\ \text { 26. "howl" } & 95 & 0.4 & 23.2 / 25 & 76.8 / 21 \\ \text { 27. "quack" } & 95 & 0.4 & 0 & 100 / 18 \\ \text { 28. "i-eee" } & 89 & 0.3 & 0 & 100 / 19 \\ \text { 29. "aaauu" } & 87 & 0.3 & 0 & 100 / 20 \\ \text { 30. "buzz" } & 61 & 0.2 & 100 / 21 & 0 \\ \text { 31. "groan" } & 57 & 0.2 & 100 / 22 & 0 \\ \text { 32. "tchee" } & 43 & 0.2 & 0 & 100 / 22 \\ \text { 33. "iy-aaoo" } & 42 & 0.2 & 33.3 / 27 & 66.7 / 27 \\ \text { 34. "grunt" } & 32 & 0.1 & 0 & 100 / 26 \\ \text { 35. others } & 745 & 2.8 & 76.9 / 29 & 23.1 / 28\end{array}$




\section{Echolocation signals.}

Two energy maxima are common in echolocation pulses of the belukha $-60 \mathrm{kHz}$ and $1.6 \mathrm{kHz}$ (Dudok van Heel 1981: Fig. 16b). A study of the directionality of echolocation signals made by belukhas showed, apart from the usual maximum in the rostral direction, an additional maximum in the ventral zone (Pilleri 1979). In another experiment, belukhas were able to detect a target at a distance of $80 \mathrm{~m}$ (Au et al. 1987).

The echolocation abilities of belukha are supposedly developed to a considerable extent (Gurevich and Evans 1976, Woods and Evans 1980, Au et al. 1983). Spectral analysis of over 32 thousand series of echolocation pulses produced by belukhas and experimental investigation of belukha echolocation allowed the definition and description of four principle classes of echolocation series (Table 4).

Table 4. Four principle classes of echolocation series in the belukha.

\begin{tabular}{lccccc}
\hline $\begin{array}{l}\text { Class } \\
\text { name }\end{array}$ & $\begin{array}{c}\text { Number of Percent } \\
\text { series } \\
\text { of total }\end{array}$ & $\begin{array}{l}\text { Repetition rate } \\
\text { (pulses/sec) }\end{array}$ & $\begin{array}{c}\text { Distance to } \\
\text { target } \\
\text { (m) }\end{array}$ & $\begin{array}{c}\text { Number of* } \\
\text { series analyzed }\end{array}$ \\
\hline $\begin{array}{l}\text { "remote target" } \\
\text { location (RT), }\end{array}$ & & & & & 11 \\
$\begin{array}{l}\text { Fig.16A } \\
\text { "intermediate target" } \\
\text { location (IT), Fig. }\end{array}$ & 3358 & 10.4 & $5-15$ & $150-50$ & 31 \\
$\begin{array}{l}\text { 16B,C } \\
\text { "close target" }\end{array}$ & 24786 & 76.9 & $16-120$ & $50-6$ & 13 \\
$\begin{array}{l}\text { (CT), Fig. 17A } \\
\text { "capture of fish" }\end{array}$ & 3301 & 10.2 & $121-200$ & $6-3$ & 37 \\
(CF), Fig. 17B,C & 791 & 2.5 & 200-400 & $3-0.1$ & \\
& & & (increasing) & & \\
\hline
\end{tabular}

* Series analyzed spectrally.

Thus, belukha sounds are very diverse, and it is evident that the belukha is one of the most "vocal" species of toothed whales. The majority of communicative and emotional signals of belukhas have dominant frequencies of $0.2-12.0 \mathrm{kHz}$. More than $70 \%$ of all signals fall into the first 8 classes. Signals of the first 7 classes are most common to belukhas of the White Sea and Amur estuary. 
The most common type of echolocation series (about $77 \%$ of the total number of series) is "intermediate target " - distance to target $6-50 \mathrm{~m}$.

\section{Chapter 3. Ethological-acoustic characteristics of the belukha.}

The authors began to study the behavior and underwater sounds of belukhas in natural environments in 1978 in the White Sea (in the village of Letnyaya Zolotitsa); later, sugsequent studies were undertaken annually. During two seasons (July-October 1980, 1983), the sounds and behavior of Far Eastern belukhas were studied in the coastal part of the Amur estuary. Some of those results were presented in Bel'kovitch and Shekotov (1986b). Here, we dwell on them in more detail.

The observation region in the White Sea (Letnyaya Zolotitsa village) is a shallow-water bay (Fig. 18) - depth of 5-12 m, sandy bottom, and sparse undergrowth of Laminarials. Beginning with the second ten-day period of July, belukhas come close to shore (at a distance of $100-500 \mathrm{~m}$ ) every day, often a few times a day. Surveys from a tower at a height of $15 \mathrm{~m}$ over the water's surface provided opportunities to observe at a wide range, and to compare particular features of behavior in the upper layer of the water with simultaneous acoustic data.

1. The belukhas of the White Sea.

A. Size and structure of groups.

The basic data obtained from observations in the coastal waters of Letnyaya Zolotitsa in July-September 1978-1980, 1986-1987 concern particular features of searching and hunting activity of small groups of White Sea belukhas.

\section{Table 5.}

\begin{tabular}{lrrrrrr}
\hline \multicolumn{1}{c}{$\begin{array}{c}\text { Number } \\
\text { of animals }\end{array}$} & $\begin{array}{c}\text { Adults } \\
\text { only }\end{array}$ & $\begin{array}{c}\text { Percent } \\
\text { of total }\end{array}$ & $\begin{array}{c}\text { Number of passings } \\
\text { Adults and }\end{array}$ & $\begin{array}{c}\text { Percent } \\
\text { young animals }\end{array}$ & \multicolumn{2}{c}{$\begin{array}{c}\text { of total } \\
\text { of passings }\end{array}$} \\
\hline 1 & 51 & 100.0 & 0 & 0.0 & 51 & 23.1 \\
$2-3$ & 64 & 56.1 & 50 & 43.9 & 114 & 51.6 \\
$4-8$ & 10 & 20.8 & 38 & 79.2 & 48 & 21.7 \\
$9-17$ & 1 & 12.5 & 7 & 87.5 & 8 & 3.6 \\
Total & 75 & 44.4 & 95 & 55.6 & 221 & 100.0 \\
\hline
\end{tabular}


Table 5 shows that $73 \%$ of the total number of passings were groups of 2-8 animals, and $51.6 \%$ were groups of $2-3$ individuals. In $55.6 \%$ of the cases, groups contained young and adolescent animals, who were most common in groups of 4-17 individuals.

The fact that large formations of belukhas were not recorded suggests that the study area was separate from migratory routes and therefore did not contain significant concentrations of whales. At the same time, dispersed concentrations of animals numbering 40-50 individuals were observed under conditions of good visibility (the distance from the tower to the belukhas was 10-15 km) in the area between the Solovetskie Islands and Zhizgin Island (location 1 in Fig. 19). This is probably the region where the whales unite from time to time into large flocks. Aerial observations during winter could be of interest in this context: groups of belukhas were observed in the unfrozen polynyas near the Solovitskie Islands (Yu. K. Timoshenko, pers. comm.). It was noted previously that single animals and small groups stayed longer than larger groups (Ognetov and Poletov 1982). Quite possibly, the belukhas we observed were resident in the area, and remained wintering in the open water near the Solovetskie Islands.

Data obtained by aerial observations (August 1988) also confirmed the specific status of whales in the area between the Solovetskie Islands and Zhizhgin Island (Fig. 2). Two herds of 10-11 and 18-20 belukhas were seen in this particular region, while in the rest of the coastal waters between Orlov and Zhizhgin islands only single individuals or groups of 2-3 animals were observed. Observations from aboard a cutter that followed the air observations also noted two (probably the same) herds of belukhas $15 \mathrm{~km}$ from Zhizhgin Island (location 2 in Fig. 19).

The largest number of passings of White Sea belukhas was recorded in the observation region within the period of mid-July through mid-August: usually 2-3, up to 5 passings per day (Fig. 20); the 5-year average during July-September was 1.1 per day.

The groups of White Sea belukhas occurring in the observation region can be divided into three types by age and sex composition:

1) groups comprised of adult animals only (32.9\%);

2) females with juveniles and immatures $(31.5 \%)$;

3) groups of mixed composition including females with juveniles and 2-3 adult animals $(35.6 \%)$. The total number of groups recorded was 73 . All data refer to the seasons of 1986-1987.

It is quite possible, as follows from the publications of Rutiovskiy (1939), Tomilin (1962), and Bel'kovitch and Yablokov (1969), that groups of adults only are comprised of mature male belukhas, but mixed ones also occur, consisting of females with juveniles as well as adult males. In other regions, for example in Canadian waters, isolated groups 
observed in fiords consisted of females with juveniles and immature animals with females only (Brodie 1969).

Fig. 20 shows the number of passings of belukha groups of different sex and age composition that were recorded in the observation area (Letnyaya Zolotitsa). Results obtained in our studies are generally in accordance with the conclusions of Bel'kovitch and Yablokov (1969), who studied group structure of belukhas:

1) beginning in mid-July (during the mating period), mixed groups of belukhas were composed of mature females with sucklings, immatures, and small numbers of mature males;

2) at the end of the breeding period (beginning in August), more distinct sex and age differentiation in belukha groups occurs.

Small groups of 2-8 individuals can unite into larger ones of 15-20 animals. As an example, we can mention the animals shifting on one day (22 July 1986). During the first half of the day, we noticed 4 adult belukhas hunting $1 \mathrm{~km}$ offshore; each animal was in a hunting area of 0.6-1.0 km². At 2 p.m., a new group of whales composed of 2 adults, 2 females with juveniles, and 2 immatures, had approached from Zhizhgin Island (Fig. 19). One of the babies had a natural mark on its right side (Fig. 21). It took them an hour to spread evenly over the coastal area of $30 \mathrm{~km}^{2}$. Searching and hunting behavior by certain individuals could be observed until 6 p.m. After that all animals formed a combined group that slowly began to move towards Zhizhgin Island. At 9 p.m., a group of 15-17 animals came from the direction of Zhizhgin Island. The animals passed by the observation tower at a distance of about $300 \mathrm{~m}$ offshore, but soon returned, moving unhurriedly towards Zhizhgin Island. The same juvenile with the mark on it side was seen in the group, so it was the same group we had seen during the day.

At night, the belukhas were often observed to simultaneously move off their hunting grounds to the same point (30 July 1986, 4 August 1986, and so on). A group that formed in this way either stayed in the observation region for the night (see below: the situation of "rest-sleep"), or left for Zhizhgin Island. The most similar process to nighttime uniting among belukhas is found in groups of pilot whales (Brown and Norris 1956), but this phenomenon has been noted in other species as well. It is probably due to temporal differences in food availability (Sergeant 1962, Pilleri and Knuckey 1969, Perrin 1970, Pilleri 1973, Saayman and Taylor 1979). Indirect influences of ebb tides on group size in bottlenose dolphins have also been demonstrated (Irvine and Wells 1972). Compared to the White Sea belukhas, white-sided dolphins have quite an opposite style of behavior: small feeding groups at night and large groups during the day (Evans 1971). 
The important role of food availability in group formation was discovered when studying the social ecology of chimpanzees (Goodall 1965, Reynolds and Reynolds 1965, Nishido 1968, van Lawick-Goodall 1968, Gyglieri 1985).

The movements of groups of White Sea belukhas that appeared offshore from Letnyaya Zolotitsa are shown in Fig. 22. This figure shows that the peak of belukha arrivals in the observation region was in the morning (8-10 a.m.), with a smaller peak at noon. The morning peak was almost always related to animals coming from the direction of Zhizhgin Island. The evening peak, which was not as pronounced as the morning one, resulted from: a) animals arriving from Zhizhgin Island to the observation region for the night's rest; b) animals arriving from the offshore area between Konykhova Bay and the Letnyaya Zolotitsa River (location 3 in Fig. 19).

The largest numbers of belukha departures from the observation region were recorded at 12-2 p.m. and 8-10 p.m. During the day, belukhas left either for Zhizhgin Island or for the offshore area between Konyukhova Bay and Letnyaya Zolotitsa River (location 3 in Fig. 19), whereas at night they went mainly to Zhizhgin Island. The third peak of departures, in very early morning (4-6 a.m.), was connected with the termination of night rest.

The time spent by belukha groups within the observation region varied: passings that took less than $0.5 \mathrm{hr}$ comprised $13.5 \%, 0.5-2 \mathrm{hr} 41.6 \%$, and $2-8 \mathrm{hr} 44.9 \%$ of the total time animals spent in the area. These data suggest that in summer months the observation region is actively used for hunting and rest.

The arrivals and distribution of belukhas in the observation region were correlated with the summer behavior of herring upon which the animals primarily feed (see below). The behavior of herring, depends on a number of factors. The most important of these are ebb tides, and wind direction and strength. Belukhas were seen from the observation tower during both ebb and flood tides. Analysis did not reveal any correlation between belukha occurrence and ebb tides, although this has been noted for other dolphin species (Hoese 1971, Caldwell and Caldwell 1972). This can probably be explained by the fact that tides influence the movement of herring in the following way: herring schools come closer to shore during flood tides and go further offshore (0.8-1.0 km) during the ebb (V. V. Makhotin, pers. comm.). Wind direction and speed are of great importance for fish distribution. Driving winds and gales bring herring towards the shore, whereas calm weather makes the fish stay at a distance of $1-1.8 \mathrm{~km}$ offshore. Offshore winds, even of rather great strength, do not cause fish to be driven closer to the shore.

Foraging is of great importance to belukhas because food is among the principal factors that cause various species of whales to concentrate, to change their behavior, and to 
migrate. The main prey of the White Sea belukhas in the observation region are the following: herring (Clupea harengus Linnaeus), smelts (Osmerus eperlanus dentex), codfish (Eleginus navaga Pallas), flounder (genus Pleuronectes), and salmonids (whitefish and lox) (Klumov 1936). But data on the behavior of these fish species, compared to the behavioral activities of belukha when hunting and searching in the observation region, give reasons to exclude codfish and flounder from the list. These two species are benthic, do not occur in schools (Altukhov et al. 1958), and occur in very low abundances (lox). According to many researchers, White Sea belukhas feed mainly on mass concentrations of herring and capelin (Tomilin 1957, Chupskiy 1976). According to studies conducted by Klumov $(1936,1937,1939)$ in Onega Bay, belukhas feed mostly on these particular fishes. Further, local fishermen consider belukhas to be an indicator of offshore herring schools. It is also known that small schools of herring fatten up in Onega Bay during June-July; the process of their concentration into larger spawning schools used to begin in August and terminate in October-November (V. V. Makhotin, pers. comm.). During the summer, herring are in the upper water layer thoughout the day (Zusser 1971).

Our own observations have also confirmed that belukhas feed on dense fish schools. Because hunting belukhas can force a school up to the surface of the water (often before the belukhas appeared, we noticed fish leaping out of the water) and "hunting" occurs at a depth of 1-1.5 m, we conclude that belukhas feeding in the observation region feed primarily on herring schools.

Analysis of data on the searching and hunting activity of White Sea belukhas allows identification of two principal types: individual and group.

\section{B. Individual activity in searching and hunting.}

Typically, in this hunting mode, each individual searches for prey separately, irrespective of the size of the group. Thus, the general mode of behavior in searching and hunting of single belukhas is independent of group size.

Individual animal's behavior in searching and hunting. It included the following stages: "orientation and searching", "pursuit of a school", and "hunting". Searching for fish concentrations consisted of considerable movement $(0.3-1.5 \mathrm{~km})$ without "hunting" actions. Surfacings are mostly calm and of virtually straight trajectory. The longest searching periods were observed when belukhas arrived at the hunting zone in the observation region. Black Sea bottlenose dolphins are known to use passive acoustic localization for fish detection (Bel'kovitch et al. 1975). Belukhas of the White Sea, according to our data, also did not echolocate during this stage in $70-80 \%$ of cases. Echolocation pulses produced in other cases were of the following two classes: IT (intermediate target distance) $-61.1 \%$, RT (remote target location) - 34.9\%. Thus, during 
"searching", belukhas echolocated only for purposes of orientation and distant detection of fish schools. The total duration of echolocation activity at this stage varied from 1.2-11.6 min per hr. Communicative and emotional signals were rather rare (0.1-0.6 signals per $\min$ ), and in $95 \%$ of cases were of classes \#4, \#7, and \#2.

"Pursuit of a school" involves choosing the proper moment to start "hunting". This was associated with a series of energetic surfacings (3-16, average 8.6) that often begin with 120-180 turns, resulting in "loops" or "zigzags" (Figs. 23, 24). We think that the tracks in Figures 23 and 24 formed as a response to the evasive behavior of a fish school (Manteyfel 1980).

The trajectory of surfacings at the end of a series was, as a rule, in the form of an arc or half-ring (Figs. 23, 24). In a little more than one-third of all surfacings, the right or left half of the tail fin was visible while the animal was swimming on its side (depending on whether the belukha's motion was clockwise or counter-clockwise).

At this stage ("pursuit of a school"), passive acoustic localization was primarily used. Short whistles, (signals of class \#7 in Fig. 25: A,B), were produced along with animals' breathing on the surface (1-8 times). Evidently, these reflected a certain level of anxiety during pursuit and capture of fish.

"Hunting", or "capture of fish", always began after a series of surfacings ("pursuit of a school" stage) and occurred underwater. A powerful spurt, characterizing the last in a series, was directed back inside a half-ring trajectory from the preceding stage (Fig. 23, 24). After that, the animals started rather slow movements on their sides for $2-4 \mathrm{sec}$ (comparable to the speed of common dives - 1-2 sec - during "pursuit of a school"). During this event, the whales also dove underwater at sharp angles (Fig. 26), moving their tails energetically such that acoustically it was referred to as "tail bumping". "Tail bangs" continued after the belukhas had gone underwater and, together with other sounds, formed distinctive sequences of sounds (SS). From tower observations, it was seen that in the 10$25 \mathrm{sec}$ after the whales disappeared underwater, disturbances shaped like "pancakes" spread over the water's surface. These were caused by water rotation, resulting from the energetic tail movements that animals made while swimming on their sides underwater (Fig. 36B). "Pancake" trajectories often had complicated and zigzag-shaped tracks. In the majority of cases, the trajectories finished at the location of the subsequent surfacing. There is probably a connection between the tendency of belukhas to swim on their sides and the discovery by Pilleri (1979) of an additional peak of echolocation emissions in the ventral zone. In this context, it could be of interest that belukhas are able to use a signal reflected off the water's surface for the purpose of target detection (Penner et al. 1986). 
During underwater "hunting", belukhas can probably trap fish schools up near the surface. One could sometimes see fish emerge out of the water before the belukhas surfaced during the peak of the "hunting" stage (in 15-20\% of observations, belukha surfaced once, seldom twice, in the middle of the "hunting" stage). Sounds inherent to those surfacings were produced at the moment of exhale-inhale and were of signal class \#7.

The average number of "huntings" per hour by a single animal was 9.1 . Total duration of the "hunting" stage was calculated per 1 hour of "searching". Hunting duration varied from 3.1-15 $\mathrm{min}$ (average $8.9 \mathrm{~min}$ ).

Monitoring a single belukha with a dictaphone enabled us to discover some specifics of breathing activities of White Sea belukhas. It is known that belukha exhalations continue for about $1 \mathrm{sec}$ (Kleinenberg et al. 1964). A series of rather frequent surfacings between two long submersions (breathing pauses) can be termed "ventilation", while the duration of such a series is the "period of ventilation". Breathing pauses of the White Sea belukha can be subdivided into several groups according to their duraion: 1) short breathing pauses during the "period of ventilation" - BP (sh) - 3-19 sec; 2) medium breathing pauses - BP (m) - 20-40 sec; BP (m) were seldom noted during "ventilation", not more than 1-2 times; 3) long breathing pauses - BP (1) - 41-631 sec; BP (1) naturally divided two "periods of ventilation", sometimes combined with $\mathrm{BP}(\mathrm{sh}) ; 4$ ) breathing pauses during the "hunting" stage - BP(h) - 17-335 sec. The shorter BP (h) were evidently connected to "failure": an animal starts "hunting", but soon halted it and appeared on the surface. Data concerning duration of "ventilation" and BP of the White Sea belukha during individual searching and hunting activity are shown in Table 6.

Table 6. Some parameters of breathing activity of the White Sea belukha (n: number of measurements; \%: proportion of the total number of BP.

$\begin{array}{lll}\text { Parameters } & \text { Single animal } \% & \text { Female with juvenile } \%\end{array}$

\begin{tabular}{|c|c|c|c|c|}
\hline 1. Duration of "ventilation" (sec) & $\begin{array}{l}5-229, \text { av. } 48.1 \\
\mathrm{n}=59\end{array}$ & --- & $\begin{array}{l}10-276, \text { av. } 90.8 \\
\mathrm{n}=55\end{array}$ & -- \\
\hline $\begin{array}{l}\text { 2. Number of surfacings during } \\
\text { "ventilation" }\end{array}$ & $\begin{array}{l}2-15, \text { av. } 5.2 \\
\mathrm{n}=59\end{array}$ & -- & $\begin{array}{l}2-22, \text { av. } 8.4 \\
n=55\end{array}$ & -.- \\
\hline 3. Duration of BP (sh), sec & $\begin{array}{l}2-19, \text { av. } 8.9 \\
\mathrm{n}=237\end{array}$ & 73.6 & $\begin{array}{l}2-19, \text { av. } 8.8 \\
\mathrm{n}=210\end{array}$ & 71.4 \\
\hline 4. Duration of BP $(\mathrm{m})$, sec & $\begin{array}{l}20-40, \text { av. } 27.8 \\
\mathrm{n}=29\end{array}$ & 9.0 & $\begin{array}{l}20-40, \text { av. } 29.5 \\
n=21\end{array}$ & 7.1 \\
\hline
\end{tabular}


5. Duration of BP (1), sec

6. Duration of BP (h), sec

7. \% of the total time searching and hunting of:"ventilations"

$\mathrm{BP}(\mathrm{l})$ and BP (h)

8. Observation time (hr)
42-631, av. 120.8

$$
\mathrm{n}=41
$$

33-335, av. 103.3

$$
\mathrm{n}=15
$$

31.1

68.9
42-285, av. $104.7 \quad 13.3$

$$
\mathrm{n}=39
$$

$4.7 \quad 17-191$, av. 93.0

$\mathrm{n}=24$
54.2

45.8

2.6

The fact that the average duration of "ventilation" for females with juveniles is longer than that for single belukhas ( 90.8 and $48.1 \mathrm{sec}$, respectively) is noteworthy. Females with juveniles surfaced during "ventilation" more often (8.4) than single belukhas (5.1). In addition, females with juveniles had a larger relative proportion of BP $(\mathrm{h})$.

In Canadian waters, belukhas surface rather frequently, on average 5.5 times (the average duration of BP between surfacings was $16 \mathrm{sec}$ ), before surfacing for longer time 35 sec. Typically, the cycle is repeated (Brodie 1971). These data differ little from those obtained by us, and may be probably explained by different prey species.

Similar values were obtained during studies of BP duration of belukhas in aquaria (Bobkhov 1986). During periods of intermediate activity level, alternations between BP (l) of 1-9 min and series of BP (sh) of 9-25 sec were observed.

As was said above, sequences of sounds (SS) were inherent to belukhas during the "hunting" stage. Analysis of 433 cases of "hunting" revealed that sounds were produced with a certain regularity. 269 SS (62.1\%) began with class \#8 signals; 266 (61.4\%) contained class \#14 signals, 114 SS (26.3\%) ended with class \#17 signals, and 297 (68.6\%) ended with long signals of class \#11 ("rumbling"). The characteristics of SS containing "rumbling" signals of different duration, as well as the frequency of occurrence of certain other classes of signals, are shown in Table 7.

This table shows that the occurrence of "rumbling" and its increase in duration corresponded to the increase of "hunting" duration and with the number of "capture of fish" (CF)(hereafter, abbreviations from Table 4 are used). In general, communicative and emotional signals in SS can be united into two groups (Table 7). The first includes signals of classes \#1, 7, 4, and 17. They occured in SS ending with "rumbling" 1.8-4.3 times 
Table 7. Some parameters of the sequences of sounds (SS) containing signals of class \#11 - "rumbling" of different duration $\left(n_{1}-n_{4}\right.$ refer to number of this SS type; $n$ refers to the number of SS containing signals of this class).

\begin{tabular}{|c|c|c|c|c|}
\hline Parameters & $\begin{array}{c}0 \mathrm{sec} \\
\left(\mathbf{n}_{1}=133\right)\end{array}$ & $\begin{array}{c}5-50 \mathrm{sec} \\
\left(\mathrm{n}_{2}=91\right) \\
\text { mean } 33.0 \pm 1.34\end{array}$ & $\begin{array}{c}51-99 \mathrm{sec} \\
\left(\mathrm{n}_{3}=92\right) \\
\text { mean } 74.2 \pm 1.35\end{array}$ & $\begin{array}{c}99-350 \mathrm{sec} \\
\left(\mathrm{n}_{4}=68\right) \\
\text { mean } 130.3 \pm 5.77\end{array}$ \\
\hline & $\mathrm{n} \%$ in $\mathrm{n}_{1}$ & $\%$ in $n_{2}$ & $\%$ in $n_{3}$ & $\%$ in $n_{4}$ \\
\hline
\end{tabular}

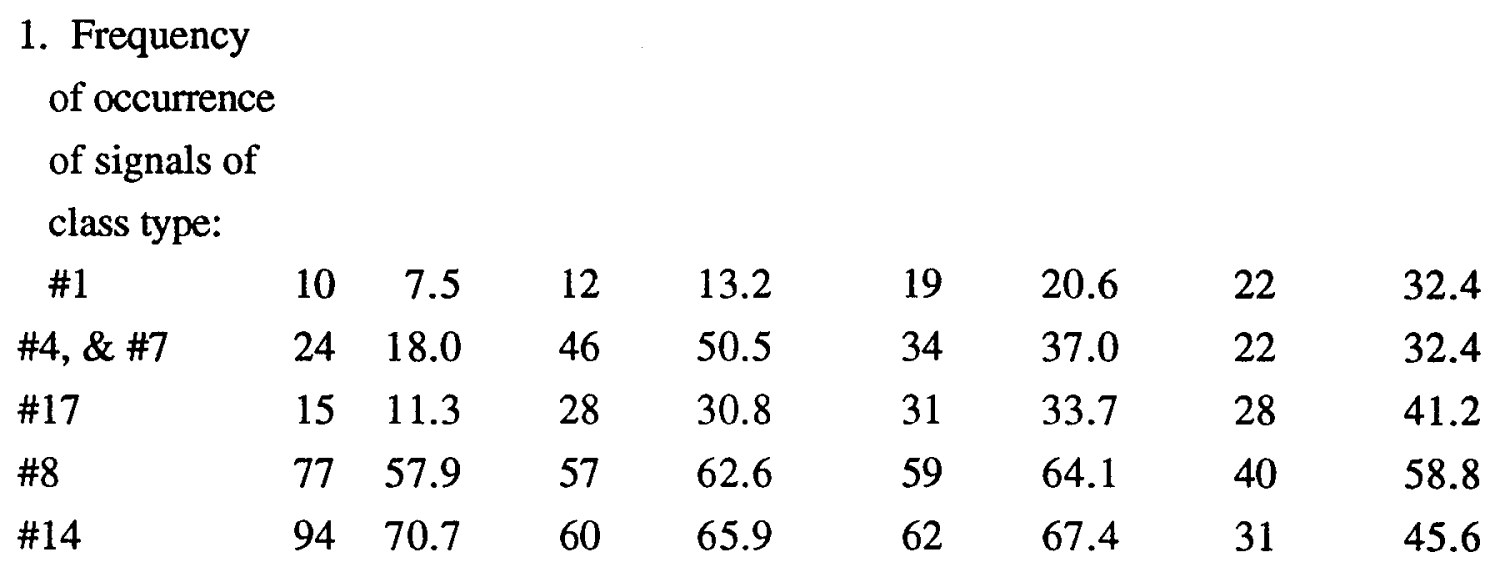

2. Average

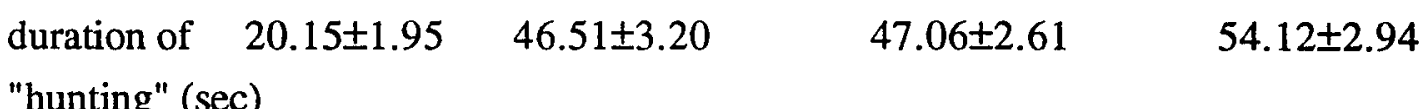

3. Average num-

ber of CF

during one

$\begin{array}{lllll}\text { "hunting" } & 0.42 \pm 0.13 & 1.32 \pm 0.13 & 1.34 \pm 0.12 & 1.8 \pm 0.15\end{array}$

4. Percent $(\%)$ of

successful

"huntings"

18.6

75.3

73.6

86.6

5). "Hunting"

results
$(\mathrm{CF} / \mathrm{min})$
1.0
1.7
1.7
2.0

more often than in SS without "rumbling". The second group is composed of signals \#8 and \# 14. They occur equally often in SS with and without "rumbling" (Table 7.).

A more detailed analysis using a computer (EC - 1045) enabled measurement of correlation indices between the occurrence of signals of different classes in SS and the 
following parameters: duration of "hunting", and number of CF-type series in SS. Calculations were conducted on the basis of 433 parallel measurements. Correlation coefficients are significant at level of $\mathrm{P}<0.01$ (except for those indicated). The main results are shown in Table 8.

Table 8. Correlation coefficients of signal occurrences in SS with two other parameters: duration of "hunting" and number of CF-type echolocation series.

Parameters

Coefficient

Duration of "hunting" Number of CF

Number of signals in SS:

classes \#1

\#4, \#7

$\# 17$

\#11

$\# 8$

\#14

Duration of the class \#11 signal
$+0.16^{*}$

$+0.18 *$

$+0.56$

$+0.39$

$+0.13 * *$

$-0.10^{* *}$

$+0.27$
$+0.09 * *$

$+0.10^{* *}$

$+0.38$

$+0.32$

$+0.09 * *$

$-0.04 * *$

$+0.23$

Correlation coefficients marked with * are significant at $\mathrm{P}<0.1$; with ** not significant.

Analysis of these data indicated that they are in general accord with those in Table 7. Low levels of linear correlations can probably be explained by the fact that we were not able to consider all factors and, in particular, those that influence the animal's state and behavior.

A number of echolocation series were recorded in SS (46.3\% out of the total number of all signals and series). Series with CT were predominant (54.1\%). CF were in $33.9 \%$ of series, IT in fewer (12\%) and RT were absent. Thus, during this stage belukhas used echolocation for close orientation and for catching fish.

It needs to be said that pulse series of high repetition rate (CT and CF) were produced by White Sea belukhas, as we noticed it, only during the "hunting" stage (in SS). This means that if belukha are even occupied with catching fish in addition to visual and acoustic control at the stage of "hunting", it occurs without echolocating.

Fig. 27 shows the dynamics of echolocation series of different classes that were produced by one belukha during its searching and hunting activity. As we can see, this figure is in conformity with the general mode of orientation behavior (Bel'kovitch 1974). 
During the stage of "orientation and search" - a remote target location - detection of fish schools occurred via passive acoustic localization, while in the case of information shortage echolocation pulses were used (RT, IT). When the reflected echo from a school of fish reached the belukha's ear, initial classification of the stimulus (positive in this particular case) occurred, as evidenced by an orientation reaction. When the target (fish school) was close, final classification of the stimulus occurred, and goal-oriented behavior began ("pursuit of a school" stage): the animal followed the school, and chose the proper moment to start "hunting", using mainly passive acoustic localization (Fig. 27). When the belukha threw itself into the middle of the school ("hunting" stage) - interaction in the contact zone it used echolocation series (CT). This provideds an opportunity to pursue and catch fish and, probably also disoriented and deafened fish that tried to slip away (Bel'kovitch and Yablokov 1963, Hult 1982, Norris and Møhl 1983, Morris 1986, Lagaeski 1987).

The total number of echolocation series produced by the White Sea belukha that were recorded during individual searching and hunting activity in the observation region was 6830 (RT - 16\%, IT - 45.7\%, CT - 28.5\%, CF - 9.5\%).

Laboratory and spectral analysis revealed that signals composing SS and of classes \#1, 4 , and 7 were slightly changeable. All of them were simple, short, stereotyped whistling signals (Fig. 25). Considering the occurrence of these signals in SS, we can conclude that they were indicative of excitement during the pursuit and capture of fish. That is in accordance with other publications. An increase in whistling activity was noted from feeding groups of short-finned pilot whales (Dreher and Evans 1964). Busnel and Dziedzic (1966) recorded whistles from hunting common dolphins. High levels of whistling activity are also inherent to feeding animals in captivity (Saayman and Taylor 1973, Titov and Nikolenko 1975). However, Caldwell and Caldwell (1968) noted that whistling activity is considerably reduced until termination of feeding.

Dolphins riding waves formed by a large ship seem to be excited. High levels of whistling activity, quite natural for such a situation, were recorded from Hawaiin spotted dolphins (Norris and Dohl 1980). The same researchers watched spotted dolphins entering shallow bays for the first time. The animals produced a lot of whistles while jumping out of the water and forming zigzag trajectories. According to Norris (1974), excited groups of moving dolphins always show high levels of whistling activity.

Studies of sounds made by belukhas at the New York Aquarium showed that peeps (class \#1 signals) are also produced by animals during the most active periods and feeding (Fish and Mowbray 1962). According to our data, signal classes \#17 and \#11 reflected emotional excitement during hunting. Class \#17 signals were always heard at the end of SS and sounded like signals of classes \#1, 4, 7 due to similar indications - slight time- 
frequency changeability and occurrence in different kinds of SS (Table 7, Fig. 28A). "Rumbles" (class \#11 signals, Fig. 28B, dominant frequency $250 \pm 50 \mathrm{kHz}$ ) made by different individuals also had very similar time-frequency characteristics. The structure and character of class \#1 signals are important to clarify this function. At its initial part, this signal was produced with short pauses, termed "swings" (Fig. 28B), having an intensive sound. Then, periods of "rumblings" and the pauses between them become longer, and power decreased until termination, evidently reflecting that the animal was calming down and relaxing. So, we consider "rumbling" (class \#11 signals) to be a reflection of the whale's emotional state and its general excitement after "hunting".

In contrast, the signals of classes \#8 and \#14 have clear time-frequency composition and bright individual character (Fig. 5A, 7, 8A, 29-35). It was easy to distinguish sounds of this type that were made by different animals. It is also interesting that they were always produced (100\% of cases) in the initial part of an SS. Additionally, when signals of both classes occurred in one SS, class \#14 signals were always the first to be produced. The fact that almost $90 \%$ of SS contained signals of class \#8 or \#14 or both testifies to their importance.

Direct observations of belukhas showed that when there were several animals in certain areas and it was possible to identify the individuals, each of them made their "own" sounds of classes \#8 and \#14 during "hunting". Figures 29-31 present sounds produced by two females that were identified by their young. One female had a small ( $1 / 3$ of the mother's length), almost black juvenile. Sounds made by this animal are shown in Fig. 29. Next to the other female was a larger ( $1 / 2$ of the mother's length), gray juvenile. Sounds of this individual are displayed in Figs. 30 and 31. For 3.5 hours, the whales were hunting at a distance of 250-500 m from one another. The first female produced five class \#8 signals and two class \#14 signals, while the second one produced three class \#8 signals and four class \#14 signals. Time-frequency parameters of the sounds made by both females are shown in Table 9. The spatial position of the females during "hunting" and the moments when they produced sounds were under steady visual and acoustic monitoring. As shown in Figs. 29-31 and in Table 9, each female produced only "her own" individually-specific signals of classes \#8 and \#14. 
Table 9. Time-frequency parameters of signals referring to classes \#8 and \#14, produced by two individually identified female dolphins.

Signal class

$\# 8$

$\# 14$

Dominant frequency $(\mathrm{kHz})$ Duration Dominant frequency Duration initial medium final

(sec)

$(\mathrm{kHz})$

(sec)

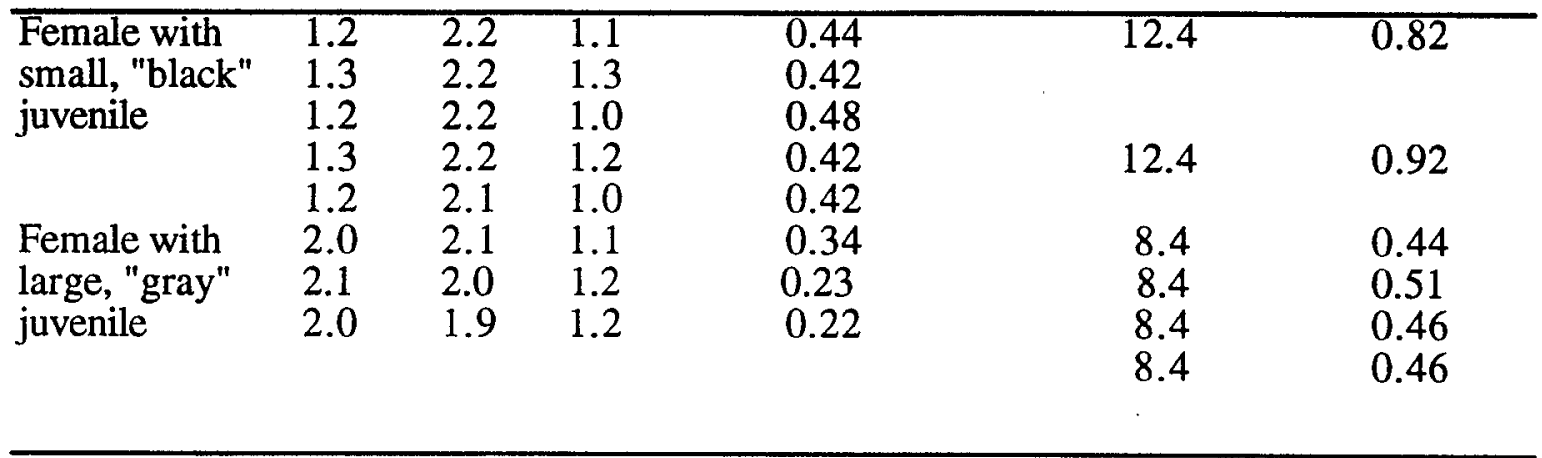

On the basis of the above we concluded that signals of classes \#8 and \#14 are of an address nature, and are used for individual identification of animals for maintaining a distant contact between them in a group. It should be noted that because of the predominance of individual searching and hunting, active groups of belukhas are rather dispersed (as a rule, animals are $0.3-0.8 \mathrm{~km}$ from each other). Many hoofed mammals living in small groups in forests and in other closed-type biotopes have similar modes of behavior. When they are moving in herds, individuals maintain contact with one another using short signals. Klingcholz et al. (1979) and Meynardt (1980) discovered individual variation in the aggregate of frequency and duration characteristics of sounds made by boars ("grunts").

It is quite possible that other species of toothed whales also produce individuallydistinctive signals. American scientists Watkins (1977) and Watkins and Schevill (1977) recorded pulsed signals produced by sperm whales. These were produced in sequences of broadband clicks (so-called "codas") that were organized into specific temporal patterns. Each sperm whale probably produced a stereotyped "coda" that was inherent only to that particular individual. The "identification" character of those signals enabled researchers to easily discern particular individuals when listening to the recording. Sperm whales are probably able to do that too. "Codas" were recorded when a group of sperm whales dived and when they met underwater. Most often, "coda" exchanges occurred between adjacent animals. Pulsed signals exchanged by free-swimming Hawaiian spinner dolphins were also discovered (Watkins and Schevill 1974). Ford and Fisher (1978) recorded a number 
of tone signals from narwhals and suggested that these may be specific to each individual. Some species of dolphins may produce whistling signals with attached identification characteristics (Kreichi et al. 1987). Identification signals are generally common among social vertebrates and particularly so in birds (Brooks and Falls 1975).

Spectral analysis of signals of class \#14 allowed identification of sounds with similar time-frequency characteristics recorded during different seasons (Table 10; Figs. 32-35). On the basis of these data, it can probably be assumed that the same individual belukhas visit the observation region many times over a number of years.

Table 10. Occurrence of individually-specific signals (class \#14) of similar timefrequency characteristics, produced by White Sea belukhas (1978-1980).

$\begin{array}{lcccccc}\text { Day } & \text { Time } & \text { Cassette \# } & \text { Tape } & \text { Signal } & \text { Dominant frequency } & \text { Dominant } \\ \text { d.m.y. } & & \text { counter } & \begin{array}{c}\text { duration } \\ \text { frequency of }\end{array} & (\mathrm{kHz}) & \text { frequen } \\ & & & (\mathrm{sec}) & \text { initial } & \text { final } & \text { overtones }\end{array}$

\begin{tabular}{|c|c|c|c|c|c|c|c|}
\hline 18.07 .79 & $10: 15$ & $11 \mathrm{~A}$ & 340 & 0.41 & 4.3 & 4.3 & - \\
\hline 18.07 .79 & $10: 30$ & $11 B$ & 110 & 0.39 & 4.3 & 4.3 & - \\
\hline 23.07 .80 & $18: 40$ & $45 \mathrm{~A}$ & 008 & 0.40 & 4.4 & 4.4 & - \\
\hline 09.07 .80 & $10: 30$ & $16 \mathrm{~B}$ & 060 & 0.61 & 9.4 & 8.5 & - \\
\hline 12.07 .80 & $16: 08$ & $29 B$ & 151 & 0.57 & 9.4 & 8.5 & - \\
\hline 04.07 .80 & $12: 52$ & $4 \mathrm{~A}$ & 106 & 0.48 & 9.9 & 8.8 & - \\
\hline 04.07 .80 & $12: 52$ & $4 \mathrm{~A}$ & 391 & 0.48 & 9.8 & 8.7 & - \\
\hline 04.07 .80 & 13.08 & $4 B$ & 056 & 0.48 & 9.8 & 8.7 & - \\
\hline 04.07 .80 & 13:08 & $4 B$ & 218 & 0.47 & 9.8 & 8.7 & - \\
\hline 12.07 .80 & $16: 58$ & $31 \mathrm{~B}$ & 144 & 0.61 & 10.0 & 8.7 & - \\
\hline 12.07 .80 & $16: 58$ & $31 B$ & 334 & 0.61 & 10.1 & 8.7 & - \\
\hline 12.07 .80 & $17: 13$ & $31 \mathrm{~B}$ & 179 & 0.62 & 10.1 & 8.5 & - \\
\hline 22.07 .79 & $19: 22$ & $17 \mathrm{~A}$ & 101 & 0.50 & 10.4 & 8.4 & - \\
\hline 23.07 .80 & $09: 15$ & $42 \mathrm{~A}$ & 298 & 0.51 & 10.3 & 8.5 & - \\
\hline 24.07 .79 & $20: 15$ & $22 \mathrm{~A}$ & 175 & 0.60 & 10.4 & 9.6 & - \\
\hline 24.07 .79 & $20: 15$ & $22 \mathrm{~A}$ & 403 & 0.60 & 10.0 & 9.5 & - \\
\hline 23.07 .80 & $09: 15$ & $42 \mathrm{~A}$ & 381 & 0.61 & 10.3 & 9.5 & - \\
\hline 23.07 .79 & $11: 40$ & $18 \mathrm{~A}$ & 005 & 0.60 & - & - & $\begin{array}{l}1-1.9 ; 2-4.0 \\
3-5.7 ; 4-7.4\end{array}$ \\
\hline 08.08 .78 & $16: 58$ & $19 \mathrm{~A}$ & 187 & 0.58 & - & - & $\begin{array}{l}1-1.9 ; 2-4.0 \\
3-5.8 ; 4-7.4\end{array}$ \\
\hline 09.07 .80 & $10: 30$ & $16 B$ & 370 & 0.35 & - & - & $1-3.3 ; 2-7.4$ \\
\hline
\end{tabular}




\begin{tabular}{|c|c|c|c|c|c|c|c|}
\hline 22.07 .79 & $19: 40$ & 17B & 077 & 0.34 & - & & $\begin{array}{c}3-11.1 ; 4-14.4 \\
1-3.2 ; 2-7.6 \\
3-11.1 ; 4-14.5\end{array}$ \\
\hline 09.07 .80 & 03:21 & $16 \mathrm{~A}$ & 322 & 0.41 & 9.1 & 8.5 & 1-1.7 (weak) \\
\hline 23.07 .80 & 09:17 & 41B & 326 & 0.42 & 9.0 & 8.5 & 1-1.7 (weak) \\
\hline 23.07 .80 & $18: 40$ & $45 \mathrm{~A}$ & 094 & 0.70 & - & - & $\begin{array}{c}2-3.8 ; 3-5.7 ; 4- \\
7.4 ; 5-9.3 ; 6-11.2\end{array}$ \\
\hline 25.07 .80 & $14: 22$ & 45B & 189 & 0.69 & - & - & $\begin{array}{c}2-3.8 ; 3-5.7 ; 4- \\
7.6 ; 5-9.5 ; 6-11.7\end{array}$ \\
\hline 09.07 .80 & 03:21 & $16 \mathrm{~A}$ & 159 & 0.59 & - & - & $\begin{array}{l}1-1.6 ; 2-4.0 \\
3-5.7 ; 4-7.4\end{array}$ \\
\hline 22.07 .79 & $19: 22$ & $17 \mathrm{~A}$ & 168 & 0.53 & - & - & $\begin{array}{l}1-1.6 ; 2-4.0 \\
3-5.7 ; 4-7.6\end{array}$ \\
\hline 22.07 .79 & $19: 40$ & 17B & 270 & 0.51 & - & 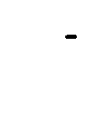 & $\begin{array}{l}1-1.6 ; 2-4.1 \\
3-6.0 ; 4-7.4\end{array}$ \\
\hline
\end{tabular}

The relative proportions of the main signal classes and their frequency of occurrence during one belukha's searching and hunting activity are presented in Table 11. It is evident that the most common classes were: identification signals \#8 (20.7\%; $0.11 \mathrm{signals} / \mathrm{min})$, \#14 (6.9\%; 0.05 signals $/ \mathrm{min})$, and \#17 "iyu" (12.3\%; 0.06 signals $/ \mathrm{min})$. Hereafter, the first number in parentheses refers to the percentage of this class of signal, and the second refers to the frequency of occurrence in signals per minute. These sounds were produced only in the final part of an SS. In addition, the following classes of signals also occurred: \#1 "peeps" (11.8\%; 0.06 signals/min), \#4 "whistles" (10.7\%; 0.05 signals/min), and \#7 "short whistles" (10.2\%; 0.05 signals/min). It is interesting that summing up the percentage of signal classes \#8,11,14 and 17 pertaining to hunting amount to more than half of all signals (52\%). 
Table 11. Signals produced by the White Sea belukhas during individual searching and hunting activity (July-Sept. 1978-80, 1986; \% = percent of total signals, sig/min = frequency of occurrence.

\begin{tabular}{|c|c|c|c|c|c|c|c|c|c|c|}
\hline \multirow{3}{*}{$\begin{array}{l}\text { Signal } \\
\text { class }\end{array}$} & \multicolumn{10}{|c|}{ Number of belukhas } \\
\hline & \multirow{2}{*}{\multicolumn{2}{|c|}{$\begin{array}{c}1 \text { adult } \\
\% \quad \text { sig/min }\end{array}$}} & \multicolumn{2}{|c|}{2 adults } & \multicolumn{2}{|c|}{ 3-5 adults } & \multicolumn{2}{|c|}{ female + juv. } & \multicolumn{2}{|c|}{$2-5$ adults $+1-3$ juv. } \\
\hline & & & $\%$ & $\mathrm{sig} / \mathrm{min}$ & $\%$ & $\mathrm{sig} / \mathrm{min}$ & $\%$ & $\mathrm{sig} / \mathrm{min}$ & $\%$ & $\mathrm{sig} / \mathrm{min}$ \\
\hline$\# 1$ & 11.8 & 0.06 & 12.5 & 0.23 & 10.5 & 0.26 & 10.0 & 0.14 & 4.0 & 0.18 \\
\hline \#2 & 3.6 & 0.02 & 12.6 & 0.23 & 6.1 & 0.15 & 3.2 & 0.05 & 16.3 & 0.71 \\
\hline \#3 & 5.6 & 0.03 & 5.6 & 0.10 & 7.9 & 0.20 & 5.5 & 0.08 & 10.2 & 0.44 \\
\hline \#4 & 10.7 & 0.05 & 6.6 & 0.12 & 16.3 & 0.41 & 8.9 & 0.13 & 11.1 & 0.48 \\
\hline \#5 & 0.0 & 0.00 & 3.3 & 0.06 & 7.8 & 0.19 & 4.2 & 0.06 & 5.7 & 0.25 \\
\hline \#6 & 0.0 & 0.00 & 1.5 & 0.03 & 1.1 & 0.03 & 3.4 & 0.05 & 14.5 & 0.62 \\
\hline \#7 & 10.2 & 0.05 & 8.9 & 0.16 & 6.3 & 0.16 & 12.2 & 0.17 & 5.8 & 0.25 \\
\hline \#8 & 20.7 & 0.11 & 9.8 & 0.181 & 10.1 & 0.25 & 10.0 & 0.14 & 4.3 & 0.19 \\
\hline \#9 & 0.2 & 0.001 & 7.2 & 0.13 & 8.4 & 0.21 & 1.0 & 0.01 & 2.9 & 0.13 \\
\hline$\# 10$ & 0.2 & 0.001 & 1.9 & 0.04 & 3.6 & 0.09 & 2.4 & 0.03 & 6.5 & 0.28 \\
\hline$\# 11$ & 10.0 & 0.05 & 6.7 & 0.12 & 4.7 & 0.12 & 8.0 & 0.11 & 2.7 & 0.12 \\
\hline \#12 & 0.0 & 0.00 & 0.2 & 0.01 & 0.9 & 0.02 & 0.2 & 0.003 & 1.2 & 0.05 \\
\hline$\# 13$ & 0.8 & 0.004 & 0.1 & 0.001 & 0.5 & 0.01 & 5.8 & 0.08 & 4.1 & 0.18 \\
\hline \#14 & 9.0 & 0.05 & 6.5 & 0.12 & 6.0 & 0.15 & 4.4 & 0.06 & 2.5 & 0.11 \\
\hline \#15 & 0.0 & 0.00 & 0.5 & 0.01 & 0.2 & 0.01 & 0.7 & 0.01 & 1.1 & 0.05 \\
\hline$\# 17$ & 12.3 & 0.06 & 4.4 & 0.08 & 1.4 & 0.04 & 4.8 & 0.07 & 1.4 & 0.06 \\
\hline other & 4.9 & 0.03 & 11.7 & 0.21 & 8.2 & 0.20 & 15.3 & 0.22 & 5.7 & 0.24 \\
\hline Total & 100 & 0.51 & 100 & 1.83 & 100 & 2.48 & 100 & 1.41 & 100 & 4.31 \\
\hline \multicolumn{11}{|c|}{ Total number } \\
\hline of sign & & 391 & & 2681 & & 1713 & & 945 & & 7140 \\
\hline \multicolumn{11}{|c|}{ Index (signal/ } \\
\hline $\min / \mathrm{in}$ & divid) & 0.51 & & 0.92 & & 0.74 & & 0.70 & & 1.10 \\
\hline \multicolumn{11}{|c|}{ Duration of } \\
\hline recordi & & 12.8 & & 24.4 & & 11.5 & & 11.2 & & 27.6 \\
\hline
\end{tabular}

Searching and hunting activity of two animals. A couple of large belukhas were observed. During the "search" stage, the animals followed parallel routes at a distance of 20-100 $\mathrm{m}$ from each other (Fig. 36A). Almost all the time, each whale was hunting separately, and only a few cases were recorded in which some interactions were observed 
(Fig. 36B). During mutual approaches, one animal often started hunting using the other one as an obstacle to fish. But the most common behavior was independent hunting, with the belukhas $0.3-1.0 \mathrm{~km}$ from each other.

The average number of "huntings" per hour for these two animals was 13.2; total duration of "hunting" per $1 \mathrm{hr}$ of searching and hunting activity varied from 2.3-15.5 min, average $8.1 \mathrm{~min}$.

The acoustic signals of a couple of belukhas are more diverse compared to those of single animals (summed up percentage of signals of classes \#8,11, 14 and 17 is not more than 27.4\%, Table 11). More common signal classes for this situation are: \#2 "squeal" (12.6\%; 0.23 signals $/ \mathrm{min}) ; \# 1$ "peep" (12.5\%; 0.23 signals $/ \mathrm{min}) ; \# 8$ (9.8\%; 0.18 signals/min); \#7 "short whistles" (8.9\%; 0.16 signals/min); \#9 "squeak" (7.2\%; 0.13 signals/min).

Searching and hunting activity of a group of adult belukhas (3-5 individuals). During the "search" stage, animals were moving at a distance of $50-300 \mathrm{~m}$ from one another. As they appeared in the exploring area, the animals became dispersed. Each animal was hunting at a distance of $0.3-0.8 \mathrm{~km}$ from other whales. The average number of "huntings" per hour was 19.4. Also evident was a reduced proportion (22.2\%; Table 11) of stereotyped signals common during "hunting" (\#8,11,14, and 17). The main classes of signals in this situation were: \#4 "whistle" (16.3\%; 0.41 signals/min); \#1 "peep" (10.5\%; 0.26 signals/min); \#8 (10.1\%; 0.25 signals/min); \#9 "squeak" (8.4\%; 0.21 signals/min); \#3 "a, o, i, ae" (7.9\%; 0.20 signals/min); and \#5 "roar" (7.8\%; 0.19 signals $/ \mathrm{min})$.

Searching and hunting activity of a female with juvenile. In the "search" stage during "pursuit of a school", the immature was near the side of the adult belukha in $30-80 \%$ of cases. It jumped out of the water for "inhale-exhale" together with the female. During joint movement in the stage of "pursuit of a school", the juvenile did not execute the last out of a series of simultaneous surfacings: the female did the last one herself. Shortly before the female's reappearance at the surface, the juvenile surfaced frequently while approaching the predicted surfacing point of the female. The trajectory of "pancakes" resulting from the female moving under the water and the trajectory made by the juvenile came together at one point - the place of the female's reappearance on the surface (Fig. 36C). Inthe next period of the "pursuit" stage, the pair either reunited or the juvenile moved independently through the area (during certain times).

The average number of "huntings" per hour in this situation was 14.7, and the total duration of "hunting" per 1 hour of searching and hunting activity varied from 5.0-19.4 min, average $11.2 \mathrm{~min}$. 
In comparison with a single animal, sounds produced by the female with juvenile are generally more diverse. Also, their signals of all classes (Table 11) occur 2.8 times more often. The following classes of signals were predominant: \#7 "short whistle" (12.2\%; 0.17); \#1 "peep" (10.0\%; 0.14); \#4 "whistle" (8.9\%; 0.13); \#13 "noise-like signal" (5.8\%; $0.08)$; \#3 "a, o, i, ae" (5.5\%; 0.08). From the acoustic point of view, it was characteristic in this situation to have rather frequent acoustic "contacts" between the female (signals of classes \#3 and \#13, Fig. 37B) and juvenile "baby" sounds (signals of classes \#2 "squeals", \#6 "bleating", Fig. 37A, and \#25 "chirping", Fig. 11B). The fact that these "baby" signals were produced by a juvenile was discovered when females were emanating long \#11 class signals after termination of "hunting". Additionaly, a juvenile animal produced powerful "calling for mother" signals when it was 100-150 m from her and a motorboat appeared. At such times, the juvenile rapidly returned to its mother (\#10 class signals; intensive "grinding" sounds, Fig. 37C). Specific sounds for mother-juvenile communication were noted in observations of bottlenose dolphins (Tavolga and Essapian 1957). The total relative proportion of signals specific for "hunting" (classes \#8, 11, 14, and 17) was considerably (1.9 times) smaller for an animal with a juvenile than for single animals (Table 11).

Searching and hunting activity of a group of belukhas composed of adults, babies and juveniles (3-8 individuals). The distance between animals in a group appearing in the observation region varied greatly from $50-300 \mathrm{~m}$. Different methods of group formation were noted. In the vicinity of the observation tower, a group often dispersed into subgroups (400-600 m between subgroups). Single animals and belukhas in a subgroup searched and hunted separately. "Gray" juveniles were always apart from females, while "black" juveniles stayed separate for $20-70 \%$ of the time. When females were rather close to them, they could form short-term pairs or trios. More rarely, when females were hunting, young belukhas stayed at a distance of 1.0-1.5 km and over, forming a compact group (see below, Situation "kindergarten").

The proportion of stereotyped signals (classes \#8,11,14, and 17) made in groups of adult and young animals is minimal (Table 11). The most widely used are signals of the following classes: \#2 "squeal" (16.3\%; 0.71 signals/min); \#6 "bleating" (14.5\%; 0.62 signals/min); \#4 "whistle" (11.1\%; 0.48 signals/min); \#3 "a, o, i, ae" (10.2\%; 0.44 signals/min); \#10 "grinding" (6.5\%; 0.28 signals/min), and \#5 "roar" (5.7\%; 0.25 signals/min). Typical in this case were frequent acoustic contacts between females and young animals and "dialogues" (see below). 


\section{Searching and hunting in groups of belukhas}

The most distinctive feature of this much rarer form of behavior was coordinated actions by group members, aimed at limiting the mobility of a fish school.

Searching and hunting activity of a group of 6-8 individuals. Compared with individual activity, a group of animals was in a more compact formation during "searching". The distance between individuals varied from 20-100 m. The main tactical tricks during "hunting" were forming a "carousel" and a "cauldron" (Fig. 38A,B). In a "carousel" (Fig. 38A), 6-8 animals moved along a circle of diameter about 30-50 m. Sometimes they formed two circles that deprived the fish of any opportunity to slip away. This or that animal would find itself in the center of such a "carousel", and would actively feed. Hunting continued for 6-9 $\mathrm{min}$; after that the "carousel" disintegrated and the whales moved in different directions for 3-4 min. ("pursuit of a school" stage); then the group became more compact and a new "carousel" formed.

"Cauldrons" were characterized by more energetic and untidy movements of belukhas towards the center of the animals' concentration (Fig. 38B). Bottlenose dolphins studied in the Black Sea (Bel'kovitch et al. 1978) used the same tactics during group hunting.

A high level of acoustic activity (4.4 signals/min) was recorded during searching and hunting of groups of White Sea belukhas (3 August 1986, 3:28 p.m., recording duration $30 \mathrm{~min}$ ). The most common in this case were signals of the following classes: \#2 "squeals" (27.5\%; 1.20 signals/min); \#4 "whistle" (19.8\%; 0.87 signals/min); \#10 "grinding" (9.9\%; 0.43 signals/min); \#3 "a, o, i, ae" (8.4\%; 0.37 signals/min). The total proportion of stereotyped signals (classes \#8, 11, 14, and 17) was only $6.9 \%$.

Thus, it is inherent to White Sea belukhas to produce lots of sounds during "searching" and "hunting". Echolocation pulse series served for the purposes of navigation, search and capture of fish.

Signals made in the "hunting" stage were extremely specific and stereotyped (signal classes - \#8,11,14, and 17). The proportion of such signals declined with increasing group size. In this case, the proportion of other signals connected with particular types of behavior in a group increased. These were of classes \#3, 2, 5, and 6 .

The acoustic activity of humpback whales is also closely connected with feeding (Jurasz and Jurasz 1979; D'Vincent et al. 1985). The same is true of killer whales (Steiner et al. 1979). However, it is difficult to draw any analogy yet.

\section{Communicative behavior in different situations.}

Situation "dialogues". In 1980-1987, we recorded 2-3 and more White Sea and Amur belukhas actively producing sounds during certain periods of time that could remind one of 
a type of "dialogue". Analysis enabled us to identify two main types of such "dialogues", here referred to as "close" and "distant" communication.

By "close" communication, we mean an intensive exchange of acoustic signals. This took place between a few individuals that were close to one another, probably even in physical contact. They were oriented similarly with regard to one another and also to the hydrophone; thus, signals made by different individuals were of nearly the same intensity. Direct observations of the White Sea belukha in its natural environment suggest that this type of "dialogue" occurred when animals were close to each other. The same behavior and acoustic activity were recorded when belukhas were kept in an aquarium - "sounds of direct contact" (Morgan 1979; Brodie 1985).

The second type of "dialogues" - "distant communication" - was represented by signals produced by whales staying at a more remote distance from one another. In this case, animals were oriented differently towards each other and thus the signal intensity made by individuals differed greatly. Also, a variety of behavior modes were inherent to this case.

Both types of "dialogues" were much more rarely noted for the White Sea belukha than for the Amur belukha. That is why fewer "dialogues" were analyzed for the White Sea belukha, and a smaller number of parameters are shown here. The relative proportions of the main signal classes used in 10 Type I ("close communication") and 15 Type II ("distant communication") "dialogues" are presented in Table 12.

Table 12. The relative proportion of main signal classes produced in Type I ("close communication") and Type II ("distant communication") "dialogues" by the White Sea belukha.

\begin{tabular}{lrrrr}
\hline $\begin{array}{l}\text { Signal } \\
\text { class }\end{array}$ & \multicolumn{4}{c}{ Dialogue type } \\
& Number of signals $\begin{array}{c}\text { I } \\
\text { \% of total } \\
\text { number of signals }\end{array}$ & Number of signals & $\begin{array}{c}\text { \% of total } \\
\text { number of signals }\end{array}$ \\
\hline$\# 1$ & 17 & 4.0 & 21 & 4.4 \\
$\# 2$ & 80 & 19.0 & 63 & 13.2 \\
$\# 3$ & 96 & 22.7 & 30 & 6.3 \\
$\# 4$ & 5 & 1.2 & 54 & 11.3 \\
$\# 5$ & 12 & 2.8 & 115 & 24.1 \\
$\# 6$ & 118 & 28.0 & 38 & 8.0 \\
$\# 7$ & 6 & 1.4 & 29 & 6.1 \\
$\# 10$ & 0 & 0.0 & 38 & 8.0 \\
& 2 & 0.5 & 44 & 9.2
\end{tabular}


It follows from Table 12 that, for the White Sea belukha, the most common classes of signals used in "close" communication are: \#6, 3, 2, and 12; in "distant communication" $\# 5,2$, and 4.

The relative proportions of signals of classes \#2 and 1 were about equal in both types of dialogues. The frequency of occurrence of all signal classes was $66.6 \mathrm{signals} / \mathrm{min}$ and 26.6 signals/min in Type I and Type II dialogues, respectively.

So, "close" communication in White Sea belukhas differed substantially from the "distant" type. \#6 signal class ("bleating") and class \#12 signals ("jaws clapping") are characteristic combinations of sounds in the first type of "dialogues". The high signal rate, and high level of excitement of animals when they are in this type of close contact (Morgan 1979), and data on the use of \#12 signal class to express a threat (McBride and Hebb 1948; Fish and Mowbray 1962) suggest an important connection between this type of "dialogue" and aggressive-subordinate and hierarchical behavior. "Distant roll call" (class \#2 signals "squeaks", \#4 - "whistle" and \#5 - "roar") was common for "distant" communication.

Situation "rest-sleep". This situation was observed in daytime, when several belukhas located at a distance of 5-20 m from each other made calm surfacings while the whole group moved along the coast or stayed in the same place. Often belukhas stayed on the surface for a long time (10-15 sec), providing an opportunity to watch 2-3 and more individuals simultaneously. "Resting" belukhas in the observation area were noticed at a distance of 0.6-1.0 km offshore mainly at 10:00 p.m. - 4: 00 a.m., and less often in daytime.

Some researchers (Nishiwaki 1966, Bateson 1974, Morejohn 1979, Würsig and Würsig 1979, Norris and Dohl 1980, Chen Peixun 1989) also described "rest-sleep" during night and daytime inherent to different kinds of dolphins. They too based their conclusions on behavioral criteria. These researchers observed animals forming compact groups and moving slowly along in a circle. It was also recorded that resting animals sharply reduce their sound-making and decrease the variety of sounds produced (Powell 1966, Norris and Dohl 1980). But it should be taken into consideration that electrophysiology is a more reliable assessment of a dolphin's state. The priority in such studies belongs to Soviet scientists L. M. Mukhametov and A. Yu. Supin. They discovered (Mukhametov et al. 1976; Mukhametov and Supin 1978) that dolphins do not 
need to be awake to breathe. Dolphins opened their eyes during sleep as though they were on guard. Additionally, an inter-hemispherical asymmetry of functional states of dolphin brains hemispheres during sleep was discovered, that had not been described for any other animals and humans.

Notes about "sleeping" belukhas have been published. Animals lying on the surface of the water "like driftwood" were seen in Tcheshskaya Inlet (Tchirkova and Folentarik 1930) and in Sakhalin Bay (Geptner 1930). Resting belukhas were also noted in Canadian waters (Hay and McClung 1976).

The acoustic activity of animals was generally very reduced in this situation, and it had an acute sporadic character. Pauses of 0.5-2.5 min gave way to short periods of signal production by one or a few individuals, sometimes in rather intensive periods (up to 10-20 signals/min. Here, the breathing pause duration observed in captive belukhas is of interest (Bobkov 1986). During rest, the alternation of inhale-exhale breathing and apnea are of regular character; apnea duration varied from $0.5-1.5 \mathrm{~min}$. It is quite possible that sounds exchanged between animals can be connected with an increase of activity during breathing and sometimes during brief "awakenings" of belukhas.

This situation had a duration of 0.5-1 hrs during the day and 1-5 hours at night. During the day, the most frequently used signals were of the following classes (Table 13): \#4 "whistles" ( $34.4 \%$ out of the total number of signals, 0.49 signals/min), \#2 "squeals" (11.2\%, 0.16 signals/min); at night \#3 "a, o, i, ae" (22.1\%; 0.23 signals/min), \#5 "roar" (17.3\%, 0.18 signals/min), \#4 "whistle" (14.0\%; 0.15 signals/min). Rather specific signals for the situation "rest-sleep", particularly at night, were low-frequency whistles (class \#4), that are presented on Fig. 37D.

An experiment was conducted to discover the reaction of "sleeping" belukhas to an acoustic irritant. Artificial underwater signals were produced at a frequency of $1 \mathrm{kHz}$. At 1:00 a.m., a boat carrying an observer, a portable listening device, and a sound generator was placed $500 \mathrm{~m}$ offshore. The boat was taken there by oars, and did not cause any marked reaction from animals about $0.8 \mathrm{~km}$ from shore. Acoustic recording was conducted at half-hour intervals. Data from records of belukha signals 20 min before and $20 \mathrm{~min}$ after the artificial signal was produced (at 2:23 a.m.) are presented in Table 13. Two large white animals approached the boat to a distance of $15-50 \mathrm{~m}$. During this period, most of the echolocation series were of the "close target" (CT) and "intermediate target" (IT) types (Table 4). 
Table 13. Sounds produced by belukhas in different situations (July-September 1986; $\%=$ proportion of total signals, $\mathrm{sig} / \mathrm{min}=$ frequency of occurrence.

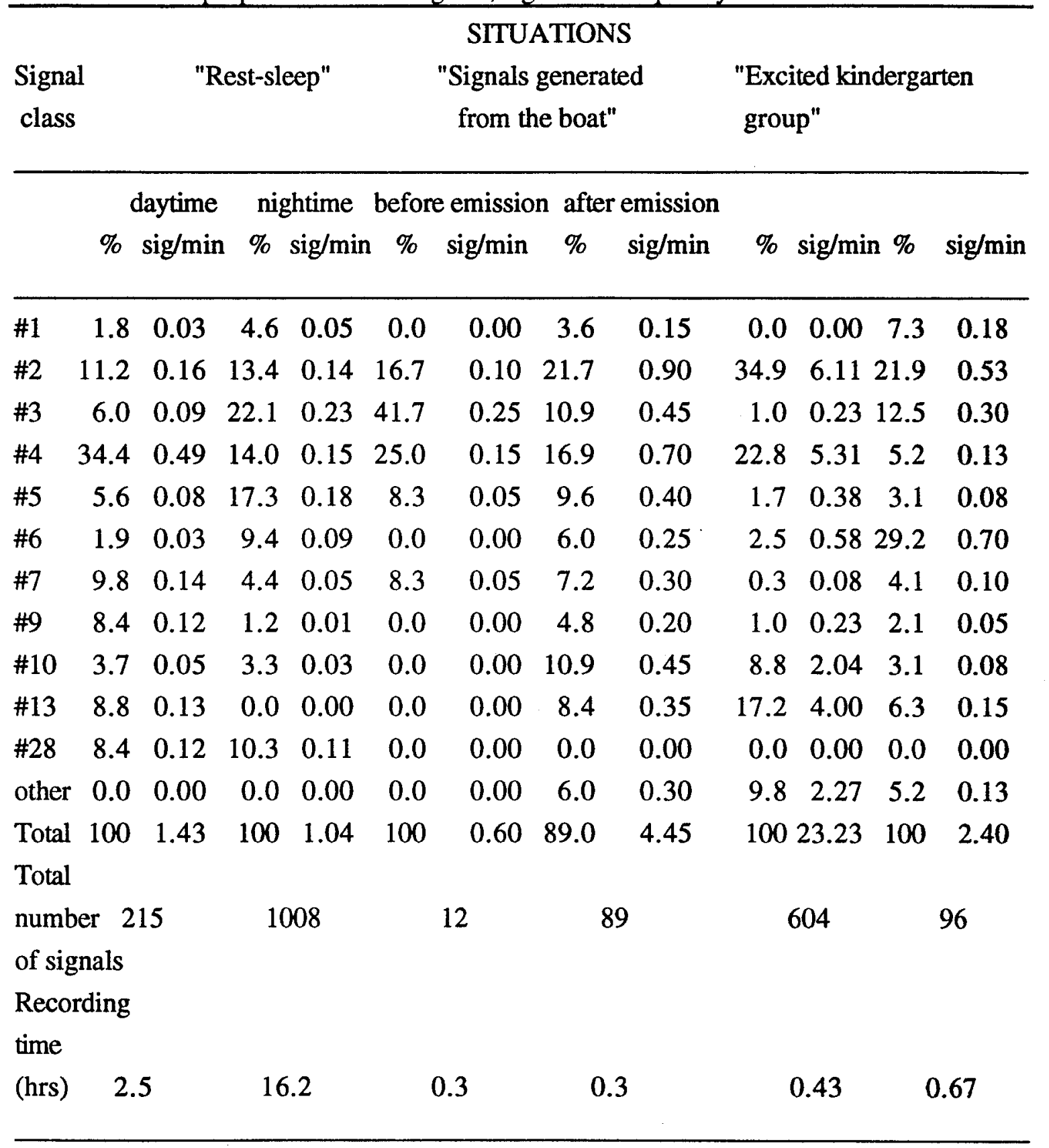

There were three main changes in belukha sounds after the acoustic irritatant was presented. First, there was an increased frequency of occurrence of the signals made by belukhas before they heard the unfamiliar sounds. Those signals were of the following classes: \#2 "squeals", \#7 "short whistle", and \#4 "whistle". Second, new signals of high frequency of occurrence were heard - "grinding", "noise-like signals", "bleating", and "squeaks". These were of classes \#10,13,6, and 9. Third, many echolocation series of "close target" (CT) and "intermediate target" (IT) types were heard. 
Situation - "excited group". Once an unusual burst of acoustic activity was recorded from White Sea belukhas during "rest-sleep" at night (11:15 - 11:41 p.m., 4 August 1986). It was probably caused by some natural factor. Signals were actively produced by a few individuals at a rate of 4.5-40.0 signals/min. The maximum signal power was recorded at the initial stage of the situation. Then it decreased to null at the end of signal emanation. Table 13 shows the relative proportions of signals of different classes and their frequencies of occurrence. The most common were signal classes \#2 "squeals" (34.9\%; 8.11 signals/min); \#4 "whistle" (22.8\%; 5.31 signals/min); \#13 "noise-like" signals (17.2\%; 4.0 signals/min). Figure 39A, B displays very specific sounds of classes \#2 and \#4 inherent to the situation "excited group". In the "excited group" situation, the rate of signal production was 22 times greater than in the "rest-sleep" situation.

Situation "kindergarten. Groups composed of 1-2 young "gray" animals and 2-3 "black" juveniles were observed in the daytime at a distance of $400-600 \mathrm{~m}$ offshore. The females left to hunt in other areas (1-1.5 offshore) for about 1-2 hours. The young belukhas stayed in the same place. The situation ended when, in the second half of the day, the females returned and formed common pairs of "female-child". The young animals were trying to approach their mothers. This happened when the distance between the "kindergarten" and the females decreased to $100-120 \mathrm{~m}$.

Similar behavioral situations ("kindergarten") have been noted for only one other cetacean species - narwhals (Silverman 1979). Young animals were alone for a considerable period of time while their mothers were hunting at depth.

The predominant behaviors of young animals in the "kindergarten" were playing and "resting" motionlessly at the very surface of the water. Play included a wide variety of behavioral elements (Table 14).

Data on the acoustics of the "kindergarten" (2 "gray" and 3 "black" White Sea belukhas) are shown in Table 13. For this situation, "children" signals of classes \#6, 2, 25 , and 3 were characteristic.

Belukhas' reaction to a SCUBA diver. This situation happened in the following way. On 26 July 1986 beginning at 9:30 a.m., three hunting belukhas were observed at a distance of $0.5-1.0 \mathrm{~km}$ from the shore. At 12:12p.m., a boat carrying a SCUBA diver went out and stopped $150 \mathrm{~m}$ from shore. The SCUBA diver produced artificial signals in the water. One-two min after the SCUBA diver went under the water, two large belukhas moved toward the boat while surfacing simultaneously. Half a minute after the last surfacing (at 12:19 p.m.), and $100 \mathrm{~m}$ from the boat, the belukhas produced 5 identical signals of class \#10 (intensive long "grinding" sounds, Fig. 39C). At 12:22 p.m., the whales appeared $250 \mathrm{~m}$ from the boat, and began to move away. After three simultaneous 
surfacings, the animals tried to reach the boat again. At 12:27 p.m., the animals disappeared at a distance of $150 \mathrm{~m}$ from the boat and 3 class \#10 signals similar to the preceding ones were recorded. For the next hour, the animals stayed $500-800 \mathrm{~m}$ from the boat. But they did not hunt any more. We think that such behavior of belukhas suggests that they have stereotyped acoustic reactions, reflecting aggression or orientational behavior.

Table 14. Elements of play behavior of juvenile and immature belukhas.

Element

Behavior

1. "Rostrum display"

Putting rostrum out of water, sometimes up to $1 / 3$ of body length.

2. "Pectoral fin display" Young animal lies on its side at the very surface of the water, moving its pectoral fin in the air.

3. "Tail fin display" Tail fin out of the water, sometimes the whole tail can be seen.

4. "Tail slap" Tail slapping the water.

5. "Small fountain out of the mouth" Spitting water out of the mouth, usually towards another animal.

6. "Chasing in a circle"

One young animal pursues another, one going around a circle of small diameter (2-3 m), sometimes exchanging roles.

7. "Touching rostrums" Two or three animals place their bodies so that they touch each other with their rostrums.

8. "Touching bellies" One young animal turns so its side is towards another animal, who touches the belly of the first one.

9. "Nodding" A young animal produces a number of nods very quickly while approaching another "black" juvenile or "gray" immature.

10. "Slight attempt to drown" A young animal tries to "straddle" a "gray" immature or other young animal.

11. "Low jump with belly landing"

A young animal jumps out of the water at a low height and then lands on its belly. 


\section{The Amur Belukha.}

The predominant behavior observed for the Amur belukha was a searching and hunting activity like that of the White Sea belukha. But environmental conditions in this observation region (offshore area in the Amur estuary, in the town of Ozerpakh) were quite different compared with the White Sea. The water was less clear (20-40 cm Secchi depth), shallower (1-5 m), and there was a current. A vast bay next to Petukha Cape (Fig. 40) serves as a reservoir for salmon (chum and Siberian) going upstream. The majority of these fishes follow a narrow channel (60-70 m) of 3-5 m depth (Fig. 40). In this very place, the highest activity level of belukhas was recorded.

\section{A. Size and structure of groups.}

Large groups of Amur belukhas were seldom seen in the observation region.

Table 15. Size and structure of groups of Amur belukhas (July-October 1983).

\begin{tabular}{lrrrrrr}
\hline $\begin{array}{l}\text { Number of } \\
\text { animals }\end{array}$ & \multicolumn{3}{c}{ Number of passings } & \multicolumn{3}{c}{ Total number of } \\
& Adults only & $\%$ & Adults and young & $\%$ & passings & $\%$ \\
\hline 1 & 10 & 100.0 & 0 & 0.00 & 10 & 17.9 \\
$2-3$ & 14 & 70.0 & 6 & 30.0 & 20 & 35.7 \\
$4-8$ & 10 & 41.7 & 14 & 58.3 & 24 & 42.9 \\
$9-18$ & 0 & 0.00 & 2 & 100.0 & 2 & 3.5 \\
Total & 24 & 52.2 & 22 & 47.8 & 56 & 100 \\
& & & & & & \\
\hline
\end{tabular}

Table 15 shows that $78 \%$ of the total number of passings were by groups of $2-8$ whales; $49 \%$ were groups of $4-8$ individuals. $47.8 \%$ of passings were made by groups containing 1-3 young animals, which was more typical of larger groups (4-18 individuals).

Like White Sea belukhas, small groups of Amur belukhas may join larger ones. A herd of 18-20 animals (26 August 1983) separated so that a group of 5-6 animals (one of which had a natural mark, see Fig. 41) explored the offshore area for an hour, leaving the rest of the herd (Fig. 42). Then this group disappeared in the opposite direction to the herd movement.

Amur belukhas also had two main forms of searching and hunting activity: individual and group.

\section{B. Individual searching and hunting activity}

In July-August, during mass migration of salmon (chum and Siberian), belukhas searched and caught fish as individuals, while maintaining a certain group unity. Groups of Amur belukhas hunting in the observation region were very dynamic. Resting or slowly 
moving animals were rarely seen. Even when the whole group was staying in the same place, some individuals were always moving along the shore or surfacing energetically, moving in various directions. The majority of the whales in the group were at a distance of 10-150 $\mathrm{m}$ from one another. During searching and hunting, young animals stayed with their mothers, surfacing synchronously for breathing. Only when a female made a quick move did the juvenile fall behind, but the pair would reunite in 2-40 sec.

Observations enabled identification of some individuals in the group on the basis of distinguishing features. These animals were: the female with the "marked" baby (Fig. 41); the large white animal who had a defective breathing valve so he made a sound like "wau" during the inhale-exhale cycle; the female with the big gray young animal ( $1 / 2$ of her own length) that was kept alongside all the time; the young and rather large "gray" animal with the "black" juvenile - a pair that had been observed for $30 \mathrm{~min}$.

Tracks of belukha movements are shown in Figures 43 and 44 . The trajectories were plotted using the space-time coordinates of surfacings of identified individuals.

Data on time of "ventilations" and breathing pauses of the Amur belukha during its searching and hunting activity are represented in Table 16 . These data were obtained when watching identified individuals.

Table 16. Some parameters of breathing activity of Amur belukha (n: number of measurements; \%: proportion of the total number of breathing pauses (BP). Abbreviations: sh (short), m (medium), l (long).

$\begin{array}{lll}\text { Parameters } & \text { Single animal } \% \text { Female with juvenile } \%\end{array}$

1. Duration of "ventilation" (sec) $15-110$, av.41.8 $\mathrm{n}=36$

2. Number of surfacings during "ventilation period"

3. Duration of BP (sh), sec

4. Duration of BP (m), sec

5. Duration of BP (1), sec
2-11, av. 4.7

$\mathrm{n}=41$

2-19, av. 10.6

$\mathrm{n}=147$

20-40, av. 26.4

$\mathrm{n}=16$

55-860, av. 259.5

$\mathrm{n}=35$
8-107, av. 40.6

$\mathrm{n}=27$

2-10, av. 4.3

$\mathrm{n}=28$

74.2

2-19, av. 10.9

68.3

$\mathrm{n}=82$

$8.1 \quad 20-40$, av. $24.8 \quad 10.0$

$\mathrm{n}=12$

17.7

56-954, av. 315.521 .7

$\mathrm{n}=26$ 

6. Proportion of the total time of searching and hunting activity of:
"ventilation"

17.8

12.7

breathing pauses (BP)

7. Observation time (hr)
82.2

3.1
87.3

2.6

According to Table 16, the behavior of a single animal was similar to that of a female with a juvenile. Animals made approximately equal numbers of surfacings during the "ventilation" period. Both had equal durations of "ventilation" and breathing pause. The index of surfacings/min for the Amur belukha was 0.75 .

Acoustic activity was different in groups of different numbers of the Amur belukha. The relative proportions of the main signal classes and their frequencies of occurrence during individual searching and hunting are shown in Table 17.

Table 17. Signals produced by the Amur belukha during individual searching and hunting activity (July-Sept. $1985 ; \%=$ proportion of the total number of signals, $\mathrm{sig} / \mathrm{min}=$ frequency of occurrence.

\begin{tabular}{|c|c|c|c|c|c|c|c|c|c|c|}
\hline \multirow{3}{*}{$\begin{array}{l}\text { Class of } \\
\text { signals }\end{array}$} & \multirow{3}{*}{\multicolumn{2}{|c|}{$\begin{array}{c}1 \text { adult } \\
\% \text { sig/min }\end{array}$}} & \multirow{2}{*}{\multicolumn{2}{|c|}{ 2-3 adults }} & \multicolumn{6}{|c|}{ Number of belukhas } \\
\hline & & & & & \multicolumn{2}{|c|}{$5-7$ adults } & \multicolumn{2}{|c|}{ group (night) } & \multicolumn{2}{|c|}{$2-5$ adult $+1-3$ juv. } \\
\hline & & & $\%$ & $\mathrm{sig} / \mathrm{min}$ & $\%$ & $\mathrm{sig} / \mathrm{min}$ & $\%$ & $\mathrm{sig} / \mathrm{min}$ & $\%$ & $\mathrm{sig} / \mathrm{min}$ \\
\hline$\# 1$ & 2.7 & 0.006 & 8.6 & 0.06 & 27.0 & 0.83 & 6.9 & 0.06 & 24.1 & 2.70 \\
\hline \#2 & 48.7 & 0.11 & 52.1 & 0.37 & 12.2 & 0.38 & 39.4 & 0.34 & 14.0 & 1.57 \\
\hline$\# 3$ & 0.0 & 0.00 & 6.2 & 0.04 & 11.8 & 0.36 & 8.1 & 0.07 & 10.2 & 1.14 \\
\hline$\# 4$ & 8.1 & 0.02 & 5.9 & 0.04 & 0.8 & 0.03 & 5.8 & 0.05 & 3.5 & 0.40 \\
\hline$\# 5$ & 0.0 & 0.00 & 4.8 & 0.03 & 9.2 & 0.28 & 4.2 & 0.04 & 9.0 & 1.00 \\
\hline \#6 & 0.0 & 0.00 & 2.8 & 0.02 & 2.0 & 0.06 & 1.4 & 0.01 & 6.4 & 0.72 \\
\hline$\# 7$ & 5.4 & 0.01 & 4.1 & 0.03 & 0.2 & 0.006 & 3.9 & 0.03 & 2.3 & 0.25 \\
\hline \#9 & 2.7 & 0.006 & 1.7 & 0.01 & 1.2 & 0.04 & 4.4 & 0.04 & 1.2 & 0.14 \\
\hline$\# 12$ & 0.0 & 0.00 & 7.6 & 0.05 & 8.0 & 0.25 & 0.6 & 0.005 & 4.2 & 0.47 \\
\hline$\# 13$ & 0.0 & 0.00 & 0.0 & 0.00 & 0.6 & 0.02 & 0.0 & 0.00 & 1.0 & 0.12 \\
\hline \#15 & 0.0 & 0.00 & 1.4 & 0.01 & 8.8 & 0.27 & 0.3 & 0.003 & 0.9 & 0.10 \\
\hline \#19 & 0.0 & 0.00 & 0.0 & 0.00 & 2.8 & 0.09 & 0.0 & 0.00 & 6.1 & 0.69 \\
\hline$\# 21$ & 0.0 & 0.00 & 0.0 & 0.00 & 0.0 & 0.00 & 0.3 & 0.003 & 1.9 & 0.22 \\
\hline$\# 26$ & 32.4 & 0.07 & 3.4 & 0.02 & 0.8 & 0.03 & 2.2 & 0.02 & 0.6 & 0.07 \\
\hline other & 0.0 & 0.00 & 1.4 & 0.01 & 14.6 & 0.45 & 22.5 & 0.20 & 14.6 & 1.63 \\
\hline
\end{tabular}


$\begin{array}{lllllllllll}\text { Total } & 100 & 0.23 & 100 & 0.70 & 100 & 3.09 & 100 & 0.87 & 100 & 11.2\end{array}$

Total number

of signals $\quad 37$

$290 \quad 500$

360

3224

Ave. index

(signals/

$\min /$ individ

0.23

0.30

0.56

1.83

Duration of

recording (h)

2.7

6.9

2.7

6.9

4.8

It follows from Table 17 that the larger the group size, the greater is the index of $\mathrm{sig} / \mathrm{min} /$ individual. So, groups of 3-8 adults with juveniles had indices 8 times greater than those of single animals. This is also true for other species (Herman and Tavolga 1980).

Having evaluated the relative proportions of different signals and their frequencies of occurrence (Table 17), one can point out the most common and specific classes of signals for groups of different sizes. For a single animal these were: \#2 "squeal" $(48.7 \% ; 0.11$ signals/min); \#26 "wail" (32.4\%; 0.07 signals/min); \#4 "whistle" (8.1\%; 0.02 signals/min). For 2-3 adults, they were: \#2 "squeal" (52.1\%; 0.37 signals/min); \#1 "peep" (8.6\%; 0.06 signals $/ \mathrm{min})$; $\# 12$ "jaw clapping" (7.6\%; 0.05 signals $/ \mathrm{min})$. For 4-8 adults: \#1 "peep" (27.0\%; 0.83 signals/min); \#2 "squeal" (12.2\%; 0.38 signals/min); \#3 "a, o, i, ae" (11.8\%; 0.36 signals/min); \#5 "roar" (9.2\%; 0.28 signals/min); \#12 "jaw clapping" (8.0\%; 0.25 signals $/ \mathrm{min})$. For a group at night: \#2 "squeal" (39.4\%; $0.34 \mathrm{signals} / \mathrm{min}) ; \# 3$ "a, o, i, ae" (8.1\%; 0.07 signals/min); \#1 "peep" (6.9\%; 0.06 signals $/ \mathrm{min})$. For a group containing juveniles: \#1 "peep" (24.1\%; 2.7 signals/min); \#2 "squeal" (14.0\%; 1.57 signals/min); \#3 "a, o, i, ae" (10.2\%; 1.14 signals/min); \#5 "roar" (9.0\%; 1.0 signals/min); \#6 "bleat" (6.4\%; 0.72 signals/min).

As we can see, signal classes \#1 and \#2 ("peep" and "squeal") were used in all kinds of groups. In a certain sense, it was a "universal" signal. At the same time, some signals were common for only a few types of groups. For example, \#26 ("wail") and \#4 ("whistle") were more typical of a single animal; \#3 ("a, o, i, ae"), \#5 ("roar"), and \#12 ("jaw clapping") of groups of several adults; and \#3 ("a, o, i, ae"), \#5 ("roar"), \#6 ("bleat") and \#12 ("jaw slapping") of groups in which there were adults with juveniles.

At night, the acoustic activity of the Amur belukha was not great $-0.88 \mathrm{signals} / \mathrm{min}$ compared to 9.5 signals/min in the day time. Those data refer to groups of approximately equal size - 3-6 individuals (the number of animals in a group at night time was counted according to breathing sounds produced). The number of main classes of echolocation series was practically the same at night and during the day -10.3 and $9.5 \mathrm{series} / \mathrm{min}$, 
respectively. The most common signals at night were classes \#2 (42.2\%) and \#28 (18.0\%). Rather large proportions of CF-type series ( 0.15 series $/ \mathrm{min})$ suggest that belukhas also hunt actively at night.

C. Searching and hunting activity of groups of belukha.

The hunting behavior of Amur belukhas changed beginning in late September (Agafonov and Schekotov 1986). The main prey in this period of time were spawning smelt and whitefish (a species that also feeds on smelt, according to fishermen). The principle hunting tactics became "carousels" and "caldrons" formed by 5-8 animals. The description of these tactics is almost the same as for White Sea belukhas.

D. Communication in different situations

"Dialogues" (see section on the White Sea belukha) were important distinguishing features of groups of 3-8 Far Eastern belukhas.

The relative proportions and frequencies of occurrence of the main signals produced by Amur belukhas in 58 Type I ("close communication") and 100 Type II ("distant communication") "dialogues" are shown in Table 18.

Analyses of these figures and the percentage of "dialogues" with signals of certain classes (Table 18) revealed the more specific and commonly-used signal classes for each type of "dialogue". In "close" communication they were: \#6 "bleat" (11.3\%; 7.3 signals/min; 64.3\% accordingly); \#12 "jaw clapping" (11.9\%; 9.7 signals/min; 67.3\%). For "distant communication": \#2 "squeal" (14.8\%; 4.8 signals/min; 68.4\%); \#5 "roar" (7.8\%; 3.6 signals/min; 39.2\%); \#4 "whistle" (6.5\%; 3.0 signals/min; 47.2\%). Signals of classes \#1 ("peep"), \#3 ("a, o, i, ae") and \#7 ("short whistle") were approximately equally used in both types of "dialogues". The difference in making these signals in different types of "dialogues" was their higher frequency of occurrence in "close communication" (Table 18). 
Table 18. The relative proportion of main signal classes produced in Type I ("close communication") and Type II ("distant communication") "dialogues" by the Amur belukhas.

\begin{tabular}{|c|c|c|c|c|c|c|c|c|}
\hline \multirow[t]{3}{*}{$\begin{array}{l}\text { Signal } \\
\text { class }\end{array}$} & \multicolumn{2}{|c|}{$\begin{array}{l}\text { Number of } \\
\text { signals }\end{array}$} & \multicolumn{2}{|c|}{$\begin{array}{c}\% \text { of the total } \\
\text { number of signals }\end{array}$} & \multicolumn{2}{|c|}{$\begin{array}{l}\% \text { of "dialogues" } \\
\text { containing signals of } \\
\text { this class }\end{array}$} & \multicolumn{2}{|c|}{$\begin{array}{l}\text { Frequency of } \\
\text { occurrence }\end{array}$} \\
\hline & \multicolumn{8}{|c|}{ Type of "dialogues" } \\
\hline & $\overline{\mathbf{I}}$ & II & I & II & $\mathrm{I}$ & II & I & II \\
\hline \#1 & 260 & 421 & 20.6 & 18.3 & 81.6 & 80.5 & 12.9 & 6.5 \\
\hline \#2 & 90 & 339 & 7.1 & 14.8 & 43.6 & 68.4 & 8.3 & 4.8 \\
\hline \#3 & 234 & 360 & 18.6 & 15.7 & 72.1 & 68.3 & 6.2 & 2.6 \\
\hline \#4 & 59 & 149 & 4.7 & 6.5 & 37.1 & 47.2 & 5.6 & 3.0 \\
\hline \#5 & 66 & 179 & 5.3 & 7.8 & 24.8 & 39.2 & 7.6 & 3.6 \\
\hline \#6 & 142 & 111 & 11.3 & 4.8 & 64.3 & 37.3 & 7.3 & 2.9 \\
\hline$\# 7$ & 52 & 94 & 4.1 & 4.1 & 28.4 & 38.2 & 6.2 & 2.6 \\
\hline \#12 & 150 & 47 & 11.7 & 2.0 & 67.3 & 29.9 & 9.7 & 1.7 \\
\hline \#15 & 53 & 99 & 4.2 & 4.3 & 22.4 & 16.0 & 9.8 & 2.4 \\
\hline other & 154 & 494 & 12.2 & 21.5 & 51.7 & 71.0 & 9.7 & 7.6 \\
\hline Total & 1260 & 2293 & 100 & 100 & - & - & 83.3 & 37.7 \\
\hline
\end{tabular}

Observations from an aquarium revealed that sounds of class \#12 are produced during direct contact of two or more animals ("close communication"), and are associated with the maximal level of excitement (Morgan 1979). For many years, researchers considered those sounds to express a threat (McBride and Hebb 1948; Fish and Mowbray 1962). Taking this fact into account, we can subdivide "dialogues" of the first type ("close communication") into 2 groups according to the presence or absence of class \#12 signals. Analysis of the structure of dialogues showed that the presence of class \#12 signals was correlated with decreases of the relative proportions of class \#2signals "squeals", and class \#5 signals ("roar") and their frequencies of occurrence: \#2 (4.3\%; 5.1 signals/min in the presence of signal \#12; and 15.2\%; 11.4 signals/min when it was absent); \#5 (4.15; 5.8 signals $/ \mathrm{min}$ and $8.5 \% ; 9.4 \mathrm{signals} / \mathrm{min})$. Signal \#12 does not affect the occurrence of sounds of other classes. 
Morgan (1979) showed that when an animal is near two different signals, its behavioral and acoustic reaction differs from that when it hears those signals separately. This means that the context may affect the perception by an animal of a particular signal. Our data can confirm that.

Our analysis was based upon the same parameters of qualitative and quantitative characteristics of "dialogues" during "close communication". Those "dialogues": a) contained \#12 class signals, but not \#6 class signals; b) contained class \#6 signals, but not class \#12; c) contained both classes of signals (Table 19). These particular two classes of signals were chosen to be the criteria for the subdivision of "dialogues" because the meaning of class \#12 signals was well-known from publications. Also, $90 \%$ of all dialogues made in "close communication" contained either signals of class \#1, or \#6, but $48 \%$ contained both classes of signals.

Table 19. Frequency of occurrence of signals, produced by Amur belukhas in "dialogues" during "close communication" (\% $s=$ proportion of signals of that particular class of the total, $\mathrm{sig} / \mathrm{min}=$ frequency of occurrence; $\% \mathrm{~d}=$ "dialogues" containing signals of certain classes.

\begin{tabular}{|c|c|c|c|c|c|c|c|c|c|}
\hline \multirow[t]{2}{*}{$\begin{array}{l}\text { Signal } \\
\text { class }\end{array}$} & \multicolumn{3}{|c|}{$\begin{array}{l}\text { "Dialogues" with } \\
\text { class \#12 signals }\end{array}$} & \multicolumn{3}{|c|}{$\begin{array}{l}\text { "Dialogues" with } \\
\text { class \#6 signals }\end{array}$} & \multicolumn{3}{|c|}{$\begin{array}{l}\text { "Dialogues" with } \\
\text { class \#6 and \#12 signals }\end{array}$} \\
\hline & $\% s$ & $\mathrm{sig} / \mathrm{min}$ & $\% \mathrm{~d}$ & $\% s$ & $\mathrm{sig} / \mathrm{min}$ & $\% \mathrm{~d}$ & $\% \mathrm{~s}$ & $\mathrm{sig} / \mathrm{min}$ & $\% \mathrm{~d}$ \\
\hline$\# 1$ & 21.7 & 40.0 & 83.3 & 20.5 & 10.3 & 75.0 & 20.0 & 13.6 & 88.0 \\
\hline$\# 2$ & 6.5 & 23.8 & 33.3 & 15.2 & 11.0 & 50.0 & 3.3 & 3.7 & 36.0 \\
\hline \#3 & 23.9 & 30.1 & 75.0 & 26.0 & 17.9 & 75.0 & 15.5 & 12.2 & 60.0 \\
\hline$\# 4$ & 5.8 & 7.5 & 41.6 & 4.1 & 5.8 & 31.3 & 4.5 & 7.0 & 44.0 \\
\hline$\# 5$ & 2.9 & 15.0 & 16.7 & 4.8 & 5.0 & 37.5 & 5.0 & 8.5 & 24.0 \\
\hline \#6 & 0.0 & 0.0 & 0.0 & 14.9 & 6.8 & 100.0 & 14.0 & 8.6 & 100.0 \\
\hline$\# 7$ & 1.5 & 10.0 & 8.3 & 6.0 & 9.7 & 37.5 & 4.9 & 5.6 & 32.0 \\
\hline$\# 12$ & 15.2 & 14.3 & 100.0 & 0.0 & 0.0 & 0.0 & 16.7 & 9.7 & 100.0 \\
\hline$\# 15$ & 6.5 & 45.0 & 16.7 & 0.7 & 1.7 & 12.5 & 6.1 & 8.3 & 32.0 \\
\hline other & 11.6 & 20.7 & 41.7 & 3.0 & 4.1 & 25.0 & 5.6 & 5.3 & 44.0 \\
\hline
\end{tabular}

Table 19 shows that the frequencies of occurrence of the main signal classes in "dialogues" that contained both class \#12 and \#6 signals was much lower than in "dialogues" that contained either one alone (\#12 or \#6). 
According to variation in two other parameters, we can make the following conclusions: 1) class \#2 signals are used more rarely in "dialogues" that contain class \#12 signals than those without them; 2) the frequency of occurrence of signal classes \#5 and \#7 in "dialogues" with class \#12 signals (but without class \#6) is remarkably lower (1.7-4.5 times) compared to "dialogues" containing either class \#6 signals or both \#6 and \#12;3) signal classes \#1, 3 and 4 are used equally in different "dialogues" (Table 19).

Thus, the presence of both signal classes \#12 and \#6 may greatly affect the frequency of occurrence and usage level of other signals.

The total recorded number of echolocation series produced by the Amur belukha during individual searching and hunting activity was 16091 (RT - 12.4\%, IT - 81.6\%, CT - 5.1\%, CF - 0.9\% - see Table 4). Discussion of the navigational strategy of the Far Eastern belukha is presented below.

\section{Conclusions: the distinguishing features of the behavior and acoustic signals of} belukhas in two areas.

As mentioned above, ethological-acoustic studies of the belukhas of the White Sea and the Amur Estuary allowed us to obtain data mainly on the searching and hunting activity of animals. We consider that the different aspects of their behavior in this area are largely related to the behavior of their principal prey species.

\section{A. Searching and hunting behavior}

Both forms of searching and hunting activity (individual and group) were observed in belukhas of the White Sea and of the Amur Estuary. But essential differences in individual behavior and acoustic activity were recorded (Table 20). The abundance of large, fastmoving prey in the Amur Estuary - chum and Siberian salmon - caused the formation of larger, more compact and dynamic groups of belukhas than in the White Sea. The White Sea belukhas employed very characteristic and stereotyped tactics of pursuit and capture of small schooling fish. Those tactics were: frequent surfacings, "loops", "zigzags" during the "pursuit of a school", and energetic jumps on their sides accompanied by tail movements during the initial stage of "hunting". Such behavior was not recorded for individual searching and hunting activity of Amur belukhas. 
Table 20. Some characteristics of searching and hunting activity of belukhas in two geographic regions: the White Sea and the Amur Estuary

\begin{tabular}{lcccc}
\hline $\begin{array}{l}\text { Observation } \\
\text { region }\end{array}$ & $\begin{array}{c}\text { Predominant size } \\
\text { of groups }\end{array}$ & $\begin{array}{c}\text { Distance between } \\
\text { individuals (m) }\end{array}$ & $\begin{array}{c}\text { Average duration of } \\
\text { breathing pauses (d) } \\
\text { (sec) }\end{array}$ & $\begin{array}{c}\text { Index } \\
\text { surfacings/ } \\
\text { min }\end{array}$ \\
\hline $\begin{array}{l}\text { Letnyaya } \\
\text { Zolotitsa }\end{array}$ & $\begin{array}{c}1-3 \text { individuals } \\
(1-23.1 \%)\end{array}$ & $300-800 \mathrm{~m}$ & $93-121$ & 2.31 \\
(The White & $(2-3-51.6 \%)$ & & & \\
Sea) & & & & \\
& & & & \\
The Amur & $2-8$ individuals & $10-150 \mathrm{~m}$ & & \\
Estuary & $(2-3-35.7 \%)$ & & & \\
& $(4-8-42.9 \%)$ & & & \\
\end{tabular}

The average duration of breathing pauses by Far Eastern belukhas was longer (Table 20), and they surfaced less than one-third as often as White Sea belukhas. Also, the average number of surfacings during "ventilation periods" was lower: 4.3-4.7 (Table 16) compared with 5.2-8.4 for White Sea belukhas (Table 6). We suppose that the long breathing pauses of Amur belukhas were connected with "waiting" tactics, with "hiding" of animals. So a belukha remained underwater while trying to choose the proper moment to start pursuit and capture of the salmon, which were going towards a river. This also evidently caused a high relative proportion of long breathing pauses (BP long)(82.2$87.3 \%$, Table 16), with a correspondingly low proportion of "ventilations" (12.7-17.8, Table 16) during searching and hunting. The corresponding values for White Sea belukhas were 45.8-68.9\% (proportion of BP(1) - Table 6) and 31.1-54.2 (proportion of ventilations - Table 6).

Additionally, the following fact draws attention - there was a stable correlation between the proportions of types of breathing pauses (BP[sh], BP [m], BP [1]) for belukhas of the White Sea and the Amur estuary. (BP[1] and BP [h] of the White Sea belukha generally correspond to BP [1] of the Amur belukha). The total relative proportion of BP (sh) and BP (m) was 78.5\%-82.6\% for the White Sea belukha and 78.3-82.3\% for the Amur belukha. Accordingly, the proportions of BP (1) were also equal: $17.4 \%-21.5 \%$ and 17.721.7\% (Tables 6, 16). 
Comparing the style of behavior of the White Sea and the Amur belukha females with juveniles, it is possible to define some differences. First, "black" White Sea juveniles were quite independent - they always stayed alone when females were "hunting", and often during the stage of "pursuit of a school" as well; distances between juveniles and females were up to $100-150 \mathrm{~m}$ (10-60\% of the entire time animals were in the observation region). In contrast, a juvenile Amur belukha fell behind its mother only when she makes energetic spurts for fish, and in 20-40 seconds the pair was reunited again. Second, in the White Sea, when several animals with juveniles were close to each other, young belukhas often formed pairs or trios for short play sessions. This was not recorded in the Amur estuary. Third, only White Sea belukhas formed "kindergartens" composed of "gray" and "black" juveniles.

The essential "independence" of the White Sea juveniles is probably explained by the many small secluded bays, within which the animals feel safe.

The behavior of White Sea and Amur belukhas during searching and hunting in groups is similar. But group hunting of Amur belukhas happens only at the beginning of October, during the migration of spawning schools of smelt when the behavior of prey of both "varieties" of belukha is practically the same. Both belukhas use the same tactics "carousel" and "caldron". Group searching and hunting behavior of White Sea belukhas is probably connected with feeding on large concentrations of herring.

\section{B. Acoustic activity}

The acoustic activity of belukhas in the different ranges differs greatly. For the White Sea belukhas, signals of the following classes were characteristic: \#8/6 (denominator is rank of classes), \#11/9, \#14/13, \#17/14, \#25/17. In contrast, the following signal classes were characteristic of Amur belukhas: \#23/14, \#27/18, \#28/19, \#29/20, \#32/22 (Table 3). The relative proportions of certain signals were also different (Fig. 45).

On the other hand, the time-frequency characteristics of signals produced by White Sea and Amur belukhas were quite similar (Table 21).

The presence of highly-specific stereotyped sequences of signals (SS) produced during each stage of "hunting" was the most distinguishing feature of the acoustic activity of belukhas. Of particular importance in SS were signals \#8,11, 14, and 17. 
Table 21. Some time-frequency characteristics of signals produced by White Sea and Amur belukha.

\begin{tabular}{lllll}
\hline \multirow{2}{*}{$\begin{array}{l}\text { Signal } \\
\text { class }\end{array}$} & \multicolumn{2}{c}{ Duration (sec) } & \multicolumn{2}{c}{ Dominant frequency (kHz) } \\
& White Sea & Amur Estuary & White Sea & Amur Estuary \\
& & & & \\
\hline$\# 1$ & $0.03-0.15$ & $0.07-0.18$ & $3.8-10.0$ & $7.5-10.0$ \\
$\# 2$ & $0.22-0.8$ & $0.4-0.5$ & $1.3-7.5$ & $1.8-11.0$ \\
$\# 3$ & $0.02-0.09$ & $0.07-0.17$ & $0.3-3.5$ & $0.5-5.6$ \\
$\# 4$ & $0.2-1.15$ & $0.23-0.93$ & $3.1-9.0$ & $2.6-10.0$ \\
$\# 5$ & $0.4-0.8$ & $0.4-2.4$ & $0.2-0.4$ & $0.2-2.2$ \\
$\# 7$ & $0.05-0.13$ & $0.06-0.13$ & $3.1-6.0$ & $2.6-10.0$ \\
& & & & \\
\hline
\end{tabular}

Individually-specific signals of classes \#8 and \#14 probably play an important role in maintaining distant contact between animals and in organizing effective exploitation of the hunting region after scattering of a group. Signals of classes \#1, 4, 7, 11, and 17 reflect, in our opinion, the emotional state of animals during pursuit and capture of fish.

No stereotyped sequences of signals were recorded from Amur belukhas. Characteristic of the sounds made by Amur belukhas was a large number of "dialogues" during "close communication". In these "dialogues", both White Sea and Amur belukhas characteristically produced signals of classes \#6, 3 , and 12 . The most common signals used by belukhas in "distant communication" were the same - \#5, \#2 and \#4.

High signal rates during "close communication" "dialogues", high levels of excitement during such contacts between animals (Morgan 1979), data on use of class \#12 signals to express threats (McBride and Hebb 1948, Fish and Mowbray 1962) - all these lead us to suppose a rather important connection between this type of "dialogue" and aggressivesubordinate and hierarchical behavior of belukhas.

On the whole, belukhas of both the White Sea and the Amur Estuary displayed much higher levels of acoustic activity when in a group than when alone, especially if there were juveniles and young animals in a group. This was reflected in the index of signal/min/individual (Fig. 46). The total relative proportion of signals of classes \#8, 11, 14 , and 17 decreases as group size of White Sea belukhas increases - from $52 \%$ for one animal to $11 \%$ for a group composed of 2-5 animals with juveniles (Fig. 47). This happens due to the increasing proportion of signals of classes \#2, 3, 5, 6, and 13 (Fig. 47). For the Amur belukha, increasing group size was accompanied by increasing 
proportions of signals of classes \#1, 5, 6, 3, and 12 (Fig. 48). These signals were evidently more closely connected with various types of group activity of both belukhas - of the White Sea and of the Amur Estuary.

Group size seems to influence greatly the frequency of occurrence of signals. It is possible, for example, to discover in each case common signals of the main classes produced by the same number of both belukhas (of the White Sea or of the Amur) in different situations. These signals were used by animals to approximately the same extent (Table 22).

Table 22. The main classes of signals commonly used by belukhas of the White Sea and the Amur Estuary in same-sized groups.

\begin{tabular}{lcrrrr}
\hline \multirow{2}{*}{$\begin{array}{l}\text { Number } \\
\text { of animals }\end{array}$} & $\begin{array}{c}\text { Signal } \\
\text { class }\end{array}$ & \multicolumn{2}{c}{ The White Sea } & \multicolumn{2}{c}{ The Amur Estuary } \\
& & $\%$ & sig/min & $\%$ & sig/min \\
& & & & & \\
\hline 1 adult & $\# 4$ & 10.7 & 0.05 & 8.1 & 0.02 \\
2-3 adults & $\# 2$ & 12.6 & 0.23 & 52.1 & 0.37 \\
& $\# 1$ & 12.5 & 0.23 & 8.6 & 0.06 \\
4-8 adults & $\# 3$ & 7.9 & 0.20 & 11.8 & 0.36 \\
& $\# 5$ & 7.8 & 0.19 & 9.2 & 0.28 \\
$4-8$ adults+juveniles & $\# 2$ & 16.3 & 0.71 & 14.0 & 1.57 \\
& $\# 3$ & 10.2 & 0.44 & 10.2 & 1.14 \\
& $\# 6$ & 14.5 & 0.62 & 6.4 & 0.72 \\
\hline
\end{tabular}

At night, much lower (4.3-11.2 times) levels of acoustic activity were recorded than during the day (average 1.04-0.88 signals/min) from groups of 3-6 belukhas both of the White Sea and of the Amur Estuary. But the White Sea belukhas stayed the whole night in practically the same place (situation "rest-sleep"). Low movement and acoustic activity levels (main signal classes: \#3 - 22.1\%, \#5 - 17.3\%, and \#4 - 14.0\%) of the White Sea belukha were also accompanied by a complete absence of echolocation pulse series. In contrast, groups of the Amur belukhas maintained high movement and acoustic activity levels- 10.3 series/min. Judging by the presence of CF-type series $(0.15 \mathrm{CF} / \mathrm{min})$, Amur belukhas were actively catching fish. Most often, in that situation, signals of class \#2 (42.2\%) and 28 (18.0\%) were produced. "'Rest-sleep" was not observed in the Amur Estuary. 


\section{Echolocation strategy.}

Both in the White Sea and in the Amur Estuary, belukhas made signals of all the main classes. But the proportions of certain classes differed (Fig. 49, Table 23).

Table 23. Common echolocation strategies of belukhas and some environmental factors.

\begin{tabular}{|c|c|c|c|c|c|}
\hline $\begin{array}{l}\text { Observation } \\
\text { region }\end{array}$ & $\begin{array}{l}\text { Relative proportion } \\
\text { of main classes } \\
\text { of echolocation } \\
\text { series (\%) }\end{array}$ & $\begin{array}{l}\text { Principal prey, } \\
\text { average weight } \\
(\mathrm{kg}), \text { average } \\
\text { size }(\mathrm{cm})\end{array}$ & $\begin{array}{l}\text { Prey } \\
\text { behavior }\end{array}$ & $\begin{array}{l}\text { Water clear- } \\
\text { ness (Secchi } \\
\text { depth, cm) }\end{array}$ & $\begin{array}{c}\text { Water } \\
\text { Depth } \\
\text { (m) }\end{array}$ \\
\hline $\begin{array}{l}\text { Letnyaya } \\
\text { Zolotitsa } \\
\text { (The White } \\
\text { Sea) }\end{array}$ & $\begin{array}{l}\text { RT }-16.3 \\
\text { IT }-45.7 \\
\text { CT }-28.5 \\
\text { CF }-9.5\end{array}$ & $\begin{array}{l}\text { herring, } \\
0.15-0.2 \\
14-18\end{array}$ & $\begin{array}{l}\text { small, typically } \\
\text { schooling fish; } \\
\text { school is a whole } \\
\text { unit maintained } \\
\text { even when predato } \\
\text { attacks. }\end{array}$ & $\begin{array}{l}300-500 \\
\text { tor }\end{array}$ & $5-12$ \\
\hline $\begin{array}{l}\text { The Amur } \\
\text { Estuary }\end{array}$ & $\begin{array}{l}\text { RT }-12.4 \\
\text { IT }-81.6 \\
\text { CT }-5.1 \\
\text { CF }-0.9\end{array}$ & $\begin{array}{l}\text { pink, } \\
1-1.7, \\
45-50 \\
\text { chum, } \\
3-5, \\
58-75\end{array}$ & $\begin{array}{l}\text { large, forms } \\
\text { a compact } \\
\text { group. The } \\
\text { school does } \\
\text { not have the same } \\
\text { integrity as herring } \\
\text { schools have and it } \\
\text { disintegrates when } \\
\text { attacked. }\end{array}$ & $\begin{array}{l}20-40 \\
\text { e } \\
\text { it } \\
\text { in }\end{array}$ & $1-5$ \\
\hline
\end{tabular}

According to our point of view, these differences were caused by differences in the behavior of the principal prey, by their different size, and by some hydrological characteristics - water clarity, current speed, and depth. The predominance of RT- and ITtype echolocation series in Amur belukhas demonstrates navigational problems (due to the poorer water clarity, shallower water, and the presence of a current) rather than difficulty in finding prey. This is particularly true in July-Sept, when the mass spawning migration of salmon occurs, and the fish swim upstream along a narrow channel (60-70 m) of 4-5 m depth. This channel formed a hunting zone for the belukhas. In the surrounding areas, 
water depth was 1-2 m. Considering the high speed animals make during a spurt (3-4 $\mathrm{m} / \mathrm{sec}$ ), it could be supposed thay they need beforehand to get information on any obstacles in their way with the help of echolocation (RT and IT). In our opinion, this explains the large relative proportion of RT- and IT-type series inherent to the Amur belukha (total 94\%).

The total proportion of echolocation series of these classes inherent to the White Sea belukha is much smaller (62\%). This is probably connected with the greater water clarity and greater depth in the observation region on the White Sea. Besides that, we think that part of the location series (RT and IT) is used by White Sea belukhas for distant detection of fish schools, because the prey concentration here is much lower than in the Amur Estuary.

Small numbers of CT-type echolocation series (Table 23) can be explained by the opportunity for the Amur belukhas to use passive acoustic localization to find big salmon moving in the water. This happens after "pursuit of a school", when the school disintegrates and the belukhas pursue single fish. The CT-series made by White Sea belukha were recorded only during the "hunting" stage. Series of this class ( $38 \%$ out of the total number of series) are widely used by belukhas to disorient and to catch small prey - White Sea herring form compact schools during attack by a predator (Table 23). As observations made in an aquarium show, bottlenose dolphins isolate one or a few fish out of a compact school, while producing intensive and frequent series of echolocation pulses (evidently it is "close target - CT). After that, the deafened fish are easy prey for the dolphins (Hult 1982).

\section{Some features of social organization.}

On the whole, studies of behavior and acoustic activity of belukhas show that this representative of the toothed whales has a complicated social organization.

Flocks of belukha are discrete social units. They probably are characterized by a certain constancy of composition and are formed on the basis of relationships (Bel'kovitch and Yablokov 1969). This is true as well for other species of resident dolphins (Bel'kovitch et al. 1978, Würsig 1978, Balcomb 1980, Hoyt et al. 1984). Small groups of belukhas (2-8 individuals), common in offshore regions (Table 5,15 ), are by our data fragments of a flock that does not exist separately for a long time. Such groups appeared regularly in the observation region in the White Sea, and the same belukhas often visited the region during the same season as well as during other seasons (Table 10, Fig. 32-35). A marked morning peak of belukha appearances (Fig. 22) was connected with their aproaching from the side of Solovetskiye Islands and Zhizhgin Island. At night, the animals used to go back 
towards the islands or remain in the observation region, keeping in a compact group at a distance of 500-800 $\mathrm{m}$ from the shore (situation "rest-sleep").

Offshore shallowness in the observation region on the White Sea (Fig. 19:3) was used by single belukhas and by small groups mainly for searching for fish and hunting. At the same time, formations from time to time of larger groups ( 15 and more) probably occur in the more deep and remote parts of the region (Fig. 19:2). There are reasons to suppose that the study animals are resident in this part of the White Sea. At the same time, belukhas from the other seas visit the White Sea periodically (Potelov 1986). Similar resident and migratory groups are common in their Okhotsk, Bering Sea, and the eastern Arctic (Fedoseev 1986).

The typical number of animals in hunting groups of White Sea belukhas is 2-3 $67.1 \%$ out of the total number of observed groups). Single animals were also often seen here (23.1\%). We should tell more about this - groups of White Sea belukhas are very dispersed during predominantly individual hunting (animals at a distance of $0.3-0.8 \mathrm{~km}$ from each other). In our opinion, this is connected with the feeding of White Sea belukhas on small schools of herring. In the observation region of the Amur Estuary, groups of belukhas were compact and larger (Table 20). This is explained by the abundance of big prey items (different species of salmon). The shallow depth (1-5 m) of the region and the rather narrow channel (Fig. 40) used by fish going upstream are probably the motivation for belukhas to increase the size of groups. According to data collected by the employees of the Laboratory of Marine Bioacoustics of the Oceanographic Institute of the Soviet Academy of Sciences in the Anadyr Estuary, belukhas often form groups of several tens to even hundreds of individuals. That could be explained by the greater depth in the estuary (6-20 $\mathrm{m})$ and the more even distribution of salmon migrating for spawning.

Belukhas also used to unite (up to several hundreds of individuals) during migration (Bel'kovitch and Schekotov 1987a): migrating flocks of belukhas are usually led by adult male animals followed by females with juveniles (Dorofeev and Klumov 1936, Arsenjev 1939).

The age and sex structure of groups are thought to vary in summer and in autumn (Fig. 20). Seasonal studies of group structure showed that composition of belukha groups in June-July is governed by the needs of breeding, while in July-October and, probably, in winter - by feeding and raising of young animals (Rutilovskiy 1939; Tomilin 1962; Kleinenberg et al. 1964, Bel'kovitch and Yablokov 1969).

We recorded complex modes of behavior displayed by belukhas that correlates well with the complexity of their communication systems. This also confirms the fact that ecological and social factors can play the leading role in the evolution of communication 
systems (Wilson 1975). Acoustic signals made by belukhas are characterized by more variability. The total number of main classes of communicative and emotional signals is 35 (Table 3). Additionally, a great variety of signals also characterized each main class, due to the complex structure of the majority of signals. It is worthwhile to stress that belukhas produce a large number of specific sounds of strict situational nature. These include: individually-identified signals of classes \#8 and \#14; emotional signals of classes \#17 and \#11, made during the stage of "hunting" (Figs. 28, 32-35); low-frequency whistles and characteristic squeals (classes \#4, \#2) in the situation "excited group" (Fig. 39A, B); class \#10 signals - belukha's reaction to a SCUBA diver (Fig. 39C); characteristic sound complexes containing "bleat" and "jaw clapping" (classes \#6 and \#12) in "dialogues" of "close communication" (Fig. 4A, Fig. 6A; intensive "calling" signals produced by a female (class \#10) in her response to a juvenile (Fig. 37C) and "child" signals produced by juveniles - high-frequency squeals and bleating (classes \#2 and \#6, Fig. 37A); number of signals made by White Sea belukhas in stressful situations (Bel'kovitch and Schekotov 1987a) and so on. On the whole, we may expect to discover more situation-specific acoustic signals in belukhas which have developed during the evolution of their complex social behavior.

Searching and hunting activity of belukhas is characterized by great complexity and is closely associated with acoustic activity. Individual and group hunting were observed.

Individual hunting of the White Sea belukhas differs from that of the Amur belukhas. In the Amur Estuary, an abundance of fast-moving prey (salmon) causes the predominance of larger, more compact and dynamic groups of animals than in the White Sea (Table 20). The different organization of searching and hunting activity in the two regions, in our opinion, engenders the characteristic sounds produced by belukhas. As mentioned above, they are: a) certain classes of signals characteristic for only one range (Table 3); b) different relative proportions of signals inherent to both White Sea and Amur belukhas (Fig. 45).

The most important characteristics of acoustic activity of the White Sea belukha during individual hunting for small schools of herring are stereotyped sequences of signals produced by animals. These signals are clearly functionally structured. Individuallyidentified signals of class \#8 and 14 that are produced in the beginning of "hunting" probably play an important role in maintaining distant contact between individuals. Signals of classes \#1,4,7,11, and 17 reflect an emotional state, a level of excitement of animals during "hunting".

In contrast, more common for the relatively large and compact groups of Amur belukhas are periods of active sound production by 2-3 and more animals, forming distinctive "dialogues", conditionally referred to "close" and "remote" communication 
(Table 12,18). "Dialogues" during "close communication" are probably connected to aggressive-subordinate and hierarchical behavior of belukhas.

On the whole, the intensity of signal exchange grows significantly, both in the White Sea and in the Amur Estuary as the number of hunting animals in a group grows (Fig. 46). These are primarily signals of classes \#1, 5, 6, 8, and 13 (Figs. 47, 48). These signals are probably more closely connected with the social activity of animals.

It was noted that a coordination of activity existed between belukhas when a group of them were hunting for big concentrations of small schooling fish - $6-8$ belukhas were moving along a circle, not allowing fish to escape. Meanwhile, one of the animals from time to time came to the center of the "carousel" to feed actively. Such behavior is associated with a large number of signals - 4.4 signals/min (classes $\# 2,4,10$, and 3 predominated). Group hunting rarely happens in the White Sea, but is common in the Amur Estuary in late September-October during spawning migration of smelt.

Our studies of hunting groups of belukhas did not reveal anything that contradicted the hypothesis of the American researchers (Johnson and Norris 1986) about the existence during group hunting of symmetrical social relations without the acute hierarchy that is inherent to group hunting in terrestrial animals (Eisenberg 1981). In support of this hypothesis, in hunting groups of Lagenorhynchus and Stenella (which are larger than those of belukhas), juveniles stay away from the feeding part of the group, while females, males and immatures tending the juveniles replace each other in order to join feeding flocks (Würsig and Würsig 1980, Norris et al. 1982). Our observations of belukhas show that juveniles follow females during group hunting and stay separately only at the moment when females are catching fish, in the same way that it happens during individual hunting. The American studies mentioned above indicated complex social behavior in dolphins. When combined with the data that exist on mutual assistance among adults, these studies suggest that there are elements of altruistic behavior inherent to these dolphins (Johnson and Norris 1986). Mutual assistance in stressful situations during whaling was recorded also for belukhas (Bel'kovitch and Schekotov 1987a). Individuals of many species of toothed whales, in the face of a threat, dispay an ability to enact mutual rescues (for example, Collet 1907, Munsterjelm 1915, Gambell 1968, Mead 1989).

The mating behavior of belukhas is associated with very high levels of acoustic activity. We managed to observe from the boat in late July 1988 a group of 7 adult belukhas close to us. Their behavior was characterized by unusual agility: animals were moving at high speed in 3 or in 4 individuals; they snuggled up to each other and pursued one another, making "abrupt" turns and sometimes jumping low out of the water. The animals' excitement was accompanied by a great number of sounds (of classes \#2, 3, and 4) - 
"squeals", "squeaks", and "whistles". Approximately 20 minutes passed before the belukhas noticed our boat, and they immediately terminated sound production. These are all reasons to suppose that this behavior was mating (Bladykov 1944, Brown et al. 1966, Pilleri 1972, Saayman et al. 1973). Mating was also seen in shallow waters (Provorov 1957).

After the belukhas noticed the boat and stopped producing signals, two large animal scouts came up to us and swam under the boat. After that, they joined the flock. Many authors mentioned the fact that dolphins have scouts in a group (Evans and Dreher 1962, Caldwell et al. 1965, Bel'kovitch et al. 1978, Würsig 1979). Other times we watched "scouts" at night. They came to the boat from a disturbed flock (situation "signals emanated from the boat"). Finally, recall the case when two large belukhas surfaced synchronously and twice approached a SCUBA diver working in the water. In all of these cases, the "scouts" were probably dominant animals.

It was noted that belukhas have complex parental behavior and long periods of contact between a mother and a child. Lactation period for this species is about half a year (Nickol'skiy 1936, Sleptsov 1955, Kleinenberg et al. 1964). However, considering published data on other species of toothed whales (Tavolga and Essapian 1957, Sergeant 1962, Benjaminsen and Christensen 1979, Best 1974, 1979), we doubt that the period of lactation is so short. Juveniles also probably stay with their mothers after termination of the lactation period. Judging by the fact that one can often observe groups of belukhas composed of a female, an immature and a juvenile, the period of close contact between mother and child continues for 2-3 years. In such groups, immatures are tended not only by mothers but also by older brothers and sisters. In groups composed of a mother, a juvenile, and an immature, a juvenile mostly spends time with immatures. "Kindergartens" inherent to belukhas, when juveniles may be tended by immatures only for a long time (2-3 hours) are unique even among the toothed whales.

Close and persistent relations between a mother and a juvenile and alloparental behavior are common for many species of dolphins (McBride and Kritzler 1951, Essapian 1953, Caldwell and Caldwell 1966, 1977, Allen et al. 1977). It has been published that a female dolphin raised in the aquarium without her mother could not properly tend her own baby in a group. As a result, one juvenile died at the age of 15 days (Tavolga and Essapian 1957, Wood 1977). This fact to some extent testifies to the importance and complexity of mutual relations of a mother and juvenile. Adult childless females, so-called "aunts", may defend a mother with a child from excited males or tend juveniles when the mother is feeding (Caldwell and Caldwell 1972; Gurevich 1977, Leatherwood 1977). Making contacts with other immatures and adults in groups, juveniles probably gain experience necessary for 
future social life. This is corroborated by observations of animals in captivity (Bondarchuk et al. 1976, Voronlin et al. 1978, Karabashian et al. 1982). Games, for example, play an important role in the development of juvenile belukhas. That is also characteristic of many other animals (Fox 1972, Gentry 1974)(Table 14). If there are several immatures at the same time in a group of belukhas, "blacks" form short-lived "pairs" or "trios" for play when females are close to them.

"Mothers" signals (classes \#3 and \#13) and "baby's" sounds (classes \#2 and \#6) are characteristic of the frequent and somewhat stereotyped acoustic contacts between a female and a juvenile. Such acoustic contacts usually occur when a female terminates "hunting", during which as a rule the juvenile stays apart. In emergency situations, females produce intensive "calling" signals - "grinding" (class \#10, Fig. 37C). A juvenile then immediately returns to its mother.

Sounds also play an essential role in relations between mother and juvenile bottlenose dolphins. Mothers may produce whistles almost constantly during the few days after birth (Caldwell and Caldwell 1968). This is probably done to provide strong acoustic imprinting for the baby. During separation from an immature, a female also constantly whistles (McBride and Kritzler 1951). The first whistles made by juveniles are rather universal, and acquire individual features a little later (Caldwell and Caldwell 1979).

Thus, our research on belukhas revealed that constant, close, personal contacts between individuals in a group are characteristic of this species. The most important components of all the various forms of behavior are sounds made by belukhas. Forms of searching and hunting activity (individual, group) are changeable and highly adaptable to different prey species and to prey abundance. The highest social displays of belukha's behavior are the ability to assist during "hunting", strong maternal instinct and long period of teaching juveniles, and alloparental behavior.

One of the factors leading to achievement of such a high level of social organization in dolphins, is the fact that animals completely converted to an aquatic way of life considerably extend the period of close contact between mothers and juveniles. In addition to nurturing and protecting, this plays an important role in teaching social behavior to the juvenile. Signals are also probably of great importance in the process of teaching. The roles of raising and teaching can be temporarily fulfilled by other members in a group of the toothed whales: by older immatures or by other adults. "Kindergartens" are very significant in this context.

An important result of the prolonged and complicated relations between a mother and a juvenile is that females with immatures of different ages became the heart of a group. This 
is the basis of the formation of more complex social connections (Irvine et al. 1981, Johnson and Norris 1986).

It should be particularly stressed that all these processes are dependent on such a factor as activity and availablity of main prey species. It is known that when feeding resources are hardly predictable in time and space, and are hardly available, it leads to increased brain development and increased complexity of social organization (Eisenberg 1981).

Studies of various species of mammals showed that the duration of close social contacts between juveniles and other individuals, and conditions of social education, influence the social structure of a species (Eisenberg 1981, 1986). We suppose that an essential role in creating the complex social organization and highly-developed communication system of the toothed whales has been the prolonged maternal care of juveniles and the close positive connections of a juvenile within the parental group. 


\section{LITERATURE CITED}

[Russian references follow order of the Cyrillic alphabet, Editors]

Agatonov, A. V., and M. N. Schekotov. 1986. Seasonal change of behavior of the Amur

Estuary belukha in summer-autumn period. Study, protection and rational utilization of marine mammals. Summary of the Reports, 9th All-Union meeting, Arkhangel'sk, pp. 2-3.

Altukhov, K. A., Mikhailovskaya, A. A., et al. 1958. Fishes of the White Sea. Petrozavodsk; Gosizdat Karelskaya ASSR. 162 pp.

Arsenjev, V. A. 1939. Distribution and migration of belukha in the Far East. Izvestiya of the TINRO, vol. 15. pp. 1-108.

Bagdonus, A. P., V. M. Bel'kovitch, and N. L. Krushinskaya. 1970. Interactions of dolphin analyzers in process of telling. Journal of Higher Cognitive Functioning 20: 1070-1074.

Bel'kovitch, V. M. 1974. Orientation of Cetacea. Itogi nauki 6: 190-210.

Bel'kovitch, V. M., F. V. Andreev, S. D. Vronskaya et al. 1975. Studies of bottlenose dolphins in their natural environment. Marine Mammals, Summary of the Reports at VI All-Union Meeting, Kiev. Part. I. Pp. 24-25.

Bel'kovitch, V. M., and N. A. Dubrovskiy. 1976. Sensory fundamentals in orientation of Cetacea. Leningrad, Nauka. 204 pp.

Bel'kovitch, V. M., and V. V. Kaznadzey. 1978. Ethological-acoustic correlates of dolphins. Marine Mammals, Summary of the Reports at VII All-Union meeting, Moscow. Pp. 26-27.

Bel'kovitch, V. M., V. V. Kaznadzey, S. A. Krejchy, and E. A. Khakhalkina. 1978a. Typological characteristics of whistles made by bottlenose dolphins. Behavior and Bioacoustics of Dolphins, Moscow. Pp. 79-103.

Bel'kovitch, V. M., V. V. Kaznadzey, S. A. Krejchy, and E. A. Khakhalkina. 1978 b.

Characteristics of impulse signals produced by bottlenose dolphins in the sea.

Behavior and Bioacoustics of Dolphins, Moscow. Pp. 104-116. ,

Bel'kovitch, V. M., S. A. Krejchy, V. V. Kaznadzey, and E. N. Chakhalkina. 1977. On structural and functional variability of impulse emissions made by bottlenose dolphins in natural environments. Summary of the Reports at IX All-Union Acoustic Conference, Moscow. Pp. 29-32.

Bel'kovitch, V. M., and A. E. Reznikov. 1971. New in sonar behavior of dolphins.

Priroda 11: 84-90. 
Bel'kovitch, V. M., and M. N. Schekotov. 1987a. Acoustics and behavior of the White Sea belukha under stressful influence. Behavior and Bioacoustics of Cetacea, Moscow. Pp. 110-147.

Bel'kovitch, V. M., and M. N. Schekotov. 1987b. Some particular features of acoustic activity inherent to the Far East and the White Sea belukha. Behavior and Bioacoustics of Cetacea, Moscow. Pp. 156-196.

Bel'kovitch, V. M., and A. V. Yablokov. 1963. Marine inhabitants "share their experience" with designers. Nauka \& zhizn' 5: 61-64.

Bel'kovitch, V. M., and A. V. Yablokov. 1969. On a structure of a flock composed by Odontoceti. Marine Mammals, Moscow. Pp. 65-69.

Bobkov, A. V. 1986. Some parameters of outside breathing of belukha. Study, protection and rational utilization of marine mammals. Summary of the Reports, 9th All-Union Meeting, Arkhangel'sk. Pp. 47-48.

Bogorodskiy, V. V., and G. A. Lebedev. 1978. Acoustic signals made by narwhals. Acoustic Journal 24: 471-476.

Bondarchuk, L. S., S. K. Matisheva, and R. N. Skibnevskiy. 1976. Behavioral development of the Black Sea juvenile bottlenose dolphin. Zoologicheskiy Zhurnal 55: 276-281.

Voronin, L. G., N. R. Vannikova, S. D. Vronskaya, and L. B. Kazarovitskiy. 1978. Some particular features of early ontogenesis of the behavior of the Black Sea Tursiops truncatus. Marine Mammals, Report Summary at 7th All-Union Conference. Simpheropol'. Pp. 69-70.

Voronov, V. A. 1978. Some particular features of probing sounds emission made by porpoise. Marine mammals, Report Summary at 7th All-Union conference. Simpheropol'. Pp. 70-71.

Geptner, V. G. 1930. Materials for learning geographic distribution and biology of belukha. Trudy of the Research Institute of Zoology, Vol. 4, issue 2, pp. 1-100.

Gigliery, M. P. 1985. Social ecology of chimpanzee. V. mire nauki. No. 8, pp. 58-66. Dorofeev, S. V., and S. K. Klumov. 1936. Fishing characteristics of belukha migration in the region of Sakhalin Island. Trudy VNIRO Vol. 3, P. 76, III.

Dubrovskiy, N. A. 1975. Echolocation of dolphins. - Leningrad, CSRI "Rumb" - 76 p.

Dubrovskiy, N. A., P. S. Drasnov, and A. A. Titov. 1970. On the matter of ultrasonic navigation signals emanated by the Azov dolphin. Acoustic Journal - 1970 - Issue 4, pp. 521-525.

Zusser, S. G. 1971. Twenty-four hours vertical migration of fish. - Moscow, Pischevaya promyshlennost. - $1971-224$ p. 
Karabashian, V. V., G. Sh. Gedzhadze, and S. I. Suglobov. 1982. Mutual relations between immatures and mother and also with other adult dolphins in captivity. Study, protection and rational utilization of marine mammals. Report Summary, 8th All-Union Meeting. - Astrakhan' - Pp. 154-155.

Kleinenberg, S. E. et al. 1964. Belukha./S. E. Kleinenberg, A. V. Yablokov, V. M. Bel'kovitch, M. N. Tarasevitch - Moscow, Nauka - 455 p.

Klumov, S. K. 1936. Distribution of belukha in the Eurasian North. Trudy of the Polar Commission of the Soviet Academy of Sciences. Issue 8 - 71 p.

Klumov, S. K. 1937. On the problem of distribution and fishing of belukha in the White Sea. Rybnae Khozyaistvo - No. 1 - p. 3-46.

Klumov, S. K. 1939. Belukha of the Soviet Union (resource base and hunting). Trudy VNIRO - Vol. 12 - pp. 1-115.

Caldwell, D. K, and M. K. Caldwell. 1978. Notes on two disputed problems concerning dolphins: "intellect" and "navigation". New Studies of Cetacea and Flipper. - Moscow - pp. 134-140.

Krejchi, S. A., E. N. Khakhalkina, and V. M. Bel'kovitch. 1987. Correlation analysis of signals produced by wild dolphins by methods of ethological-acoustic tests. Behavior and Bioacoustics of Cetacea. Moscow, p. 26-54.

Lepekhin, I. 1805. Day-by-day notes of traveling different provinces of the Russian State. Part IV.

Lindgol'm, O. V. 1888. Whale fishing. - St. Petersburg.

Manteifel, B. P. 1980. Behavioral ethology of animals. - Moscow, Nauka, 220 p.

Morozov, V. P., A. I. Acopian, V. I. Burdin et al. 1972. Recurrence frequency of location signals produced by dolphins taken as a function of distance to the target. Biophysics 17, issue 1 - p. 139-145.

Mukhametov, L. M., and A. Ya. Supin. 1978. Dolphins, sleeping and staying awake. Marine Mammals. - Moscow, p. 66-77.

Mukhametov, L. M., A. Ya. Supin, and I. G. Strokova. 1976. Interhemispherical asymmetry of functional states of brain during dolphin's sleep. Soviet Academy of Sciences. - Vol. 229, No. 3 - p. 767-770.

Myasnikov, V. S. 1972. Sonic sounds of immature belukhas. Problems of Hydrobiology in Some Regions of the Pacific. - Vladivostok, p. 100-106. Neproshin, A. Yu. 1975. Sounds in belukha's behavior. Priroda, No. 4, p. 99-102. Nikol'skiy, G. E. 1936. On the reproductive biology of Delphinapterus leucas. Trudy VNIRO, Vol. 3, p. 35-52. 
Potelov, V. A. 1986. Scientific results of the state resources of marine mammals in the North. Study, protection and rational utilization of marine mammals. - Report Summary, 9th All-Union meeting. - Arkhangel'sk, p. 327-329.

Provorov, N. V. 1957. On the matter of biology and fishing of the White Sea belukha in Kandalaksha Bay in the White Sea. Trudy of Arctic Research Inst., Vol. 205, p. 7386.

Rutilovskiy, L. G. 1939. Commercial mammals of the Cheluskin Peninsula and Strait of Vil'kitskogo. Trudy institute polyarnogo zemiledeliya. Series: Promyslovoe khozyaistvo, Issue 8, p. 110-145.

Sleptsov, M. M. 1955. Cetacea of the far-eastern seas. Vladivostok, $161 \mathrm{p}$.

Tarasov, N. I. 1960. Live sounds of the sea. Izvestiya of the Soviet Academy of Sciences. No. 7.

Titov, A. A. 1971. Particular features of sound-making by white-sided dolphins in new conditions. Bionika, No. 5, p. 62-67.

Titov, A. A., and G. V. Nikolenko. 1975. Quantitative evaluation of sound-making by the three species of the Black Sea dolphins. Bionika, No. 9, p. 115-119.

Titov, A. A., and A. G. Tomilin. 1970. About sonic activity of white-sided dolphins and porpoises in different situations. Bionika, No. 4, p. 88-94.

Titov, A. A., A. G. Tomilin, and N. S. Baryshnikov. 1971. Communicative-emotional signals made by the Black Sea dolphins. Bionika, No. 5, p. 67-72.

Titov, A. A., and L. I. Yurkevitch. 1971. Physical characteristics of nonlocational sounds made by the Black Sea dolphins. Bionika, No. 5, p. 57-62.

Tomilin, A. G. 1955. About behavior and sound-making by Cetacea. Trudy IO Soviet Academy of Sciences, Vol. 18, p. 28-47.

Tomilin, A. G. 1957. Cetacea of the USSR and neighboring counties - Moscow; Soviet Academy of Sciences. - 756 pp.

Tomilin, A. G. 1962. Cetacean fauna of the USSR's seas: guide to Soviet fauna. Moscow, Soviet Academy of Sciences - $212 \mathrm{pp}$.

Fedoseev, G. A. 1986. Seasonal changes in distribution and ecological differentiation of belukha of the northern part of the Pacific and of the eastern Arctic. Study, protection and rational utilization of marine mammals. Report Summary, 9th All-Union meeting Arkhangel'sk, p. 406-408.

Chapskiy, K. K. 1976. Flippers. Mammals of the Soviet Union.. V. G. Geptner, K. K. Chapskiy,V. A. Arseniev, and V. E. Sokolov. Moscow, Vol. 2, part 3. 
Chirkova A., and S. Foletarik. 1930. About belukha and fishing for belukha in Cheshskaya Bay and Indiga Bay. Trudy institute zoologii of the Moscow University Vol. 4.

Shishkova, E. V. 1965. Sounds made by the Black Sea dolphins. Rybnoye khozyaistov, No. 1, p. 25-28.

[References from Western languages, listed in alphabetical order, Editors] Allen, J. F. 1977. Dolphin reproduction in oceanaria in Australasia and Indonesia. Pp. 85-108 in Breeding Dolphins: Present Status and Suggestions for the Future (S. H. Ridgway and K. Benirschke, Eds.). Washington, D.C.

Andersen, S., and G. Pilleri. 1970. Audible sound production in captive Platanista gangetica. Pp. 83-86 in Investigations on Cetacea (G. Pilleri, Ed.). Berne. Anonymous. 1969. Singing whales. Nature 224: 217.

Asa-Dorian, P. V., and P. J. Perkins. 1967. The controversial production of sound by the California gray whale, Eschrichtius gibbosus. Norsk. Hvalfangst-Tid. 56: 74-77. Au, W. W. L. 1980. Echolocation signals of the Atlantic bottlenose dolphin (Tursiops truncatus) in open water. Pp. 251-282 in Animal Sonar Systems (R. J. Busnel, J. F. Fish, Eds.). London.

Au, W. W. L., D. A. Carder, R. H. Penner, and B. L. Scronce. 1983. Measurements of a beluga whale, Delphinapterus leucas, echolocation signals in two different ambient noise environments. Fifth Biennial Conf. Biol. Mar. Mamm. [Abstract]. Boston. Au, W. W. L., and P. W. Moore. 1986. Target strength characterization by echolocating dolphins. Animal Sonar Systems Symposium. Helsingor.

Au. W. W. L., R. H. Penner, and C. W. Turl. 1987. Propagation of beluga echolocation signals. J. Acoust. Soc. Am. 82: 807-813.

Awbrey, F. T., J. C. Norris, A. B. Hubbard, and W. E. Evans. 1979. The bioacoustics of the Dall's porpoise salmon drift net interaction. H/SWRI Tech. Rept. 79-120. San Diego. $37 \mathrm{pp}$.

Backus, R. H., and W. E. Schevill. 1966. Physeter clicks. Pp. 510-528 in Whales, Ddolphins and Porpoises (K. S. Norris, Ed.). California Press, Berkeley.

Baker, C. S., and L. M. Herman. 1984. Agressive behavior between humpback whales (Megaptera novaeangliae) wintering in Hawaiian waters. Can. J. Zool. 62: 1922-1937. Balcomb, K. S. 1980. The killer whale, Orcinus orca, in Puget Sound. Cetus 2(5): 6-7. Bateson, G. 1974. Observations of a cetacean community. Pp. 146-169 in Mind in the Water (J. McIntyre, Ed.). New York.

Beamish, P. 1974. Whale acoustics. J. Can. Acoust. Assoc. 2(4): 8-12. 
Beamish, P. 1978. Evidence that a captive humpback whale (Megaptera novaeangliae) does not use sonar. Deep-Sea Res. 25: 469-472.

Beamish, P. 1979. Behavior and significance of entrapped baleen whales. Pp. 291-309 in Behavior of Marine Animals (H. E. Winn and B. L. Olla, Eds.). New York, London.

Beamish, P. and B. Mitchell. 1971. Ultrasonic sounds recorded in the presence of a blue whale Balaenoptera musculus. Deep-Sea Res. 18: 803-809.

Beamish, P. and E. Mitchell. 1973. Short pulse length audio frequency sounds recorded in the presence of a minke whale Balaenoptera acutorostrata. Deep-Sea Res. 20: 375.

Beddard, F. E. 1900 . A Book of Whales. London. 320 pp.

Benjaminsen, T. and I. Christensen. 1979. The natural history of the bottlenose whale, Hyperoodon ampullatus (Forster). Pp. 143-164 in Behavior of Marine Mammals (H. E. Winn and B. L. Olla, Eds.). New York, London.

Best, P. B. 1974. The biology of the sperm whale as it relates to stock management. Pp. 257-293 in The Whale Problem: a Status Report (W. E. Schevill, Ed.). Cambridge.

Brodie, P. F. 1969. Duration of lactation in Cetacea: an indicator of required learning? Am. Midl. Nat. 82: 312-314.

Brodie, P. F. 1971. A reconsideration of aspects of growth, reproduction and behavior of the white whale (Delphinapterus leucas) with reference to the Cumberland Sound, Baffin Island population. J. Fish. Res. Board Can. 28: 1309-1318.

Brodie, P. F. 1985. The acoustical Arctic aquabat. Pp. 559-562 in BBC Wildlife, vol. 3. Bristol.

Brodie, P. F. 1989. The white whale Delphinapterus leucas (Pallas, 1776). Pp. 119-144 in Handbook of Marine Mammals, vol. 4 (S. H. Ridgway and R. J. Harrison, Eds.). London.

Brooks, R. J., and J. B. Falls. 1975. Individual recognition by song in white-throated sparrows. I. Discrimination of song of neighbors and strangers. Can. J. Zool. 53: 879-888.

Brown, S. G. 1960. Swordfish and whales. Norsk. Hvalfangst-Tid. 48: 345-351.

Brown, D. H., D. K. Caldwell, and M. C. Caldwell. 1966. Observations on the behavior of false killer whales, with notes on associated behavior of other genera of captive delphinids. Los Angeles County Mus. Contrib. Sci. 95: 1-32.

Brown, D. H., and K. S. Norris. 1956. Observations of captive and wild cetaceans. J. Mammal. 37: 311-326. 
Busnel, R. G., and A. Dziedzic. 1966. Acoustic signals of the pilot whale Globicephala melaena and of the porpoises Delphinus delphis and Phocoena phocoena. Pp. 607-646 in Whales, Dolphins and Porpoises (K. S. Norris, Ed.). Berkeley.

Busnel, R. G., and A. Dziedzic. 1967. Observations sur le comportement et les émissions acoustiques du cachalot lors de la chasse. Bocagiana 14: 1-15.

Busnel, R. G., and A. Dziedzic. 1968. Caractéristiques physiques des signaux acoustiques de Pseudorca crassidens Owen (Cetace, Odontocete). Extr. d. Mammal. 32: 1-12.

Busnel, R. G., A. Dziedzic, and A. Alcuri. 1974. Études préliminaires de signaux acoustiques du Pontoporia blainvillei Cervais et d'Orgibny (Cetacea, Platanistidae). Mammalia 38: 449.

Busnel, R. G., A. Dziedzic, and S. Andersen. 1963. Sur certaines caractéristiques des signaux acoustiques du marsouin Phocoena phocoena L. C.r. hebd. Seanc. Acad. Sci. 257: 2545-2548.

Busnel, R. G., B. Escuidie, A. Dziedzic, and A. Hellion. 1971. Structure des clics doubles d'écholocation du globicephale (Cetace, Odontocete). C.R. Acad. Sci. 272: 2459-2461.

Busnel, R. G., and J. F. Fish. 1980. Animal Sonar Systems. Plenum Press, New York. $1135 \mathrm{pp}$.

Caldwell, D. K, and M. C. Caldwell. 1967. Dolphins, porpoises and behavior. Underwater Nat. 4: 14-19.

Caldwell, D. K, and M. C. Caldwell. 1971. Sounds produced by two rare cetaceans stranded in Florida. Cetology 4: 1-6.

Caldwell, D. K, and M. C. Caldwell. 1972. The World of the Bottlenosed Dolphin. J. B. Lippincott Co., Philadelphia.

Caldwell, D. K, and M. C. Caldwell. 1987. Underwater echolocation-type clicks by captive stranded pygmy sperm whales, Kogia breviceps. Pp. 1-8 in 7th Biennial Conf. on the Biol. of Mar. Mammals. [Abstract]. Miami.

Caldwell, D. K, J. H. Prescott, and M. C. Caldwell. 1966. Production of pulsed sounds by the pygmy sperm whale, Kogia breviceps. Bull. Soc. Calif. Acad. Sci. 65: 246248.

Caldwell, M. C., and D. K. Caldwell. 1965. Individualized whistle contours in bottlenosed dolphins, Tursiops truncatus. Nature 207: 434-435.

Caldwell, M. C., and D. K. Caldwell. 1966. Epimeletic (care-giving) behavior in cetacea. Pp. 755-782 in Whales, Dolphins and Porpoises (K. Norris, Ed.). Berkeley. 
Caldwell, M. C., and D. K. Caldwell. 1967. Intraspecific transfer of information via the pulsed sound in captive Odontocete cetaceans. Pp. 879-936 in Animal Sonar Systems: Biology and Bionics, vol. 2 (R. G. Busnel, Ed.). Jouy-en-Josas.

Caldwell, M. C., and D. K. Caldwell. 1968. Vocalizations of naive captive dolphins in small groups. Science 159: 1121-1123.

Caldwell, M. C., and D. K. Caldwell. 1970. An experimental demonstration of the ability of an Atlantic bottlenosed dolphin to discriminate between playbacks of recorded whistles of conspecifics. Pp. 141-148 in Proc. 7th Ann. Conf. on Biol. Sonar and Diving Mammals. Menlo Park.

Caldwell, M. C., and D. K. Caldwell. 1971. Statistical evidence for individual signature whistles in Pacific white-sided dolphins, Lagenorhynchus obliquidens. Cetology 3: 19.

Caldwell, M. C., and D. K. Caldwell. 1972. Vocal mimicry in the whistle mode by an Atlantic bottlenosed dolphin. Cetology 9: 1-8.

Caldwell, M. C., and D. K. Caldwell. 1977. Social interactions and reproduction in the Atlantic bottlenosed dolphin. Pp. 133-142 in Breeding Dolphins: Present Status and Suggestions for the Future (S. H. Ridgway and K Benirschke, Eds.). Washington, D.C.

Caldwell, M. C., and D. K. Caldwell. 1979. The whistle of the Atlantic bottlenosed dolphin (Tursiops truncatus) - ontogeny. Pp. 369-401 in Behavior of Marine Animals: Current Perspectives in Research, Vol. 3 (H. E. Winn and B. L. Olla, Eds.). New York.

Caldwell, M. C., D. K. Caldwell, and W. E. Evans. 1966. Sounds and behavior of captive Amazon freshwater dolphins, Inia geoffrensis. Los Angeles Count Mus. Contr. Sci. 107: 1-24.

Caldwell, M. C., D. K. Caldwell, and N. R. Hall. 1973a. Ability of an Atlantic bottlenosed dolphin (Tursiops truncatus) to discriminate between and potentially identify to individual, the whistles of another species, the common dolphin (Delphinus delphis). Cetology 14: 1-7.

Caldwell, M. C., D. K. Caldwell, and J. F. Miller. 1973b. Statistical evidence for individual signature whistles in the spotted dolphin, Stenella plagiodon. Cetology 16: $1-21$.

Caldwell, M. C., D. K. Caldwell, and J. B. Siebenaler. 1965. Observations on captive and wild Atlantic bottlenosed dolphins, Tursiops truncatus, in the northeastern Gulf of Mexico. Los Angeles County Mus. Nat. Hist. Contrib. Sci. 91: 1-10. 
Caldwell, M. C., N. R. Hall, and D. K. Caldwell. 1971. Ability of an Atlantic bottlenosed dolphin to discriminate between, and potentially identify to individual, the whistle of another species, the spotted dolphin. Cetology 6: 1-6.

Caldwell, M. C., N. R. Hall, and D. K. Caldwell. 1972. Ability of an Atlantic bottlenosed dolphin to discriminate between, and respond differentially to, whistles of eight conspecifics. Pp. 57-65 in Proc. 8th Ann. Conf. on Biol. Sonar and Diving Mammals. Fremont.

Caldwell, M. C., R. M. Haugen, and D. K. Caldwell. 1962. High energy sound associated with fright in the dolphin. Science 138: 907-908.

Chen Peixun. 1989. Baiji lipotes vexillifer Miller, 1918. Pp. 25-43 in Handbook of Marine Mammals, Vol. 4 (S. H. Ridgway and R. J. Harrison, Eds.). London.

Chu, K., and P. Harcourt. 1986. Behavioral correlations with aberrant patterns in humpback whale (Megaptera novaeangliae) songs. Behav. Ecol. Sociobiol. 19: 309312.

Clapham, P. J., and D. K. Mattila. 1990. Humpback whale songs as indicators of migration routes. Mar. Mammal Sci. 6: 155-160.

Clark, C. W. 1983. Acoustic communication and behavior of the southern right whale (Eubalaena australis). Pp. 163-198 in Communication and Behavior of Whales ( $R$. Payne, Ed.). Boulder.

Clark, C. W., and J. H. Johnson. 1984. The sounds of the bowhead whale, Balaena mysticetus, during the spring migrations of 1979 and 1980. Can. J. Zool. 62: 14361441.

Collett, R. 1907. Nogle meddelelser om naebhvalen (Hyperoodon) og hvidfisken (Delphinapterus). Bergens Mus. Aarbog. 1906: 1-25.

Creig, J. A. 1898. Mesoplodon bidens, Sowerby. Bergens Mus. Aarbog. 1897: 1-31.

Cummings, W. C., J. F. Fish, and P. O. Thompson. 1972. Sound production and other behavior of southern right whales, Eubalaena glacialis. Trans. San Diego Soc. Nat. Hist. 17: 1-13.

Cummings, W. C., and D. V. Holliday. 1987. Sounds and source levels from bowhead whales off Pt. Barrow, Alaska. J. Acoust. Soc. Am. 82: 814-821.

Cummings, W. C., and L. A. Philippi. 1970. Whale phonations in repetitive stanzas. NUC TP 196. $4 \mathrm{pp}$.

Cummings, W. C., and P. O. Thompson. 1971a. Bioacoustics of marine mammals: R/V Hero cruise 70-3. Antarctic J. U.S. 6: 158-160.

Cummings, W. C., and P. O. Thompson. 1971b. Underwater sounds from the blue whale, Balaenoptera musculus. J. Acoust. Soc. Am. 50: 1193-1198. 
Cummings, W. C., and P. O. Thompson. 1985. Unpublished report, as cited in Cummings W. C., Bryde's whale Balaenoptera edeni Anderson, 1878. Pp. 137-154 in Handbook of Marine Mammals (S. H. Ridgway and R. Harrison, Eds.). London.

Cummings, W. C., P. O. Thompson, and R. Cook. 1968. Underwater sounds of migrating gray whales, Eschrichtius glaucus. J. Acoust. Soc. Am. 44: 1278.

Cummings, W. C., P. O. Thompson, and S. J. Ha. 1986. Sounds from Bryde's, Balaenoptera edeni, and finback B. physalus, whales in the Gulf of California. Fish. Bull. 84: 359-370.

Darling, J. D., K. M. Gibson, and G. K. Silber. 1983. Observations on the abundance and behavior of humpback whales (Megaptera novaeangliae) off West Mani, Hawaii, 1977-1979. Pp. 201-222 in Communication and Behavior of Whales (R. Payne, Ed.). Boulder.

Dawson, S. M. 1988. The high frequency sounds of free-ranging Hector's dolphins, Cephalorhynchus hectori. Pp. 339-344 in Biology of the Genus Cephalorhynchus (R. L. Brownell and G. P. Donovan, Eds.). Cambridge.

Dierks, K. J., R. T. Trochta, and W. E. Evans. 1973. Delphinid sonar: measurement and analysis. J. Acoust. Soc. Am. 54: 200-204.

Doan, K. H., and C. W. Douglas. 1953. Beluga of the Churchill region of the Hudson Bay. Bull. Fish. Res. Board Can. 98.

Dreher, J. J., and W. E. Evans. 1962. Linguistic considerations of cetacean sound production. Rept. No. 16175. Lockheed California Co.

Dreher, J. J., and W. E. Evans. 1964. Cetacean communication. Pp. 373-393 in Marine bio-acoustics (W. N. Tavolga, Ed.). Oxford.

Dudok van Heel, W. H. 1981. A proposal for an ecological classification of odontocetes in relation with sonar. Aquatic Mammals 8(2).

Dumortier, B. 1839. Mémoire sur le delphinorhynque microptere échou a Ostende. Académie Royale des Sciences des lettres et des Beauz-arts de Belgique, vol. 12. Brussels.

Dunn, J. L. 1969. Airborne measurements of the acoustic characteristics of a sperm whale. J. Acoust. Soc. Am. 46: 1052

D'Vincent, C. G., R. M. Nilson, and R. E. Hanna. 1985. Vocalization and coordinated feeding behavior of the humpback whale in southeastern Alaska. Sci. Rept. Whales Res. Inst. 36: 41-47.

Earle, S. A. 1979. Humpbacks: the gentle giants. Nat. Geogr. 155: 2-17.

Eberhardt, R. L., and W. E. Evans. 1962. Sound activity of the California gray whale, Eschrichtius glaucus. J. Aud. Eng. Soc. 10: 324-328. 
Edds, P. L. 1982. Vocalizations of the blue whale, Balaenoptera musculus, in the St. Lawrence River. J. Mammal. 63: 345-347.

Eisenberg, J. F. 1981. The Mammalian Radiations. Univ. Chicago Press, Chicago. 610 pp.

Eisenberg, J. F. 1986. Dolphin behavior and cognition: evolutionary and ecological aspects. Pp. 261-270 in Dolphin Cognition and Behavior: a Comparative Approach (R. J. Schusterman, J. A. Thomas, and F. G. Wood, Eds.). London.

Essapian, F. S. 1953. The birth and growth of a porpoise. Nat. Hist. 58: 385-392. Evans, W. E. 1967. Vocalization among marine mammals. Pp. 159-186 in Marine Bioacoustics, vol. 2 (W. N. Tavolga, Ed.). Oxford.

Evans, W. E. 1971. Orientation behavior of delphinids: radiotelemetric studies. Ann. N.Y. Acad. Sci. 188: 142-160.

Evans, W. E. 1973. Echolocation by marine delphinids and one species of fresh-water dolphin. J. Acoust. Soc. Am. 54: 191-199.

Evans, W. E., F. T. Awbrey, and H. Hackbarth. 1988. High frequency pulses produced by free-ranging Commerson's dolphin (Cephalorhynchus commersonii) compared to those of Phocoenids. Pp. 173-181 in Biology of the Genus Cephalorhynchus (R. L. Brownell and G. P. Donovan, Eds.). Cambridge.

Evans, W. E., and J. J. Dreher. 1962. Observations on scouting behavior and associated sound production by the Pacific bottlenosed porpoise (Tursiops gilli Dall). Bull. South. Calif. Acad. Sci. 61: 217-226.

Evans, W. E., and J. H. Prescott. 1962. Observations of the sound production capabilities of the bottlenosed porpoise: a study of whistles and clicks. Zoologia 47: 121-128.

Fink, B. D. 1959. Observation of porpoise predation on a school of Pacific sardines. Calif. Fish Game 45: 216-217.

Fish, M. R., and W. H. Mowbray. 1962. Production of underwater sounds by the white whale or beluga Delphinapterus leucas (Pallas). J. Mar. Res. 2: 20.

Fish, J. F., J. L. Sumich, and G. E. Lingle. 1974. Sounds produced by the gray whale, Eschrichtius robustus. Mar. Fish. Rev. 36: 38-45.

Fish, J. F., and P.O. Thompson. 1972. Sound production and other behavior of southern right whales, Eubalena glacialis. Trans. San Diego Soc. Nat. Hist. 17.

Fish, J. F., and C. W. Turl. 1977. Acoustic source levels of four species of small whales. Naval Undersea Center Tech. Publ. 547: 1-13.

Fish, J. F., and J. S. Vania. 1971. Killer whale, Orcinus orca, sounds repel white whales Delphinapterus leucas. U.S. Fish. Bull. 69: 531-535. 
Fleischer, G. 1976. On bony microstructures in the dolphin cochlea related to hearing. N. J. Geol. Paleontol. 151: 166.

Ford, J. K. B. 1989. Acoustic behavior of resident killer whales (Orcinus orca) off Vancouver Island, British Columbia. Can. J. Zool. 67: 727-745.

Ford, J. K. B., and H. D. Fischer. 1978. Underwater acoustic signals of the narwhal (Monodon monoceros). Can. J. Zool. 56: 552.

Ford, J. K. B., and H. D. Fischer. 1983. Group-specific dialects of killer whales (Orcinus orca) in British Columbia. Pp. 129-161 in Communication and Behavior of Whales (R. Payne, Ed.). Boulder.

Fox, M. W. 1972. Socio-ecological implications of individual differences in wolf litters: a developmental and evolutionary perspective. Behavior 41: 289-295.

Frumhoff, P. 1983. Aberrant songs of humpback whales (Megaptera novaeangliae): clues to the structure of humpback songs. Pp. 81-127 in Communication and Behavior of Whales (R. Payne, Ed.). Boulder.

Gales, R. S. 1966. Pickup, analysis and interpretation of underwater acoustic data. Pp. 435-444 in Whales, Dolphins and Porpoises (K. S. Norris, Ed.). Berkeley.

Gambell, R. 1968. Aerial observations of sperm whale behavior based on observations, notes and comments by K. J. Pinkerton. Norsk. Hvalfangst-Tid. 57: 126-138.

Gentry, R. L. 1974. The development of social behavior through play in the Stellar sea lion. Am. Zool. 14: 393-403.

Gilmore, R. Populations, distribution and behavior of whales in the western South Atlantic: cruise 69-3 of R/V Hero. Antarct. J. U.S. 4: 307-308.

Glockner, D. A. 1983. Determining the sex of humpback whales (Megaptera novaeangliae) in their natural environment. Pp. 447-464 in Communication and Behavior (R. Payne, Ed. ). Boulder.

Goodall, J. 1965. Chimpanzees of the Gombe Stream Reserve. Pp. 425-473 in Primate Behavior (I. DeVore, Ed.). New York.

Goodall, R. N. P. K. S. Norris, A. R. Galeazzi, J. A. Oporto, and I. S. Cameron. 1988. On the Chilean dolphin Cephalorhynchus eutropia (Gray, 1846). Pp. 197-257 in Biology of the Genus Cephalorhynchus (R. L. Brownell and G. P. Donovan, Eds.). Cambridge.

Goodson, A. D., M. Klinowski, and R. Morris. 1988. Interpreting the acoustic pulse emissions of a wild bottlenose dolphin (Tursiops truncatus). Aquatic Mammals 14:712.

Gray, J. E. 1866. Catalogue of seals and whales in the British Museum. London. 
Griffin, D. R. 1955. Hearing and acoustic orientation in marine animals. Deep-Sea Res. 3: 406-417.

Guinee, L. N., K Chu, and E. M. Dorsey. 1983. Changes over time in the song of known individual humpback whales (Megaptera novaeangliae). Pp. 59-79 in Communication and Behavior of Whales. (R. Payne, Ed.). Boulder.

Gurevich, V. S. 1977. Post-natal behavior of an Atlantic bottlenosed calf (Tursiops truncatus, Montagu) born at Sea World. Pp. 168-184 in Breeding Dolphins: Present Status and Suggestions for the Future (S. H. Ridgway and K. Benerischke, Eds.). Washington, D.C.

Hackbarth, H., F. T. Awbrey, and W. E. Evans. 1985. Short-time spectral analysis of echolocation sounds in Commerson's dolphins, Cephalorhynchus commersoni. H/SWRI Tech. Rept. 85-180, San Diego. 33 pp.

Hafner, G., L. Hamilton, W. Steiner, T. Thompson, and H. E. Winn. 1977. Evidence for signature information in the song of humpback whale. Pp. 35 in Proc. 2nd Conf. Biol. Mar. Mammals, San Diego.

Hay, K. A., and R. McClung. 1976. Observations on beluga and narwhal in the Canadian high arctic, summer 1974. Fish Res. Board Can. Rept. No. 1385.

Herald, E. S., R. L. Brownell, R. L. Frye, E. J. Morris, W. E. Evans, and A. B. Scott. Blind river dolphin: first side-swimming cetacean. Science 166: 1408.

Herman, L. M., and W. N. Tavolga. 1980. The communication systems of cetaceans. Pp. 149-210 in Cetacean Behavior: Mechanisms and Functions (L. W. Herman, Ed.). New York.

Hoese, H. D. 1971. Dolphin feeding out of water in a salt marsh. J. Mamm. 52: 222223.

Hole, H. M. 1939. Rare whales in South Australia. South Austral. Nat. 14(4).

Hoyt, E. 1984. The whales called "killer". Nat. Geogr. 166: 220-237.

Hult, R. W. 1982. Another function of echolocation for bottlenosed dolphins (Tursiops truncatus). Cetology 47: 1-7.

Irvine, A. B., M. D. Scott, R. S. Wells, and J. H. Kaufman. 1981. Movements and activities of the Atlantic bottlenose dolphin, Tursiops truncatus, near Sarasota, Florida. Fish. Bull. U.S. 79: 671-688.

Irvine, A. B., and R. S. Wells. 1972. Results of attempts to tag Atlantic bottlenosed dolphins (Tursiops truncatus). Cetology 13: 1-5.

Jehl, J. R., W. E. Evans, F. T. Awbrey, and W. S. Drieschman. 1980. Distribution and geographic variation in the killer whale (Orcinus orca) population of the Antarctic and adjacent waters. Antarct. J. U.S. 15: 161-163. 
Jing Xianying, Xiao Youfu, and Jing Rongcai. 1981. Acoustic signals and acoustic behavior of Chinese river dolphins (Lipotes vexillifer). Sci. Sinica 24: 407-415.

Jing Xianying, Xiao Youfu, and Jing Rongcai. 1982. The acoustic function of the melon of Chinese river dolphins (Lipotes vexillifer). Acta Acoust. 7: 14-22.

Johnson, S. M., and K. S. Norris. 1986. Delphinid social organization and social behavior. Pp. 335-346 in Dolphin cognition and behavior: a comparative approach ( $R$. J. Schusterman, J. A. Thomas, and F. G. Wood). London.

Jurasz, C. M., and V. P. Jurasz. 1979. Feeding modes of the humpback whales, Megaptera novaeangliae, in southeast Alaska. Sci. Rept. Whales Res. Inst. 31: 69-83.

Kamminga, C., and J. G. van Velden. 1987. Investigations on cetacean sonar. VIII. Sonar signals of Pseudorca crassidens in comparison with Tursiops truncatus. Aquat. Mammals 13: 43-49.

Kamminga, C., and H. Wiersma. 1981. Investigations on cetacean sonar. V. The true nature of the sonar sound of Cephalorhynchus commersonii. Aquat. Mammals 9: 95104.

Kamminga, C., H. Wiersma, and W. H. Dukok van Heel. 1983. Investigations on cetacean sonar. VI. Sonar sounds in Orcaella brevirostris of the Makaham River, East Kalimantan, Indonesia: first descriptions of acoustic behavior. Aquat. Mammals 10: 83-94.

Kellogg, W. N. 1953. Ultrasonic hearing in the porpoise, Tursiops truncatus. J. Comp. Physiol. Psychol. 44: 446-450.

Kellogg, W. N. 1961. Porpoises and Sonar. Univ. Chicago Press, Chicago.

Kibblewhite, A. C., R. N. Denham, and D. J. Barnes. 1967. Unusual low-frequency signals observed in New Zealand waters. J. Acoust. Soc. Am. 42: 644-655.

Kinne, O. 1975. Orientation in space: animals: mammals. Pp. 702-852 in Marine Ecology, Vol. 2 (O. Kinne, Ed.). London.

Klingholz, F., C. Siegert, and H. Meynhardt. 1979. Die akustische Kommunikation des Europäschen Wildschweines (Sus scrofa L.). Pp. 277-303 in Zool. Garter (N. F. Gena, Ed.). Bd. 49, H.4/5.

Kritzler, H. 1952. Observations on the pilot whale in captivity. J. Mamm. 33: 321-334.

Layne, J. N. 1958. Observations on freshwater dolphins in the upper Amazon. J. Mamm. 39: 1-22.

Layne, J. N., and D. K. Caldwell. 1964. Behavior of the Amazon dolphin (Inia geoffrensis) in captivity. Zoologica 49: 81-108. 
Leatherwood, S. J. 1977. Mother-infant interactions of bottlenosed dolphins in captivity and at sea. Pp. 143-167 in Breeding Dolphins: Present Status and Suggestions for the Future (S. H. Ridgway and K. Benirschke, Eds.). Washington.

Leatherwood, S., and W. A. Walker. 1979. The northern right whale dolphin Lissodelphis borealis Peale in the eastern North Pacific. Pp. 85-141 in Behavior of Marine Animals (H. E. Winn and B. L. Olla, Eds.). New York, London.

Levenson, C. 1969. Behavior, physical and acoustics of humpback whales (Megaptera novaeangliae) at Argus Island. Pp. 13 in Naval Oceanogr. Off. Inf. Rept. 69-54.

Levenson, C. 1972. Characteristics of sounds produced by humpback whales (Megaptera novaeangliae). Pp. 17 in NAVOCEANO Tech. Note 7700-6-72.

Levenson, C. 1974. Source level and bistatic target strength of the sperm whale (Physeter catodon) measured from an oceanographic aircraft. J. Acoust. Soc. Am. 55: 1100.

Levenson, C., and W. T. Leapley. 1976. Humpback whale distribution in the eastern Caribbean determined acoustically from an oceanographic aircraft. Pp. 7 in NAVOCEANO Tech. Note 3700-46-96.

Levenson, C., and W. T. Leapley. 1978. Distribution of humpback whales (Megaptera novaeangliae) in the Caribbean determined by a rapid acoustic method. J. Fish. Res. Board Can. 35: 1150-1152.

Lilly, J. C. 1961. Man and Dolphin. Appleton Co., New York. 312 pp.

Lilly, J. C. 1962. Vocal behavior of the bottlenosed dolphin. Proc. Am. Phil. Soc. 106: 520-529.

Lilly, J. C. 1963. Distress call of the bottlenose dolphin: stimuli and evoked behavioral responses. Science 139: 116-118.

Lilly, J. C. 1967. The Mind of the Dolphin. Doubleday, New York. 243 pp.

Lilly, J. C., and A. M. Miller. 1961. Sounds emitted by the bottlenose dolphin. Science 133: 1689-1693.

Ljungblad, D. K., S. Leatherwood, and M. E. Dahlheim. 1980. Sounds recorded in the presence of an adult and calf bowhead whale. Mar. Fish. Rev. 42: 86-87.

Ljungblad, D. K., P. O. Thompson, and S. E. Moore. 1982. Underwater sounds recorded from migrating bowhead whales, Balaena mysticetus, in 1979. J. Acoust. Soc. Am. 71: 477-482.

Matthews, L. H. 1938. Notes on the southern right whale, Eubalaena australis. Discovery Repts. 17: 169-182.

Mattila, D. K., L. N. Guinee, and C. A. Mayo. 1987. Humpback whale songs on a North Atlantic feeding ground. J. Mamm. 68: 880-883. 
McBride, A. F., and D. O. Hebb. 1948. Behavior of the captive bottlenose dolphin (Tursiops truncatus). J. Comp. Phys. Psychol. 41: 111-123.

Mead, J. G. 1989. Bottlenose whales Hyperoodon ampulutus and Hyperoodon planiformes. Pp. 321-348 in Handbook of Marine Mammals, Vol. 4 (S. H. Ridgway and R. J. Richardson, Eds.). London.

Meynhardt, H. 1980. Untersuchungen zur akustischen, olfaktorischen und visuellen Kommunikation des Europäschen Wildschweines (Sus scrofa L.). Pp. 72-82 in Beitr. Forstwirt. Bd. 14, H.2.

Millais, J. G. 1906. The mammals of Great Britain and Ireland, vol. 3. London.

Mitson, R. B., and R. J. Morris. 1988. Evidence of high-frequency acoustic emissions from the whitebeaked dolphin (Lagenorhynchus albirostris). J. Acoust. Soc. Am. 83: 825-826.

Mizue, T., M. Nishiwaki, and A. Takemura. 1971. The underwater sound of Ganges river dolphins (Platanista gangetica). Sci. Rept. Whales Res. Inst. 23: 123.

Mizue, T., A. Takemura, and K. Nakasai. 1967. Studies on the little toothed whales in the west sea area of Kyushu. XIII. Mating calls and other sounds of the bottlenosed dolphin caught at Arikawa in Goto Island, Nagasaki Pref. Bull. Fac. Fish. Nagasaki Univ. 23: 197.

Mizue, T., A. Takemura, and K. Nakasai. 1968. Studies on the little toothed whales in the west sea area of Kyushu. XV. Underwater sounds of the Chinese finless porpoise caught in the Japanese coastal sea. Bull. Fac. Fish Nagasaki Univ. 25: 25.

Morejohn, G. V. 1979. The natural history of Dall's porpoise in the north Pacific Ocean. Pp. 45-83 in Behavior of Marine Animals (H. E. Winn and B. L. Olla, Eds.). New York, London.

Morgan, D. W. 1970. The reactions of belugas to natural sound playbacks. Pp. 61-66 in Proc. 7th Ann. Conf. Biol. Sonar and Diving Mammals. Menlo Park.

Morgan, D. W. 1979. The vocal and behavioral reactions of the beluga, Delphinapterus leucas, to playback of its sounds. Pp. 311-342 in Behavior of Marine Animals (H. E. Winn and B. L. Olla, Eds.). New York, London.

Morris, R. J. 1986. The acoustic faculty of dolphins. Pp. 369-399 in Research on Dolphins (M. M. Bryden and R. Harrison, Eds.). Oxford.

Møhl, B., and S. Andersen. 1973. Echolocation: high frequency component in the click of the harbour porpoise (Phocoena phocoena). J. Acoust. Soc. Am. 54: 1368-1372.

Møhl, B. A. Surlykke, and L. A. Miller. 1990. High Intensity Narwhal Clicks. University of Aarhus, Aarhus. 
Mullins, J., H. Whitehead, and L. S. Weilgart. 1988. Behavior and vocalizations of two single sperm whales, Physeter macrocephalus, off Nova Scotia. Can. J. Fish. Aquat. Sci. 45: 1736-1743.

Munsterjelm, L. 1915. Anteckningar om Hyperoodom rostratus (Müller) gjorda under en eshavaresa sommaren 1910. Troms $\varnothing$ Mus. Arsh. 37: 1-13.

Murchison, A. E. 1980. Detection range and range resolution of echolocating bottlenose porpoise (Tursiops truncatus). Pp. 43-70 in Animal Sonar Systems (R. G. Busnel and J. F. Fish, Eds.). New York, London.

Nakasai, K., and A. Takemura. 1975. Studies on underwater sound. VI. On the underwater calls of freshwater dolphins in South America. Bull. Fac. Fish. Nagasaki Univ. 40: 7-13.

Nishida, T. 1968. The social group of wild chimpanzees in the Mahali mountains. Pp. 167-224 in Primates, vol. 9.

Nishiwaki, M. 1966a. Distribution and migration of marine mammals in the North Pacific area. 11th Pacific Sci. Congress, Symp. No. 4: 40-41.

Nishiwaki, M. 1966b. Distribution and migration of marine mammals in the North Pacific area. Coll. Rept. Ocean Res. Inst. 5: 103-123.

Nishiwaki, M. 1972. General biology. Pp. 3-204 in Mammals of the Sea, Biology and Medicine (S. H. Ridgway, Ed.). Springfield.

Norris, K. S. 1964. Some problems of echolocation in Cetacea. Pp. 317-336 in Marine Bioacoustics, Vol. 1 (W. N. Tavolga, Ed.). Pergamon Press, Oxford.

Norris, K. S. 1969. The echolocation of marine mammals. Pp. 391-423 in The biology of Marine Mammals (H. T. Andersen, Ed.). New York.

Norris, K. S. 1974. The Porpoise Watcher. Norton, New York. 212 pp.

Norris, K. S., and T. P. Dohl. 1980. The structure and functions of cetacean schools. Pp. 211-261 in Cetacean Behavior: Mechanisms and Functions (L. M. Herman, Ed.). New York.

Norris, K. S., and W. E. Evans. 1967. Directionality of echolocation clicks in the roughtoothed porpoise, Steno bredanensis (Lesson). Pp. 305-3116 in Proc. 2nd Symp. on Marine Bioacoust. New York.

Norris, K. S., R. M. Goodman, B. Villa-Ramirer, and L. Hobbs. 1977. Behavior of California gray whale, Eschrichtius robustus, in southern Baja California. Fish. Bull. 75: 159-172.

Norris, K. S., and G. W. Harvey. 1972. A theory for the function of the spermaceti organ of the sperm whale (Physeter catodon L.). NASA-SP 262: 397-417. 
Norris, K. S., G. W. Harvey, L. A. Buzzel, and T. D. K. Kartha. 1972. Sound production in the freshwater porpoises, Sotalia fluviatillis Gervais and Deville and Inia geoffrensis Blainville in the Rio Negro, Brazil. Invest. Cetacea 4: 251-260.

Norris, K. S., and B. Møhl. 19833. Can odontocetes debilitate prey with sound? Am. Nat. 122: 85-104.

Norris, K. S., B. Würsig, R. S. Wells, M. Würsig, S. M. Brownlee, C. M. Johnson, and J. Solo. 1982. The behavior of the Hawaiian spinner dolphin, Stenella longirostris: final report. Nat. Mar. Fish. Serv., La Jolla. 96 pp.

Ognetov, G. N. and V. A. Potelov. 1982. Peculiarities of white whale distribution and population dynamics in the White Sea. Pp. 415-418 in 32nd Rept. Int. Whal. Comm. Cover. 32nd Financial Yr. 1980-1981. Cambridge.

Painter, D. W. 1963. Ambient noise in a coastal lagoon. J. Acoust. Soc. Am. 35: 14581459.

Patterson, B., and G. R. Hamilton. 1964. Repetitive 20 cycle per second biological hydroacoustic signals at Bermuda. Pp. 125-146 in Marine Bioacoustics, vol. 1 (W. N. Tavolga, Ed.). New York.

Payne, R. 1972. The song of the whale. Pp. 144-166 in The marvels of Animal Behavior. Washington, D.C.

Payne, R. 1977. "Deep voices", a long playing album produced by R. Payne. Capitol Records Inc., Surv. Angl. Ltd.

Payne, R. 1979. Humpbacks: their mysterious songs. Nat. Geogr. 155: 18-25.

Payne, R., and L. N. Guinee. 1983. Humpback whale (Megaptera novaeangliae) songs as an indicator of "stocks". Pp. 333-258 in Communication and Behavior of Whales (R. Payne, Ed.). Boulder.

Payne, R., and S. McVay. 1971. Songs of humpback whales. Science 173: 585-597.

Payne, R., and K. Payne. 1971. Underwater sounds of southern right whales. Zoologica 4: 159-165.

Payne, R., and K. Payne. 1972. Underwater sounds of southern right whales. Zoologica 56(4): 159-165.

Payne, K., and R. Payne. 1979. Annual changes in songs of humpback whales. Z. Tierpsychol. 62:

Payne, K., and R. S. Payne. 1985. Large-scale changes over 17 years in songs of humpback whales in Bermuda. Z. Tierpsychol. 68: 89-114.

Payne, K., P. Tyack, and R. Payne. 1983. Progressive changes in the songs of humpback whales (Megaptera novaeangliae): a detailed analysis of two seasons in 
Hawaii. Pp. 9-57 in Communication and Behavior of Whales (R. Payne, Ed.). Boulder.

Payne, R. S., and D. Webb. 1971. Orientation by means of long range acoustic signalling in baleen whales. Ann. N.Y. Acad. Sci. 188: 110-141.

Penner, R. H., and A. E. Murchinson. 1970. Experimentally demonstrated echolocation in the Amazon River porpoise Inia geoffrensis (Blainville). Naval Undersea Ctr. Tech. Publ. 187, San Diego.

Penner, R. H., C. W. Turl, and W. W. Au. 1986. Target detection by the beluga using a surface reflected path. J. Acoust. Soc. Am. 80: 1842-1843.

Perkins, P. J. 1966. Communication sounds of finback whales. Norsk. Hval.-Tid. 10: 199-200.

Perkins, P. J., M. P. Fish, and W. H. Mowbray. 1966. Underwater communication sounds of the sperm whale Physeter catodon L. Norsk. Hval..-Tid. 55: 225.

Perrin, W. F. 1970. The problem of porpoise mortality in the U.S. tropical tuna fishery. Pp. 45-48 in Proc. 6th Ann. Conf. on Biology Sonar and Diving Mammals. Menlo Park.

Pilleri, G. 1972. Field observations carried out on the Indus dolphin Platanista indi in the winter of 1972. Pp. 23-29 in Investigations on Cetacea, vol. 4.

Pilleri, G. 1973. Cetelogische Expedition zum Indus und Persischen Golf und nach Goa und Thailand im Jahre 1973. Verlag Hirnanatomisches Institut, Walday-Bern.

Pilleri, G. 1979. Sonar field patterns in Cetaceans' feeding behavior and the functional significance of the pterygoschisis. Pp. 147-156 in Investigations on Cetacea, Vol. X (G. Pilleri, Ed.). Berne.

Pilleri, G., and J. Knuckey. 1969. Behavior patterns of some Delphinidae observed in the western Mediterranean. Z. Tierpsychol. 26: 48-72.

Pilleri, G., C. Kraus, and M. Gihr. 1970. Frequenzanalyse der Laute von Platanista indi (Cetacea). Rev. Suisse Zool. 77: 922-935.

Poulter, T. C. 1966. Biosonar. McGraw-Hill yearbook of science and technology. New York.

Poulter, T. C. 1967. Systems of echolocation. In: Animal Sonar Systems: Biology and Bionics. (R. G. Busnel, Ed.). Jouy-en-Josas.

Poulter, T. C. 1968. Vocalizations of the gray whales in Laguna Oja de Liebre (Scammon's Lagoon), Baja California, Mexico. Norsk. Hval.-Tid. 57: 53.

Poulter, T. C. 1971. Recording of marine mammals in the arctic. U.S. Navy J. Underwater Acoust. 1: 97-104. 
Powell, B. A. 1966. Periodicity of vocal activity of captive Atlantic bottlenosed dolphins: Tursiops truncatus. Bull. South. Calif. Acad. Sci. 65: 237-244.

Puente, A. G., and D. A. Dewsberry. 1976. Courtship and copulatory behavior of bottlenosed dolphins (Tursiops truncatus). Cetology 21: 1-9.

Purves, P. E., and G. E. Pilleri. 1983. Echolocation in Whales and Dolphins. Academic Press, New York. 261 pp.

Racovitza, E. G. 1903. Resultat du voyage du S. V. Belgica en 1887-1899. Zoologia. Cetaces.

Rasmussen, R. A., and N. E. Head. 1965. The quiet gray whale (Eschrichtius glaucus). Deep-Sea Res. 12: 869-877.

Rawitz, B. 1899. Über Megaptera boops nebst Bemerkungen zur Biologie der Norwegischen Mystacoceten. Archiv für Naturgeschichte. Bd. 1, H. 1.

Rawitz, B. 1900. Pp. 245-249 in Die Anatomie des Kehlkopfes und der Nase von Phocoena communis. Inter. Monatsschr. Anat. Phys. Bd. 17, H. 6-8.

Rehman, J. R. 1961. Porpoise aids research. Pp. 36-39 in Undersea Tech. Mag. No. 2. Reynolds, V., and F. Reynolds. 1965. Chimpanzees of the Budongo Forest. Pp. 368424 in Primate Behavior (I. DeVore, Ed.). New York.

Reysenbach de Haan, F. W. 1957. Hearing in whales. Acta Oto-laryngologica 134: 1114.

Ridgway, S. H. 1966. Dall porpoise, Phocoenoides dalli (True): observations in captivity and at sea. Norsk. Hval.-Tid. 55: 97-109.

Saayman, G. S. and C. K. Taylor. 1973. Social organization of inshore dolphins (Tursiops aduncas S.) in the Indian Ocean. J. Mammal. 54: 1-93.

Saayman, G. S., and C. K. Taylor. 1979. The socioecology of humpback dolphins (Sousa sp.). Pp. 165-226 in Behavior of Marine Animals (H. E. Winn and B. L. Olla, Eds.). New York, London.

Saayman, G. S., C. K. Taylor, and D. Bower. 1973. Diurnal activity cycles in captive and free-ranging Indian Ocean bottlenose dolphins (Tursiops aduncus Ehrenburg). Behavior 44: 212-223.

Schevill, W. E. 1964. Underwater sounds of cetaceans. Pp. 307-316 in Marine Bioacoustics, vol. 1 (W. N. Tavolga, Ed.). New York.

Schevill, W. E., R. H. Backus, and J. B. Hershey. 1962. Sound production by marine animals. In The Sea, Vol. 1 (M. N. Hill, Ed.). New York.

Schevill, W. E., and B. Lawrence. 1949. Underwater listening to the white porpoise (Delphinapterus leucas). Science 109: 143-144. 
Schevill, W. E., and B. Lawrence. 1950. A phonograph of the underwater calls of Delphinapterus leucas. Woods Hole Oceanogr. Inst. Ref. No. 50. 1 pp.

Schevill, W. E., and W. A. Watkins. 1962. Whale and porpoise voices: a phonograph record. Woods Hole Oceanogr. Inst., Woods Hole. 24 pp.

Schevill, W. E., and W. A. Watkins. 1966. Sound structure and directionality in Orcinus (killer whale). Zoologica 51: 70-76.

Schevill, W. E., and W. A. Watkins. 1971. Pulsed sounds of the porpoise Lagenorhynchus australis. Breviora 366: 1.

Schevill, W. E., and W. A. Watkins. 1972. Intense low-frequency sounds from an Antarctic minke whale, Balaenoptera acutorostrata. Breviora 388: 1.

Schevill, W. E., W. A. Watkins, and R. H. Backus. 1964. The 20 cycle signals and Balaenoptera (fin whale). Pp. 147-152 in Marine Bioacoustics, Vol. 1 (W. N. Tavolga, Ed.). New York.

Schevill, W. E., W. A. Watkins, and G. C. Ray. 1969. Click structure in the porpoise, Phocoena phocoena. J. Mammal. 50: 721.

Sergeant, D. E. 1962. The biology of the pilot or pothead whale Globicephala malaena (Traill) in Newfoundland waters. Bull. Fish. Res. Board Can. 132: 1-84.

Sergeant, D. E., and P. F. Brodie. 1969. Body size in white whales, Delphinapterus leucas. J. Fish. Res. Board Can. 26: 2561-2580.

Shochi, Y., K. Zbinden, C. Kraus, M. Gihr, and G. Pilleri. 1982. Characteristics and directional properties of the sonar signals emitted by the captive Commerson's dolphin, Cephalorhynchus commersonii (Ardy, 1846). Invest. Cetacea. 13: 177-202.

Silber, G. K. 1986. The relationship of social vocalizations to surface behavior and aggression in the Hawaiian humpback whale (Megaptera novaeangliae). Can. J. Zool. 64: 2075-2080.

Silverman, H. B. 1979. Social organization and behavior of the narwhal Monodon monoceros L. in Lancaster Sound, Pond Inlet and Tremblay Sound, Northwest Territories. Mar. Sci. Ctr., Montreal. 147 pp.

Singleton, R. C., and T. C. Poulter. 1968. Spectral analysis of the call of the male killer whale. Pp. 11 in Progr. Rept. on Echo Ranging Signals (T. C. Poulter, Ed.). Menlo Park.

Steiner, W. W., J. H. Hain, W. E. Winn, and P. J. Perkins. 1979. Vocalizations and feeding behavior of the killer whale (Orcinus orca). J. Mammal. 60: 823-827.

Stone, G. S., S. K. Katona, and E. B. Tucker. 1987. History, migration and present status of humpback whales, Megaptera novaeangliae, at Bermuda. Biol. Conserv. 42: 133-145. 
Taruski, A. G. 1979. The whistle repertoire of the North Atlantic pilot whale (Globicephala melaena) and its relationship to behavior and environment. Pp. 345-368 in Behavior of Marine Animals (H. E. Winn and B. L. Olla, Eds.). New York, London.

Tavolga, M. C. 1966. The behavior of the bottlenosed dolphin (Tursiops truncatus): social interactions in a captive colony. Pp. 718-773 in Whales, Dolphins and Porpoises (K. Norris, Ed.). Berkeley.

Tavolga, M. C., and E. S. Essapian. 1957. The behavior of the bottlenose dolphin (Tursiops truncatus): mating, pregnancy, parturition and mother-infant behavior. Zoologica 42: 11-31.

Tavolga, W. N. 1968. Marine annual data atlas. U.S. NAVTRADEVCEN Tech. Rept. No. 1212-2. 239 pp.

Taylor, C. K., and G. S. Saayman. 1972. The social organization and behavior of dolphins (Tursiops aduncus) and baboons (Papio ursinus): some comparisons and assessments. Ann. Cape Prov. Mus. 9: 11-49.

Thomas, J. A., P. W. B. Moore, P. E. Nachtigall, and W. G. Gilmarth. 1990. A new sound from a stranded pygmy sperm whale. Aquat. Mammals 16: 28-30.

Thompson, P. O., and W. C. Cummings. 1969. Sound production of the finback whale, Balaenoptera physalus, and Eden's whale, B. edeni, in the Gulf of California. Pp. 109 in Proc. 6th Annual Conf. of Biological Sonar and Diving Animals. Menlo Park.

Thompson, P. O., W. C. Cummings, and S. J. Ha. 1986. Sound source levels and associated behavior of humpback whales, southeast Alaska. J. Acoust. Soc. Am. 80: 735-740.

Thompson, P. O., and W. A. Friedl. 1982. A long term study of low frequency sounds from several species of whales of Oahu, Hawaii. Cetoloty 45: 1-19.

Thompson, T. J., and H. E. Winn. 1977. Temporal aspects of the humpback whale song. Anim. Behav. Soc. Meeting. [Abstract].

Thompson, T. J., H. E. Winn, and P. J. Perkins. 1979. Mysticete sounds. Pp. 403-431 in Behavior of Marine Animals, Vol. 3 (H. E. Winn and B. L. Olla, Eds.). New York. Turl, C. W., and R. H. Penner. 1989. Differences in echolocation click patterns of the beluga (Delphinapterus leucas) and the bottlenose dolphin (Tursiops truncatus). J. Acoust. Soc. Am. 86:

Turner, R. H., and K. S. Norris. 1966. Discriminative echolocation in porpoise. J. Exp. Anal. Behav. 19: 535-544.

Tyack, P. 1980. The function of song in humpback whales, Megaptera novaeangliae. Pp. 41 in 14th Nat. Meeting, San Francisco. [Abstract]. 
Tyack, P. 1981. Interactions between singing Hawaiian humpback whales and conspecifics nearby. Behav. Ecol. Sociobiol. 8: 105-116.

van Lawick-Goodall, J. 1968. The behavior of free-living chimpanzees in the Gombe Stream Reserve. Anim. Behav. Monogr. 1: 161-311.

Vincent, F. 1960. Étude préliminaires de certaines émissions acoustiques de Delphinus delphis L. en captivité. Bull. Inst. Oceanogr. 57: 1-23.

Vincent, F. 1963. Acoustic signals for auto-information or echolocation. Pp. 183-227 in Acoustic Behavior of Animals. Amsterdam.

Vladykov, V. D. 1944. Études sur les mammifères aquatiques. Vol. 3, Dépt. Pêcheries Proc. Quebec, Quebec.

von Haast, J. 1876. Further notes on Oulodon, a new genus of ziphioid whale from the New Zealand seas. Proc. Zool. Soc. London 1876: 457-458.

Walker, R. A. 1963. Some intense, low-frequency underwater sounds of wide geographic distribution, apparently of biological origin. J. Acoust. Soc. Am. 35: 1816-1824.

Wang Ding, Lu Wenxiang, and Wang Zhifan. 1989. A preliminary study of the acoustic behavior of the baiji, Lipotes vexillifer. Pp. 137-140 in Biology and Conservation of the River Dolphins (W. F. Perrin, R. L. Brownell, Zhou Kaiya, and Liu Jiankang, Eds.). Gland.

Watkins, W. A. 1967a. Air-borne sounds of the humpback whale Megaptera novaeangliae. J. Mammal. 48: 573.

Watkins, W. A. 1967b. The harmonic interval: fact or artifact in spectral analysis of pulse trains. Pp. 14-43 in Marine Bioacoustics, Vol. 2 (W. N. Tavolga, Ed.). New York. Watkins, W. A. 1974. Bandwidth limitations and analysis of cetacean sounds, with comments on delphinid sonar measurements and analysis (K. J. Diercks, R. T. Trochta, and W. E. Evans, J. Acoust. Soc. Am. 54: 200 [1973]). J. Acoust. Soc. Am. 55: 849.

Watkins, W. A. 1977. Acoustic behavior of sperm whales. Oceanus 2: 50-58.

Watkins, W. A. 1980a. Acoustics and the behavior of sperm whales. Pp. 283-290 in Animal Sonar Systems (R. G. Busnel and J. F. Fish, Eds.). New York, London. Watkins, W. A. 1980b. Click sounds from animals at sea. Pp. 291-297 in Animal Sonar Systems (R. G. Busnel and J. F. Fish, Eds.). New York, London.

Watkins, W. A. 1981. Activities and underwater sounds of fin whales. Sci. Rept. Whales Res. Inst. 33: 83-117. 
Watkins, W. A., and K. E. Moore. 1982. An underwater acoustic survey for sperm whales (Physeter catodon) and other cetaceans in the southeast Caribbean. Cetology 46: 1-7.

Watkins, W. A., K. E. Moore, and P. Tyack. 1985. Sperm whale acoustic behaviors in the southeast Caribbean. Cetology 49: 1-15.

Watkins, W. A., and W. E. Schevill. 1974. Listening to Hawaiian spinner porpoises, Stenella cf. longirostris, with a three-dimensional hydrophone array. J. Mammal. 55: 319-328.

Watkins, W. A., and W. E. Schevill. 1976. Right whale feeding and baleen rattle. J. Mammal. 57: 58-66.

Watkins, W. A., and W. E. Schevill. 1977a. Sperm whale codas. J. Acoust. Soc. Am. 62: 1485-1490.

Watkins, W. A., and W. E. Schevill. 1977b. Spatial distribution of Physeter catodon (sperm whales) underwater. Deep-Sea Res. 24: 693-699.

Watkins, W. A., and W. E. Schevill. 1980. Characteristic features of the underwater sounds of Cephalorhynchus commersonii. J. Mammal. 61: 738-739.

Watkins, W. A., W. E. Schevill, and P. B. Best. 1977. Underwater sounds of Cephalorhynchus heavisidii (Mammalia, Cetacea). J. Mammal. 58: 316-320.

Watkins, W. A., W. E. Schevill, and C. Ray. 1971. Underwater sounds of Monodon (narwhal). J. Acoust. Soc. Am. 49: 595.

Watkins, W. A., and D. Wartzok. 1985. Sensory biophysics of marine mammals. Mar. Mammal Sci. 1: 219-260.

Wenz, G. M. 1964. Curious noises and the environment in the ocean. Pp. 101-119 in Marine bioacoustics (W. N. Tavolga, Ed.). New York.

Wilson, E. O. 1975. Sociobiology: the New Synthesis. Harvard Univ. Press, Cambridge. 695 pp.

Winn, H. E., W. L. Bischoff, and A. G. Taruski. 1973. Cytological sexing of cetacea. Mar. Biol. 23: 343-346.

Winn, H. E., R. K. Edel, and A. G. Taruski. 1975. Population estimate of the humpback whale (Megaptera novaeangliae) in the West Indies by visual and acoustic techniques. J. Fish. Res. Board Can. 32: 499-506.

Winn, H. E., and P. J. Perkins. 1976. Distributions and sounds of the minke whale with a review of mysticete sounds. Cetology 19: 1-12.

Winn, H. E., P. J. Perkins, and T. C. Poulter. 1970a. Sounds of the humpback whale. Pp. 39-52 in Proc. 7th Ann. Conf. Biology Sonar and Diving Mammals. Menlo Park. 
Winn, H. E., P. J. Pekins, and L. Winn. 1970b. Sounds and behavior of the northern bottle-nosed whale. Pp. 53-59 in 7th Ann. Conf. Biol. Sonar Diving Mammals. Menlo Park.

Winn, H. E., and L. K. Winn. 1978. The song of the humpback whale (Megaptera novaeangliae) in the West Indies. Mar. Biol. 47: 97-114.

Wolman, A. A. 1978. Humpback whales. Pp. 46-63 in Marine Mammals of Eastern North Pacific and Arctic Waters (D. Haley, Ed.). Seattle.

Wood, F. G. 1952. Porpoise sounds. A phonograph record of underwater sounds made by Tursiops truncatus and Stenella plagiodon. Marineland Res. Lab., Marineland.

Wood, F. G. 1953. Underwater sound production and concurrent behavior of captive porpoises, Tursiops truncatus and Stenella plagiodon. Bull. Mar. Sci. Caribbean 3: 120-133.

Wood, F. G. 1977. Birth of dolphins at Marineland of Florida, 1939-1969 and comments on problems involved in captive breeding of small cetacea. Pp. 47-60 in Breeding Dolphins: Present Status and Suggestions for the Future (S. H. Ridgway and K. Benirschke, Eds.). Washington.

Wood, F. G., and W. E. Evans. 1980. Adaptiveness and ecology of echolocation in toothed whales. Pp. 381-425 in Animal Sonar Systems (R. G. Busnel and J. F. Fish, Eds.). New York, London.

Worthington, L. V., and W. E. Schevill. 1957. Underwater sounds heard from sperm whales. Nature 180: 291.

Wright, B. S. 1962. Notes of North Atlantic whales. Can. Field Nat. 76: 62-65.

Würsig, B. 1978. Occurrence and group organization of Atlantic bottlenosed porpoises (Tursiops truncatus) in the Argentine Bay. Biol. Bull. 154: 348-359.

Würsig, B. 1979. Dolphins. Sci. Am. 240: 108-117.

Würsig, B., C. W. Clark, E. M. Dorsey, M. A. Fraker, and R. S. Payne. 1982. Normal behavior of bowheads. In Behavior, Disturbance Responses and Feeding of Bowhead Whales Balaena mysticetus in the Beaufort Sea, 1980-81 (W. J. Richardson, Ed.). Unpubl. Rept., LGL Ecol. Res. Assoc., Inc., Bryan, Texas for U.S. Bureau of Land Management, Washington, D.C.

Würsig, B. and M. Würsig. 1979. Day and night of the dolphin. Nat. Hist. 88: 60-67. Würsig, B. and M. Würsig. 1980. Behavior and ecology of dusky dolphins, Lagenorhynchus obscurus, in the South Atlantic. Fish. Bull. 77: 871-890. Xiao Youfu, and Jing Rongcai. 1989. Underwater acoustic signals of the baiji (Lipotes vexillifer). Pp. 129-136 in Biology and Conservation of the River Dolphins (W. F. Perrin, R. L. Brownwell, Zhou Kaiya, and Liu Jiankang, Eds.). Gland. 
Zagaeski, M. 1987. Some observations on the prey stunning hypothesis. Mar. Mammal Sci. 3: 275-279. 


\section{FIGURE LEGENDS}

Fig. 1. Main classes of acoustic signals produced by belukhas: A \#1; B,C \#2. Time: 1 tick $=0.2 \mathrm{sec}$.

Fig. 2. Main classes of acoustic signals produced by belukhas: A \#2; B,C \#3. Time: 1 tick $=0.2$ sec.

Fig. 3. Main classes of acoustic signals produced by belukhas: A,B \#4; C,D \#5. Time: 1 tick $=0.2 \mathrm{sec}$.

Fig. 4. Main classes of acoustic signals produced by belukhas: A \#6; B,C \#7. Time: 1 tick $=0.2 \mathrm{sec}$.

Fig. 5. Main classes of acoustic signals produced by belukhas: A \#8; B,C \#9; D \#10. Time: 1 tick $=0.2 \mathrm{sec}$.

Fig. 6. Main classes of acoustic signals produced by belukhas: A \#12; B,C \#13. Time: 1 tick $=0.2$ sec.

Fig. 7. Acoustic signals of class $\# 14$ produced by belukhas. Time: 1 tick $=0.2 \mathrm{sec}$.

Fig. 8. Main classes of acoustic signals produced by belukhas: A \#14; B \#15; C \#16. Time: 1 tick $=0.2 \mathrm{sec}$.

Fig. 9. Main classes of acoustic signals produced by belukhas: A \#18; B \#19; C \#20. Time: 1 tick $=0.2 \mathrm{sec}$.

Fig. 10. Main classes of acoustic signals produced by belukhas: A \#20; B \#21; C \#22. Time: 1 tick $=0.2 \mathrm{sec}$.

Fig. 11. Main classes of acoustic signals produced by belukha: A \#24; B \#25; C \#26. Time: 1 tick $=0.2 \mathrm{sec}$.

Fig. 12. Main classes of acoustic signals produced by belukhas: A \#26; B \#27; C \#28. Time: 1 tick $=0.2 \mathrm{sec}$.

Fig. 13. Main classes of acoustic signals produced by belukhas: A, B \#29; C \#30. Time: 1 tick $=0.2$ sec.

Fig. 14. Main classes of acoustic signals produced by belukhas: A \#31; B,C \#32; D \#33. Time: 1 tick $=0.2 \mathrm{sec}$.

Fig. 15. Main classes of acoustic signals produced by belukhas: A \#34; B,C \#35. Time: 1 tick $=0.2 \mathrm{sec}$.

Fig. 16. Main classes of echolocation series produced by belukhas. A - remote target location (RT), B,C - intermediate target distance (IT). Time: 1 tick $=0.2 \mathrm{sec}$.

Fig. 17. Echolocation series of main classes produced by belukhas. A - close target location (CL), B,C - capture of fish (CF). Time: 1 tick $=0.2$ sec.

Fig. 18. Chart of the observation region (Letnyaya Zolotitsa, the White Sea, JulySeptember 1978-1980, 1986-1987). GF - location of hydrophones. 
Fig. 19. Diagram of the observation region "Letnyaya Zolotitsa" (The White Sea).

Fig. 20. Dynamics of passings of belukhas in groups of different sex-age composition

("Letnyaya Zolotitsa", July-September 1986-1987).

Fig. 21. The juvenile White Sea belukha with the natural mark on its side.

Fig. 22. Time of arrival and departure of groups of White Sea belukhas in the observation region (Letnyaya Zolotitsa).

Fig. 23. Chart of single belukha track (The White Sea, 14:55.03 - 15:36.25 hrs, 2 August 1986).

Fig. 24. Chart of single belukha track (The White Sea, 11:40.08 - 12:27.17 hrs, 10 August 1986).

Fig. 25. Spectrogram of signals made by the White Sea belukha. A - \#1 \& \#7, B - \#7, C \#4.

Fig. 26. Body position of the White Sea belukha at the beginning of "hunting".

Fig. 27. Use of echolocation series of main classes by the White Sea belukha during individual activity in searching and hunting (cassette 11a, 1979; cassette 41b, 1980).

Fig. 28. Spectrograms of signals produced by belukha: A - class \#17, B - class \#11.

Time: 1 notch $=0.2 \mathrm{sec}$.

Fig. 29. Signals of class \#14, made by: A, B - a female with a small baby; C - a female with a large baby.

Fig. 30. Signals of class \#14, made by a female with a large baby.

Fig. 31. Signals of class \#8, made by: A - a female with a large baby; B,C - a female with a small baby.

Fig. 32. Spectrograms of signals of class \#14 produced by the White Sea belukha;

recorded: A - 18:40 hrs, 23 July 1980 (cassette 45a - 094); B - 14:22 hrs, 25 July 1980 (cassette $45 \mathrm{~b}-189$ ). Time: 1 tick $=0.2 \mathrm{sec}$.

Fig. 33. Spectrograms of signals of class \#14 produced by the White Sea belukha; recorded: A - 19:22 hrs, 22 July 1979 (cassette 17a - 101); B - 9:15 hrs, 27 July 1980 (cassette $42 \mathrm{a}-298$ ). Time: 1 tick $=0.2 \mathrm{sec}$.

Fig. 34. Spectrograms of signals of class \#14 produced by the White Sea belukha; recorded: A - 10:30 hrs, 9 July 1980 (cassette 16b - 060); B - 16:08 hrs, 12 July 1980 (cassette $29 \mathrm{~b}-151$ ). Time: 1 tick $=0.2 \mathrm{sec}$.

Fig. 35. Spectrograms of signals of class \#14 produced by the White Sea belukha; recorded: A - 3:20 hrs, 9 July 1980 (cassette 16a - 322); B - 9:17 hrs, 23 July 1980 (cassette $41 \mathrm{~b}-326)$. Time: 1 tick $=0.2 \mathrm{sec}$.

Fig. 36. Tracks of White Sea belukhas; A,B - two adults (18:06.22 - 18:12.41 hrs, 25 July 1986); C - female with juvenile (16:40.18 - 16:45.15 hrs; 3 August 1986). 
Fig. 37. Spectrograms of signals produced by the White Sea belukha: A - class \#6; B class \#3; C - class \#10; D - class \#4. Time: 1 tick $=0.2 \mathrm{sec}$.

Fig. 38. Belukhas' tactical tricks during hunting in a group: A - "carousel"; B - "caldron".

Fig. 39. Spectrograms of the White Sea belukha: A - class \#2; B - class \#4; C - class \#10.

Fig. 40. A map of the observation region (Amur Estuary, July-October 1980, 1983).

Fig. 41. The juvenile Amur belukha with the mark on its back.

Fig. 42. Tracks of a "flock" of Amur belukhas and a group separated from the "flock". (9:26 - 10:22 hrs, 26 August 1983).

Fig. 43. Tracks of Amur belukhas; A - one individual (11:39.49 - 12:14.11 hrs, 22 Sept. 1983); B - female with baby (9:34.05 - 10:00.09 hrs, 28 August 1983).

Fig. 44. Tracks of Amur belukhas: A - female with baby (18:58.25 - 19:45.38 hrs, 24 August 1983); B - one individual (9:29.07 - 10:30.42 hrs, 29 August 1983).

Fig. 45. Relative proportion of main signal classes made by belukha in two ranges (the White Sea and the Amur Estuary).

Fig. 46. Levesl of acoustic activity in differently-sized groups of belukha.

Fig. 47. Relative proportions of certain classes of signals made by groups of White Sea belukhas.

Fig. 48. Relative proportions of certain classes of signals made by groups of Amur belukhas.

Fig. 49. Relative proportions of the main classes of echolocation series of belukhas in two ranges (the White Sea and the Amur Estuary). 


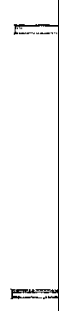



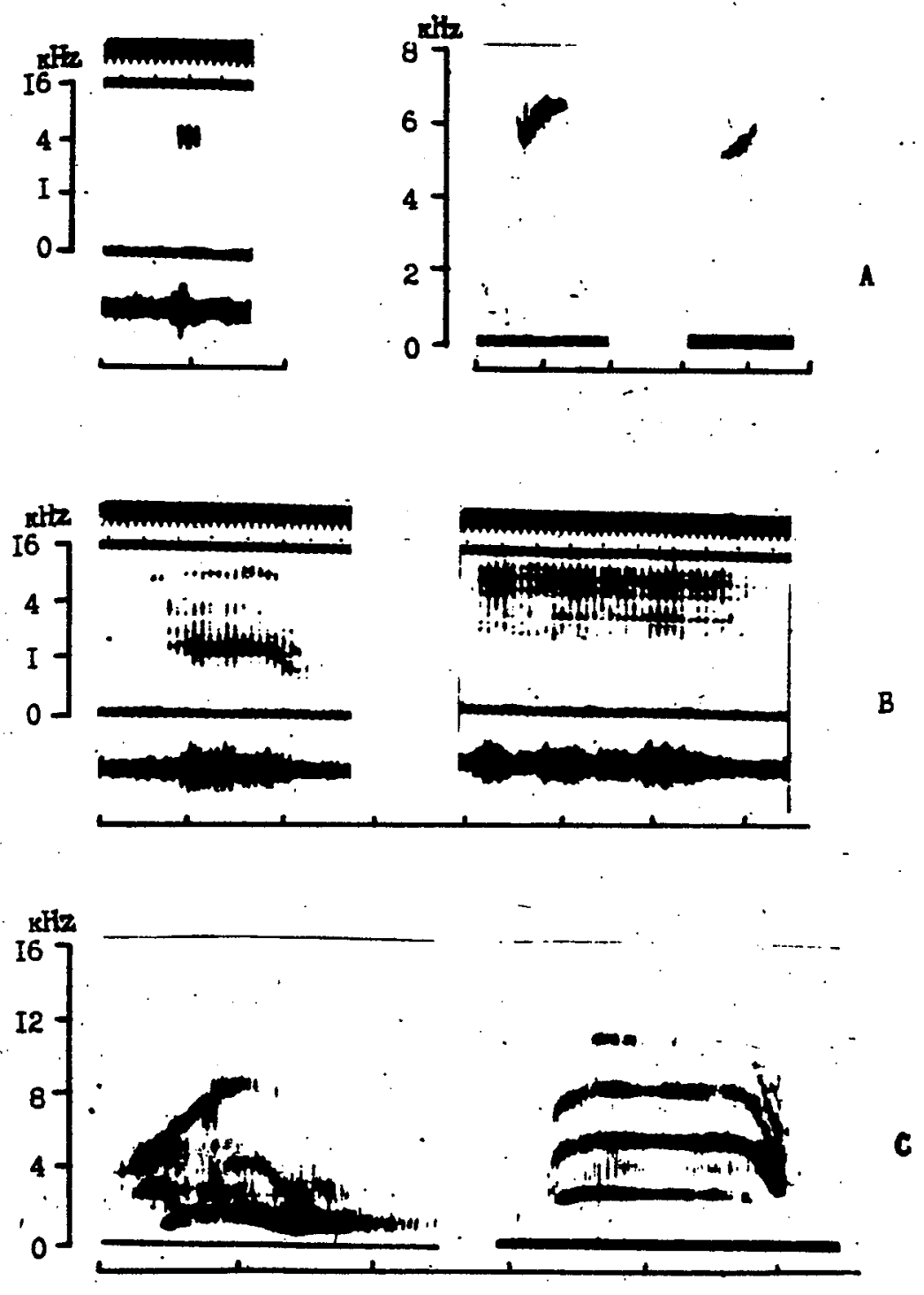

Figure 1 

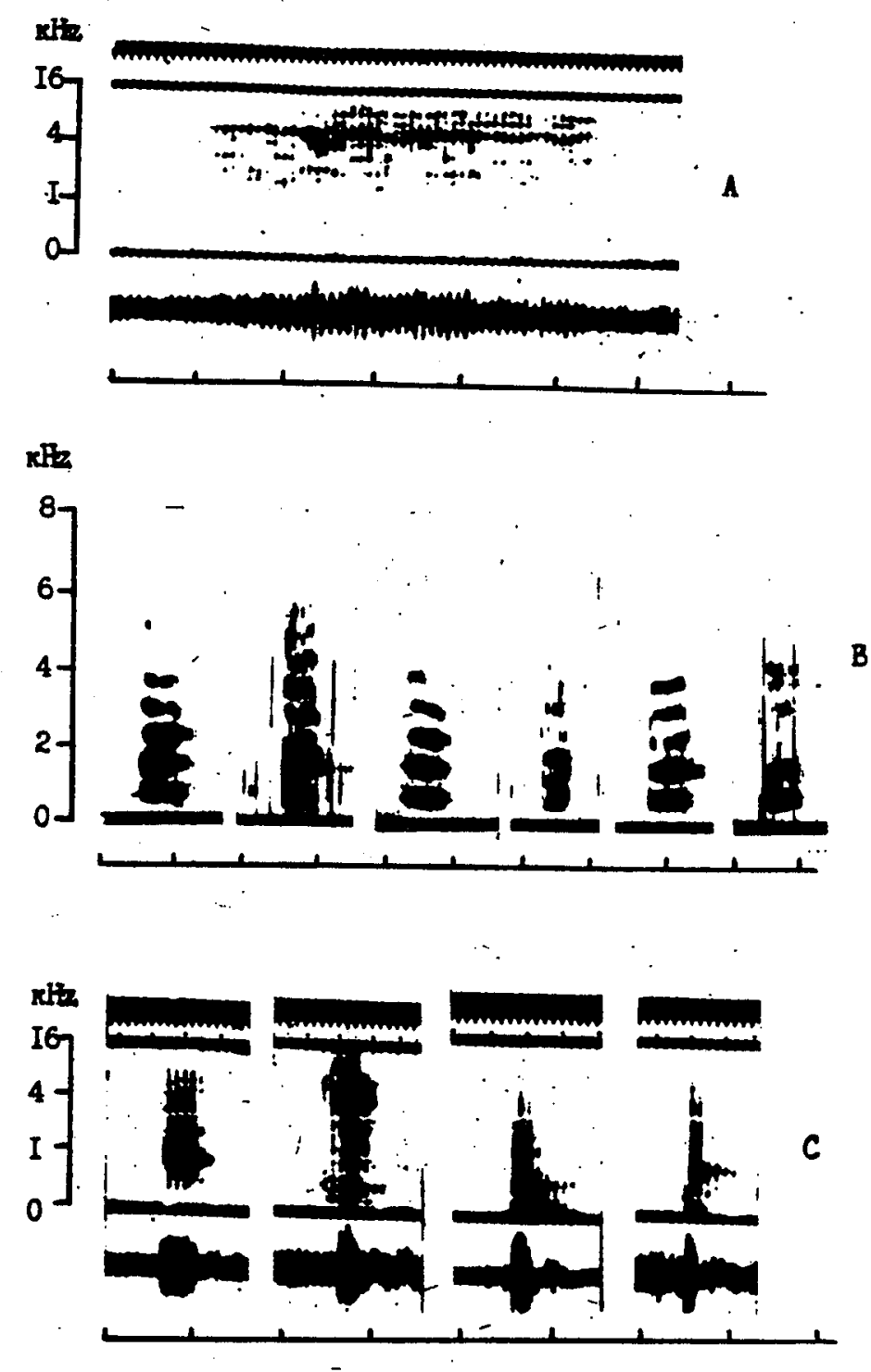

Figure 2 

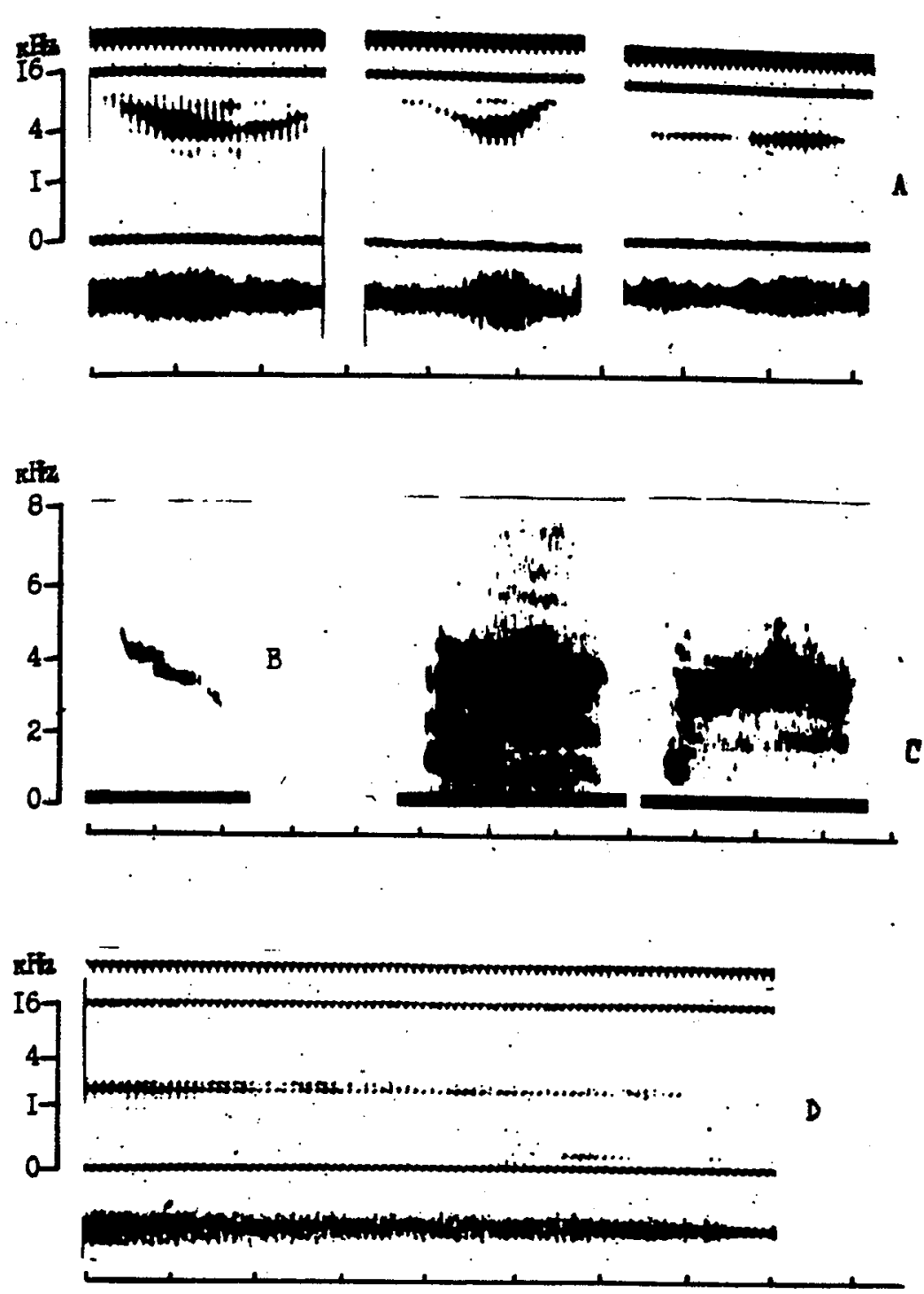

Figure 3 

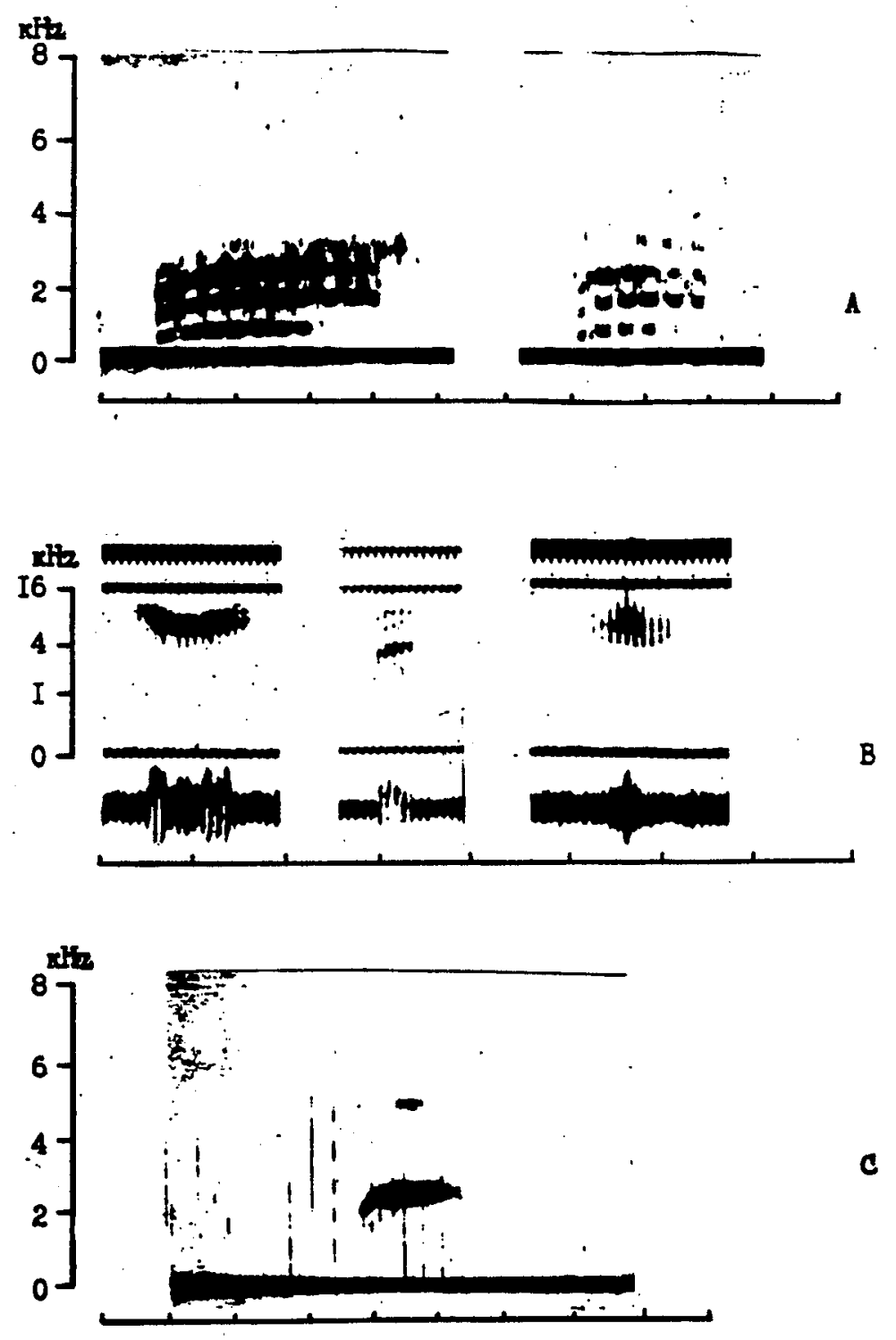

Figure 4 

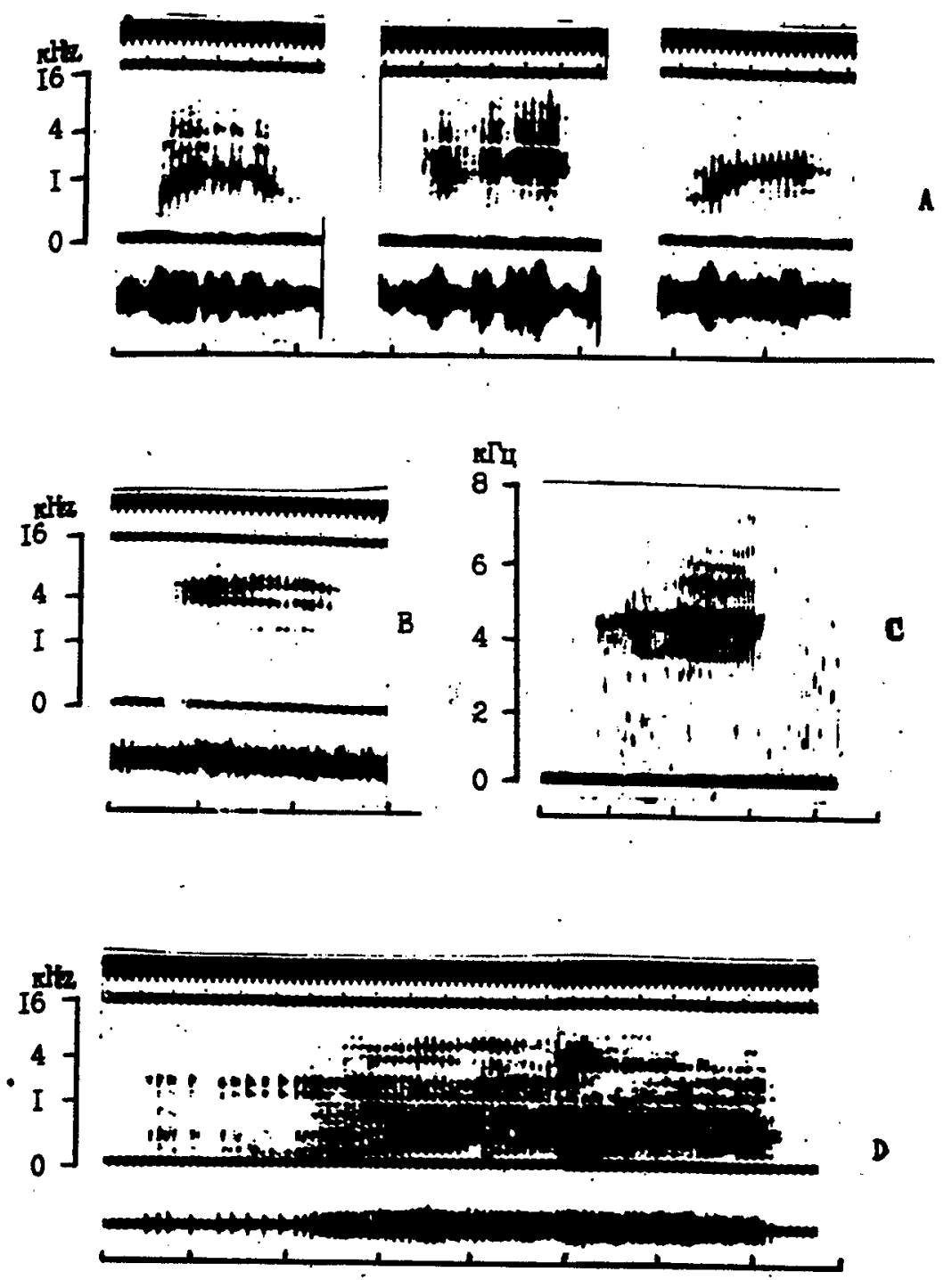

Figure 5 

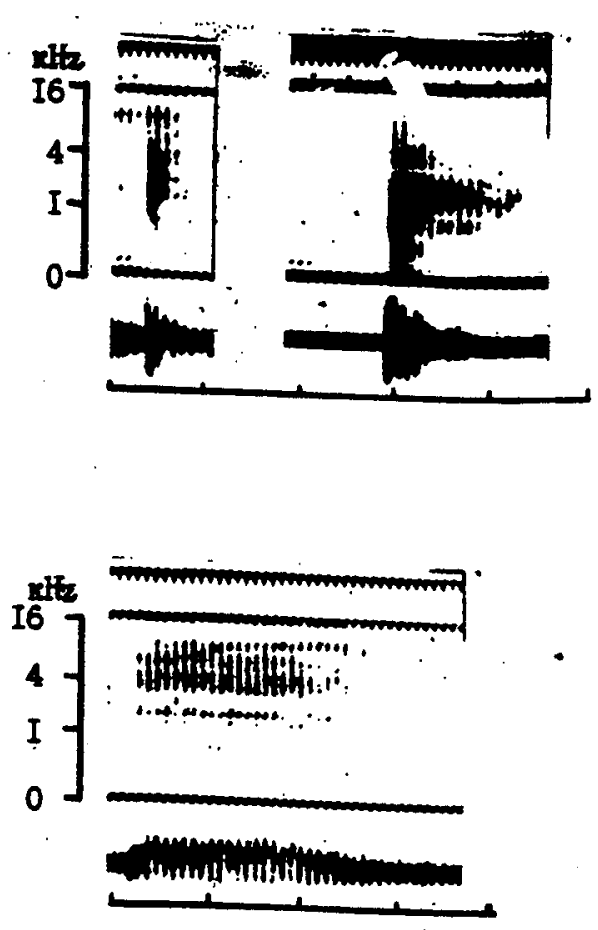

B

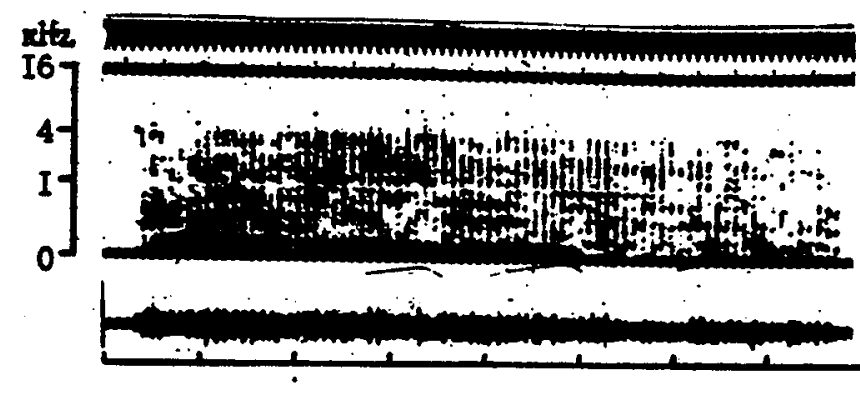

C

Figure 6 

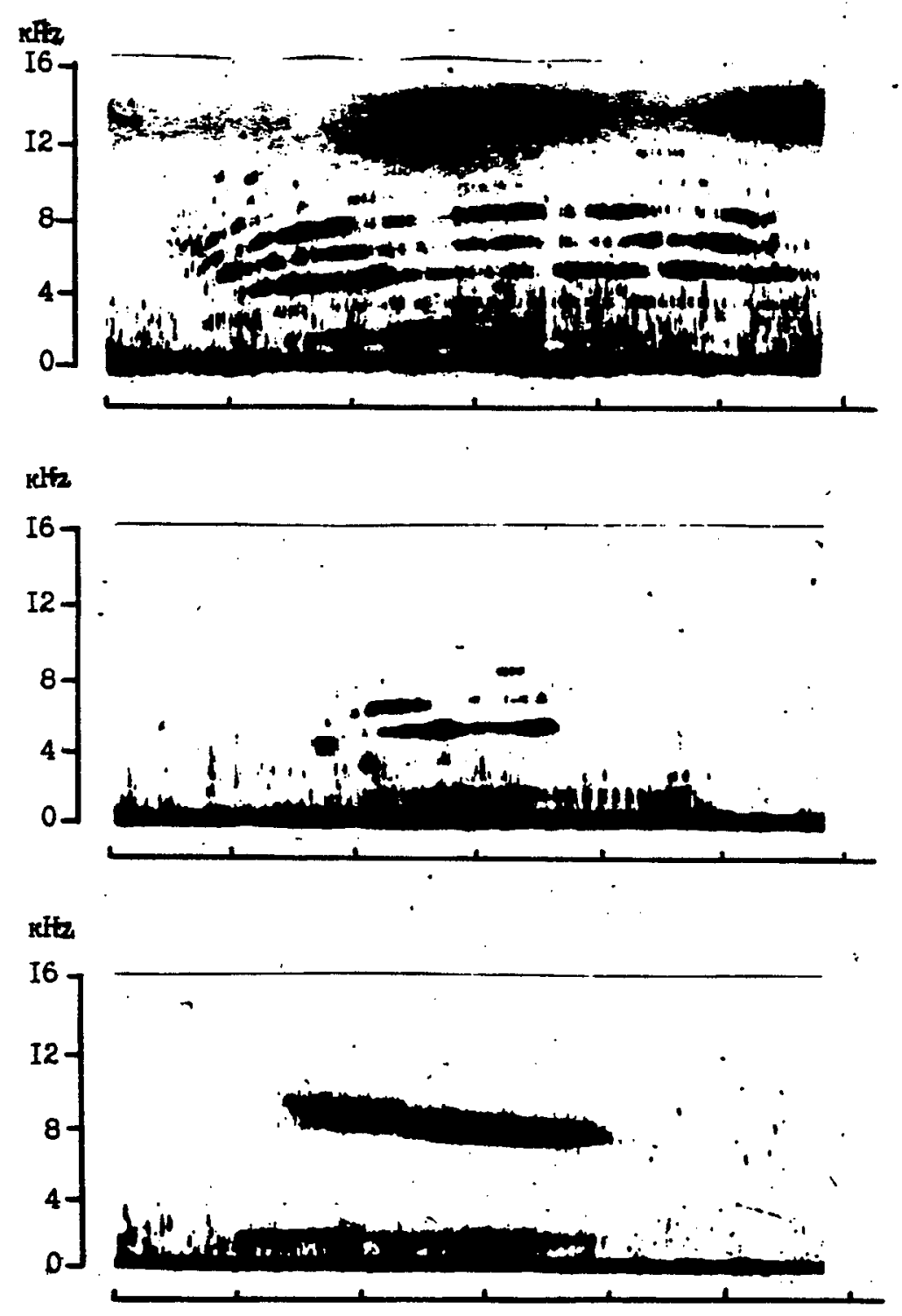

Figure 7 

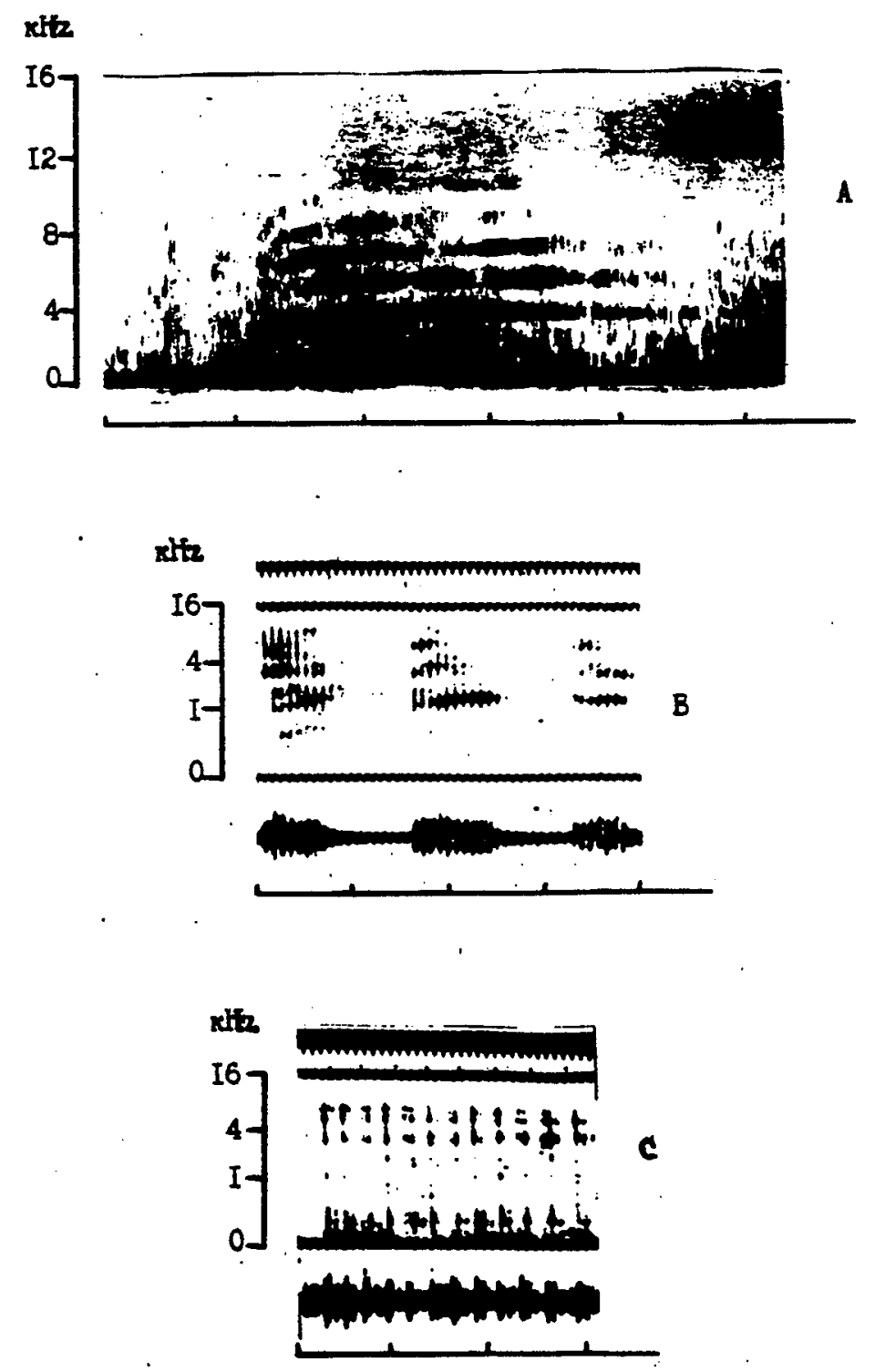

Figure 8 

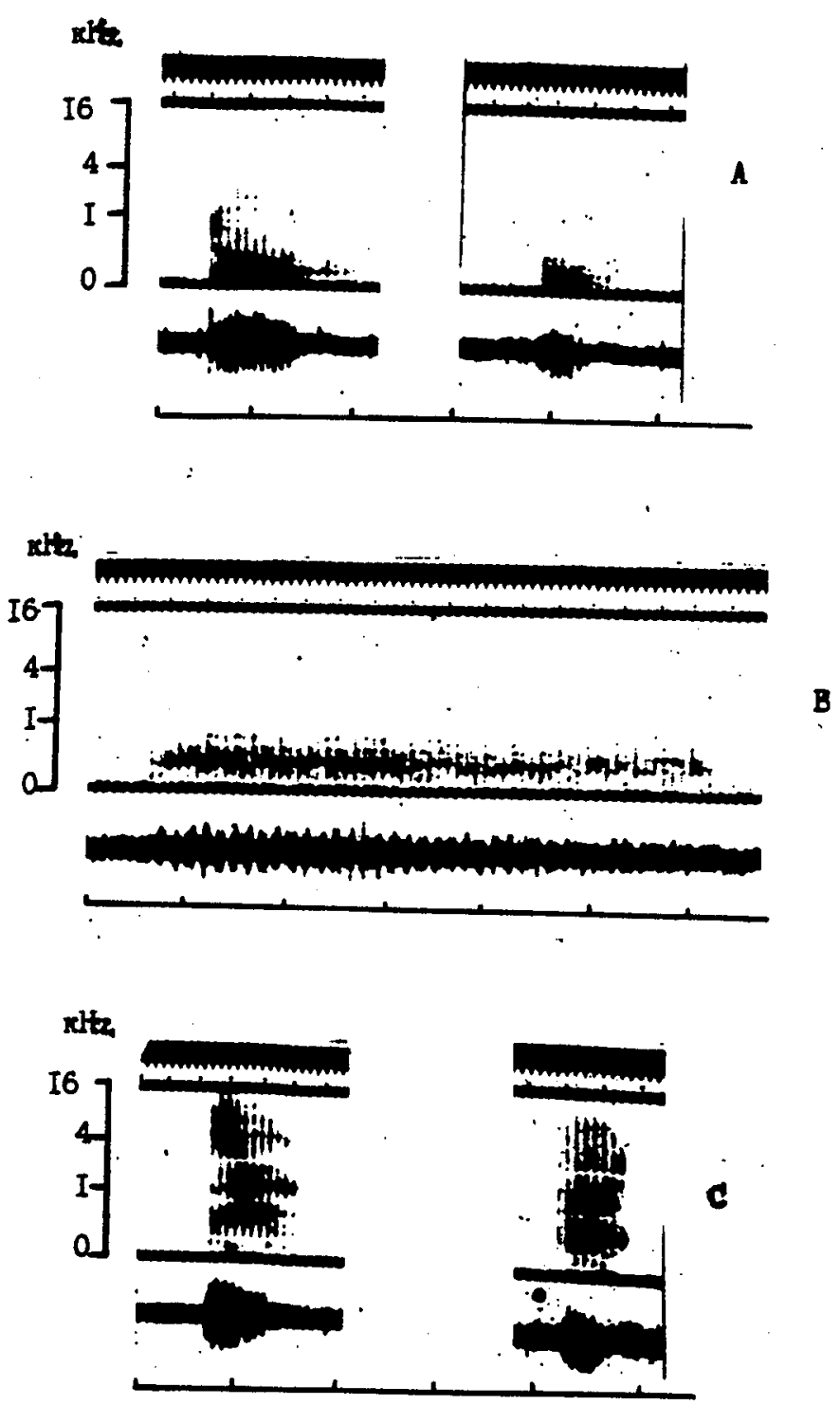

Figure 9 


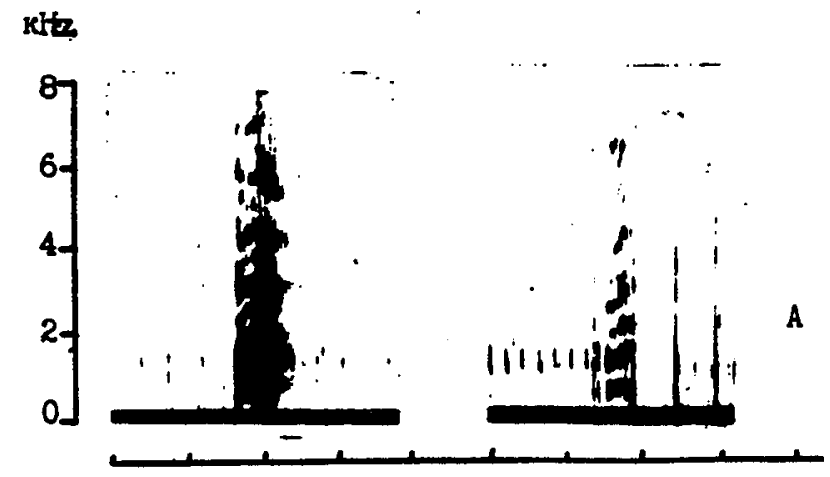

xith
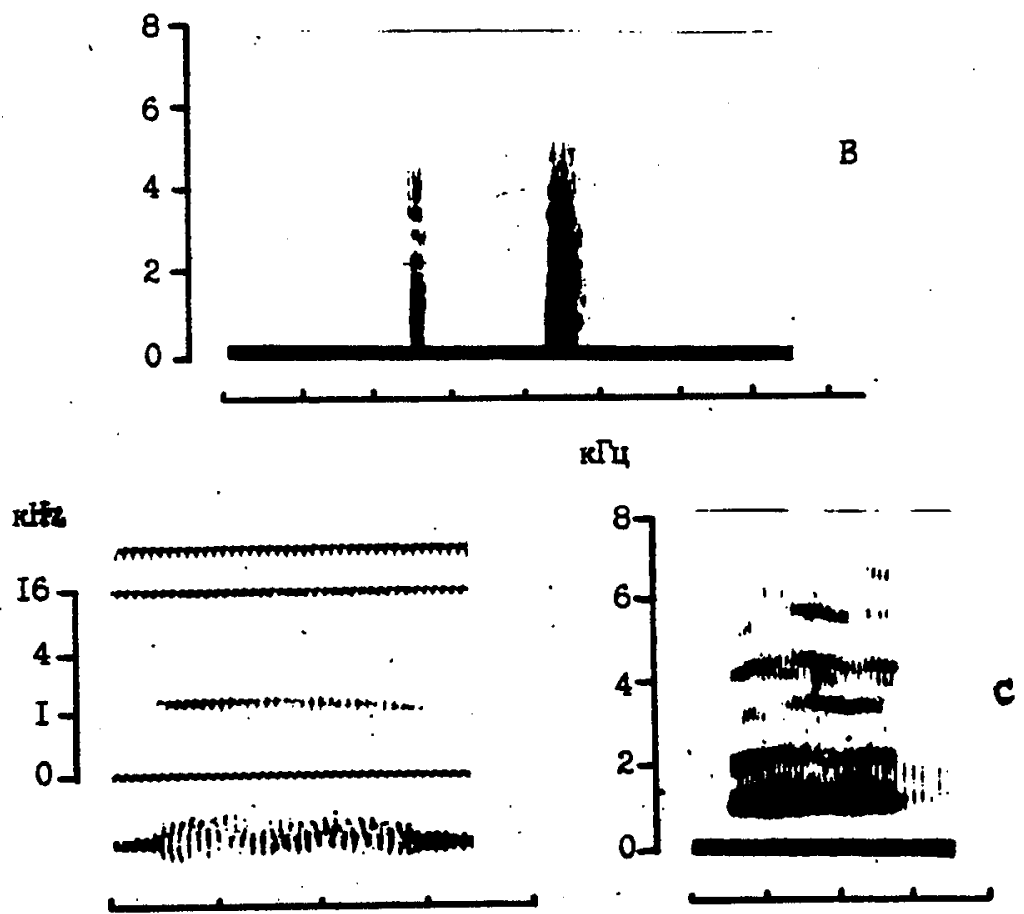

Figure 10 

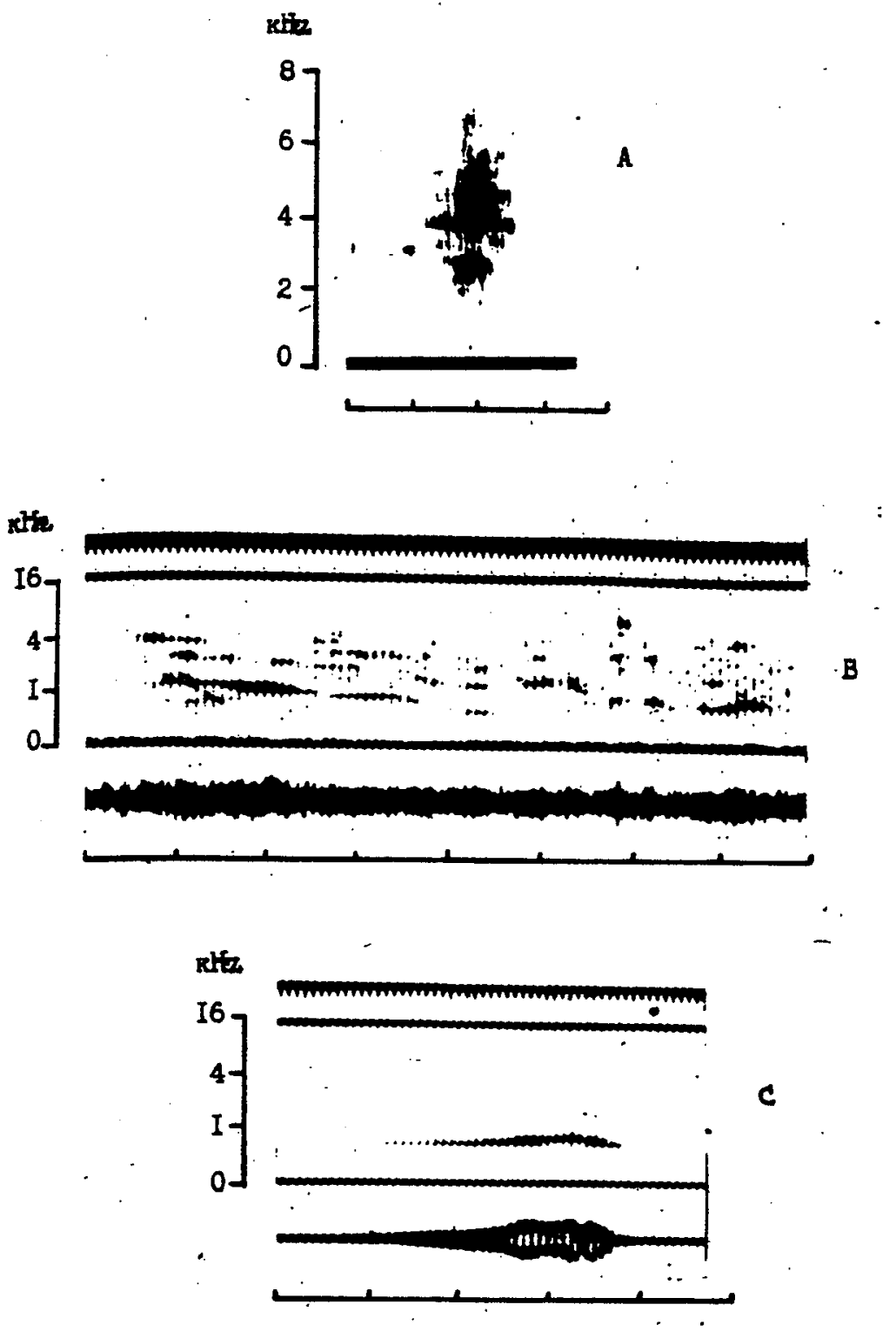

Figure 11 

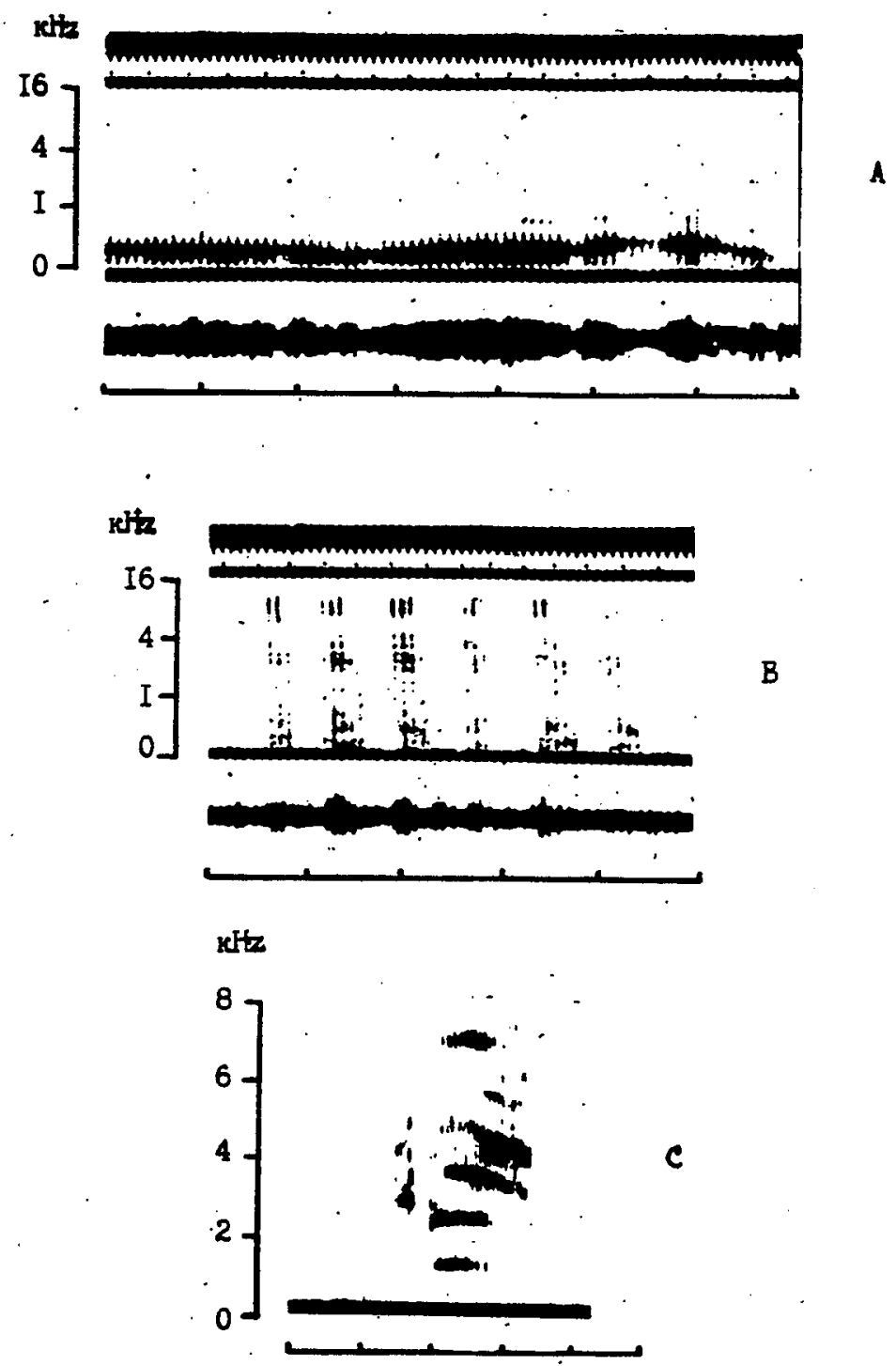

Figure 12 

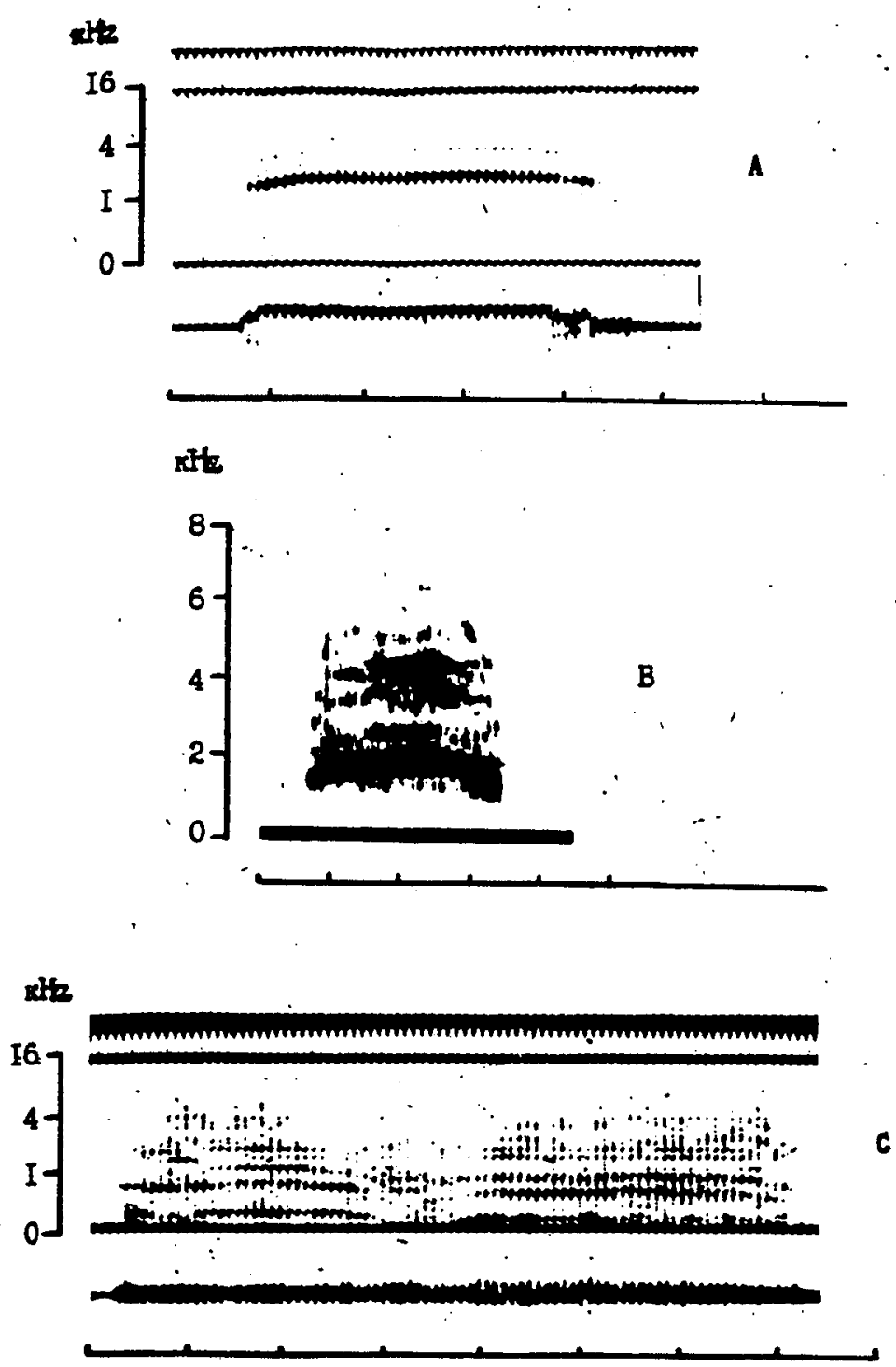

Figure 13 


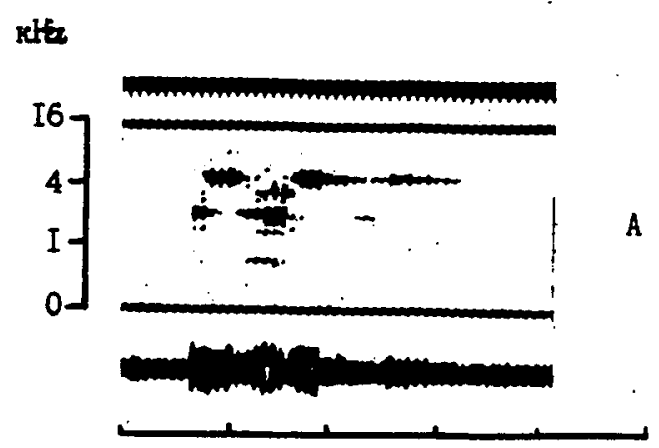

sitte

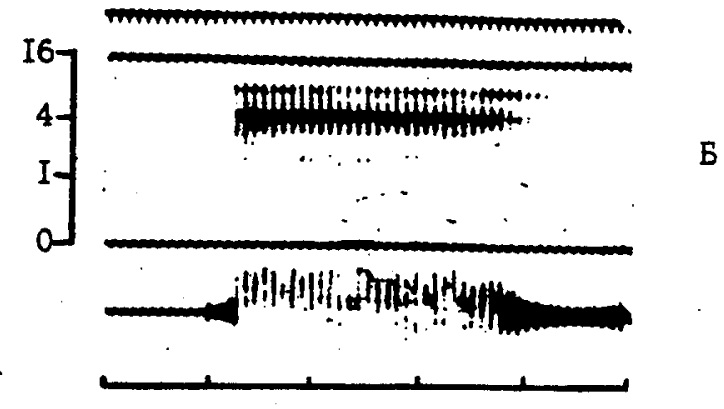

chlt
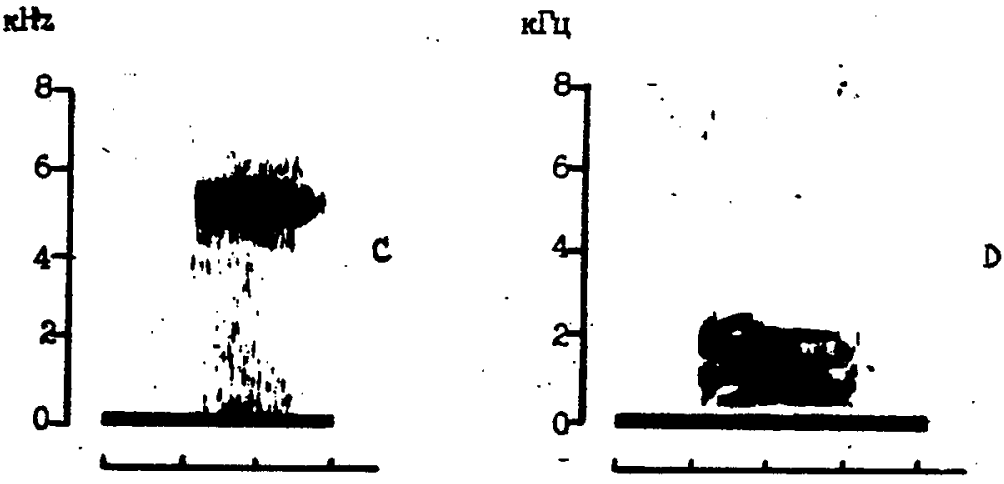

Figure 14 

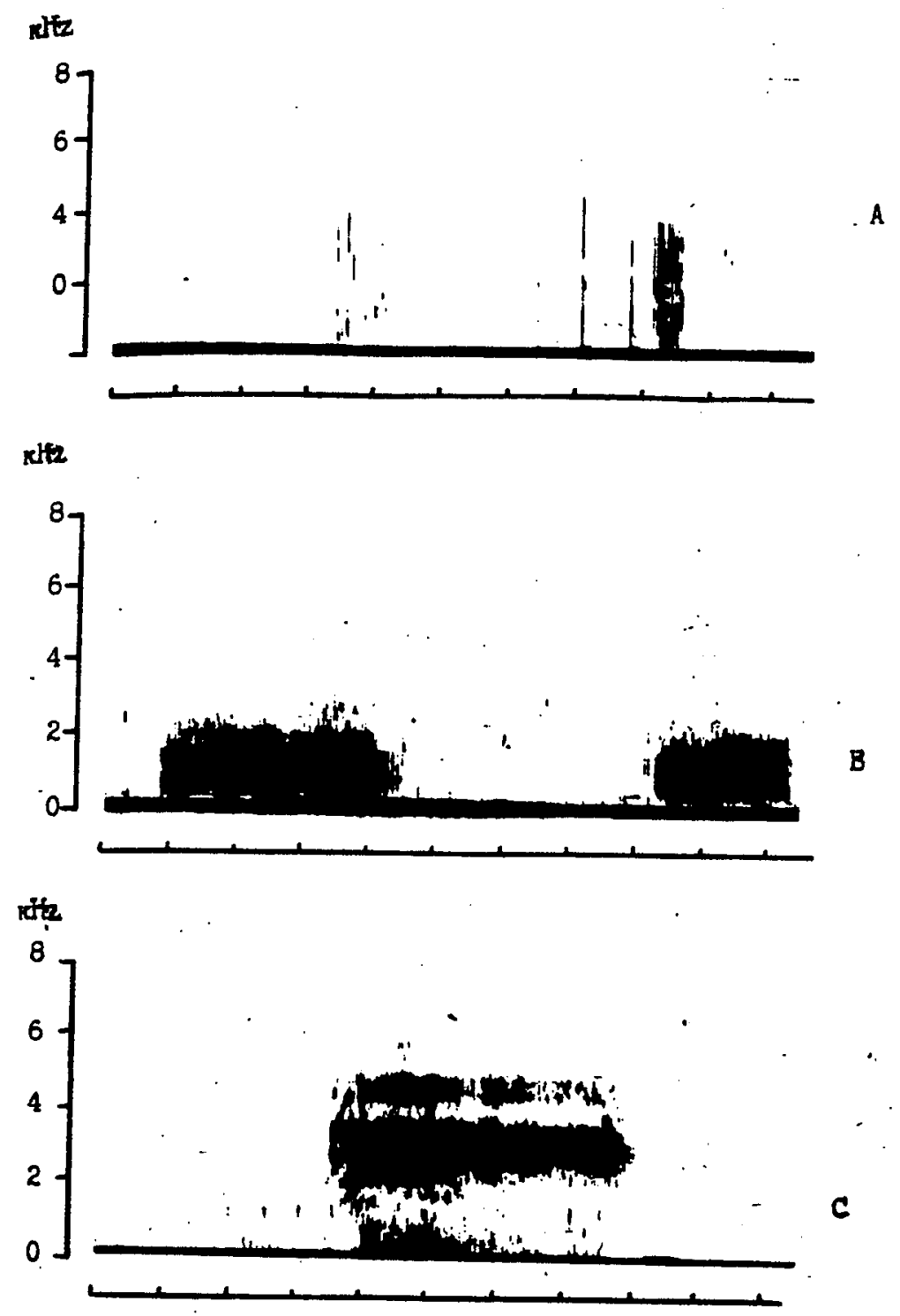

Figure 15 

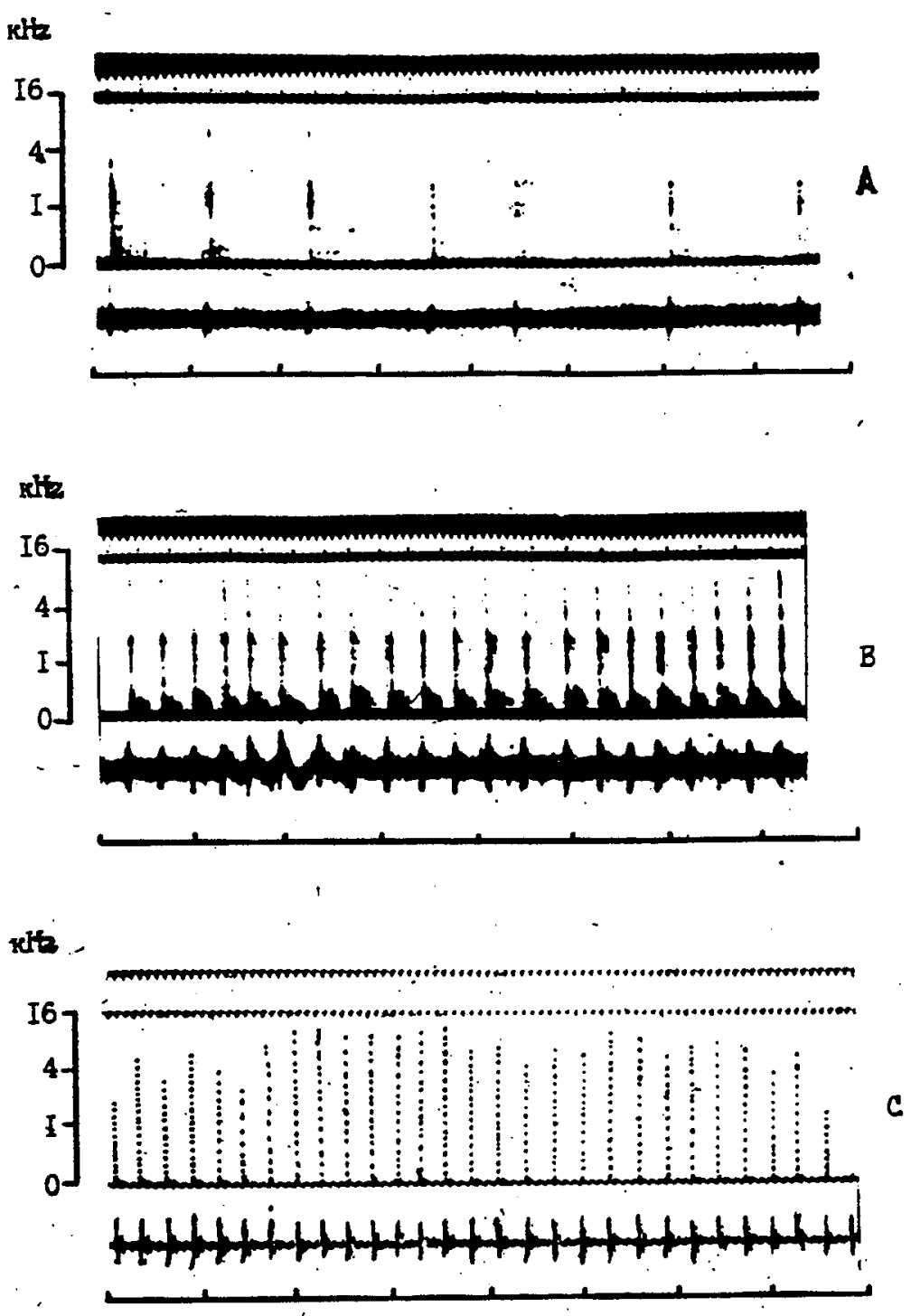

Figure 16 

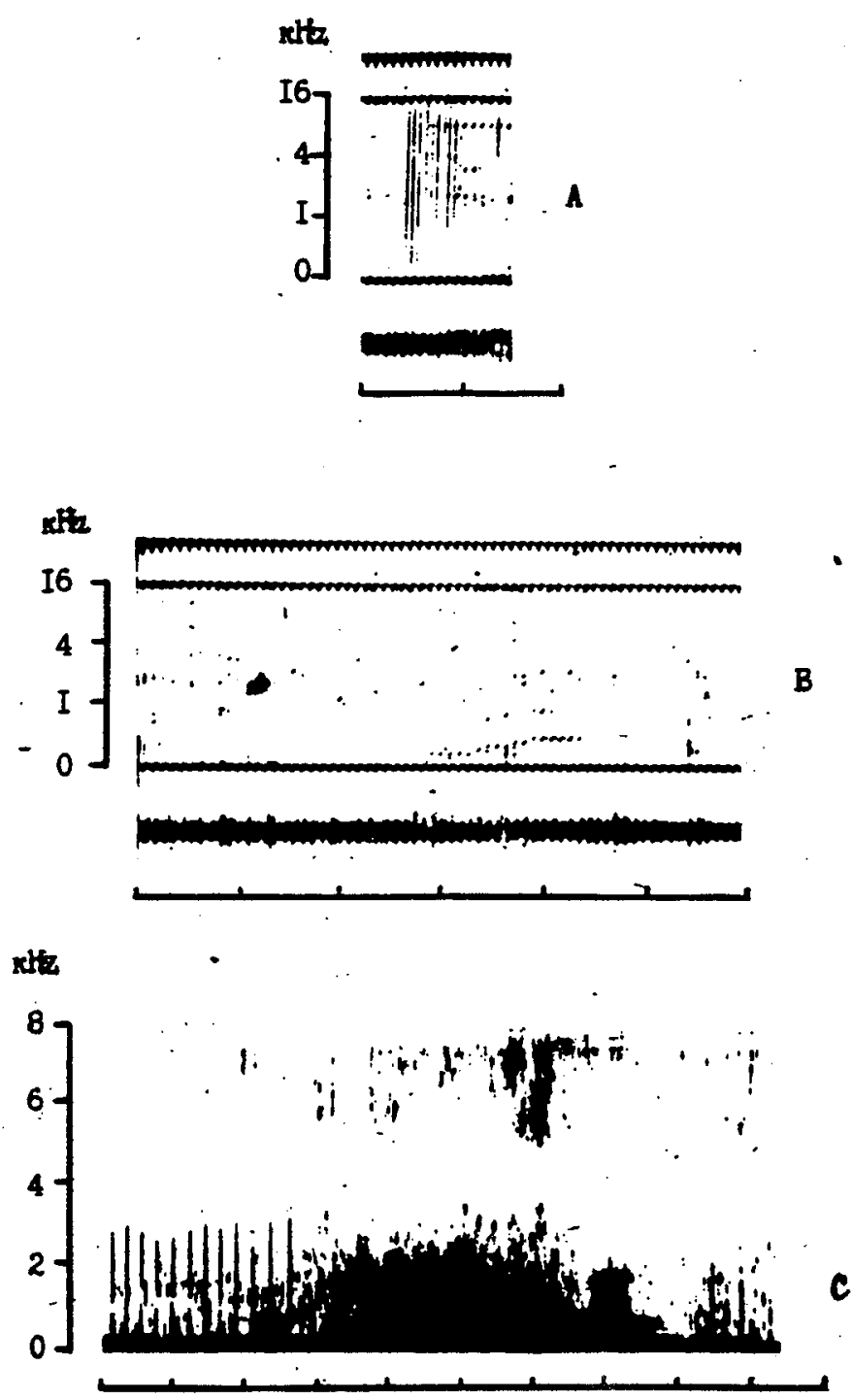

Figure 17 


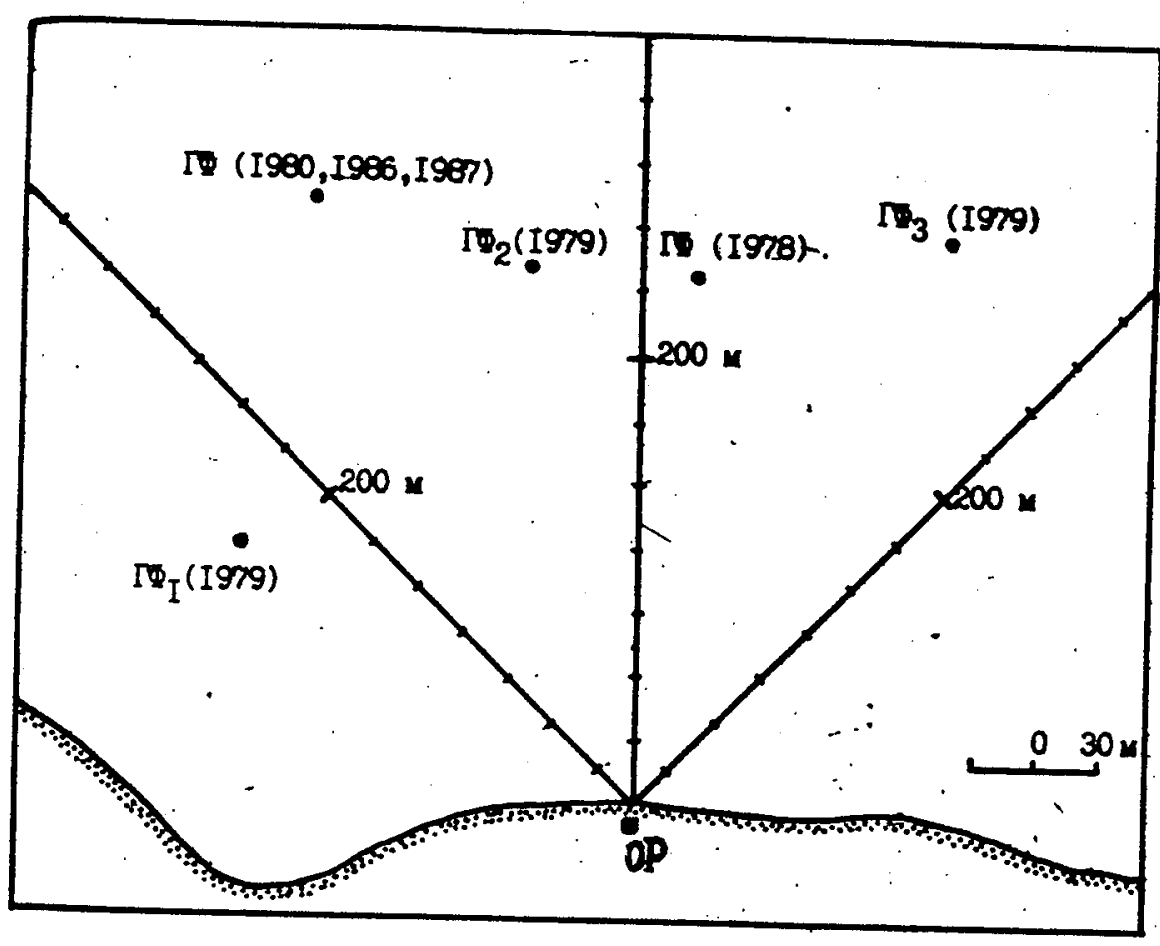

Figure 18 


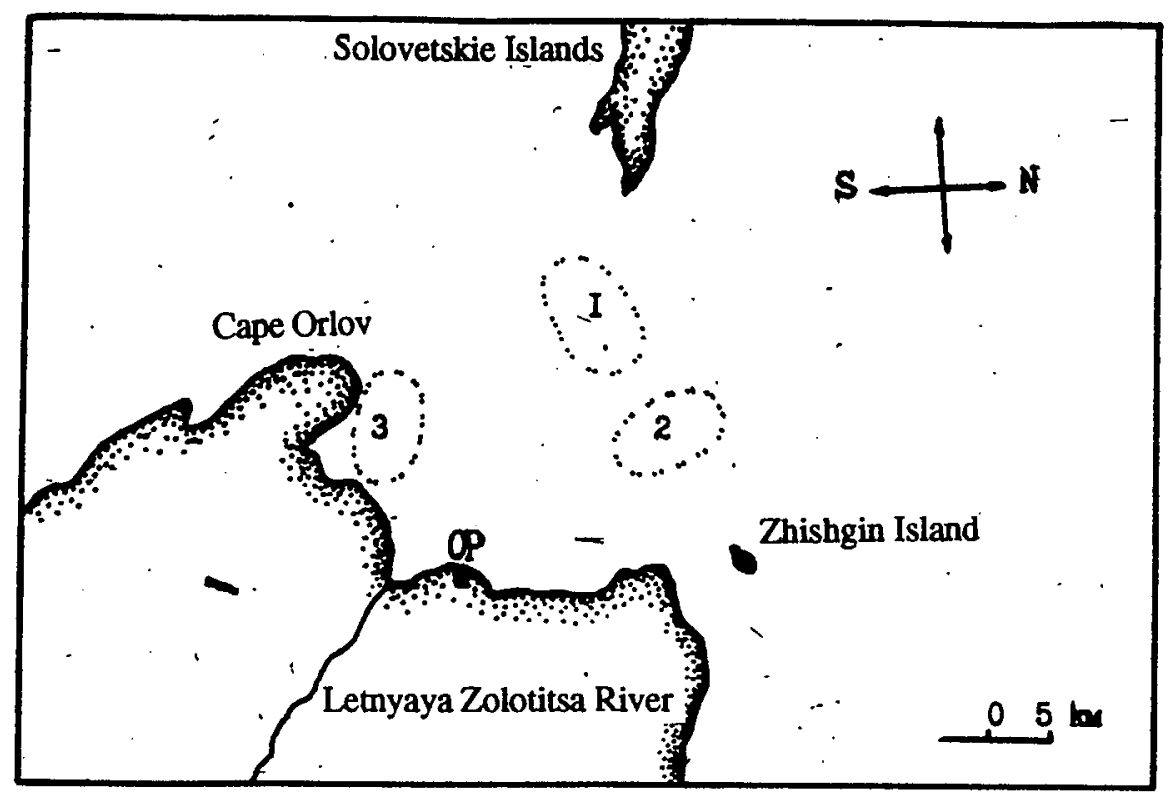

Figure 19 

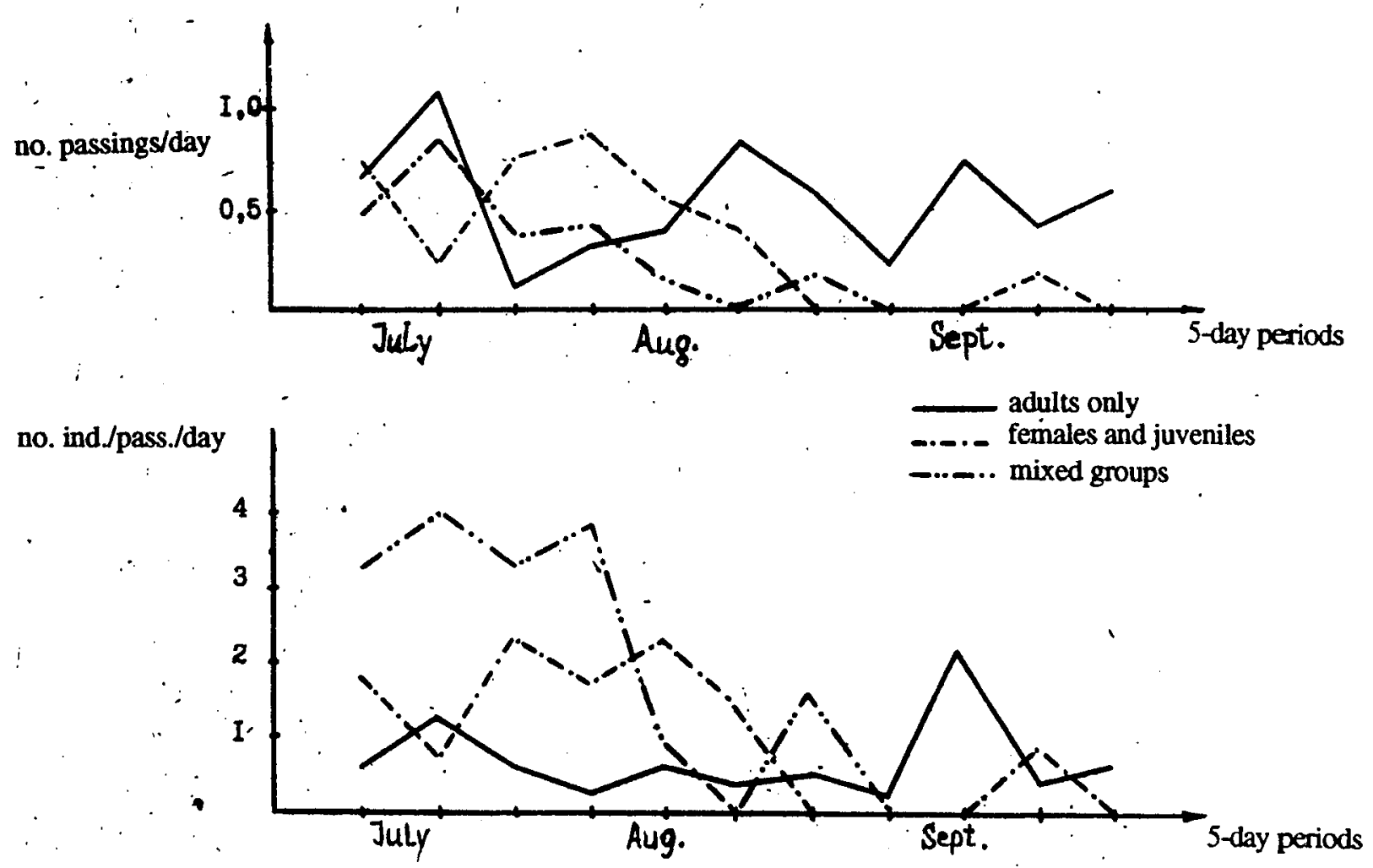

Figure 20 


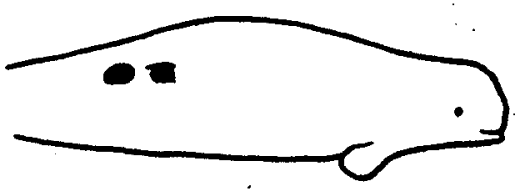

Figure 21 


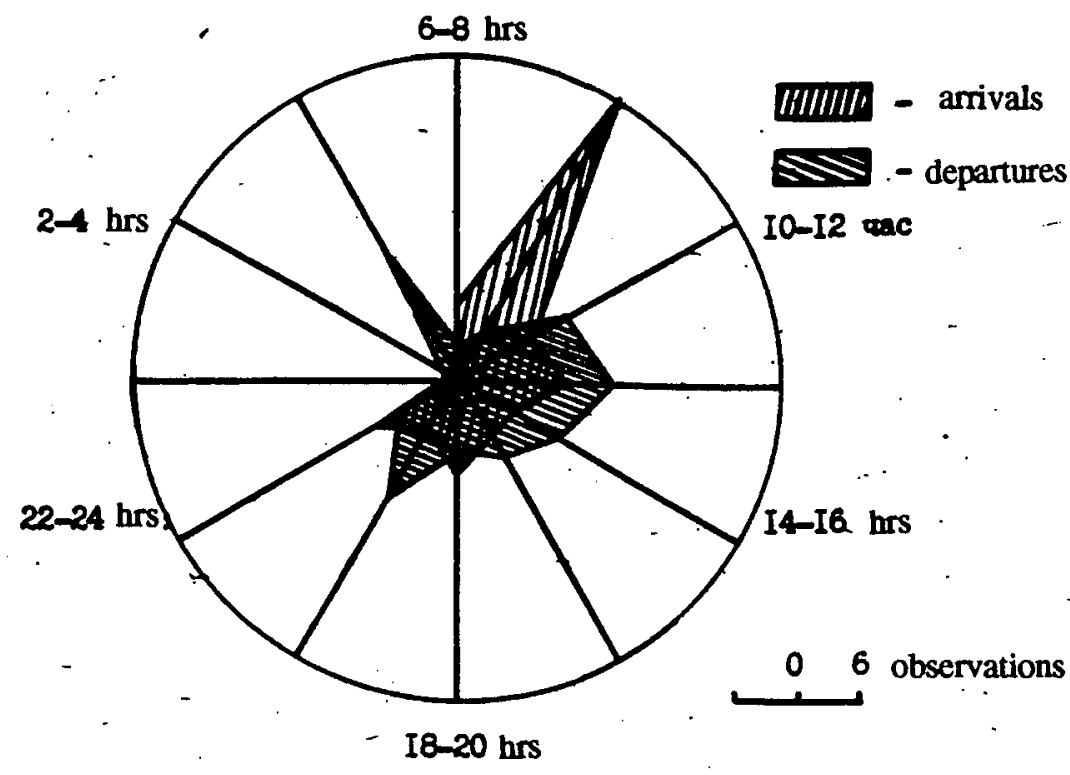

Figure 22 


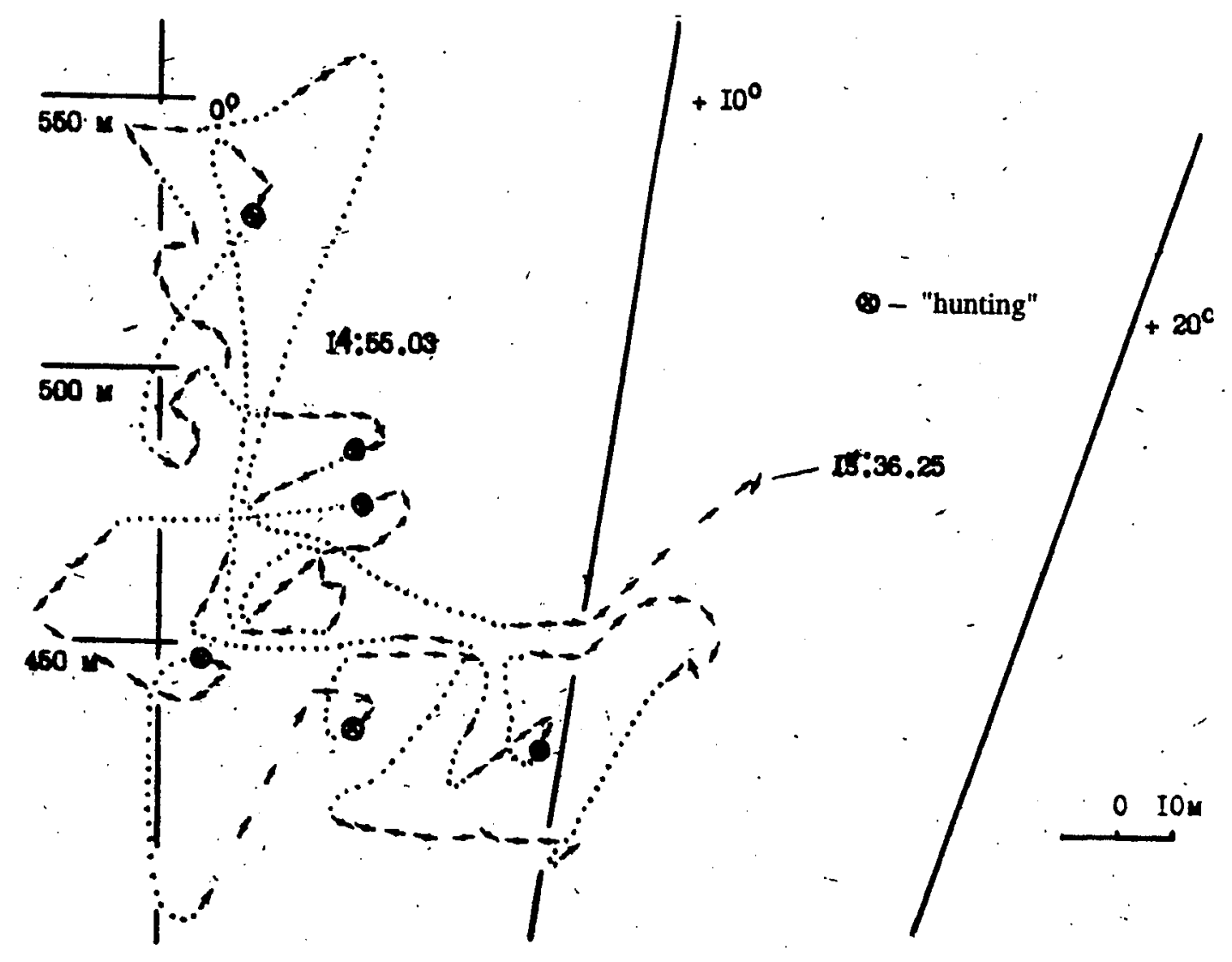

Figure 23 


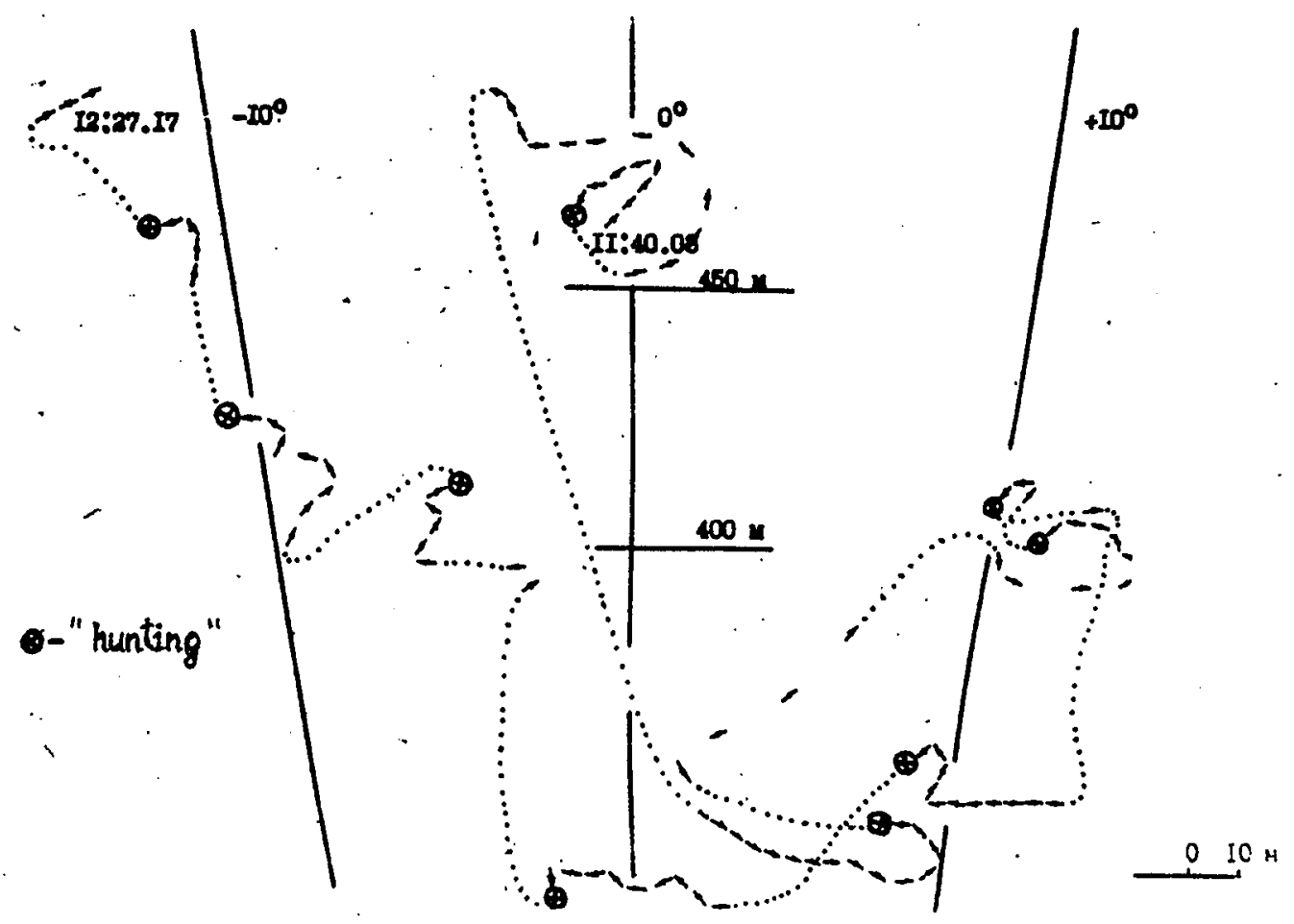

Figure 24 

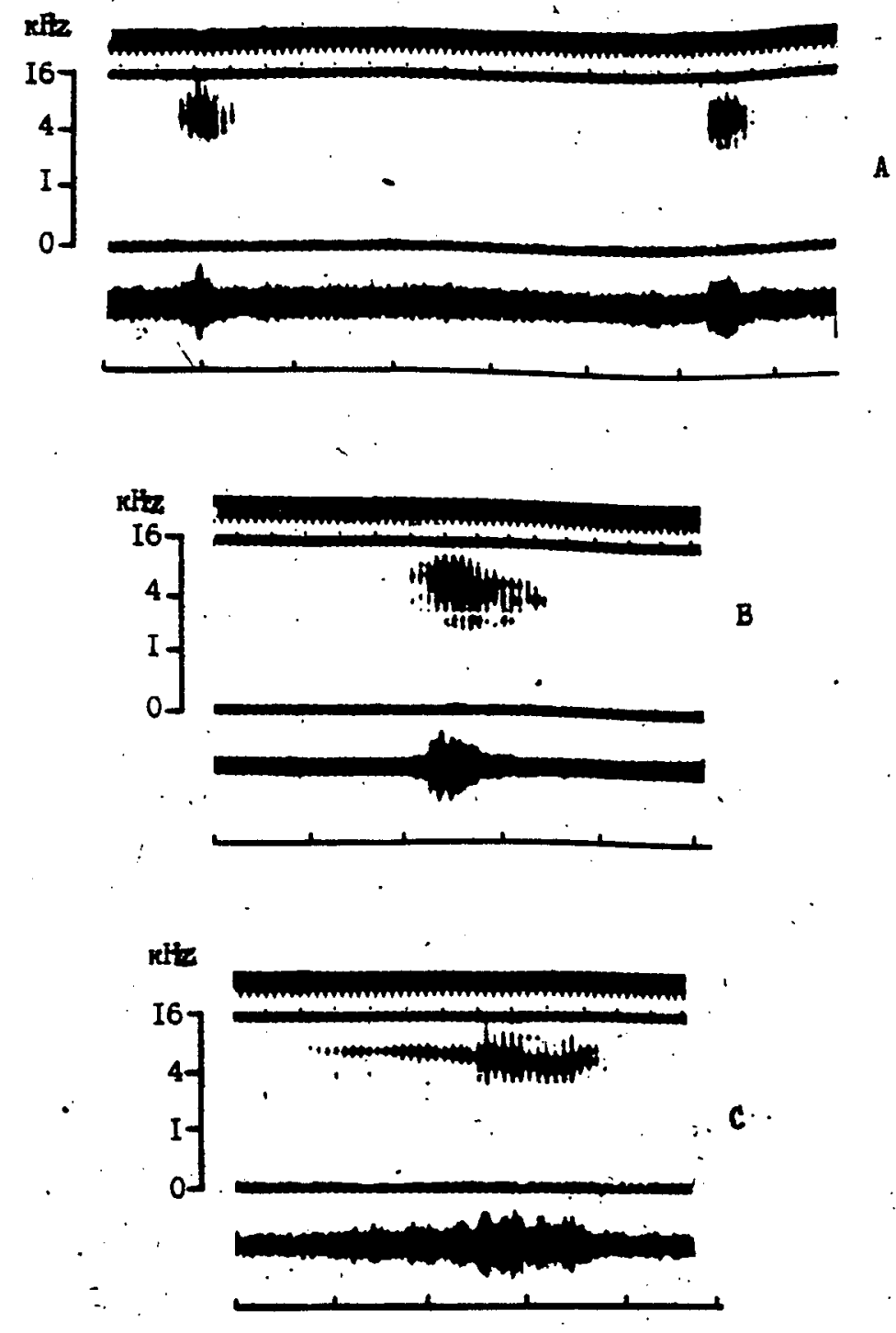

Figure 25 


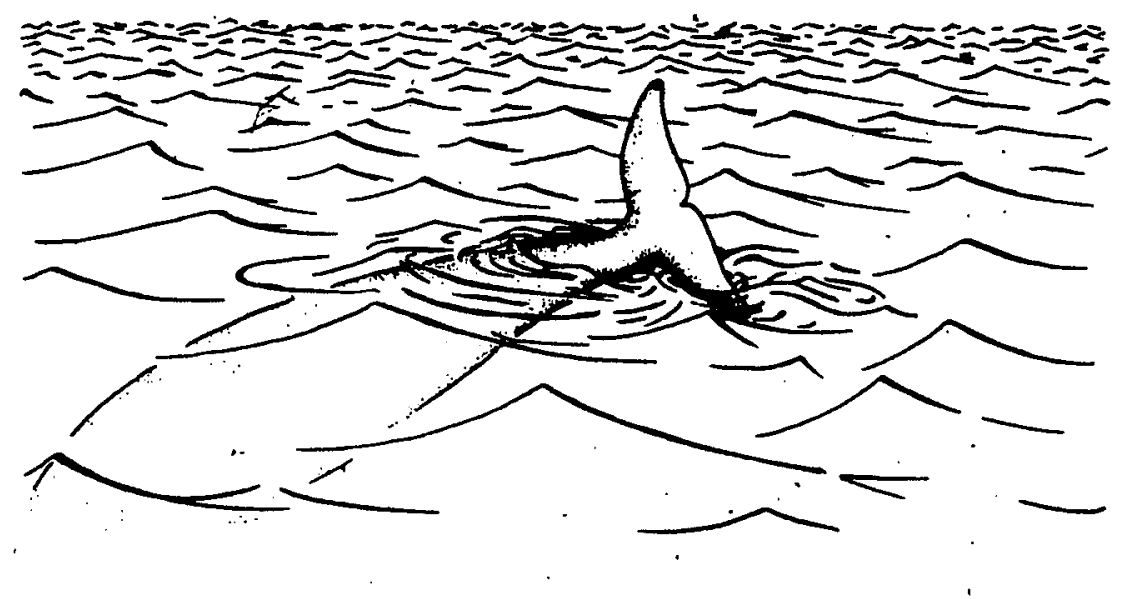

Figure 26 

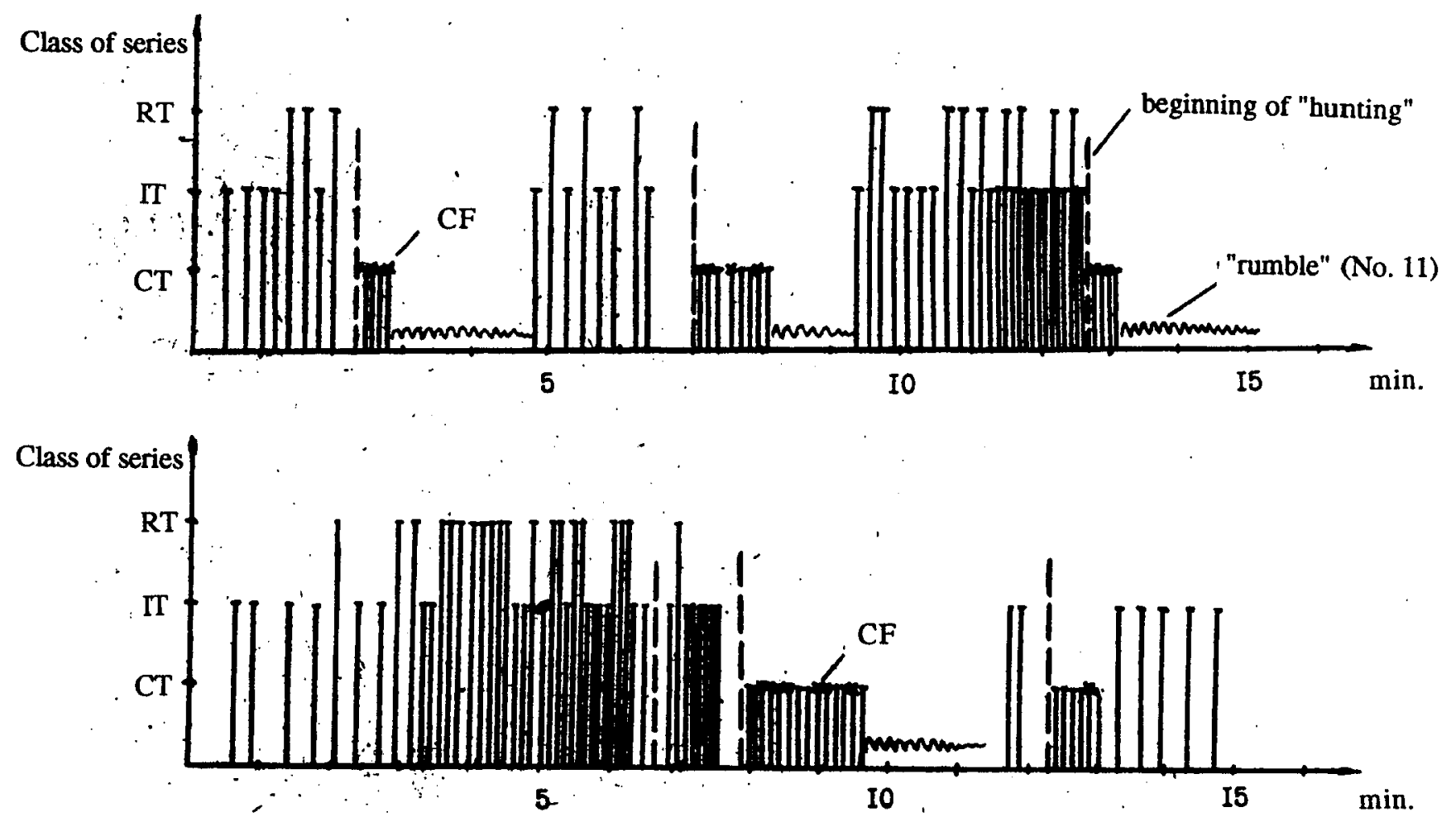

Figure 27 

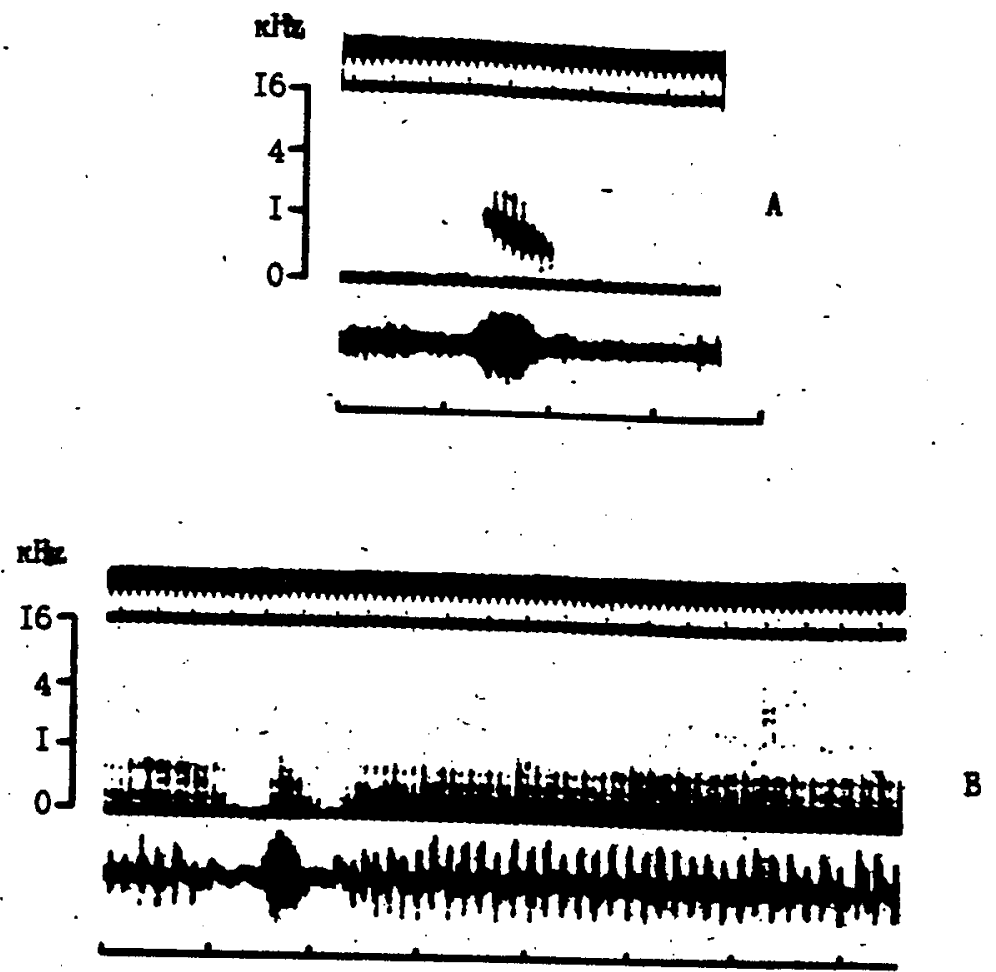

Figure 28 


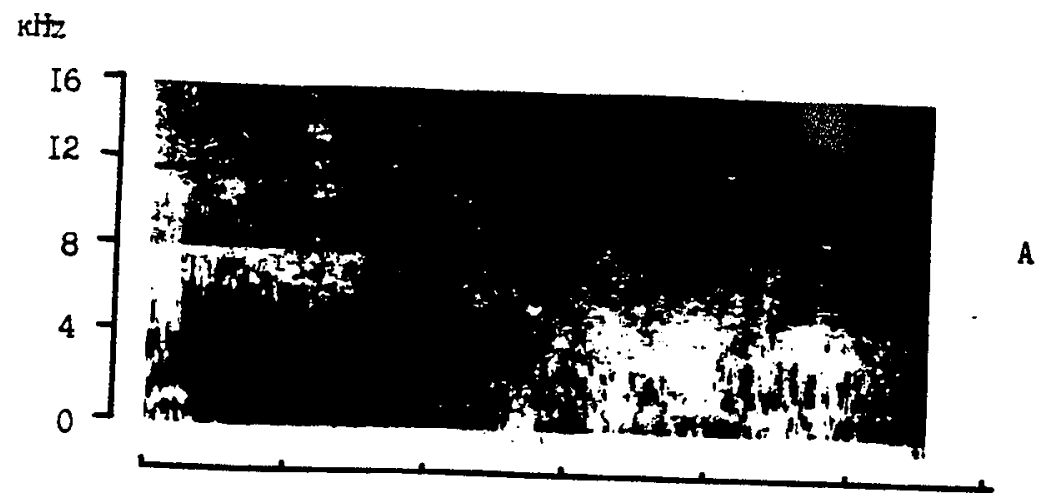

ktz
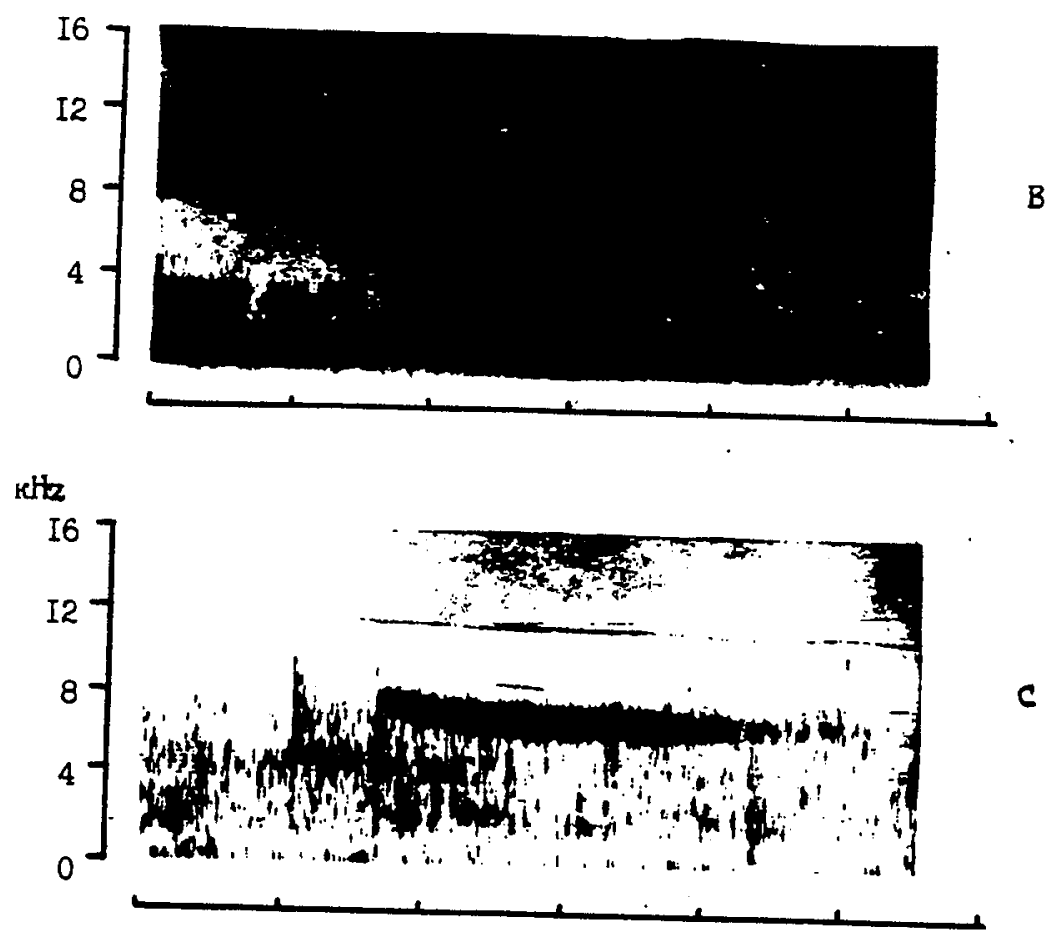

Figure 29 


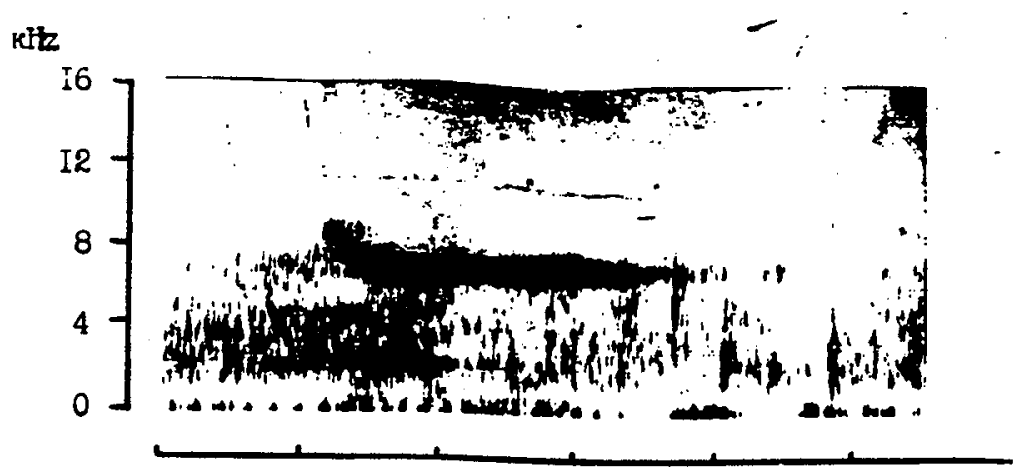

rette
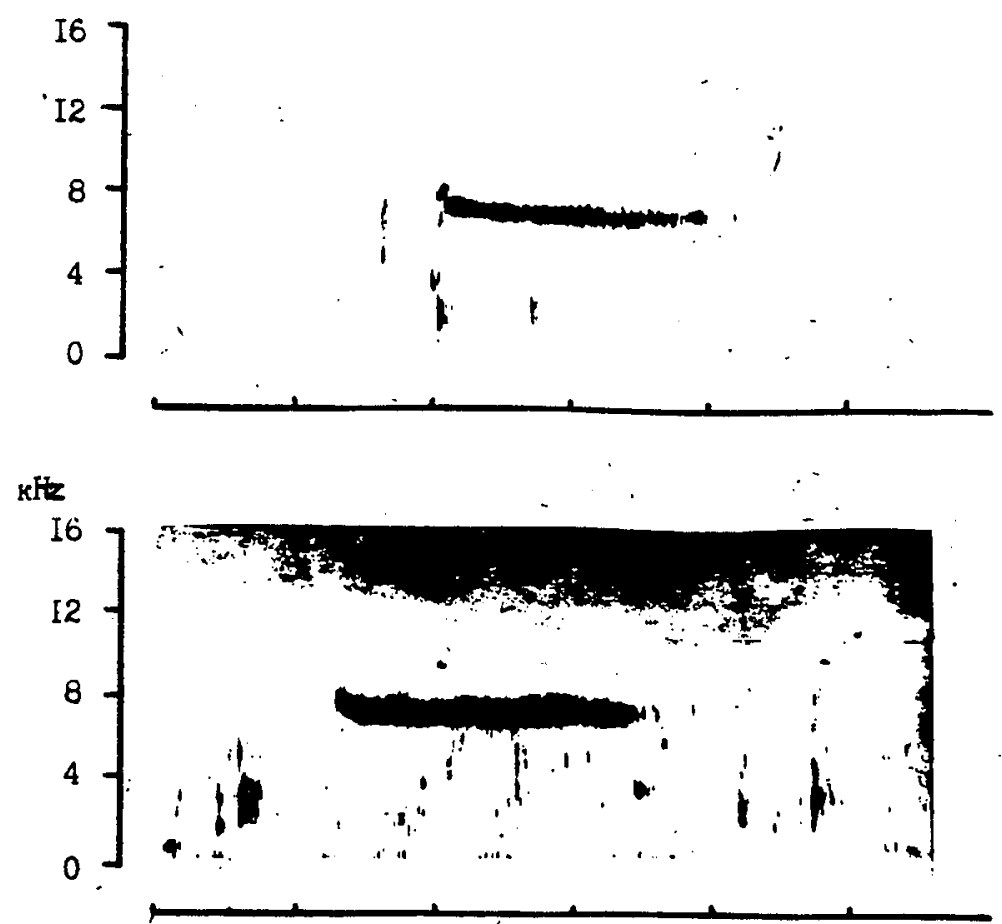

Figure 30 


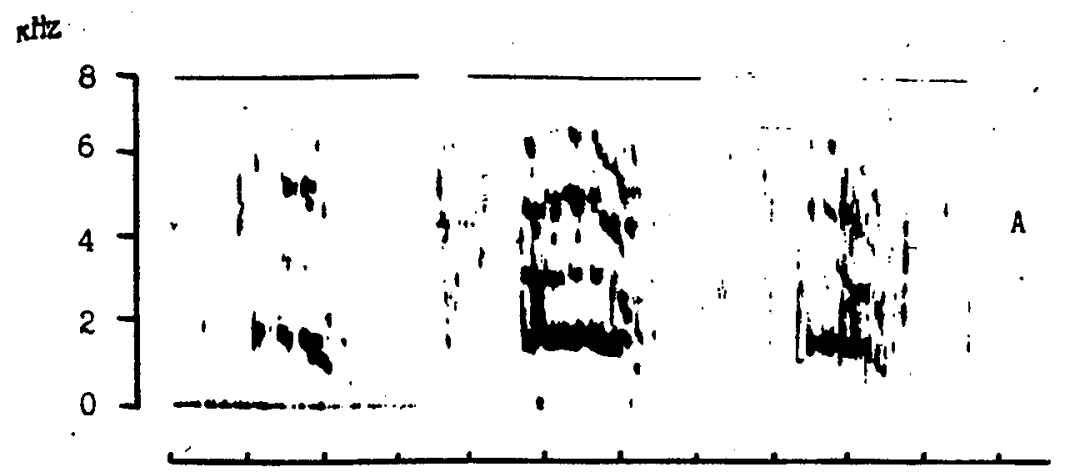

nte

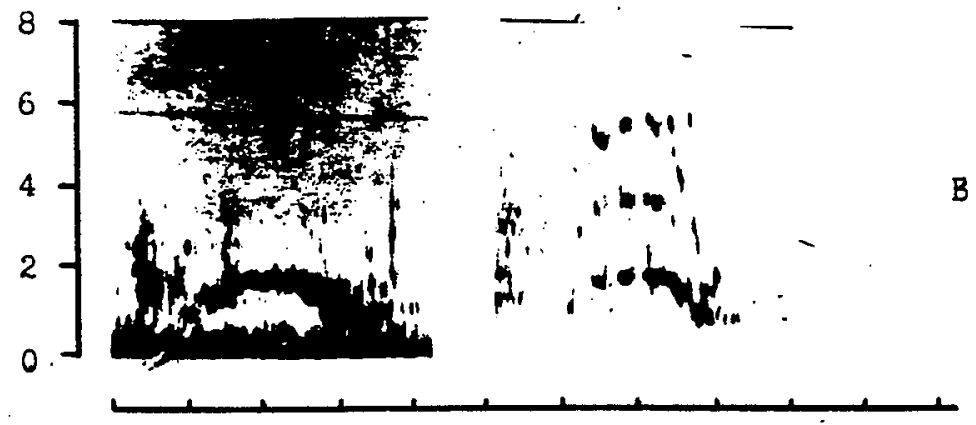

setwo

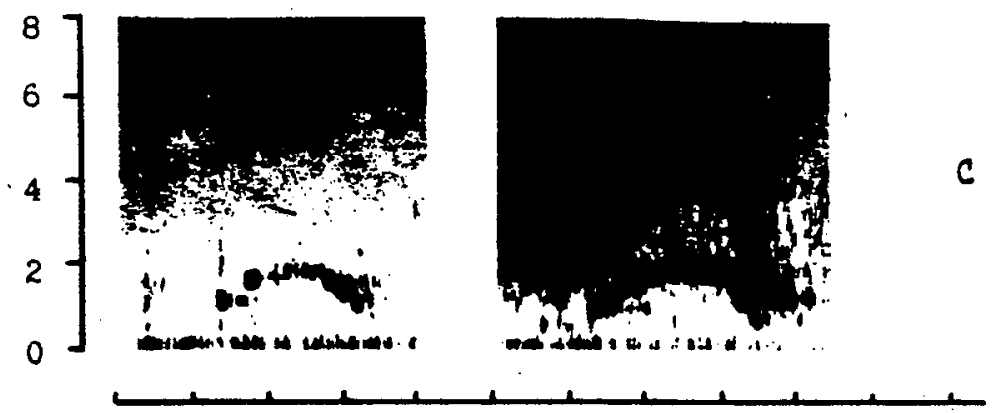

Figure 31 

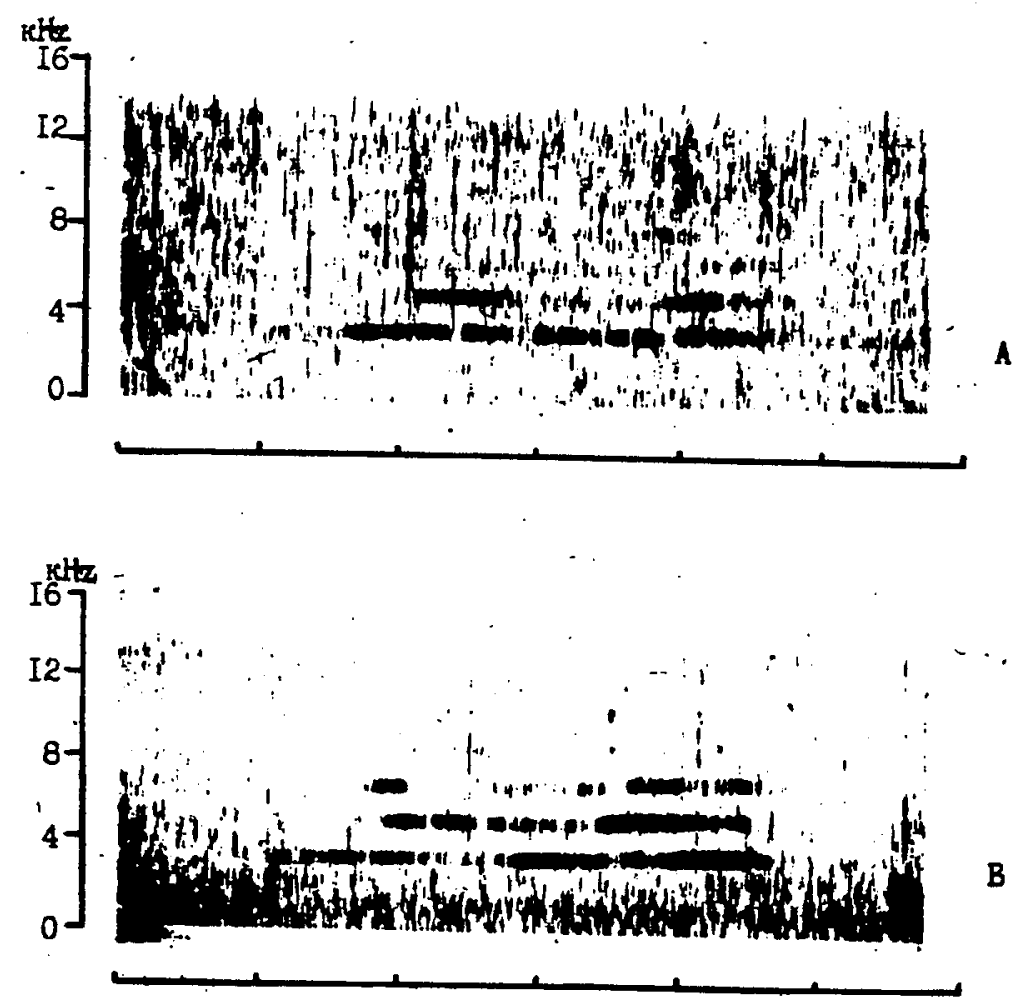

Figure 32 

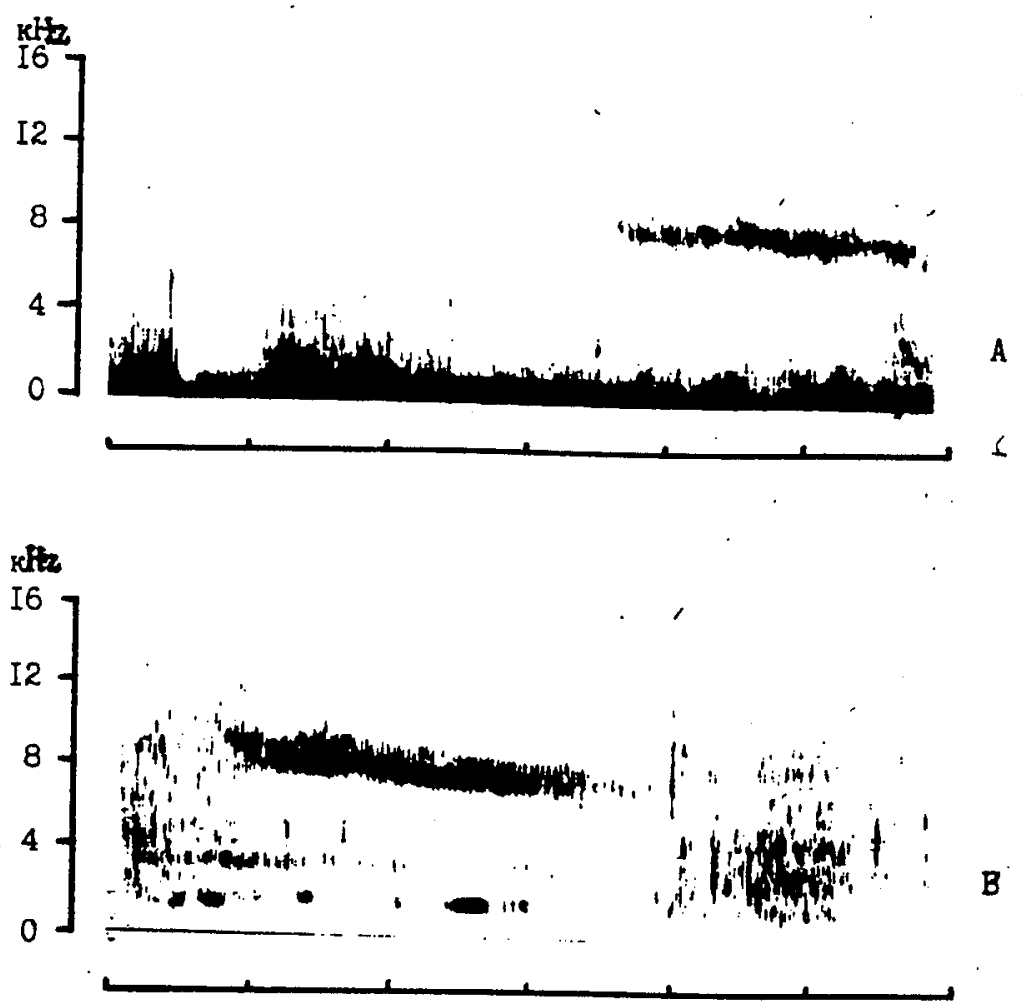

Figure 33 

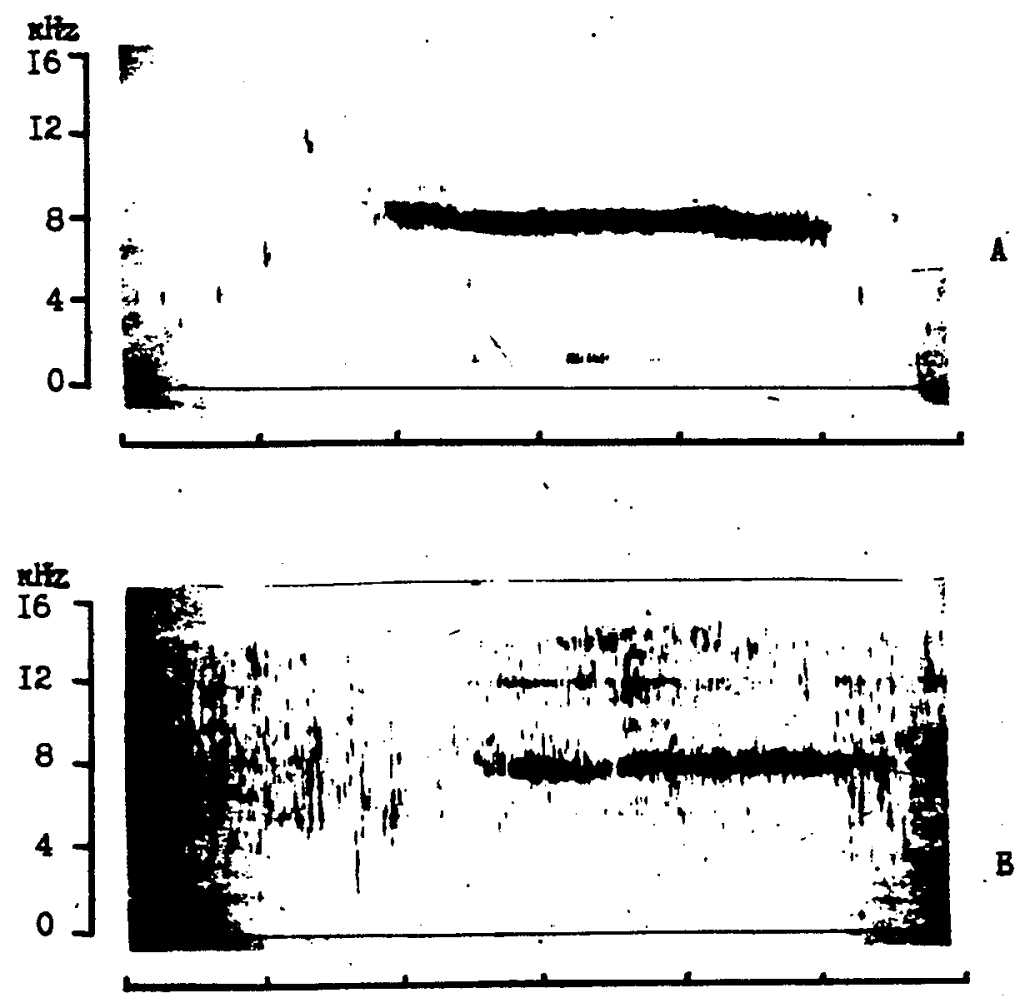

Figure 34 

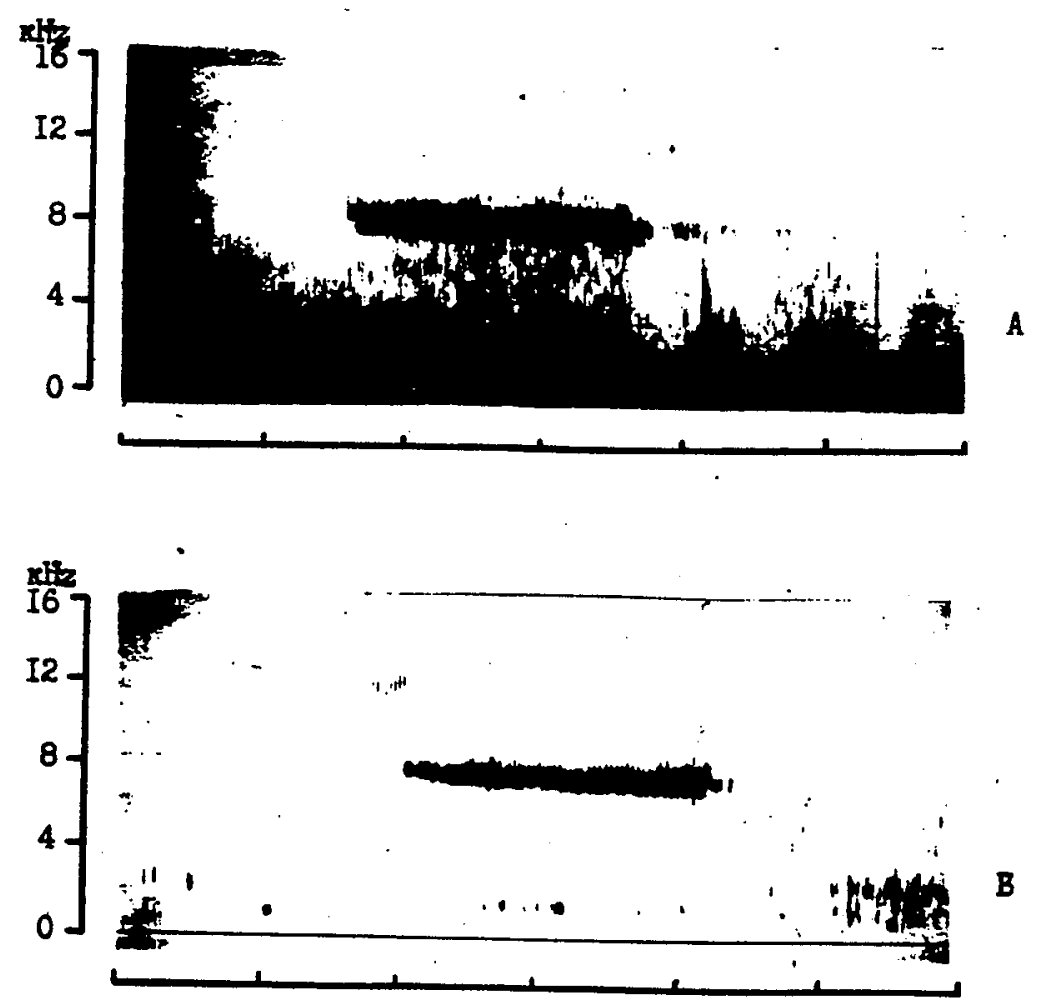

Figure 35 

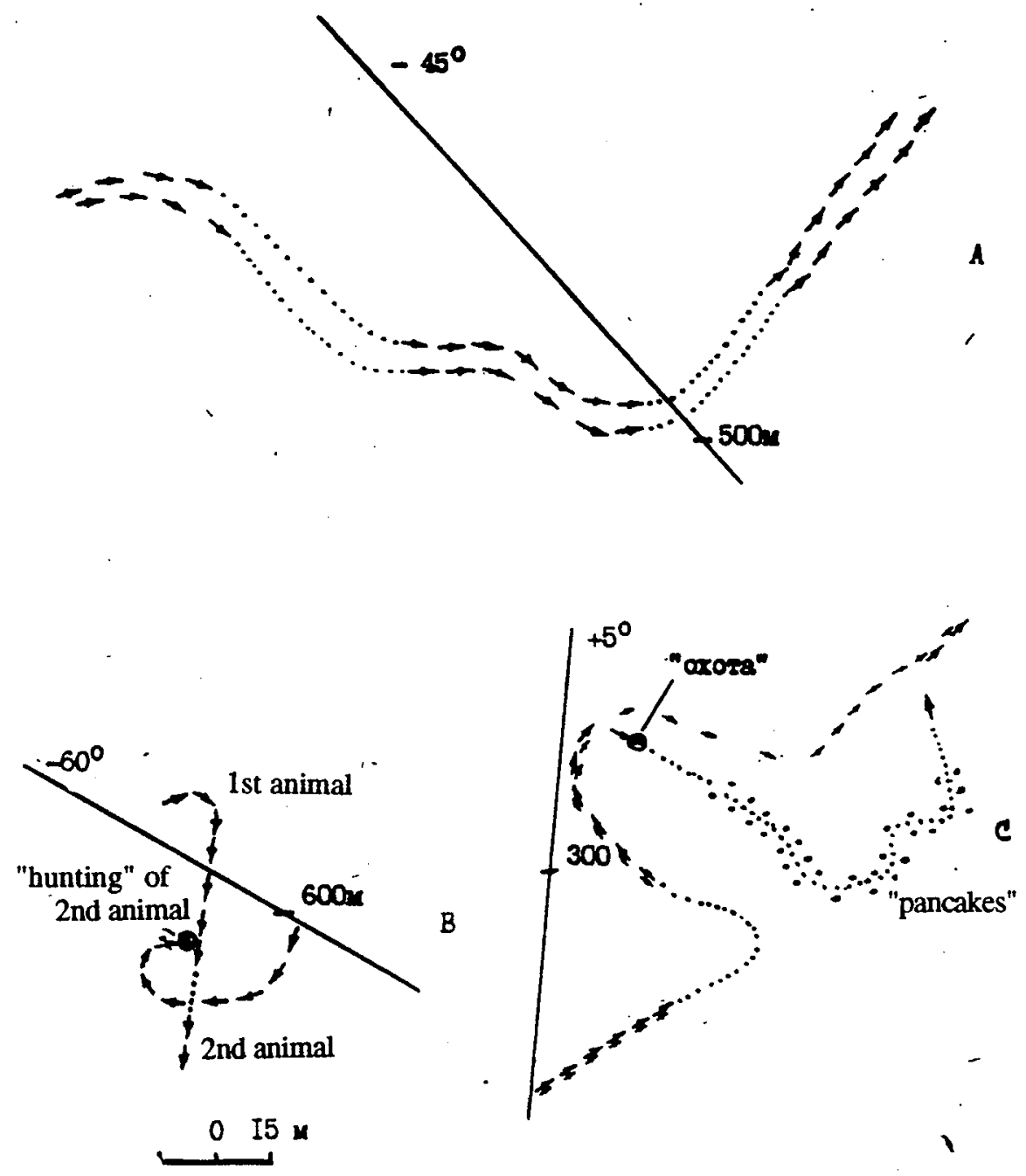

Figure 36 


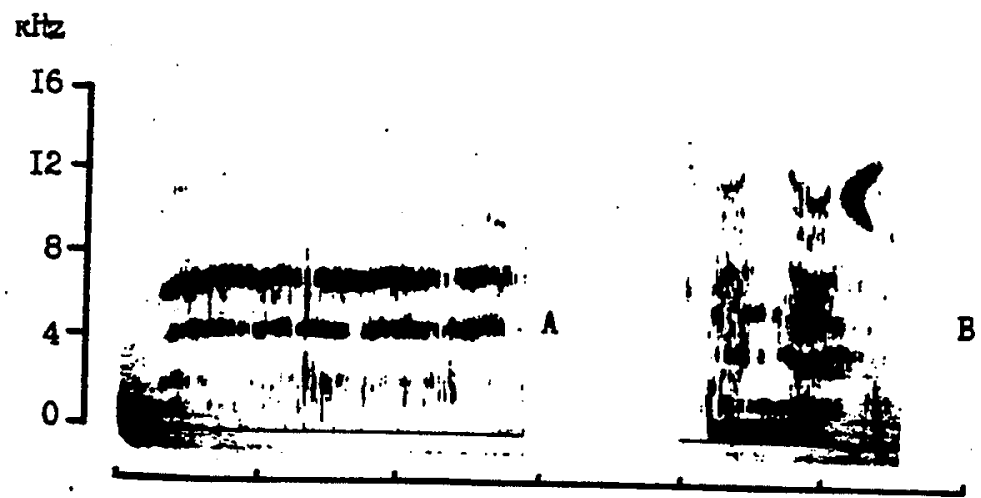

rete

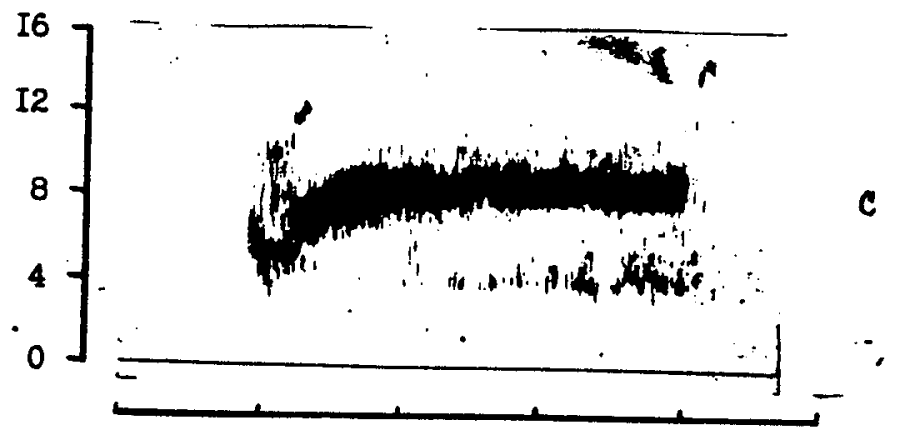

rete

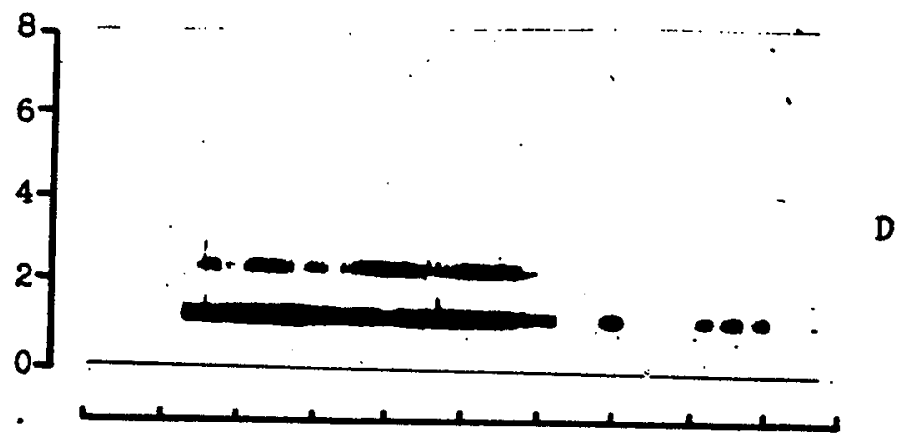

Figure 37 


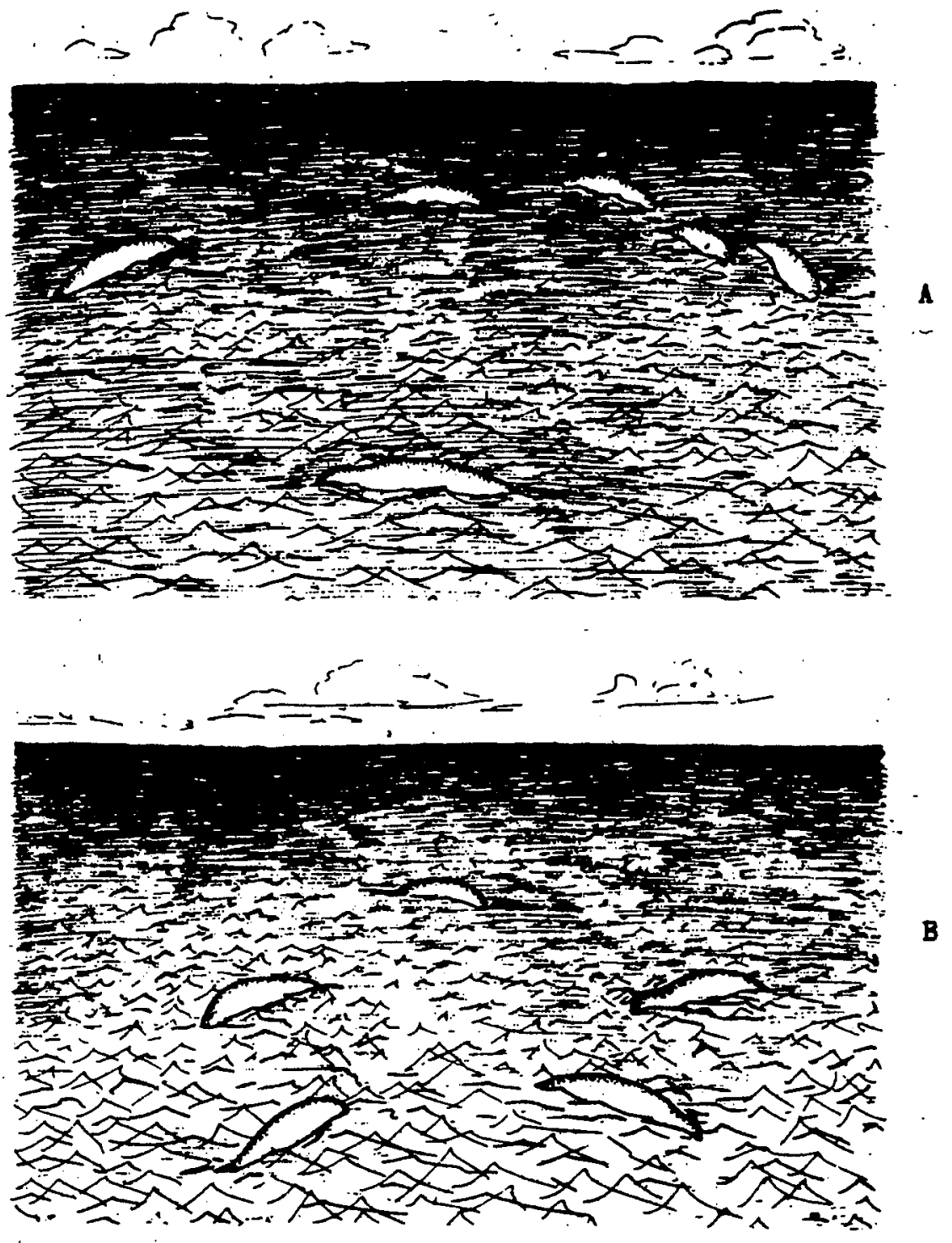

Figure 38 

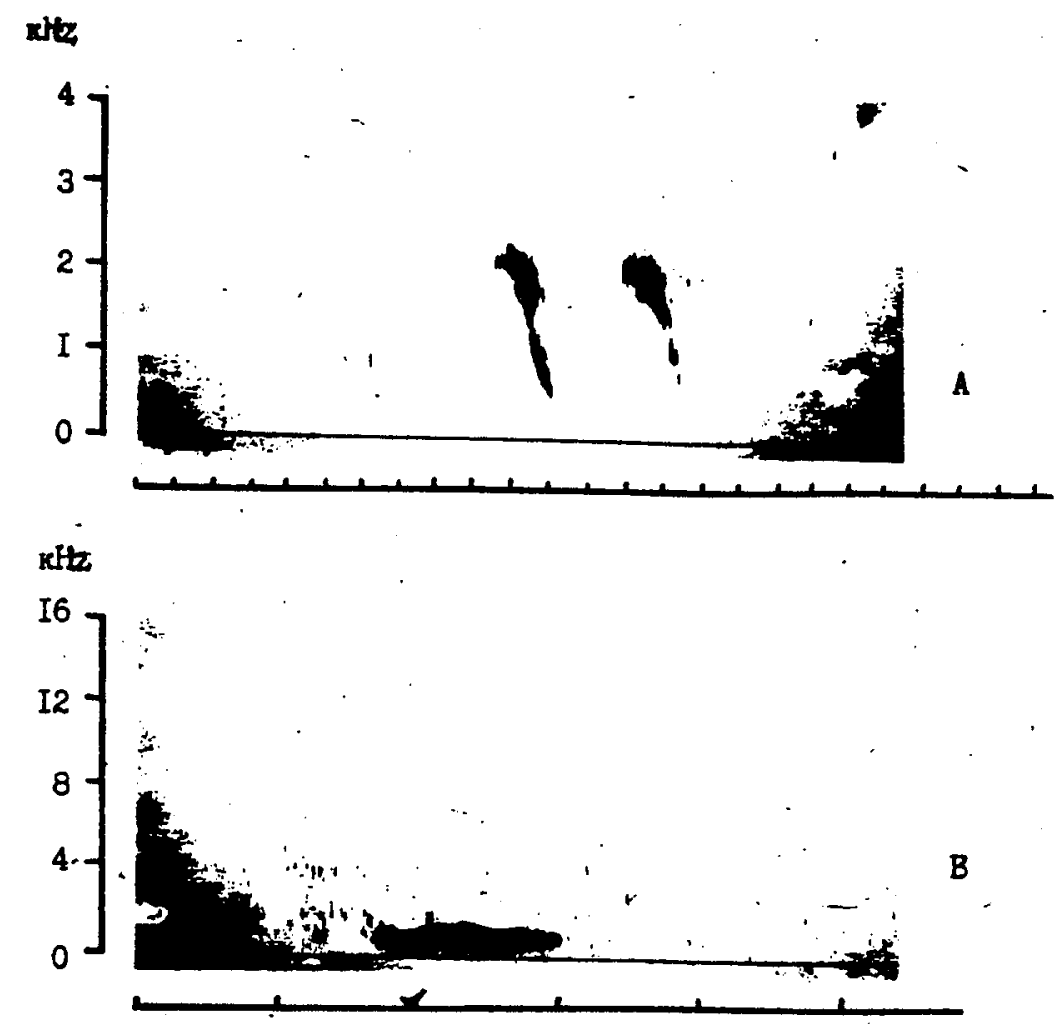

kttz

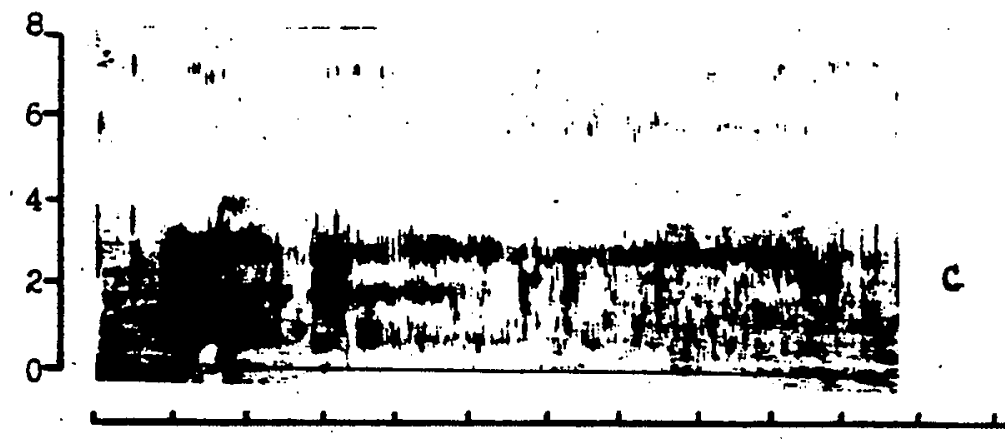

Figure 39 


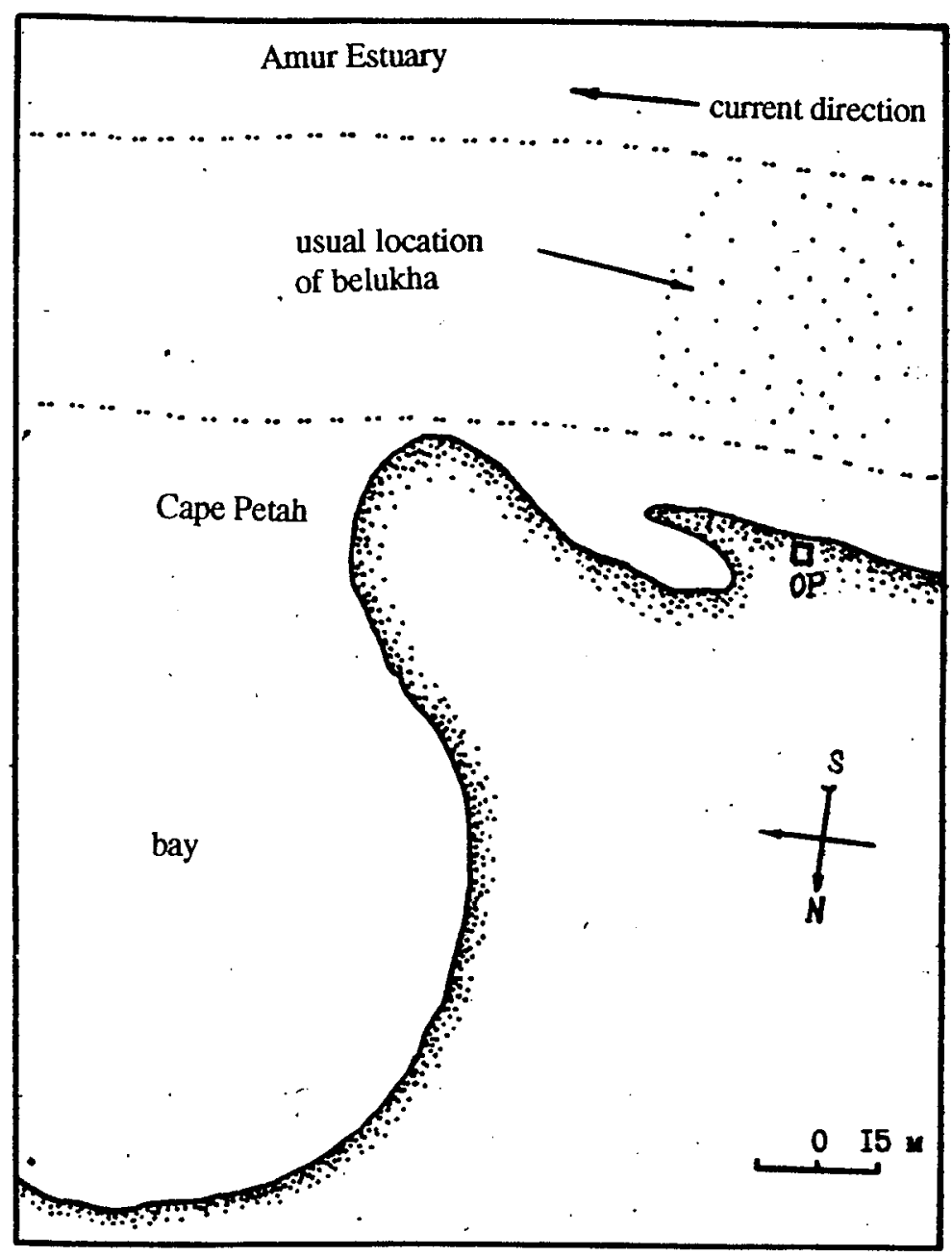

Figure 40 


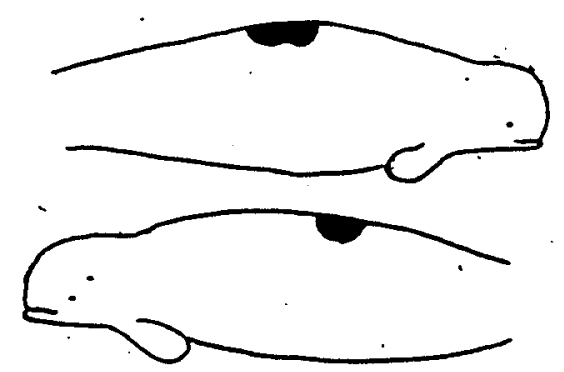

Figure 41 


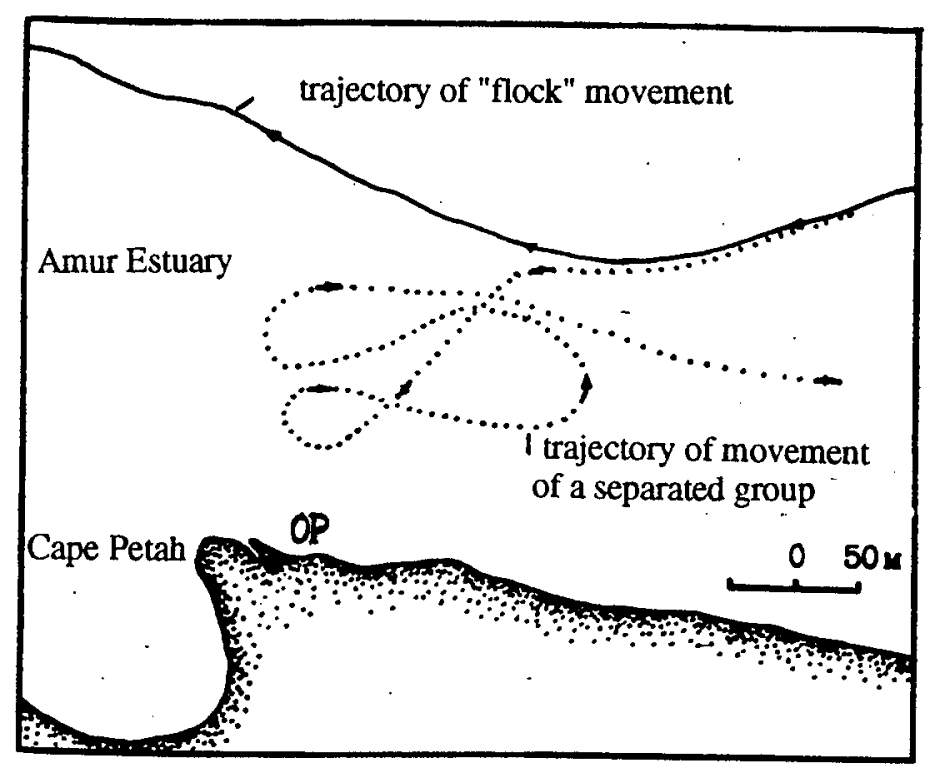

Figure 42 

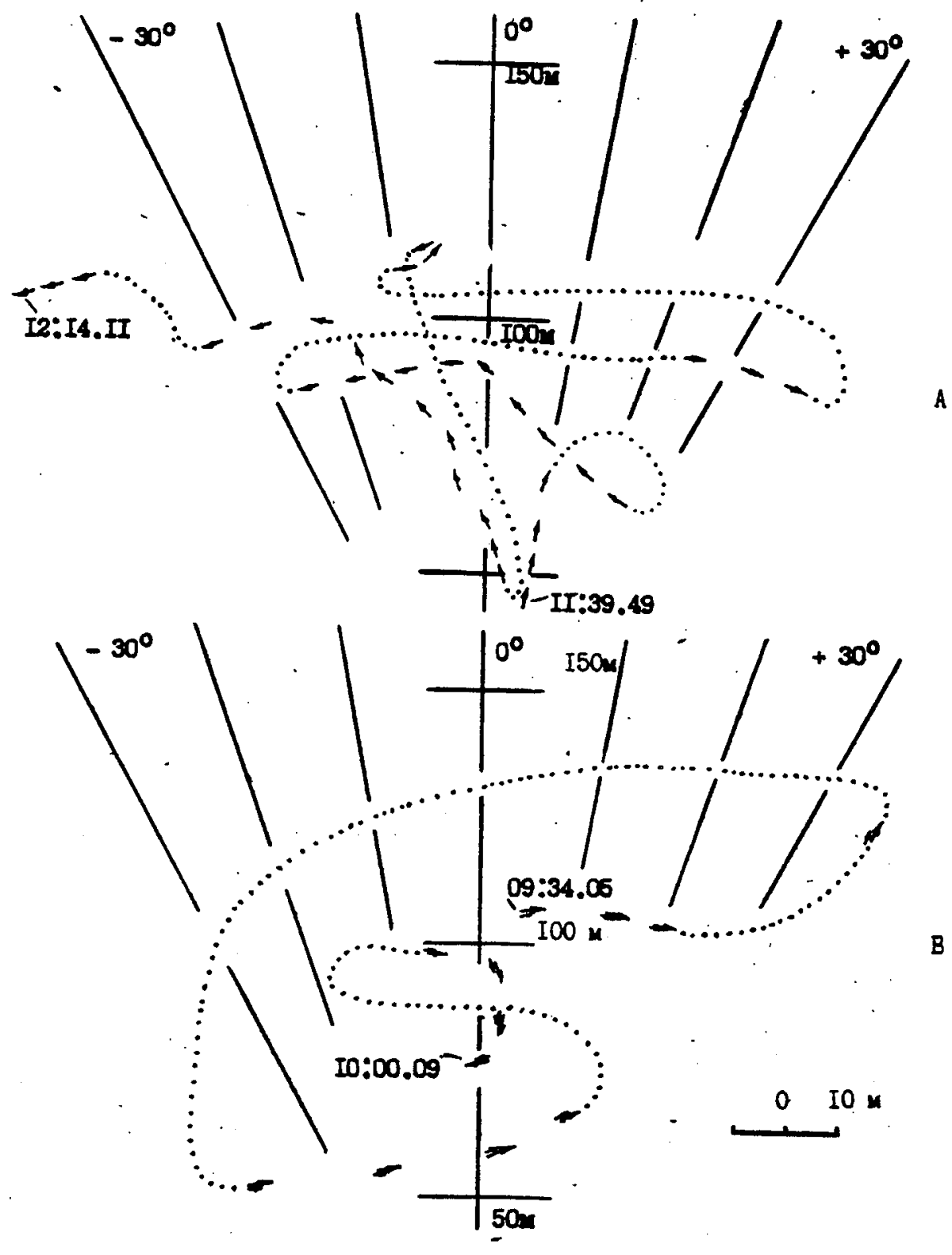

Figure 43 

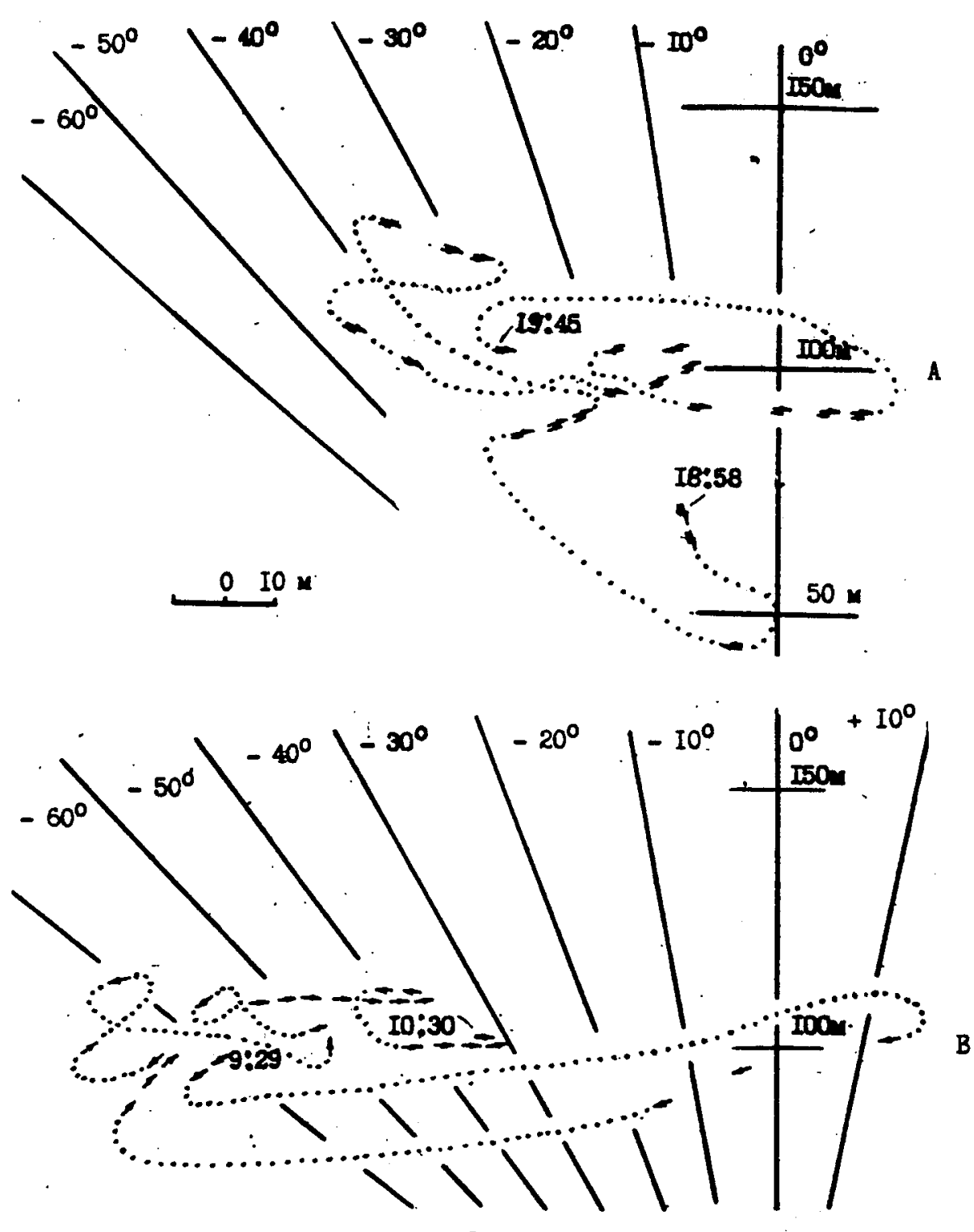

Figure 44 


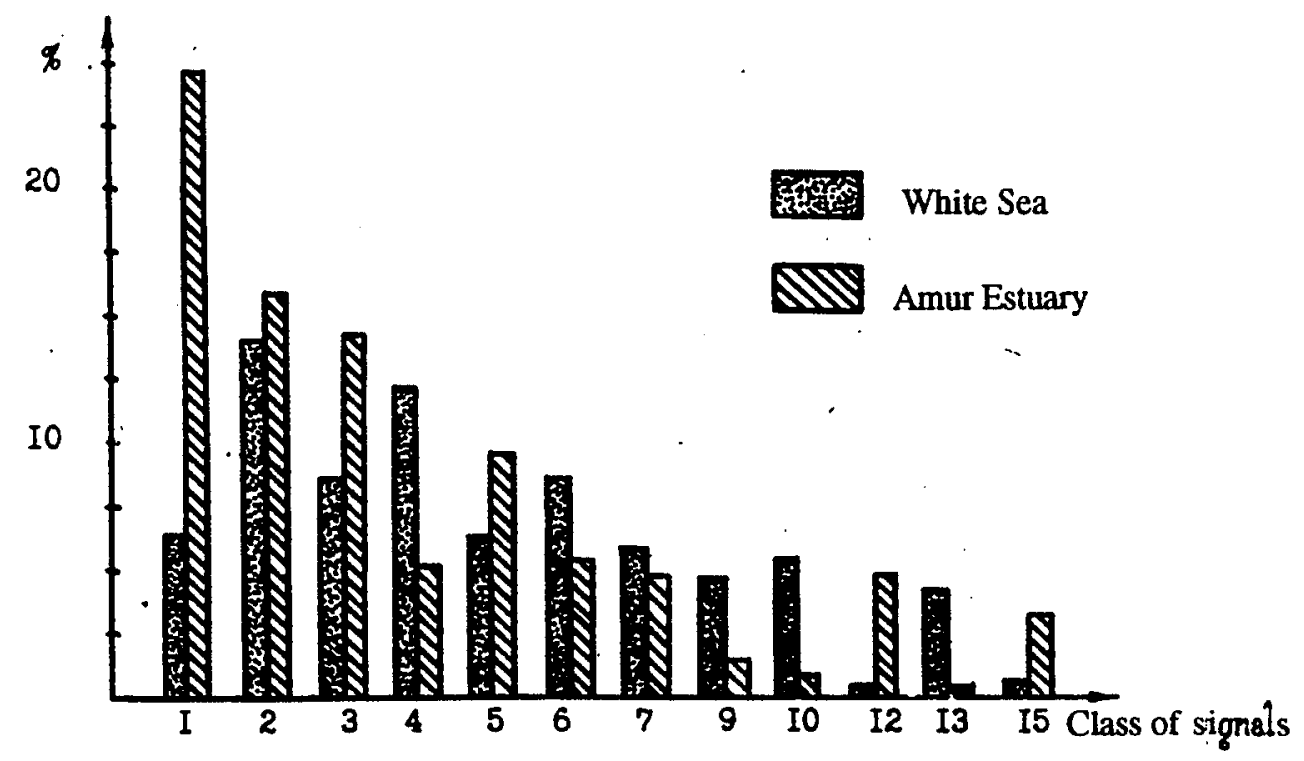

Figure 45 


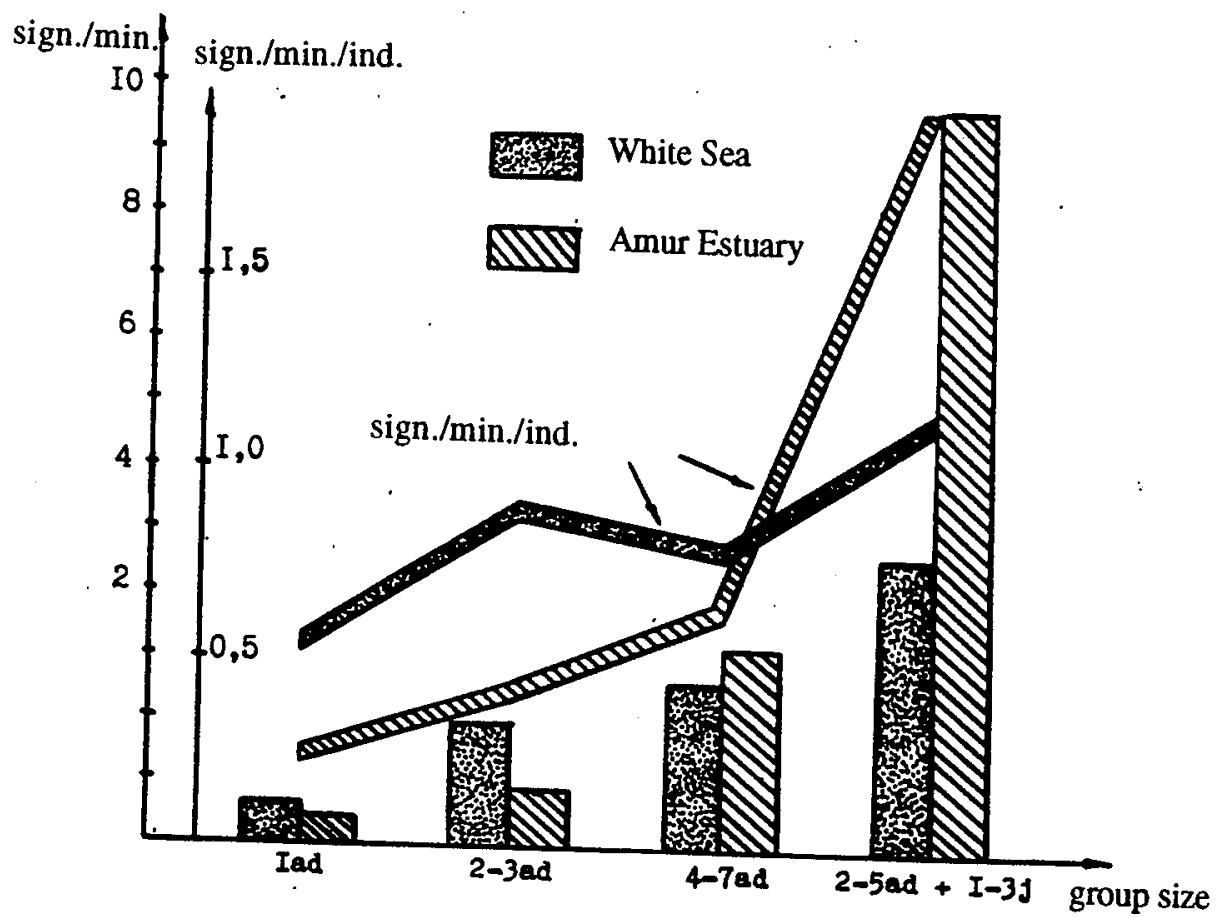

Figure 46 


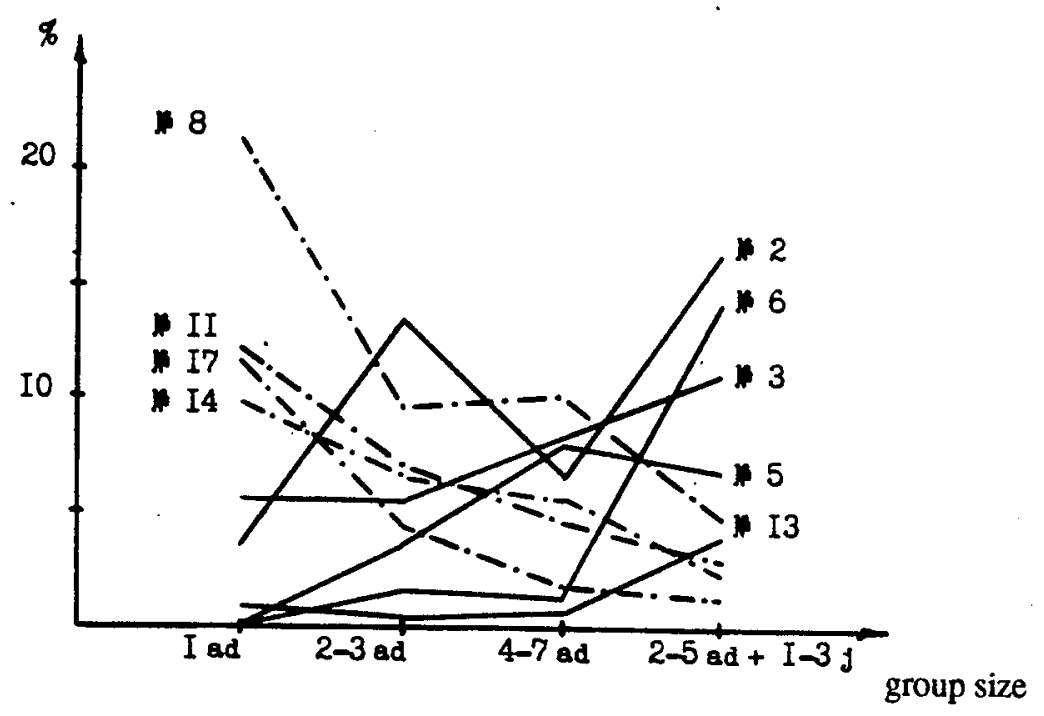

Figure 47 


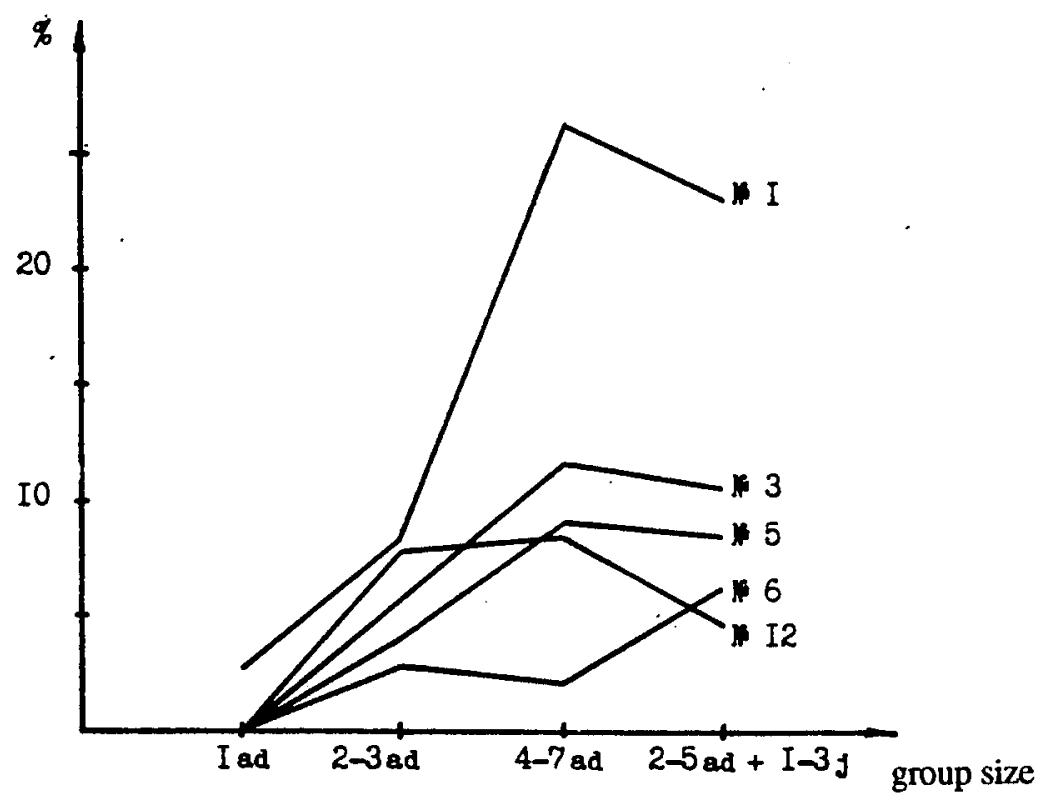

Figure 48 


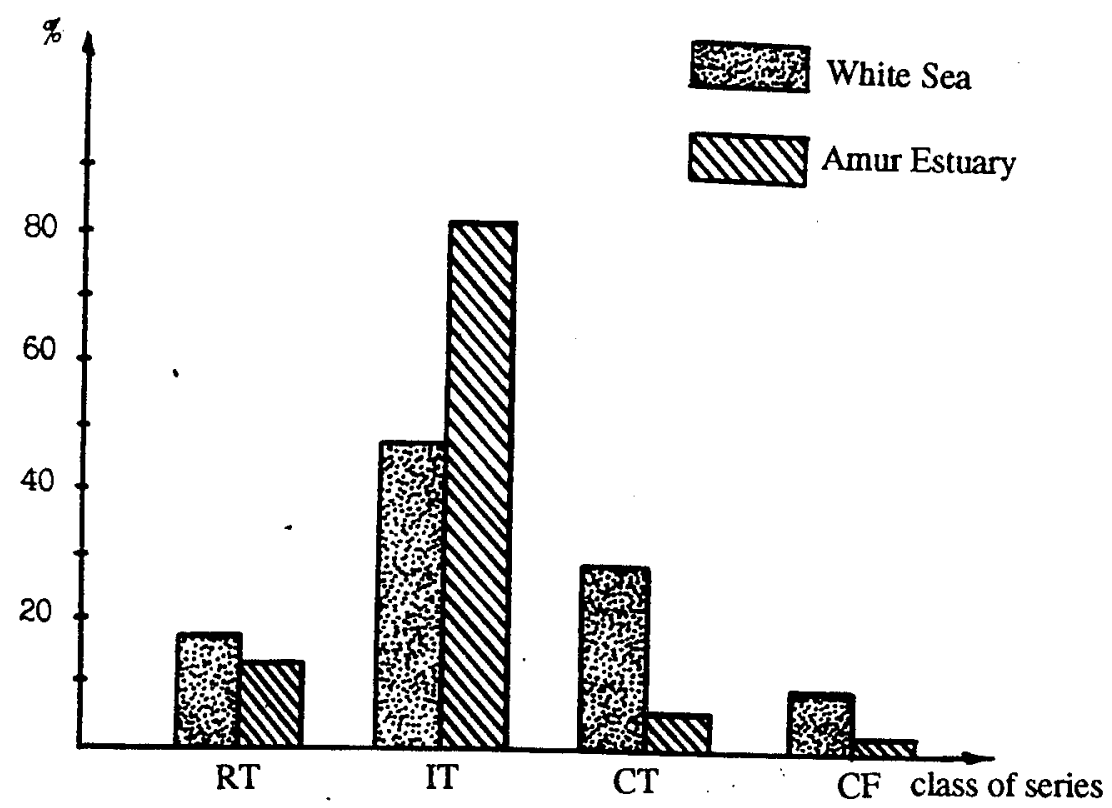

Figure 49 
,

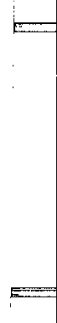

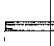

